Final Report

FHWA/IN/JTRP-2002/7

\title{
DEVELOPMENT OF A DECISION SUPPORT SYSTEM FOR SELECTION OF TRENCHLESS TECHNOLOGIES TO MINIMIZE IMPACT OF UTILITY CONSTRUCTION ON ROADWAYS
}

\author{
By \\ Dulcy M. Abraham, Ph.D. \\ Associate Professor \\ and \\ Hyeon Shik Baik \\ Graduate Research Assistant \\ School of Civil Engineering \\ Purdue University \\ West Lafayette, Indiana \\ and \\ Sanjiv Gokhale, Ph.D., P.E. \\ Associate Professor \\ School of Civil Engineering \\ Vanderbilt University \\ Joint Transportation Research Program \\ Project No: C-36-67HHH \\ File No: 9-10-59 \\ SPR- 2453 \\ Conducted in Cooperation with the \\ Indiana Department of Transportation \\ and the U.S. Department of Transportation \\ Federal Highway Administration
}

The contents of this report reflect the views of the authors, who are responsible for the facts and the accuracy of the data presented herein. The contents do not necessarily reflect the official views or policies of the Indiana Department of Transportation or the Federal Highway Administration at the time of publication. The report does not constitute a standard, specification, or regulation.

Purdue University

West Lafayette, IN 47907

August 2002 


\section{ACKNOWLEDGEMENTS}

The authors thank the members of the Study Advisory Committee (SAC) of this project: Jeff James, Dennis Kuchler, John McFadden, Dwane Myers, and David Ward (INDOT); Dan Liotti (Midwest Mole); and Edward Ratulowski (FHWA) for their enthusiastic support and assistance during the course of this study. James Synder, Matt Thomas, Dan Smith, Greg Pankow, Steve Thieroff, James Pendleton, and Richard Lively (INDOT) also participated in the research meetings and provided valuable input. Special thanks to David Miller and Bill Fuchs (Midwest Mole); Keith Miller and Brian Smith (Miller Pipeline Corp.) and Hart Wilson, (Westcon Microtunneling, Inc.) for providing access to their project sites and for assisting in data collection. The authors also thank Felix Rantow, Kok Kuan Ng, Beth Ritzert, and Michelle Leung for their assistance in the development of SETT - the Decision Support System (DSS) and the web-based educational tool. 


\section{TECHNICAL Summary}

INDOT Research

Technology Transfer and Project Implementation Information

TRB Subject Code:21-4 Utilities Accommodation

Publication No.: FHWA/IN/JTRP-2002/7, SPR-2453

August 2002

Final Report

\section{DEVELOPMENT OF A DECISION SUPPORT SYSTEM FOR SELECTION OF TRENCHLESS TECHNOLOGIES TO MINIMIZE IMPACT OF UTILITY CONSTRUCTION ON ROADWAYS}

\section{Introduction}

The need to replace deteriorating underground utility infrastructure and to expand utility services increases the need for utility conduits to intersect roadways. Open-trench method is currently the most widely used method for installation of underground pipelines and conduits of all sizes. However, opencut construction has several shortcomings, chief amongst which are: health and safety concerns of workers, surface disturbance, disruption to vehicular/pedestrian traffic and reduction of pavement life. Cost-effective alternatives that do not require roadway excavation are needed in order to minimize traffic disruption. Trenchless technologies provide promise for the installation of conduits beneath roadways with minimal trenching (excavation). These technologies also have the potential of reducing environmental impacts, and have the added benefit of minimizing the handling, treatment and/or disposal of contaminated soil.

While the benefits of trenchless technology are quite apparent when compared to the conventional open-cut process, it is necessary to carefully evaluate the suitability and appropriateness of trenchless technologies on a project-by-project basis through due consideration of site conditions such as, access, right-of-way, geotechnical conditions, etc. Unfortunately, this is not always done due to the lack of a proper evaluation tool that takes into account all the project-specific criteria in a systematic fashion. Consequently, in some instances, the improper use of trenchless technologies has resulted in failures such as heaving or subsidence of the pavement damage to nearby utilities and facilities, and even fatalities.

A study was conducted to identify key trenchless technologies that have been successfully used for trenchless installation of new underground utility conduits, and to develop a decision support tool for the selection of trenchless technologies for the installation of conduits under highways. Based on an extensive literature review, discussions with contractors, and numerous site visits, five trenchless technologies have been selected for further analysis. These include: auger boring, horizontal directional drilling, microtunneling, pipe bursting and pipe ramming. Pipe bursting is also included in the research, as it is a trenchless renewal method. In addition, key features of pilot tube microtunneling, which is a hybrid of microtunneling and horizontal directional drilling, are described in this report.

\section{Findings}

The following objectives were addressed through this study:

a) Trenchless technologies comprise an array of different methods or techniques, with each method having certain capabilities and limitations. Installing conduits beneath roadways with trenchless technology requires not only different equipment but 
also different personnel skills than those needed when open excavation is used. Thus, not only is it critical to ensure that the proper equipment and method are selected for a particular application, but also that the operator and crew have adequate skills and experience. In addition, municipalities, state transportation agencies, and utility companies need good tools for sound decision-making regarding the selection of appropriate technologies for the project of installation of conduits. A decision support tool, named SETT - Selection and Evaluation of Trenchless Technologies, was developed in order to facilitate the decision-making processes for the selection of trenchless technologies during the early stages of utility and pipeline infrastructure projects.

b) In 1989, when the current specifications related to trenchless pipeline installation were adopted, the area of trenchless construction was in its infancy, with very little track record, and even fewer instances of documented performance criteria or specifications. Since that time, the technologies examined addressed in the specifications (namely, horizontal earth boring, pipe jacking and utility tunneling) have been enhanced; and new technologies have been developed. The new technologies rely on sophisticated guidance systems, and increased instrumentation and operator skill requirements to carry out the tasks. The current INDOT specifications fail to address the newer trenchless technologies such as horizontal directional drilling, pipe bursting, pipe ramming, etc. Hence, specifications were developed, in collaboration with INDOT engineers and designers, and contractors for the evaluation and use of trenchless methods for utility installations. These specifications were adopted by the INDOT Specifications Committee in March 2002.

c) Extensive discussions with the Study Advisory Committee indicated the importance of having an appropriate training tool to assist entry-level engineers and infrastructure asset managers in gaining a basic understanding of trenchless technologies. A multimedia educational tool was developed using photographs and video clips that were collected from project sites. The video clips enable the users to "see" the different steps in each of the trenchless technologies, the installation of equipment, the drilling mechanisms, and so on.

\section{Implementation}

Personnel from the Information Technology and Systems Technology groups at INDOT have been involved with the research team and the Study Advisory Committee regarding implementation issues.

a) The source code of Decision Support Tool, SETT, has been transferred to Mr. James Pendleton and Mr. Richard Lively, INDOT Systems Technology group.

b) The multimedia educational tool will be hosted on the JTRP server. At present it is hosted on a Purdue server.
It is recommended that technical details in SETT and the descriptions in multimedia educational tool be updated every two-three years.

c) The specifications developed as part of this study have been adopted by the INDOT Specifications Committee and are available to INDOT engineers.

It is recommended that INDOT conduct an evaluation of the utilization of the decision tool, SETT and the multimedia education tool, after they have been deployed. Such an evaluation will provide valuable information when updates are planned on these tools. 


\section{Contacts}

For more information:

Prof. Dulcy Abraham

Principal Investigator

School of Civil Engineering

Purdue University

West Lafayette IN 47907

Phone: (765) 494-2239

Fax: (765) 494-0644
Indiana Department of Transportation

Division of Research

1205 Montgomery Street

P.O. Box 2279

West Lafayette, IN 47906

Phone: (765) 463-1521

Fax: (765) 497-1665

\section{Purdue University}

Joint Transportation Research Program

School of Civil Engineering

West Lafayette, IN 47907-1284

Phone: (765) 494-9310

Fax: (765) 496-1105 
TECHNICAL REPORT STANDARD TITLE PAGE

\begin{tabular}{|c|c|c|}
\hline $\begin{array}{l}\text { 1. Report No. } \\
\text { FHWA/IN/JTRP-2002/7 }\end{array}$ & 2. Government Accession No. & 3. Recipient's Catalog No. \\
\hline \multirow{2}{*}{\multicolumn{2}{|c|}{$\begin{array}{l}\text { 4. Title and Subtitle } \\
\text { Development of a Decision Support System for Selection of Trenchless Technologies to } \\
\text { Minimize Impact of Utility Construction on Roadways }\end{array}$}} & $\begin{array}{l}\text { 5. } \quad \text { Report Date } \\
\text { August } 2002\end{array}$ \\
\hline & & 6. Performing Organization Code \\
\hline \multicolumn{2}{|c|}{$\begin{array}{l}\text { 7. Author(s) } \\
\text { Dulcy M. Abraham, Hyeon Shik Baik, Sanjiv Gohale }\end{array}$} & $\begin{array}{l}\text { 8. Performing Organization Report No. } \\
\text { FHWA/IN/JTRP-2002/7 }\end{array}$ \\
\hline \multirow{2}{*}{\multicolumn{2}{|c|}{$\begin{array}{l}\text { 9. Performing Organization Name and Address } \\
\text { Joint Transportation Research Program } \\
1284 \text { Civil Engineering Building } \\
\text { Purdue University } \\
\text { West Lafayette, IN 47907-1284 }\end{array}$}} & 10. Work Unit No. \\
\hline & & $\begin{array}{l}\text { 11. Contract or Grant No. } \\
\text { SPR-2453 }\end{array}$ \\
\hline \multirow{2}{*}{\multicolumn{2}{|c|}{$\begin{array}{l}\text { 12. Sponsoring Agency Name and Address } \\
\text { Indiana Department of Transportation } \\
\text { State Office Building } \\
100 \text { North Senate Avenue } \\
\text { Indianapolis, IN } 46204\end{array}$}} & $\begin{array}{l}\text { 13. Type of Report and Period Covered } \\
\text { Final Report }\end{array}$ \\
\hline & & 14. Sponsoring Agency Code \\
\hline \multicolumn{3}{|l|}{ 15. Supplementary Notes } \\
\hline
\end{tabular}

\section{Abstract}

The need to replace deteriorating underground utility infrastructure and to expand utility services, increases the need for utility conduits to intersect roadways. Open-trench method is currently the most widely used method for installation of underground pipelines and conduits of all sizes. However, open-cut construction has several shortcomings, chief amongst which are: health and safety concerns of workers, surface disturbance, disruption to vehicular/pedestrian traffic and reduction of pavement life. Today, other cost-effective alternatives exist to traditional open-trench construction. These methods are categorized as "Trenchless Technologies" as they require minimum trenching (excavation).

While the benefits of trenchless technology are quite apparent when compared to the conventional open-cut process, it is necessary to carefully evaluate the suitability and appropriateness of trenchless technologies on a project-by-project basis through due consideration of site conditions such as, access, right-of-way, geotechnical conditions, etc. Unfortunately, this is not always done due to the lack of a proper evaluation tool that takes into account all the project-specific criteria in a systematic fashion. Consequently, in some instances, the improper use of trenchless technologies has resulted in failures such as heaving or subsidence of the pavement damage to nearby utilities and facilities; and even fatalities.

The primary objectives of this study included the following:

a) Development of a Decision Support System for the selection and performance of trenchless technologies for the installation of conduits under roadways:

b) Development of specifications for selected trenchless construction methods:

c) Development of a multimedia educational tool to train INDOT engineers.

All these objectives were accomplished. The deployment of the specifications and tools developed as part of this study will be undertaken by the Indiana Department of Transportation (INDOT).

\section{Key Words}

Trenchless technologies, auger boring, microtunneling, pipe ramming, pipe jacking, horizontal directional drilling, pilot tube microtunneling, specifications, decision support system, multimedia educational tool.

\section{Distribution Statement}

No restrictions. This document is available to the public through the National Technical Information Service, Springfield, VA 22161

\begin{tabular}{|c|c|c|c|}
\hline $\begin{array}{c}\text { 19. Security Classif. (of this report) } \\
\text { Unclassified }\end{array}$ & 20. Security Classif. (of this page) & 21. No. of Pages & 22. Price \\
\hline
\end{tabular}




\begin{abstract}
The need to replace deteriorating underground utility infrastructure and to expand utility services, increases the need for utility conduits to intersect roadways. Open-trench method is currently the most widely used method for installation of underground pipelines and conduits of all sizes. However, open-cut construction has several shortcomings, chief amongst which are: health and safety concerns of workers, surface disturbance, disruption to vehicular/pedestrian traffic and reduction of pavement life. Today, other cost-effective alternatives exist to traditional open-trench construction. These methods are categorized as "Trenchless Technologies" as they require minimum trenching (excavation).

While the benefits of trenchless technology are quite apparent when compared to the conventional open-cut process, it is necessary to carefully evaluate the suitability and appropriateness of trenchless technologies on a project-by-project basis through due consideration of site conditions such as, access, right-of-way, geotechnical conditions, etc. Unfortunately, this is not always done due to the lack of a proper evaluation tool that takes into account all the project-specific criteria in a systematic fashion. Consequently, in some instances, the improper use of trenchless technologies has resulted in failures such as heaving or subsidence of the pavement damage to nearby utilities and facilities; and even fatalities.
\end{abstract}

The primary objectives of this study included the following:

a) Development of a Decision Support System for the selection and performance of trenchless technologies for the installation of conduits under roadways:

b) Development of specifications for selected trenchless construction methods:

c) Development of a multimedia educational tool to train INDOT engineers.

All these objectives were accomplished. The deployment of the specifications and tools developed as part of this study will be undertaken by the Indiana Department of Transportation (INDOT).

\title{
KEYWORDS
}

Trenchless technologies, auger boring, microtunneling, pipe ramming, pipe jacking, horizontal directional drilling, pilot tube microtunneling, specifications, decision support system, multimedia educational tool. 


\section{TABLE OF CONTENTS}

List of Figures.............................................................................................................iv

List of Tables ............................................................................................................................. viii

CHAPTER 1 INTRODUCTION ...................................................................................

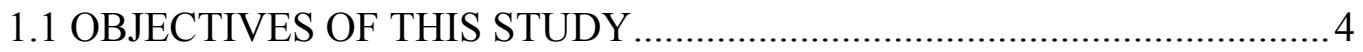

1.2 ORGANIZATION OF THE REPORT ....................................................

CHAPTER 2 OVERVIEW OF TRENCHLESS TECHNOLOGIES ........................6

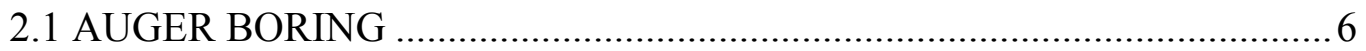

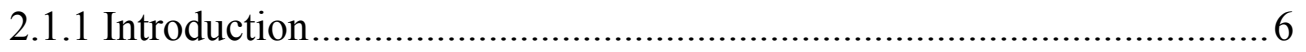

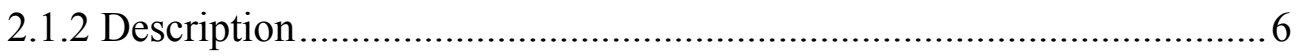

2.1.3 Main Features and Application Range................................................ 14

2.2 HORIZONTAL DIRECTIONAL DRILLING ............................................. 18

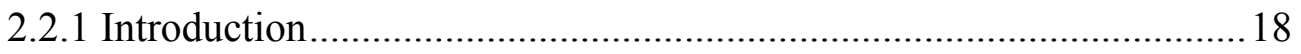

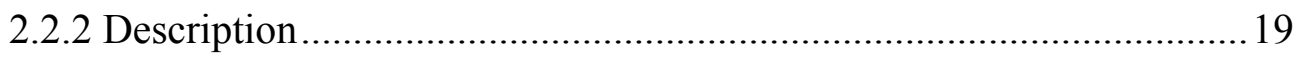

2.2.3 Main Features and Application Range...................................................26

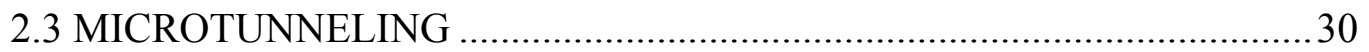

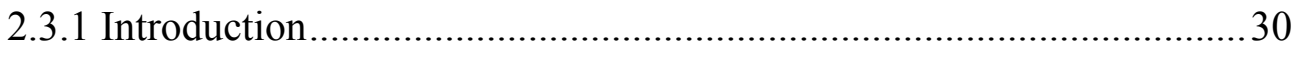

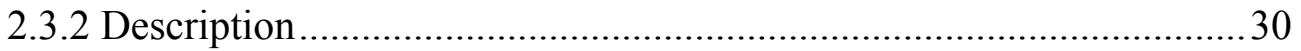

2.3.3 Main Features and Application Range..................................................4 40

2.4 PILOT TUBE MICROTUNNELING........................................................

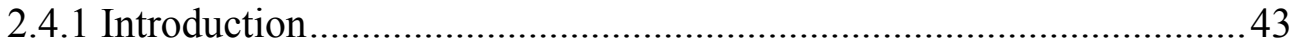

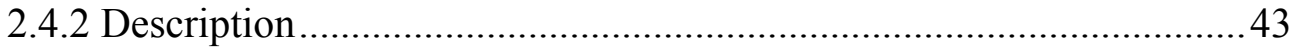

2.4.3 Main Features and Application Range.................................................50

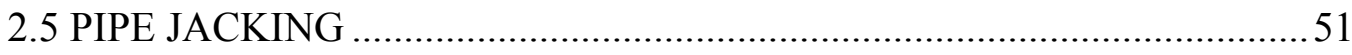

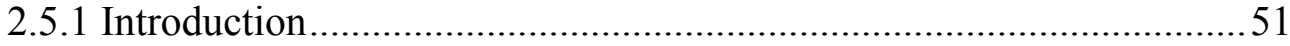

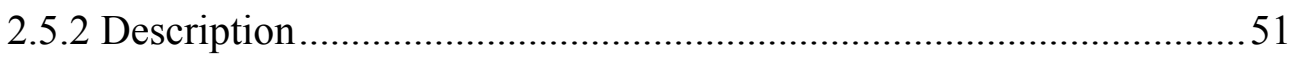

2.5.3 Main Features and Application Range...............................................57

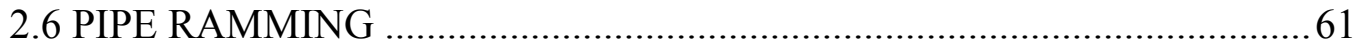




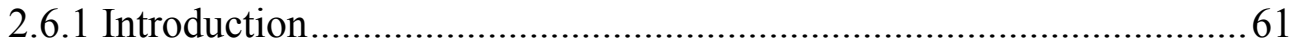

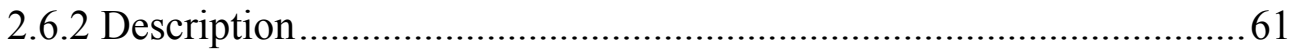

2.6.3 Main Features and Application Range..................................................65

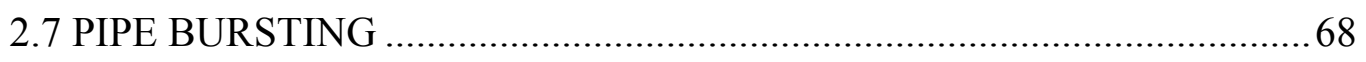

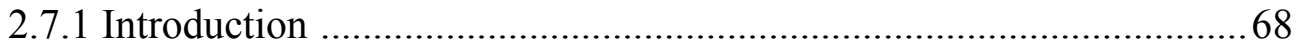

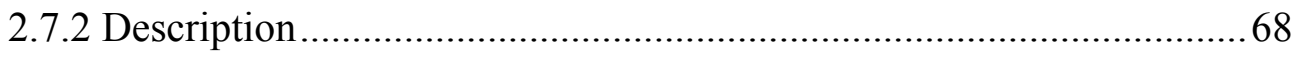

2.7.3 Main Features and Application Range............................................. 77

CHAPTER 3 SPECIFICATIONS FOR TRENCHLESS TECHNOLOGIES ......79

CHAPTER 4 MULTIMEDIA EDUCATIONAL TOOL …......................................84

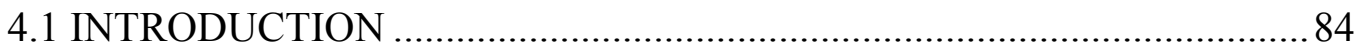

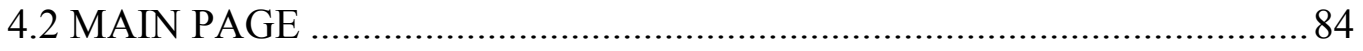

4.3 WEB PAGES FOR TRENCHLESS TECHNOLOGIES …………………..... 85

4.4 WEB PAGE FOR RELATED LINKS ………………………………...... 87

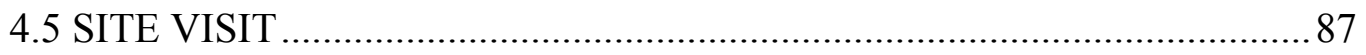

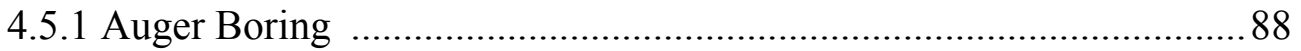

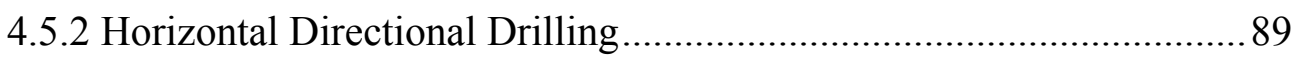

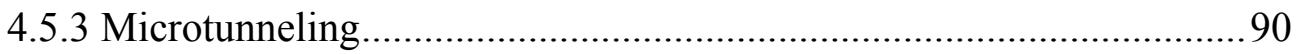

4.5.4 Pilot Tube Microtunneling (Guided Boring) .........................................91

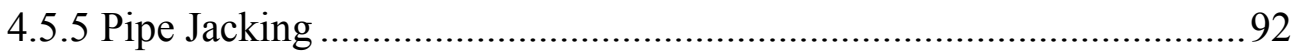

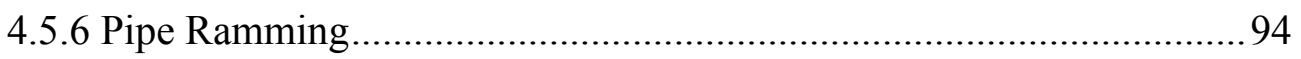

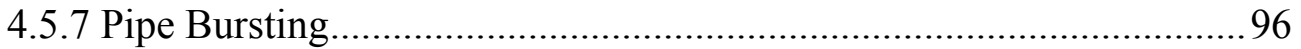

\section{CHAPTER 5 A DECISION SUPPORT SYSTEM FOR THE SELECTION OF} TRENCHLESS TECHNOLOGIES ...................................................................................98

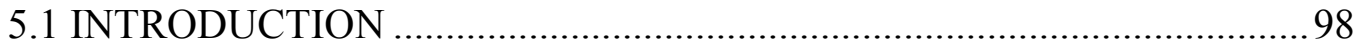

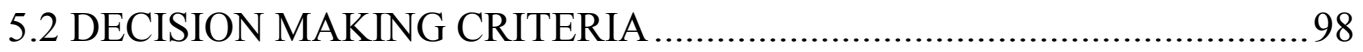

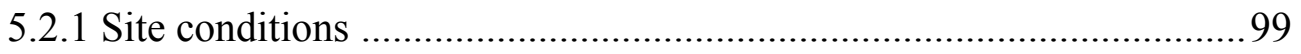

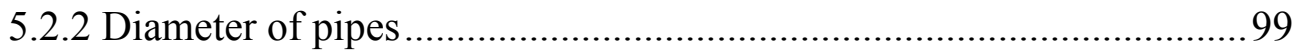

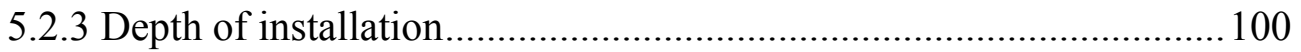

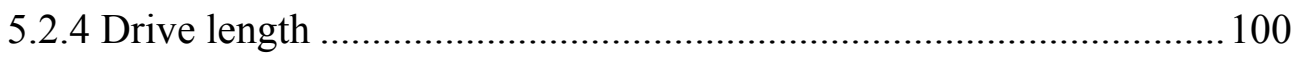

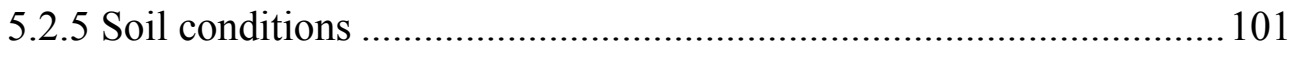




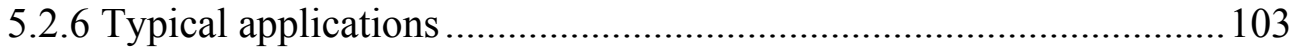

5.3 SETT FOR THE SELECTION OF TRENCHLESS TECHNOLOGIES ... 104

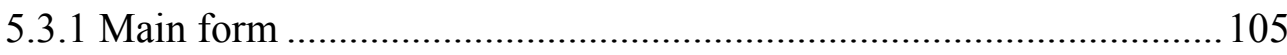

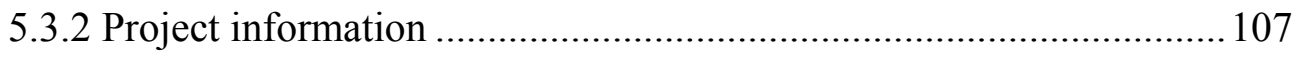

5.3.3 Evaluation of site conditions............................................................ 110

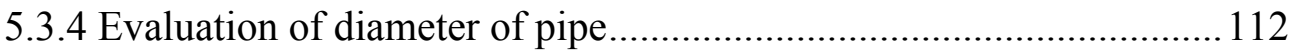

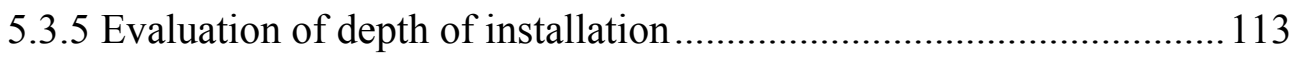

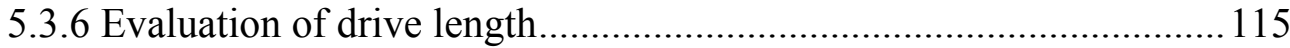

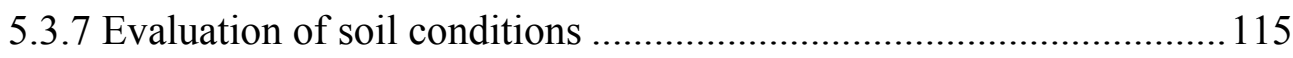

5.3.8 Evaluation of typical application .................................................... 116

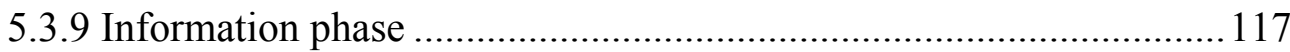

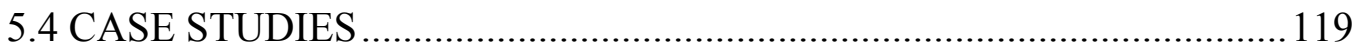

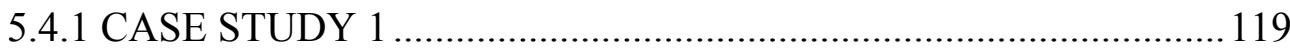

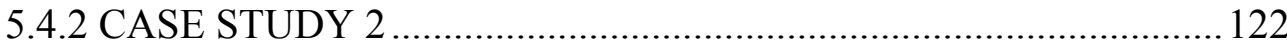

CHAPTER 6 SUMMARY, RECOMMENDATIONS,

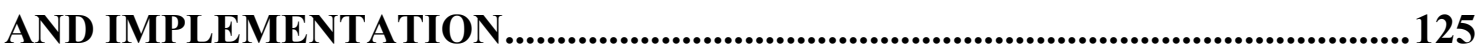

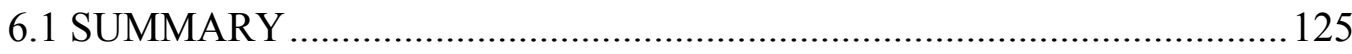

6.2 RECOMMENDATIONS FOR FUTURE WORK ……………………...... 131

6.3 IMPLEMENTATION OF THE FINDINGS OF THE STUDY ..................132

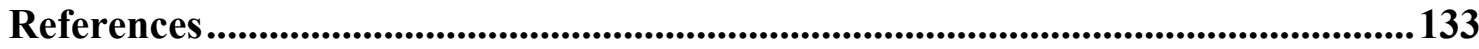

APPENDIX A: Part of Visual Basic Code ...............................................................137

APPENDIX B: Questionnaire used for Data Collection .............................................150 


\section{LIST OF FIGURES}

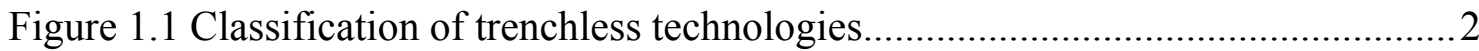

Figure 2.1 Track type auger boring ……….............................................................

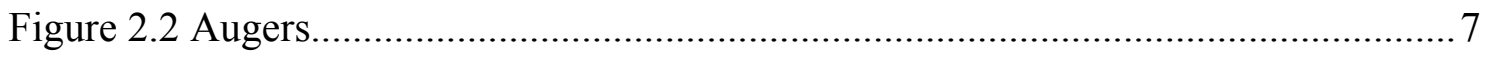

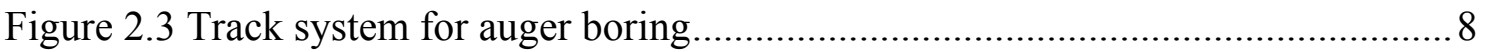

Figure 2.4 Auger boring machine on the track ......................................................... 10

Figure 2.5 Water level............................................................................................ 10

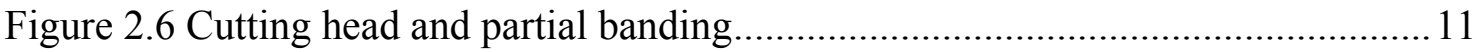

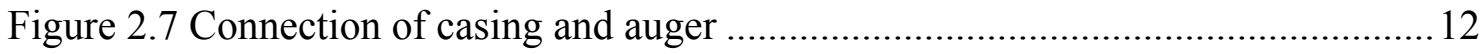

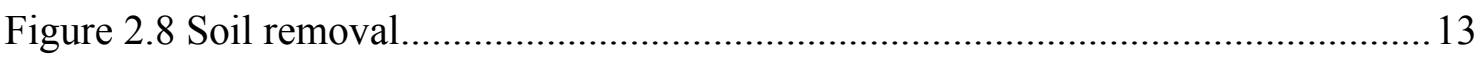

Figure 2.9 Cradle type auger boring ....................................................................... 14

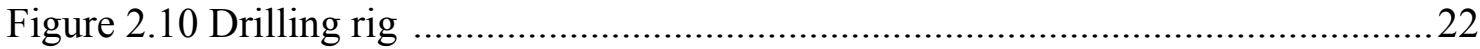

Figure 2.11 Components of pullback operation......................................................24

Figure 2.12 Receiver for walkover tracking system .....................................................25

Figure 2.13 Typical slurry type MTBM ………………………………………........ 31

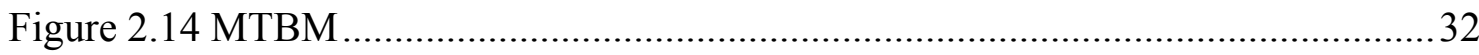

Figure 2.15 Cutting head....................................................................................... 32

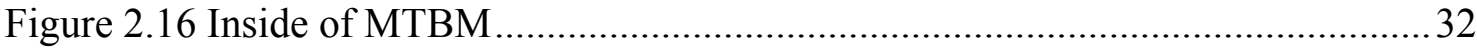

Figure 2.17 Jacking frame for microtunneling ............................................................33

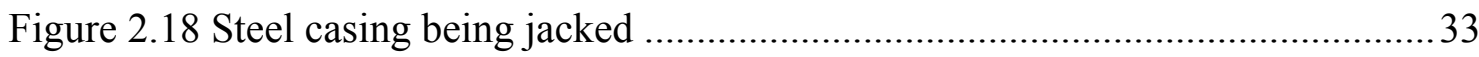

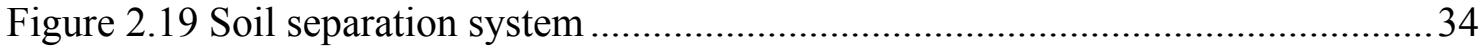

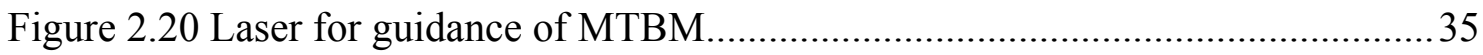

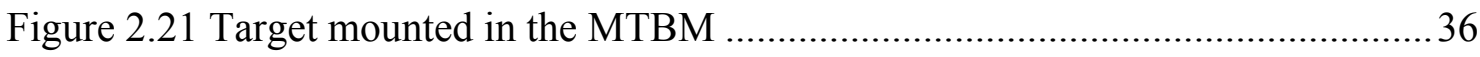

Figure 2.22 Operation board ...................................................................................... 36

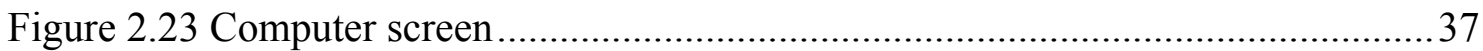

Figure 2.24 Monitor for communication ……………................................................. 37

Figure 2.25 Monitor showing a view inside the MTBM ...................................................38

Figure 2.26 Overview of construction site for the slurry type method.............................38

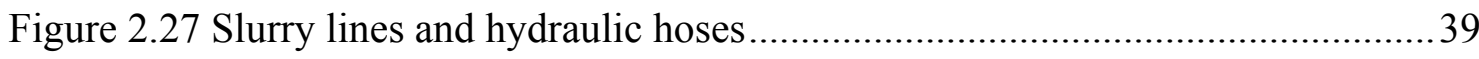

Figure 2.28 MTBM at the receiving shaft .................................................................40 
Figure 2.29 Steering heads for PTMT ………………................................................4

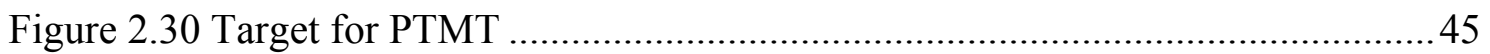

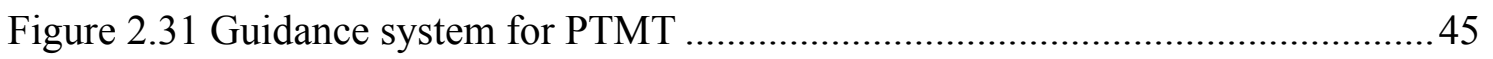

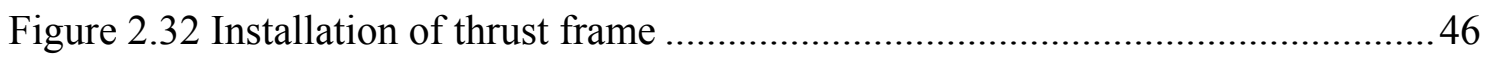

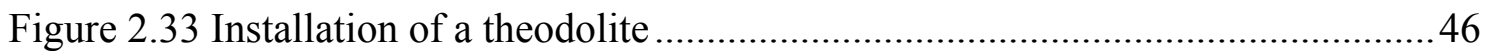

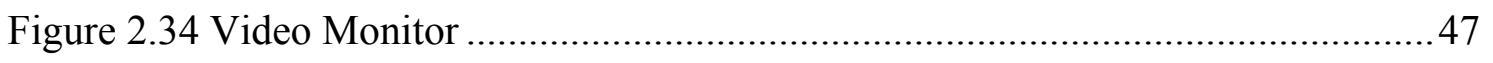

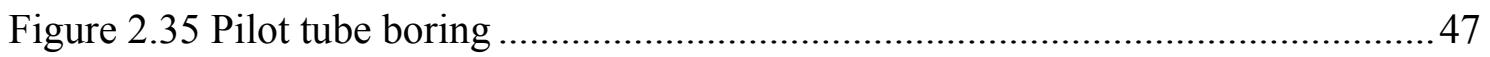

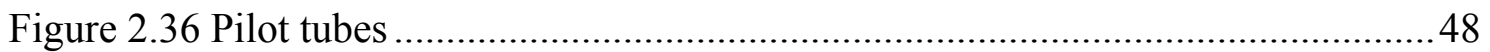

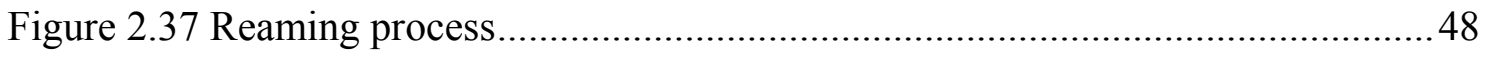

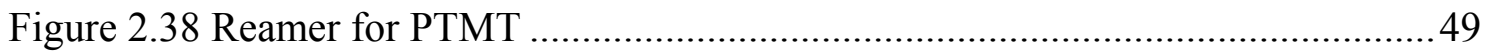

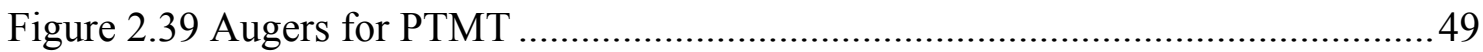

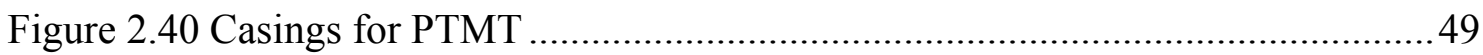

Figure 2.41 Installation of pipes using PTMT …………........................................50

Figure 2.42 Pipe adapter for PTMT .................................................................5

Figure 2.43 Typical components of a pipe jacking operation.......................................52

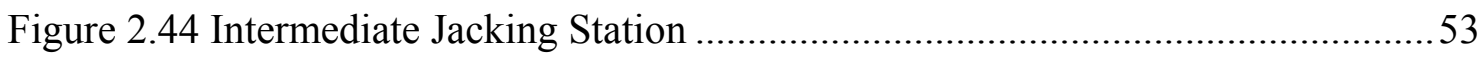

Figure 2.45 Laser guidance system for pipe jacking ………………........................54

Figure 2.46 Laser point for alignment control ..........................................................5

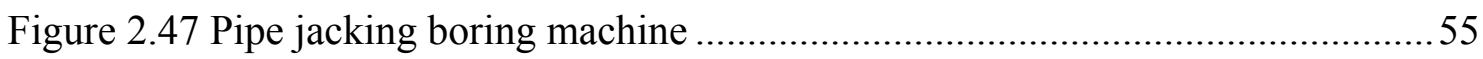

Figure 2.48 Control panel for the jacking machine ………….................................56

Figure 2.49 The set up for pipe jacking operation ......................................................57

Figure 2.50 Open-face pipe ramming process ...........................................................62

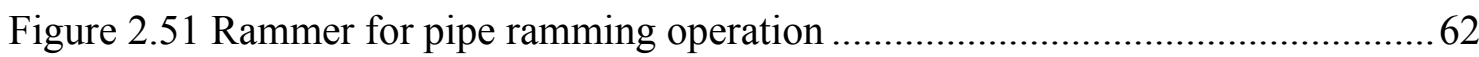

Figure 2.52 Steel casings and augers for pipe ramming projects ...................................63

Figure 2.53 Rammer and casing supported by a backhoe ............................................64

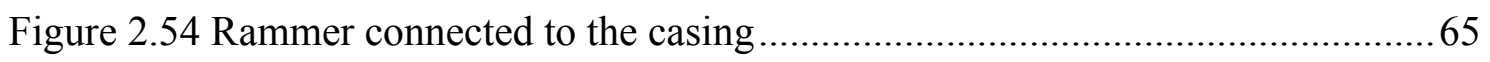

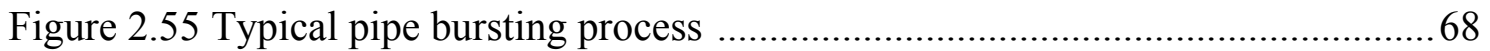

Figure 2.56 Bursting head and product pipe ..................................................................69

Figure 2.57 Winch for pipe bursting operation.......................................................... 70

Figure 2.58 Pneumatic pipe bursting process ……………......................................... 71

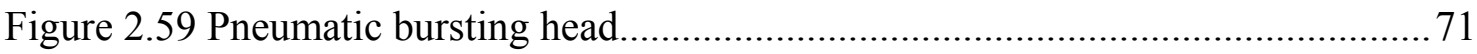


Figure 2.60 Static Pull System and static head.......................................................... 72

Figure 2.61 Hydraulic bursting head ...................................................................

Figure 2.62 Control panel for hydraulic bursting system ............................................ 74

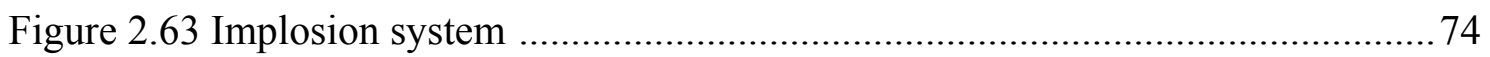

Figure 2.64 Pipe joint using butt fusion.......................................................................

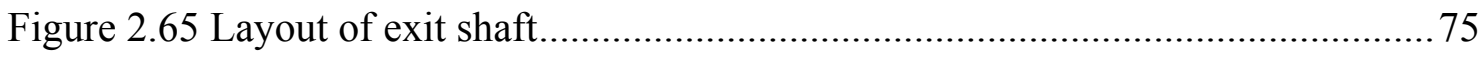

Figure 2.66 Connection of bursting head and pipe ...................................................

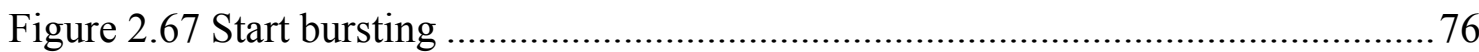

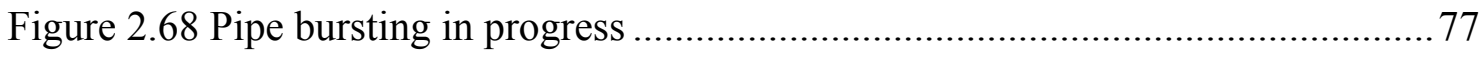

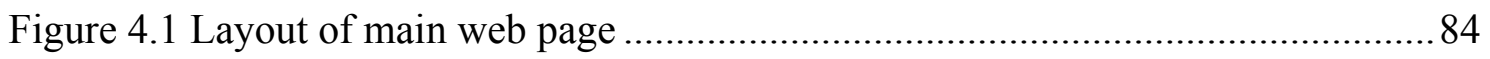

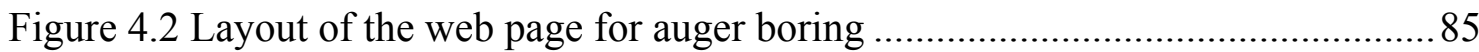

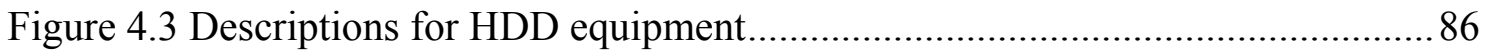

Figure 4.4 Captured image of video clip movie ............................................................8

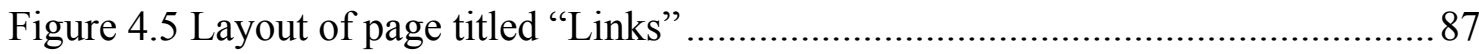

Figure 4.6 Installation of storm water pipe using auger boring .................................. 88

Figure 4.7 Installation of gas line using horizontal directional drilling.........................8 89

Figure 4.8 Installation of sewer pipe using microtunneling .........................................90

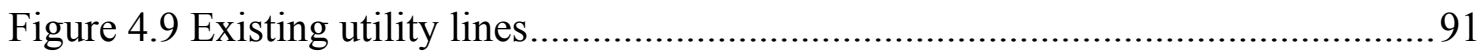

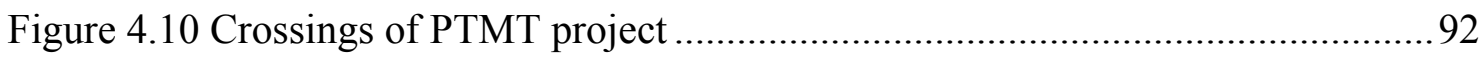

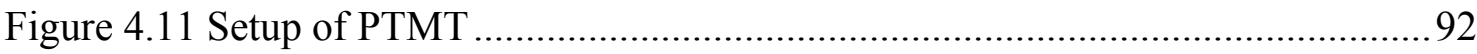

Figure 4.12 Layout of working area of pipe jacking …………..................................93

Figure 4.13 Soil excavated from the bore hole .......................................................... 94

Figure 4.14 Railroad crossing for pipe ramming project...........................................94

Figure 4.15 Layout of pipe ramming site.....................................................................95

Figure 4.16 Soil condition of pipe ramming project.................................................96

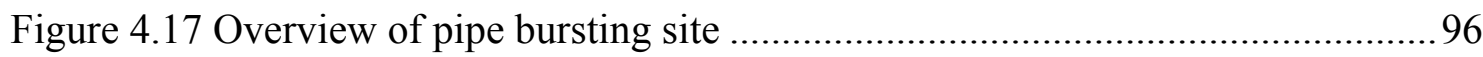

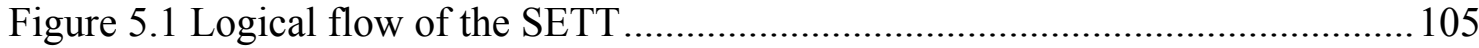

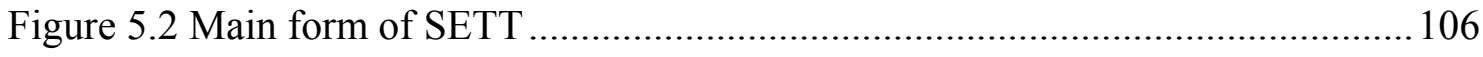

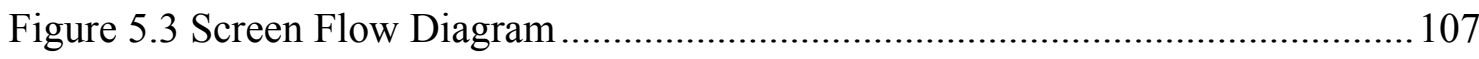

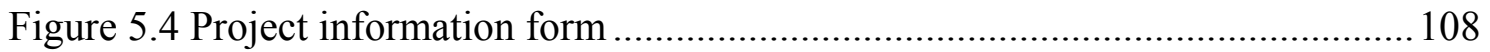

Figure 5.5 Error message for missing input data ……........................................... 108 


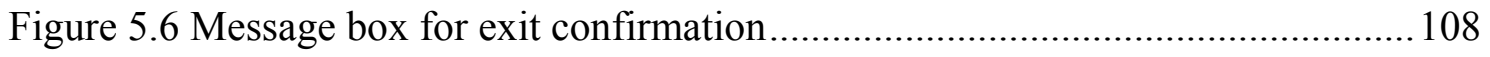

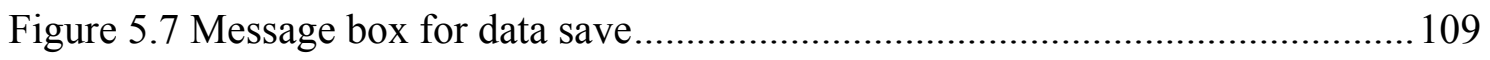

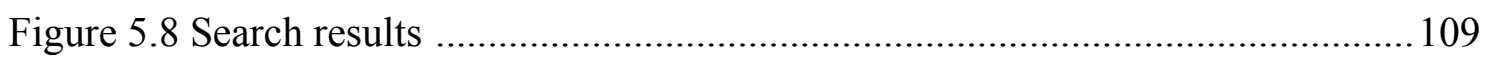

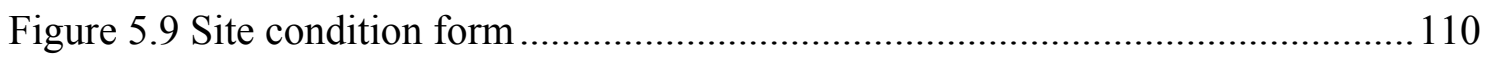

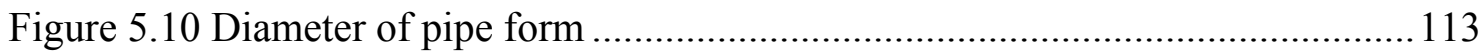

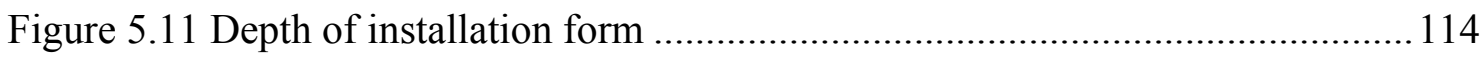

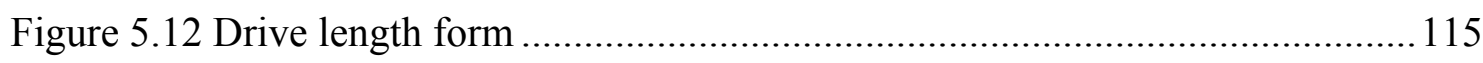

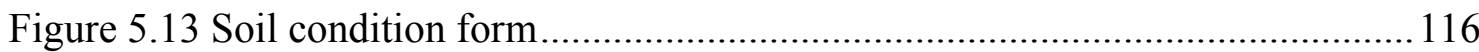

Figure 5.14 Typical application ...................................................................117

Figure 5.15 Type of pipes used for trenchless technologies ........................................118

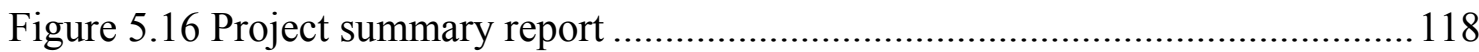

Figure 5.17 Storm water installation using auger boring........................................... 119

Figure 5.18 The evaluation of site conditions.........................................................120

Figure 5.19 Method selection using diameter of pipe................................................ 121

Figure 5.20 Summary of the evaluation results ...................................................... 121

Figure 5.21 Overview of the gas project.................................................................... 122

Figure 5.22 Method selection using length of drive ................................................ 123

Figure 5.23 Summary of the evaluation results of gas project .................................... 124

Figure 5.24 Concerns to be addressed during preplanning........................................... 124 


\section{LIST OF TABLES}

Table 2.1 Comparison of main features of typical HDD methods ............................... 19

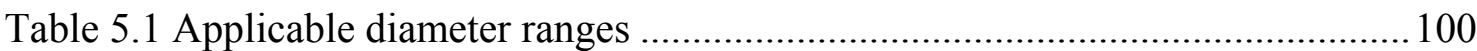

Table 5.2 Applicable depth of installation ranges ............................................... 100

Table 5.3 Applicable drive length ranges ............................................................. 101

Table 5.4. Applicability of trenchless technologies in various soil conditions ............. 102

Table 5.5 Applicability of trenchless technologies for soil conditions

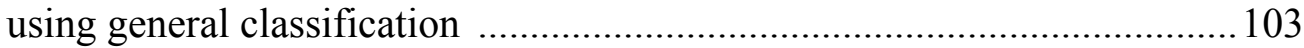

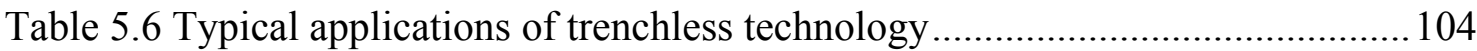

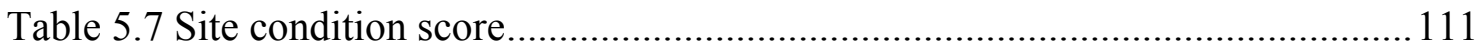

Table 5.8 Type of pipe used for trenchless technology ......................................... 117

Table 5.9 Data summary for storm water project ................................................ 120

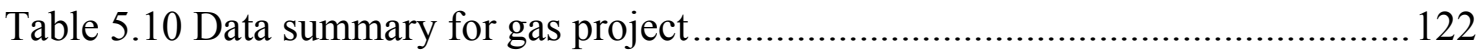

Table 6.1 Description of trenchless construction methods ....................................... 126

Table 6.2 Overview of trenchless technology methods ......................................... 128 


\section{CHAPTER 1 INTRODUCTION}

Utility demand in the United States is projected to expand 3 percent annually to 183 million feet in the year 2003, with a valuation exceeding \$7 billion (Underground Construction 1999). The need to replace deteriorating underground utility infrastructure and to expand utility services, increases the need for utility conduits to intersect roadways. Open-trench method is currently the most widely used method for installation of underground pipelines and conduits of all sizes. However, open-cut construction has several shortcomings, chief amongst which are: health and safety concerns of workers, surface disturbance, disruption to vehicular/pedestrian traffic and reduction of pavement life (Iseley and Gokhale 1997).

Today, other cost-effective alternatives exist to traditional open-trench construction. These methods are categorized as "Trenchless Technologies" as they require minimum trenching (excavation). Some of the trenchless technologies have been used for the installation of conduits for decades. For example, Auger Boring (AB) has been used since the 1940s and Pipe Jacking (PJ) has been used since the early 1900s. Since then, many new trenchless techniques have been introduced and many advancements have taken place with the more traditional techniques. Figure 1.1 shows the classification

of trenchless technologies (Iseley and Tanwani 1993). This system segments the industry into three major categories: (1) Horizontal Earth Boring (HEB); (2) Pipe Jacking (PJ); and (3) Utility Tunneling (UT).

Horizontal earth boring includes methods in which the borehole excavation is accomplished through mechanical means without workers being inside the bore hole. Both PJ and UT techniques require workers inside the bore hole during excavation and casing installation process. However, PJ is differentiated from UT by the support structure. PJ methods utilize prefabricated pipe sections. New pipe sections are installed in the pit when the jacks are in a retracted position so that the complete string of pipe can be jacked forward. While UT techniques may use the same excavation equipment, the support structure is constructed at the face. The support structure is traditional tunnel liner plates or steel ribs with wooden lagging. 


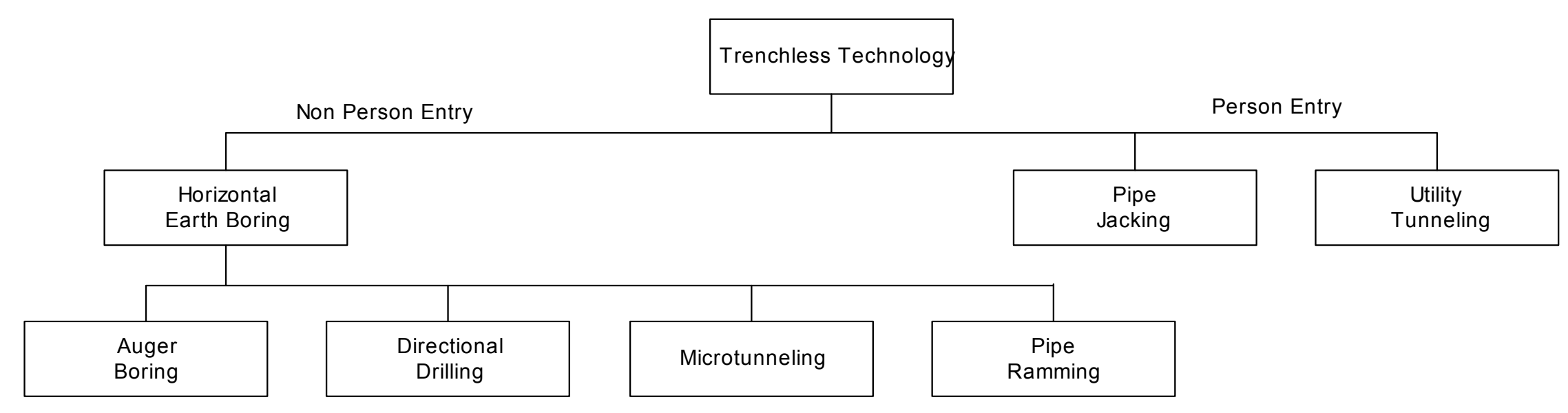

Figure 1.1 Classification of trenchless technologies 
While the benefits of trenchless technology are quite apparent when compared to the conventional open-cut process, it is necessary to carefully evaluate the suitability and appropriateness of trenchless technologies on a project by project basis through due consideration to site conditions such as, access, right-of-way, geotechnical conditions, etc. Unfortunately, this is not always done due to the lack of a proper evaluation tool that takes into account all the project specific criteria in a systematic fashion. Consequently, in some instances, improper use of trenchless technologies has resulted in failures such as heaving or subsidence of the pavement (Gas Research Institute 1991); damage to nearby utilities and facilities; and even fatalities (Indianapolis Star 1997).

State departments of transportation (DOTs) are being asked by utility owners and contractors to evaluate the feasibility and compatibility of trenchless methods for a wide range of utility installations. In some cases, the DOT is directly involved in the design and construction of trenchless projects, whereas, in other cases, the DOT is responsible for issuing a permit to a utility owner for the installation of conduits beneath its roadways.

Trenchless technologies comprise an array of different methods or techniques, with each method having certain capabilities and limitations. Installing conduits beneath roadways with trenchless technology requires not only different equipment but also different personnel skills than those needed when open excavation is used. Thus, not only is it critical to ensure that the proper equipment and method are selected for a particular application, but also that the operator and crew have adequate skills and experience. In addition, municipalities, state transportation agencies, and utility companies need good tools for sound decision-making regarding the selection of appropriate trenchless technologies for the project of installation of conduits.

In 1988, the Indiana Department of Transportation funded an investigative study to document case studies of some of the early applications of trenchless technologies for utility construction under highways (Iseley et al. 1989). At that time, the area of trenchless construction was in its infancy, with very little track record, and even fewer instances of documented performance criteria or specifications. Since that time, the technologies examined in the INDOT study (horizontal earth boring, pipe jacking and utility tunneling) have been enhanced; and new technologies have been developed. The 
new technologies rely on sophisticated guidance systems, and increased instrumentation and operator skill requirements to carry out the tasks. Current INDOT specifications fail to address the newer trenchless technologies such as horizontal directional drilling, pipe bursting, pipe ramming, etc. INDOT personnel have little experience and training in the selection and inspection of trenchless technologies.

\subsection{OBJECTIVES OF THIS STUDY}

When the research project (SPR-2453) was funded in June 2000, the primary objective of the study was to develop a Decision Support System for the selection and performance of trenchless technologies for the installation of conduits under roadways. The Study Advisory Committee (SAC) for this project suggested that the research team add the following enhancements to the project:

a) development of specifications for selected trenchless construction methods,

b) development of a multimedia educational tool.

All these objectives were accomplished, and will be discussed in this report.

\subsection{ORGANIZATION OF THE REPORT}

This report presents an overview of trenchless technologies that can be employed to install new conduits under the ground. The trenchless technologies considered in this research include auger boring (AB), horizontal directional drilling (HDD), microtunneling (MT), pipe jacking (PJ) and pipe ramming (PR). Pipe bursting (PB) is also included in the research, even though PB is not a trenchless method for new installation. Chapter 2 provides an overview of each of these technologies. Specifications relating to the use of trenchless technologies alternatives on INDOT projects were developed. These specifications were approved by the INDOT Specifications Committee in March 2002. The complete text of these specifications is provided in Chapter 3. A multimedia educational tool was developed to provide information about the trenchless technologies and to assist the municipalities, state transportation agencies, and contractors to understand the trenchless technology more easily. The multimedia tools 
include photographs and movie clips taken at the construction sites, and are accompanied by the web pages with the descriptions about the trenchless technologies. A short description of this tool is provided in Chapter 4. In order to facilitate the decisionmaking processes for the selection of trenchless technologies during the early stages of utility and pipeline infrastructure projects, a tool named "Selection and Evaluation of Trenchless Technologies (SETT)" was developed. Details of this tool are presented in Chapter 5. The final chapter, Chapter 6 discusses recommendations for future research in this area, and also presents a preliminary plan for implementing the findings of this study. 


\section{CHAPTER 2 OVERVIEW OF TRENCHLESS TECHNOLOGIES}

\subsection{AUGER BORING}

\subsubsection{Introduction}

Auger boring is one of the trenchless technologies that can drill bore holes by rotating the cutting head. The cutting head is attached to the augers which stay inside the casings. The auger boring machine generates torque which is transmitted to the cutting head through the flighted tube. The auger boring operation requires a driving shaft and reception shaft. The boring equipment including auger boring machine, augers, and cutting head is located in the driving shaft and drills horizontal bore holes in the ground. Spoil is removed from the bore hole to the backside of the casing by the movements of helicalwound auger flights. The vertical alignment of the auger boring operation can be controlled using a water level. However, it is difficult to control the horizontal alignment in auger boring operation. In some cases, the auger boring operation can drill the ground without using casings. However, since this uncased auger boring may induce some hazards, it is not desirable to use this method for general cases.

\subsubsection{Description}

\subsubsection{Track type auger boring method}

There are two types in auger boring methods. One is the track type auger boring method and the other is the cradle type auger boring method. The track type auger boring operation consists of other equipment such as boring machine, casings, cutting head, and augers. The track type also can employ casing lubrication system, steering system, locating system, and casing leading-edge band for its operation. The auger boring machine is located on the track and moves back and forth along the track while providing jacking and rotating force to the augers and casings during the boring operation. The layout of track type auger boring operation is shown in Figure 2.1. 


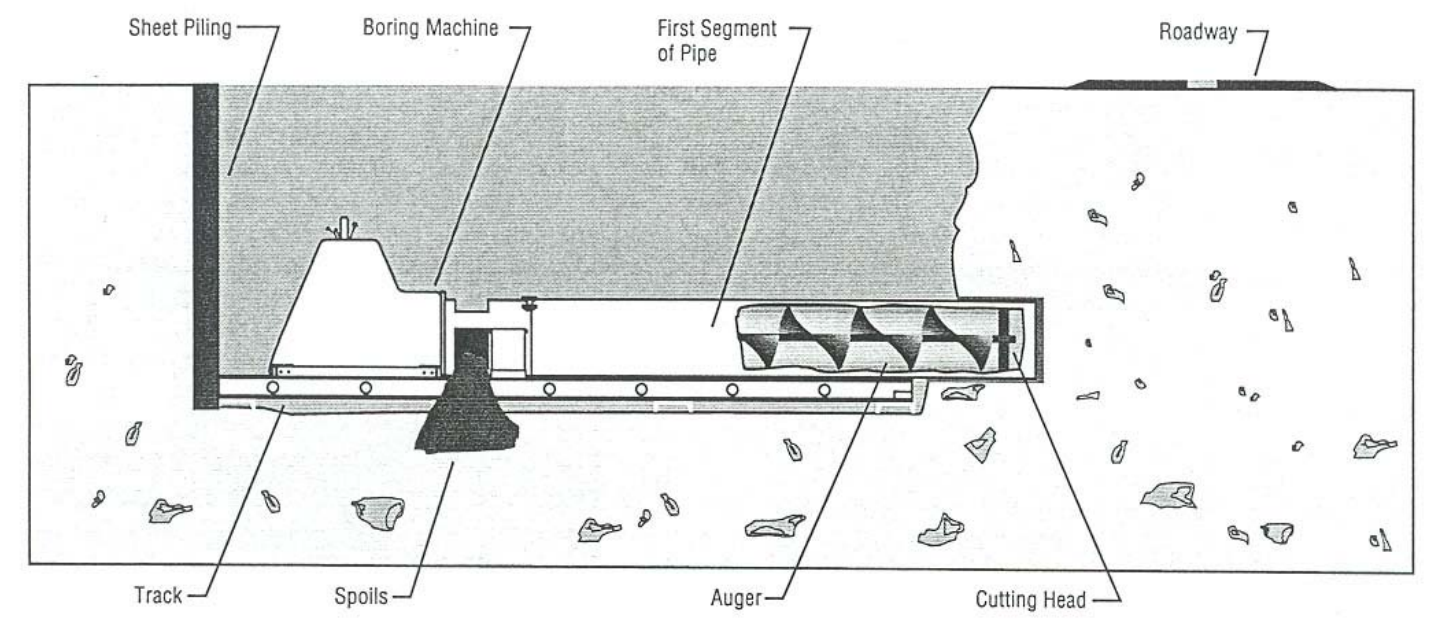

Figure 2.1 Track type auger boring (Iseley and Gokhale 1997)

The auger string is composed of connected augers end to end. One end of the auger string is connected to the boring machine, and the other end is linked to the cutting head. The torque and thrust force generated by the boring machine is transported through the auger string to the cutting head. The rotation of the cutting head and augers can cut out the ground and remove the spoils from the front of the casing to the back. At the same time, boring machine can proceed forward using the hydraulic jacking force supported by the thrust block. By repeating this operation, casing can be installed in the ground. Figure 2.2 shows the augers before connection.

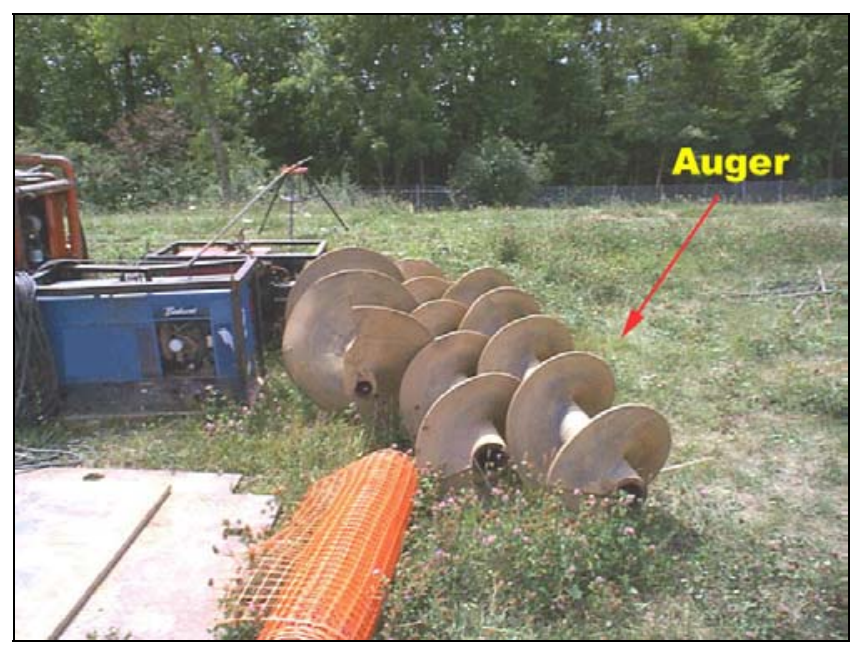

Figure 2.2 Augers 
The two main factors that affect auger boring are the torque and thrust. The torque is created by the power source which can be pneumatic, hydraulic or an internal combustion engine through a mechanical gearbox. The torque rotates the auger which, in turn, rotates the cutting head. One end of the rams is attached to the boring machine while the other end is attached to lugs that lock into the track system (Iseley and Tanwani 1993).

Since auger boring operation has a limited line and grade control, the initial set up of the track system in the driving shaft is critical to the accuracy of the auger boring operation. Therefore, a properly constructed drive shaft is important for the success of a track-type auger boring project. The shaft requires a stable foundation and adequate thrust block. The foundation must support the tracks, permitting the machine to move forward and backward without vertical movement. The track system must be placed on the same line and grade as the desired bore hole. If the track foundation settles, accuracy will be affected and binding forces could result within the bore hole. Often this foundation will require crushed stone or concrete as shown in Figure 2.3.

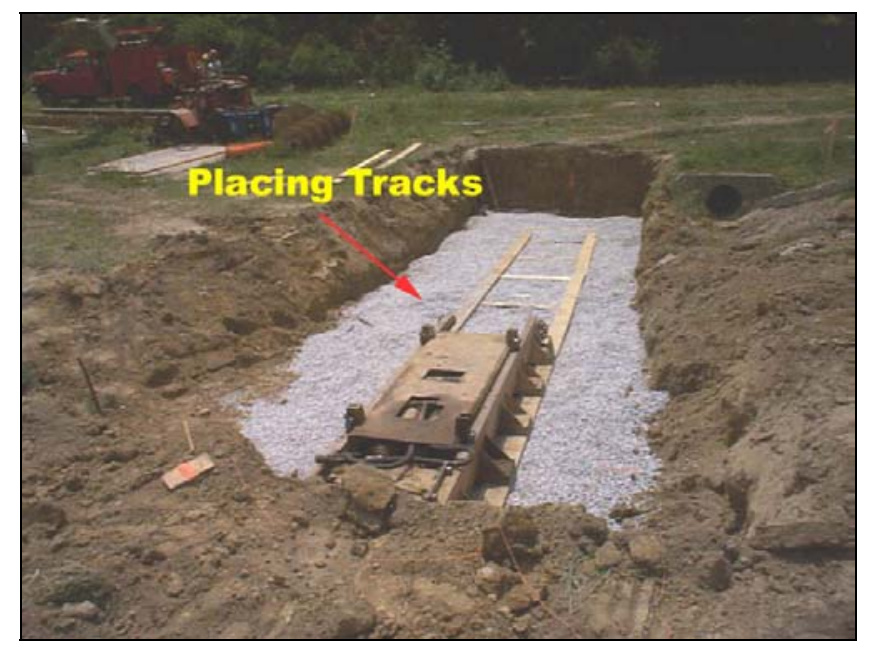

Figure 2.3 Track system for auger boring

The thrust block transmits the horizontal jacking forces from the tracks to the ground at the rear of the drive shaft. The thrust block must be designed to distribute the jacking force over sufficient area so that the allowable compressive strength of the soil is not exceeded. If the thrust block fails or moves, borehole accuracy will be compromised and binding forces could result within the bore hole. 
The track-type auger boring operation involves the following (Iseley et al. 1999):

1. Jobsite preparation

The step involves in the investigation of underground utilities and designing layout of jobs site securing enough space for boring and loading materials.

2. Bore pit excavation and preparation

The entrance and exit pits (or drive and reception shafts) are excavated. The excavation should follow the instructions given by local codes and OSHA manuals for pit wall sloping and sheeting. The typical size of pits is 38 feet long and 10 or 12 feet wide. The bottom of the pits is 2 feet 8 inches below center of casing (Miller the Driller 2002).

3. Equipment setup

Different types of equipment may be required on or around the boring site. Excavators or cranes are needed to dig the boring pit and set the equipment. Boring machine and tracks appropriate for the job are required. Augers must be placed in the casing sections. A cutting head is selected depending on the ground conditions and is installed in front of the first auger section.

The most critical part of the bore is the setting of the machine track on line and grade. If the alignment is not right when the bore is started, it is not likely to improve during the boring process. Figure 2.4 shows the installed auger boring machine and track system. 


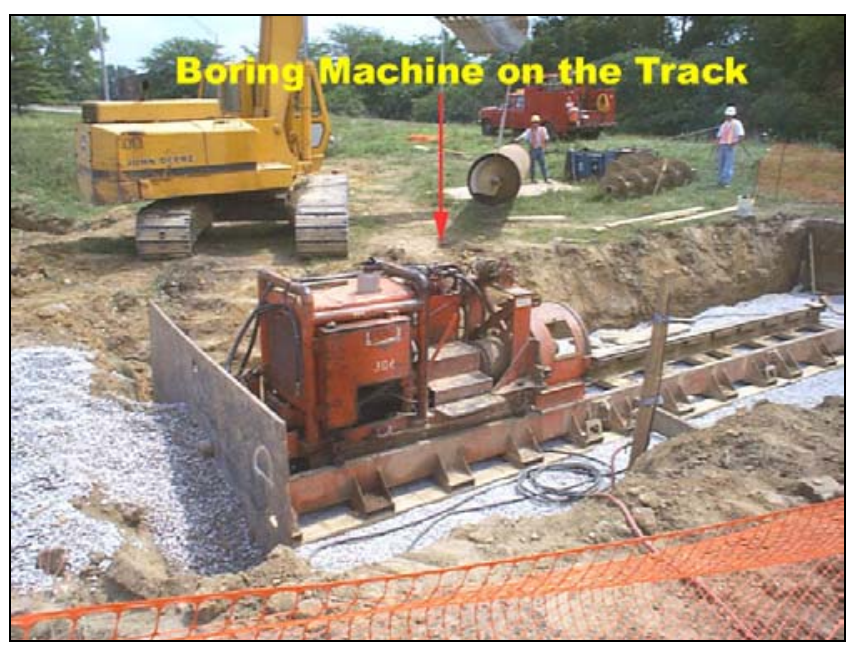

Figure 2.4 Auger boring machine on the track

Other optional systems may be employed for the auger boring operation. These include:

Lubrication system: To reduce the friction between the casing and soil, a lubricant may be applied to the outer skin of the casing. This also can reduce the requirement for the thrust capacity of boring machine. Two basic types of lubricants are bentonite and polymers.

Water level: The water level is a device to measure the grade of pipe casing as it is being installed. It permits the monitoring of grade by using a water level sensing head attached to the top of the leading edge of the casing. A hose connects the bottom of the indicator tube to a water pipe running along the top of the casing as shown in Figure 2.5 .

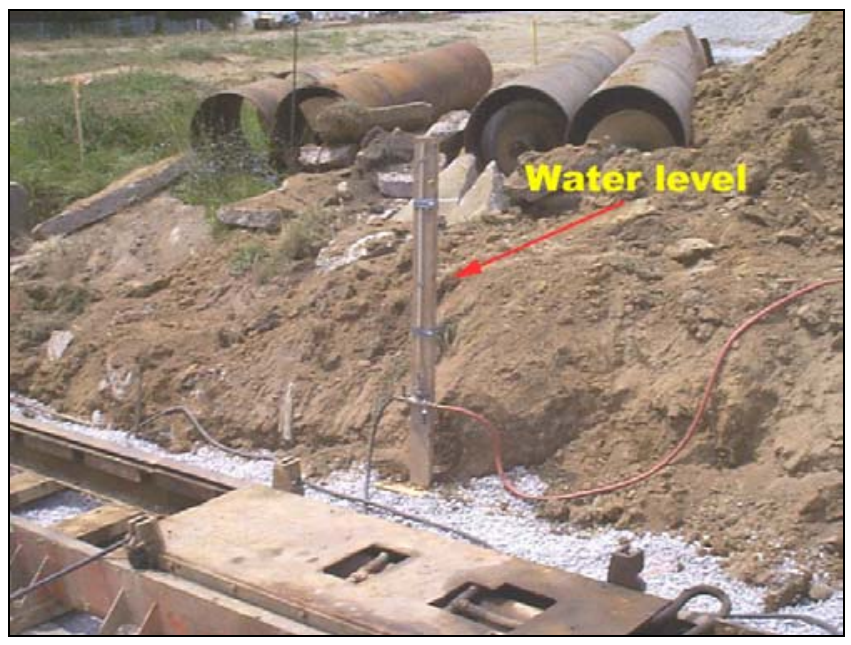

Figure 2.5 Water level 
Grade control head: The grade control head is used for making minor corrections in the grade. It can be used to make vertical corrections only. During the boring process, the actual grade can be monitored with the water level and the necessary adjustments can be made with the grade control head.

\section{Preparation of casing}

In most cases, the lead casing is prepared in the yard prior to its transport to the jobsite and arrives at the jobsite with the auger inside and the cutting head attached to the leading end of the auger. A partial band at or near the head end of the casing is recommended when boring in most soil conditions. The band compacts the soil and relieves pressure on the casing by decreasing the skin friction. The cutting head and auger inside the casing as well as partial band are shown in Figure 2.6.

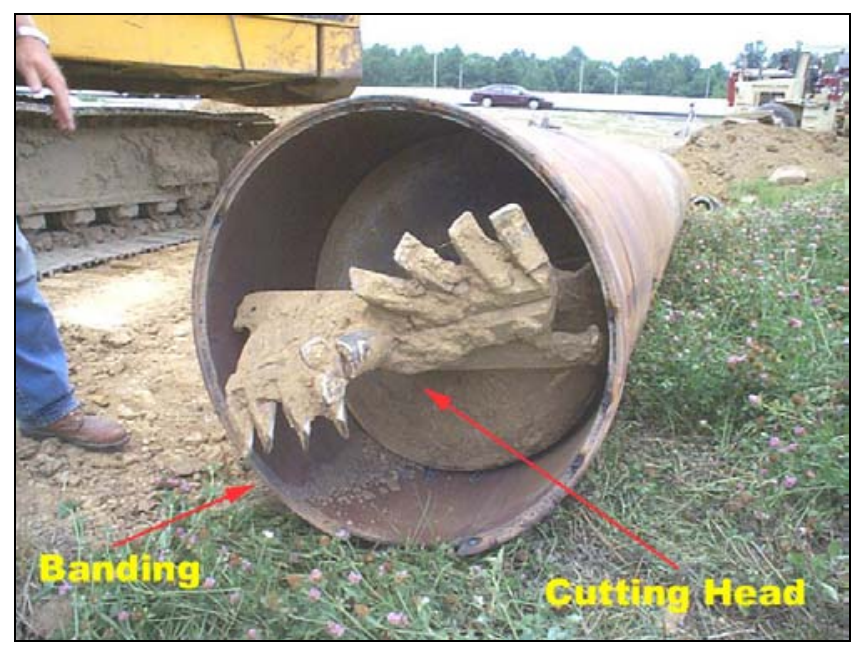

Figure 2.6 Cutting head and partial banding

5. Installation of casing

When casings are prepared and the auger boring is set up, the leading casing is moved onto the track and connected to the boring machine by welding as shown in Figure 2.7. "Collaring," which is the first operation, pushes the cutting head into the ground without lifting the casing out of the saddle. When about 4 feet (1.3 meters) of casing has entered the ground, the engine is shut down, the saddle is removed, and the line and grade of the casing is checked. 
After the first section of the casing has been installed in the ground, the casing is cleaned by rotating the auger until all the spoil is removed. The machine is then shut down and the auger pin in the spoil chamber is removed. The machine is then moved to the rear of the track and is again shut down. Then the next section of the casing and auger are lowered into position. The augers at the face are aligned flight to flight, the hexagonal joint is coupled and the auger pin is installed. Once the casing to be installed is aligned with the installed casing, the two are tacked together then welded fully. The process is then repeated until the bore is completed. Figure 2.8 shows the soil removal during auger boring.

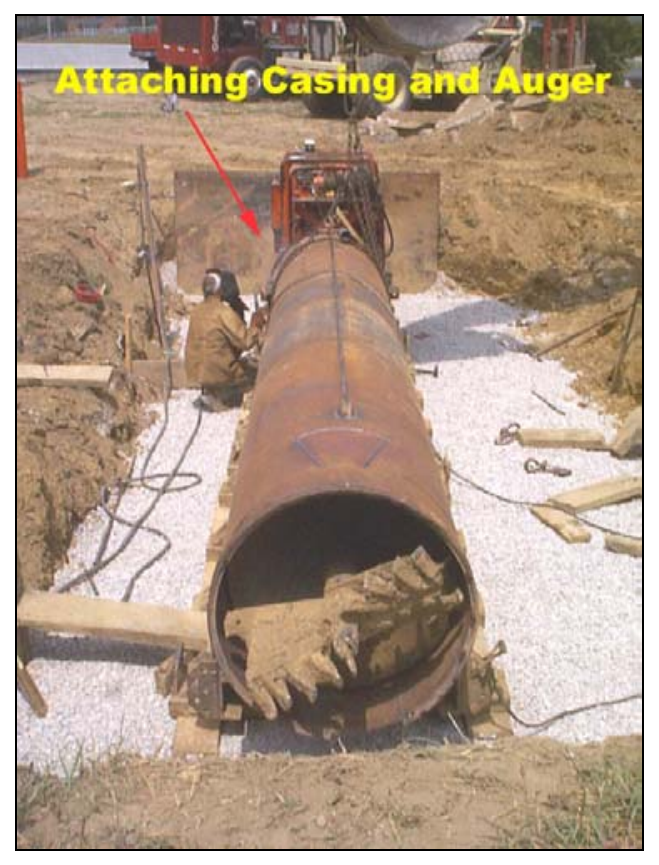

Figure 2.7 Connection of casing and auger 


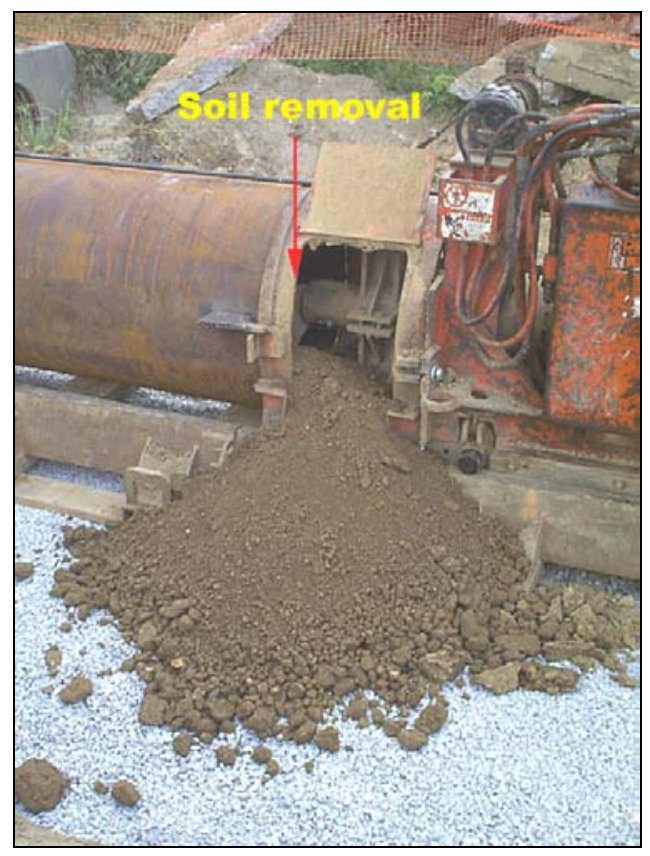

Figure 2.8 Soil removal

6. Completion of drilling

Once the bore is completed, the machine is shut down and the cutting head is removed. The casing is then cleaned by rotating the augers. The torque plates are then removed to detach the machine from the casing and the augers are retracted till the coupling is well outside the casing. The auger section is uncoupled from the machine and the other auger sections and is then removed. The machine is coupled to the next auger and the process is repeated until all the auger sections are removed.

7. Site restoration

Once all the augers are removed, the boring machine and the tracks are removed from the pit, the desired utilities are installed through the casing and the required connections are made. The entrance and exit shafts are then backfilled.

\subsubsection{Cradle type auger boring}

The cradle type auger boring method is suitable for projects that provide adequate room. The bore pit size is a function of the bore diameter and the length of the bore. This method is commonly used on petroleum pipeline projects where large rights-of-way are essential. 
This method offers the advantage that all work is performed at the ground level rather than in the pit. The bore pit is excavated several feet deeper than the invert of the casing pipe to allow space for the collection of spoil and water as the bore hole is excavated. The method does not require any thrust structures, however, a jacking lug must be securely installed at the bore entrance embankment. Figure 2.9 shows the operation of cradle type auger boring method.

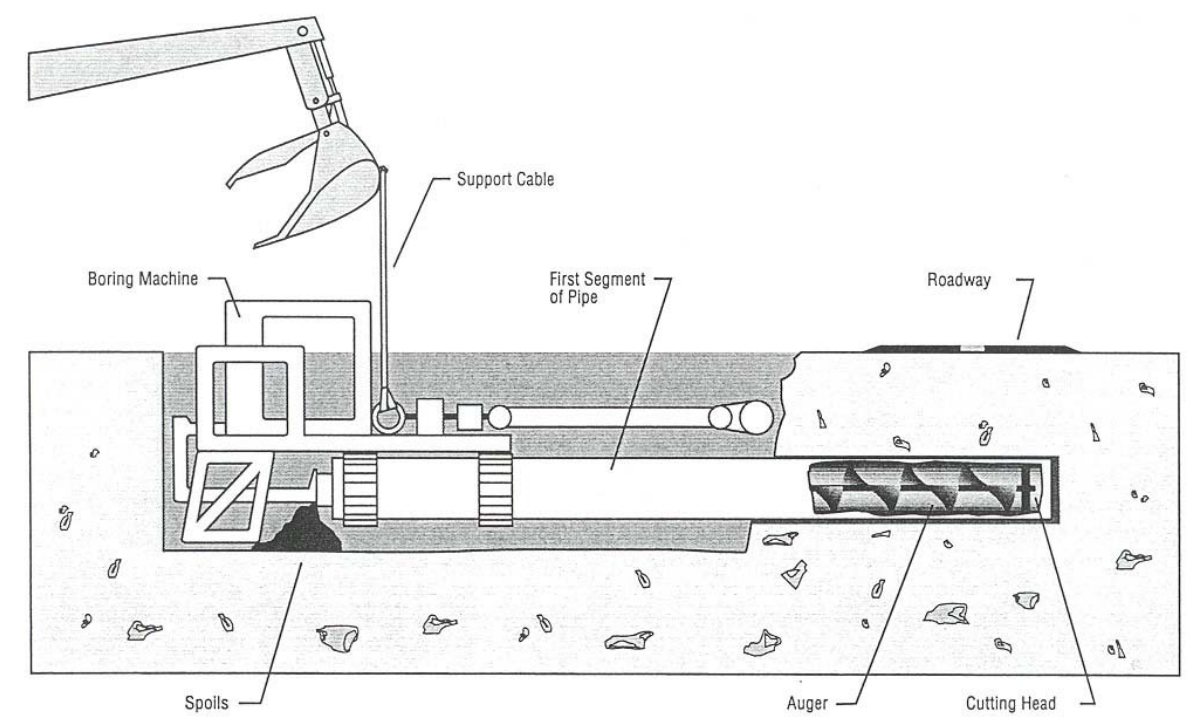

Figure 2.9 Cradle type auger boring (Iseley and Gokhale 1997)

\subsubsection{Main Features and Application Range (Iseley and Gokhale 1997)}

\subsubsection{Diameter range}

Auger boring can be used to install casing pipe ranging from $100 \mathrm{~mm}$ (4 in) to at least $1,500 \mathrm{~mm}$ (60 in) in diameter, with the most common diameters ranging from 200 $\mathrm{mm}$ ( 8 in) to $900 \mathrm{~mm}$ (36 in). When the diameter of pipe to be installed is less than $200 \mathrm{~mm}$ (8 in), other trenchless technologies are more appropriate and economical, especially, where the line and grade are not very critical. For larger diameters where the line and grade are more critical, pipe jacking and microtunneling can be the better alternatives since they provide greater accuracy and cost effectiveness. 


\subsubsection{Drive length}

Auger boring was initially developed to cross under a two-lane roadway with an average length of $12 \mathrm{~m}(40 \mathrm{ft})$ and a maximum length of $21 \mathrm{~m}(70 \mathrm{ft})$. However, typical project lengths range from $30 \mathrm{~m}(100 \mathrm{ft})$ to $91.5 \mathrm{~m}(300 \mathrm{ft})$, with the demand for longer installations increasing. The longest continuous track-type auger boring project is $270 \mathrm{~m}$ (886 ft).

\subsubsection{Type of casing}

Because the augers rotate inside the pipe, the pipe and coating material must resist potential damage caused by rotating augers. Therefore, the typical casing pipe is made of steel. The product or carrier pipe installed inside the casing can be made of any material suitable for the product being carried.

\subsubsection{Required working space}

Shafts are required at both ends of the bore. The drive shaft is primary working shaft. The size of the shaft is determined by the diameter of the bore hole and the length of

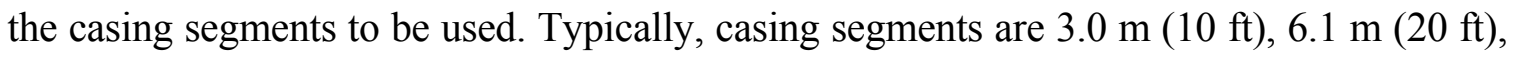

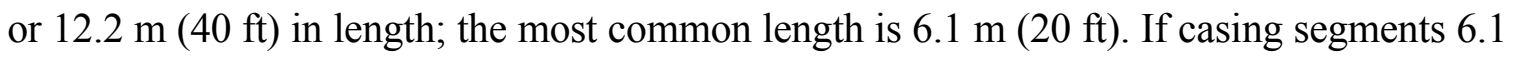

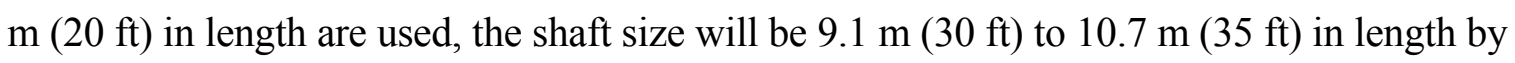
$2.5 \mathrm{~m}(8 \mathrm{ft})$ to $3.6 \mathrm{~m}(12 \mathrm{ft})$ in width. The surface area should be approximately $23 \mathrm{~m}(75 \mathrm{ft})$ by $46 \mathrm{~m}(150 \mathrm{ft})$. The minimum surface area should be $9 \mathrm{~m}(30 \mathrm{ft})$ by $25 \mathrm{~m}(82 \mathrm{ft})$. Sufficient space should be available for loading, unloading and storage of materials and equipment.

\subsubsection{Soil condition}

Auger boring can be used in a wide range of soil conditions, from dry sand to firm dry clay to solid rock. Firm sandy clay is the most compatible soil condition for using this method. Boulders or cobbles as large as one-third of the casing diameter can be accomplished. In case of unstable soils, care should be taken regarding the cutting edge leading the casing edge as this may result in spoil being removed without any advancement 
in the casing which means that excessive spoil is being removed. This situation can create a void between the casing and the bore hole, leading to surface subsidence.

\subsubsection{Productivity}

It is important that the drive shaft construction crew understand that the success of the project depends to a large extent on the quality of the drive shaft. Shaft construction may take 1 day for shafts less than $3 \mathrm{~m}$ (10 ft) when the excavation embankments can be sloped. Shaft construction could take several weeks if the shaft is greater than $10 \mathrm{~m}(33 \mathrm{ft})$ and the excavation support system is steel sheet piling.

The auger boring operation takes a four-person crew 3 to 4 hours to set up the auger boring equipment for a steel casing project $610 \mathrm{~mm}$ (24 in) in diameter utilizing segments $6.1 \mathrm{~m} \mathrm{(20} \mathrm{ft)} \mathrm{in} \mathrm{length.} \mathrm{A} \mathrm{typical} \mathrm{production} \mathrm{rate} \mathrm{for} \mathrm{such} \mathrm{a} \mathrm{project} \mathrm{is} 12 \mathrm{~m} \mathrm{(40} \mathrm{ft)} \mathrm{to} 18 \mathrm{~m}$ (60 ft) per 8-hr shift. Depending on soil conditions and casing diameter and length, auger boring typically takes place at a rate of 1 to $3.6 \mathrm{~m} / \mathrm{hr}$ ( 3 to $12 \mathrm{ft} / \mathrm{hr}$ ).

\subsubsection{Accuracy}

If a steering head is not used in the $\mathrm{AB}$ system, accuracy depends on groundwater conditions, length of drive, initial setup, and operator skill. An accuracy of $\pm 1 \%$ of the length of the bore is normally achieved. For projects that require a higher accuracy, an oversized casing is generally installed to provide maneuvering room for the carrier pipe inside the casing to obtain the specified tolerance.

\subsubsection{Major advantages}

The major advantage of auger boring is that the casing is installed as the borehole excavation takes place. Hence, there is no uncased bore hole which substantially reduces the probability of a cave-in which could result in surface subsidence. Also this method can be used in a wide variety of soil types - making it very versatile method.

\subsubsection{Major disadvantages}

The auger boring method requires different size cutting heads and augers for each casing which entails substantial investment for equipment. This method also calls for a 
substantial investment in terms of the bore pit construction and the initial setup. The auger boring operation may not be successful in runny sands and unstable soils. The accuracy in line and grade is limited in auger boring operations. 


\subsection{HORIZONTAL DIRECTIONAL DRILLING}

\subsubsection{Introduction}

Horizontal Directional Drilling (HDD) is defined as "A steerable system for the installation of pipes, conduits, and cables in a shallow arc using a surface launched drilling rig. Traditionally HDD is applied to large scale crossings such as rivers in which a fluid filled pilot bore is drilled without rotating the drill string, and this is then enlarged by a wash over pipe and back reamer to the size required for the product pipe (Trenchless Data Service 2000)".

HDD technology originated from the oil fields in the 1970s and evolved by merging technologies used in utilities and water well industries. Since then, HDD has been broadly used in pipeline installation industries. The first known river crossing using the

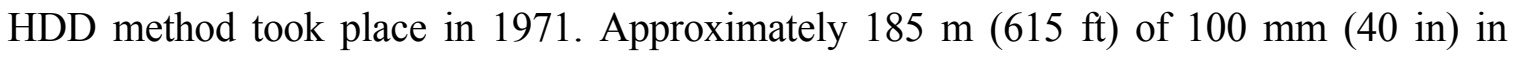
diameter steel pipe was installed across the Pajaro River near Watsonville, California, for the Pacific Gas and Electric Co. (DCCA 1994). By integrating existing technology from the oil well drilling industry and modern surveying and steering techniques, today's directional drilling methods have become the preferred approach for installing utility lines, ranging from large-size pipeline river crossings to small-diameter cable conduits.

The HDD industry is divided into three major sectors - large-diameter HDD (maxiHDD), medium-diameter HDD (midi-HDD), and small-diameter HDD (mini-HDD, also called guided boring) - according to their typical application areas. Although there is no significant difference in the operation mechanisms among these systems, the different application ranges often require corresponding modification to the system configuration and capacities, mode of spoil removal, and directional control methods to achieve optimal cost-efficiency. Table 2.1 compares typical maxi-, midi-, and mini-HDD systems. 
Table 2.1 Comparison of main features of typical HDD methods (Iseley and Gokhale 1997)

\begin{tabular}{|l|l|l|l|l|l|l|l|}
\hline Type & Diameter & Depth & $\begin{array}{l}\text { Drive } \\
\text { Length }\end{array}$ & Torque & $\begin{array}{l}\text { Thrust/ } \\
\text { Pullback }\end{array}$ & $\begin{array}{l}\text { Machine } \\
\text { Weight }\end{array}$ & $\begin{array}{l}\text { Typical } \\
\text { Application }\end{array}$ \\
\hline Maxi & $\begin{array}{l}600-1,200 \mathrm{~mm} \\
(24-48 \mathrm{in})\end{array}$ & $\begin{array}{l}\leq 61 \mathrm{~m} \\
(200 \mathrm{ft})\end{array}$ & $\begin{array}{l}\leq 1800 \mathrm{~m} \\
(6000 \mathrm{ft})\end{array}$ & $\begin{array}{l}\leq 108.5 \mathrm{KN}-\mathrm{m} \\
(80,000 \mathrm{ft}-\mathrm{b})\end{array}$ & $\begin{array}{l}\leq 445 \mathrm{KN} \\
(100,000 \mathrm{lb})\end{array}$ & $\begin{array}{l}\leq 30 \mathrm{ton} \\
(267 \mathrm{KN})\end{array}$ & $\begin{array}{l}\text { River, Highway } \\
\text { crossings }\end{array}$ \\
\hline Midi & $\begin{array}{l}300-600 \mathrm{~mm} \\
(12-24 \mathrm{in})\end{array}$ & $\begin{array}{l}\leq 23 \mathrm{~m} \\
(75 \mathrm{ft})\end{array}$ & $\begin{array}{l}\leq 270 \mathrm{~m} \\
(900 \mathrm{ft})\end{array}$ & $\begin{array}{l}1-9.5 \mathrm{KN}-\mathrm{m} \\
(900-7000 \mathrm{ft}-\mathrm{lb})\end{array}$ & $\begin{array}{l}89-445 \mathrm{KN} \\
(20,000- \\
100,000 \mathrm{lb})\end{array}$ & $\begin{array}{l}\leq 18 \mathrm{ton} \\
(160 \mathrm{KN})\end{array}$ & $\begin{array}{l}\text { Under rivers and } \\
\text { roadways }\end{array}$ \\
\hline Mini & $\begin{array}{l}50-300 \mathrm{~mm} \\
(2-12 \mathrm{in})\end{array}$ & $\begin{array}{l}\leq 4.5 \mathrm{~m} \\
(15 \mathrm{ft})\end{array}$ & $\begin{array}{l}\leq 600 \mathrm{ft} \\
(180 \mathrm{~m})\end{array}$ & $\begin{array}{l}\leq 1.3 \mathrm{KN}-\mathrm{m} \\
(950 \mathrm{ft}-\mathrm{lb})\end{array}$ & $\begin{array}{l}\leq 89 \mathrm{KN} \\
(20,000 \mathrm{lb})\end{array}$ & $\begin{array}{l}\leq 9 \mathrm{ton} \\
(80 \mathrm{KN})\end{array}$ & $\begin{array}{l}\text { Telecom } \\
\text { Power cables, } \\
\text { and Gas lines }\end{array}$ \\
\hline
\end{tabular}

\subsubsection{Description}

Directional drilling methods utilize steerable soil drilling systems to install both small- and large-diameter lines. In most cases, HDD is a two-stage process. Stage 1 involves drilling a pilot hole approximately 25 to $125 \mathrm{~mm}$ ( 1 to $5 \mathrm{in}$ ) in diameter along the proposed design centerline. In stage 2, the pilot hole is enlarged to the desired diameter to accommodate the pipeline. At the same time, the product pipe is connected to the end of the drilling rod by swivel and pulled through the pilot hole. However, for large diameter pipes, the backreaming and pullback operations are performed separately.

The pilot hole is drilled with a surface-launched rig with an inclined carriage, typically adjusted at an angle of 8 to 18 degrees with the ground for entrance and 8 to 12 degrees for exit angle (Miller the Driller 2002). The preferred minimum radius in feet for steel pipe is 100 times of diameter of pipe in inch. For plastic pipe, the multiplication factor is 40 , i.e., 40 times of diameter of pipe in inch.

Most systems adopt either fluid-assisted drilling or a high pressure fluid jetting method to create or enlarge the bore hole. In a few instances, some mini-HDD systems utilize dry bore systems (with compressed air) in hard, dry soils and calcified or soft rock formations (Iseley and Gokhale 1997).

\subsubsection{Fluid-Assisted Mechanical Drilling}

Soil cutting in the mechanical drilling process is performed by rotating the drill bit, assisted by the thrust force transferred from the drill string. The mechanical drill bits may vary from a slim cutting head with a slanted face for small and short bore applications to a 
diamond-mounted roller cutter used with mud motors for large and long crossings. For small systems used mini-HDD, directional steering control is accomplished mainly by the bias caused by the slanted cutter head face. For large systems used for maxi-HDD, a bent housing (a slightly bent section between 0.5 and $1.5 \mathrm{deg}$ of the drill rod) is used to deflect the cutter head axis from the following drill string. In both small and large systems, a curved path can be followed by pushing the drill head without rotating, and a straight path can be drilled by applying simultaneous thrust and torque to the drill head (Iseley and Gokhale 1997).

\subsubsection{High-Pressure Fluid Jetting}

In a typical fluid jetting process, a soil cavity is formed by injecting a small amount of high-pressure (7 to $28 \mathrm{Ma}(1,000$ to $4,000 \mathrm{psi})$ ), high-velocity fluid from small jetting nozzles. For short bores with stable soil conditions, the jetting fluid can be water; however, in most cases, bentonite or polymer-based slurry is used to stabilize the bore hole and prevent its collapse. Because the energy of high-pressure flow dissipates quickly after the fluid exits the nozzles, soil overcutting is unlikely and the risk of cutting through adjoining utilities is virtually eliminated. However, for maxi- and midi-HDD systems in which the fluid circulation method is used, there is a potential that soil will be eroded by the drilling fluid (Iseley and Gokhale 1997).

In mini-HDD, drill bits usually are rotated by the torque transferred from the drill string. For larger systems, the required drilling torque can be derived from a down-hole mud motor located just behind the drill bit. A medium-pressure, low-volume (3.5 to 7 $\mathrm{L} / \mathrm{min}$ (1 to $2 \mathrm{GPM})$ ), drilling fluid is used to assist in the mechanical drilling process. There are two variants of drilling fluid use: fluid recirculation and fluid suspension. Fluid recirculation involves (1) moving the soil cutting from the bore hole in the form of slurry with a larger volume of drilling fluid, (2) cleaning the hole, and (3) refilling the hole with the slurry. The fluid suspension method, which uses only a small amount of fluid, keeps the soil cuttings in the slurry, with few or none removed from the hole. Theoretically, the choice between these two approaches depends on soil conditions; however, in practice, the fluid recirculation method usually is used in maxi-HDD systems and the fluid suspension method is used extensively in mini-HDD systems (Iseley and Gokhale 1997). 
Midi-HDD systems employ a combination of recirculation and suspension methods. For long crossings requiring the use of a down-hole mud motor, high flow rates and large amount of drilling fluid are necessary for providing the soil cutting torque. Such large volumes of fluid can act as the conveyance medium for spoil removal. Recirculation reduces the extra stress in the drill string caused by suspended soil cutting, which might be very high for a long drive. For small, short bores at a shallow depth, a down-hole mud motor is not used and the spoil removal usually is not required because the soil cuttings can be kept in the fluid suspension.

A unique technique for maxi-HDD involves the use of a washover pipe or casing with a large internal diameter, to be slid over the drill string during the pilot bore drilling process. When in place, the washover pipe can significantly reduce the friction around the drill string and provide stiffness to the drilling system. It also can be used to perform the prereaming and final reaming and pullback operation.

Directional steering capacity is achieved by incorporating offset jets and direction sensing and steering devices into the system. The deflection force created by the offset and angled fluid jets is used to form a curved drill path. An alternative to the offset jets is a special steerable head that will bend slightly under increased fluid pressure. Rotation of the jetting head can be accomplished by using a hydraulically or electrically driven down-hole motor, rotating a string of steel drilling rods, or attaching a special auger-type fin device behind the jetting head.

\subsubsection{Drilling process}

1. Preconstruction preparation

A design plan and profile drawings have to be prepared for each crossing. Owners typically provide these design, drawings and relevant data such as soil conditions. After the design work is complete, site preparation is performed. A drilling rig is set up at the proper location. Slurry is prepared to stabilize the borehole and to lubricate the surface of borehole. A transmitter is inserted into the housing provided on the pilot drilling string near the cutting head. Other equipment and facilities such as generators, pumps, storages, and offices are prepared at this stage. 
A drilling rig for HDD operation is shown in Figure 2.10. The drill strings are connected one after another by pushing and rotating them clockwise. To remove the strings, they are pulled and rotated counterclockwise.

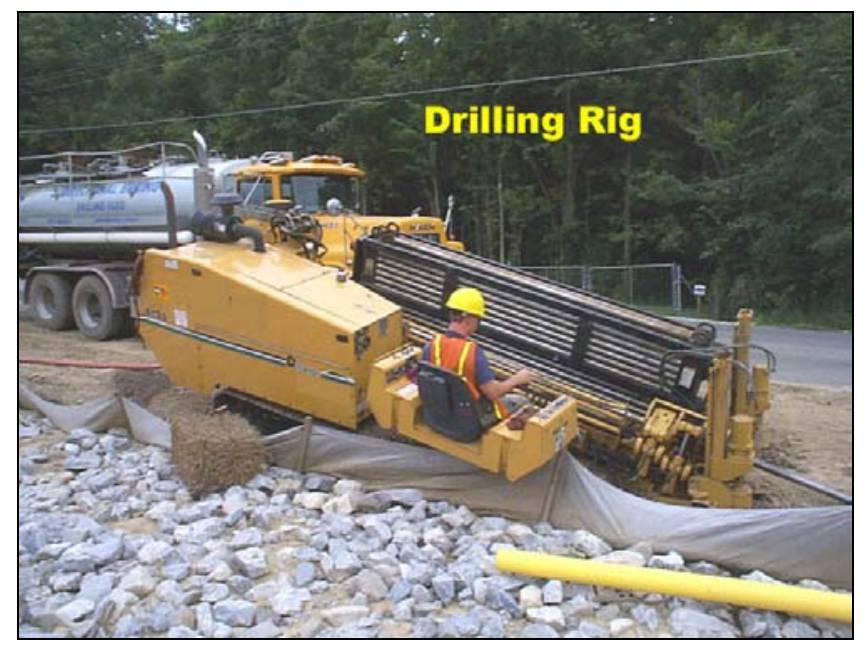

Figure 2.10 Drilling rig

On the other side of the proposed alignment, pipelines, reamer and storage spaces that are required for prereaming and pullback are prepared.

\section{Pilot hole}

Drilling of the pilot hole is the most important phase of an HDD project, because it determines the ultimate position of the installed pipe. A small diameter ( 25 to $125 \mathrm{~mm}$ ( 1 to 5 in)) drilling string penetrates the ground at the prescribed entry point at a predetermined angle routinely between $8-18$ degrees. The drilling continues under and across the obstacles along a design profile.

Concurrent to drilling pilot hole, a larger diameter pipe, called "wash pipe," can be installed for maxi-HDD. The wash pipe follows and encases pilot drill string. The wash pipe protects the small diameter pilot drill string from the surrounding ground, and reduces the friction around the drilling string. It also preserves the drilled hole in case the drill string is retracted for bit change (DCCA 1994).

Fluid-assisted mechanical method and high-pressure fluid jetting method are most typical methods to be adopted to facilitate the drilling process. Using fluid assisted 
mechanical method, the drilling process is performed by rotating the drill bit and thrusting force from the drill string. The high-pressure fluid jetting method penetrates the ground by injecting small amount of fluid with high pressure and high velocity. This fluid causes the void to create a space for the drill string to proceed. The typical jetting fluid is bentonite or polymer-based slurry while water may be used for short bores with stable soil conditions.

The drill path is monitored by a special electronic tracking system housed in the pilot drill string near the cutting head. The electronic tracking system detects the relation of the drill string to the earth's magnetic field and its inclination. The location data are transmitted to the receiver which calculates the location of the cutting head. It is recommended that the measurements be made at least every $30 \mathrm{ft}(10 \mathrm{~m})$. If the underground condition is complex, more frequent measurements may be required. By comparing the detected location and designed location, the direction of next drill is determined (DCCA 1994).

Once the drill head surfaces at the exit point, the location of the drill head is compared with planned location to determine that the actual location is within the allowable tolerance. A reasonable drill target at the pilot hole exit location is $10 \mathrm{ft}(3 \mathrm{~m})$ left or right, and $-10 \mathrm{ft}(-3 \mathrm{~m})$ to $+30 \mathrm{ft}(+10 \mathrm{~m})$ in length. This accuracy is improving with the enhancement in equipment and operation skills. If the exit point is out of the tolerance, some part of the bore should be re-drilled. When the exit location is acceptable, the drill head is removed to prepare the next phase, prereaming and pullback (DCCA 2000).

\section{Prereaming}

In general, the final size of the bore should be at least $50 \%$ larger than the outside diameter of the product pipe. This overcut is necessary to allow for an annular void for the return of drilling fluids and spoils and to allow for the bend radius of the pipeline. To create a hole that accommodates the required size of pipe, prereaming is necessary.

Typically, the reamer is attached to the drill string at the pipe side and pulled back into the pilot hole. Large quantities of slurry are pumped into the hole to maintain the borehole and to flush out the soil cuttings (DCCA 1994). The type of reamer varies based on the soil type. A blade reamer is used for soft soils, a barrel reamer for mixed soils, and a rock reamer with tungsten carbide inserts is used for rock formations. The soil condition, 
type of reamer, and the correct amount of drilling fluid are critical to the successful and economical completion of the project (DCCA 2000).

\section{Pullback}

Once the prereaming is completed, the pipe or conduit can be pulled back into the reamed hole filled with drilling fluid. The pipe is prefabricated and tested at the pipe side. If the pipe is made of steel, it is recommended that the pipe be placed on rollers to reduce the friction and to protect pipe coating. However, this operation is usually not required for HDPE pipe installation.

The drill pipe is connected to the product pipe using a pull head or pulling eye and a swivel. The swivel is a device used to prevent the rotation of the pipeline during pullback. A reamer is also located between the pull head and the drill string to ensure that the hole remains open and to allow lubricating fluid to be pumped into the hole during the pullback. The pullback operation will continue until the pipe or conduit surface at the drill rig. The pull head is disconnected, the drill rig removed, and clean-up and tie-ins are started (DCCA 2000). The components used for pullback operation are shown in Figure 2.11.

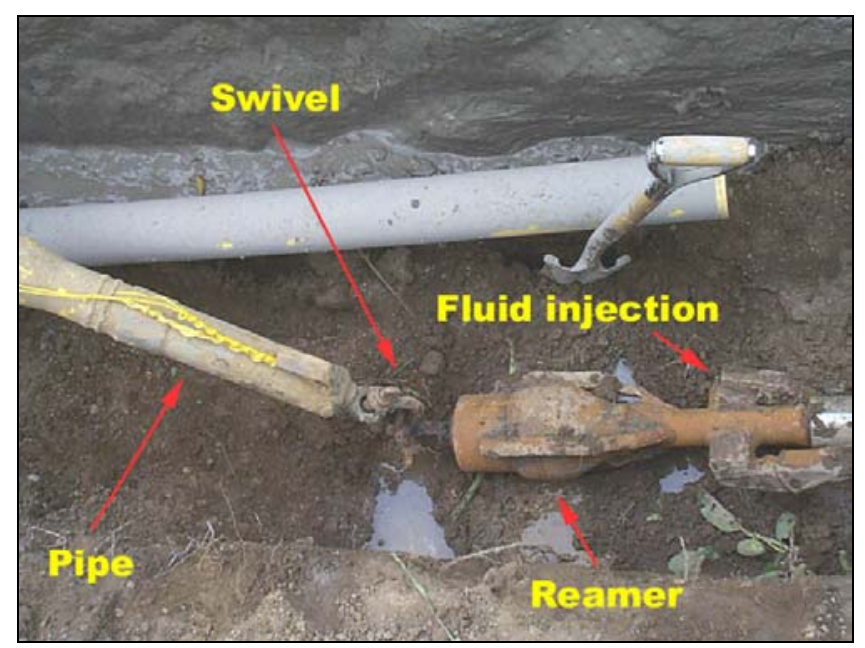

Figure 2.11 Components of pullback operation

\subsubsection{Tracking system}

The greatest technological potential and development for directional drilling lies in the area of tracking systems. Wireless steering tool systems are an example of the 
development. The walkover system and wireline steering system are the most common tracking system currently in use. However, other tracking systems such as the Electromagnetic Telemetry (EMT) system, and the Mud-Pulse-Telemetry system are also available for tracking the drilling path.

Basic features of walkover and wireline tracking systems are briefly described in the following sections.

- Walkover system

○ Basic features

The walkover system is the most widely used system in drilling operation. A transmitter or sonde equipped in a housing behind the drill bit is the major component of this system. The sonde transmits a signal to the surface. On the surface, a hand-held receiver picks up the signal and analyzes the data. Remote receiver also can be used for this data collection and analysis. Since the walkover system is generally regarded as the most economical tracking method, it is commonly employed in jobs using small to mid- size drill bits. This system has been adopted from the cable locating technology, while the other tracking systems have been adopted from the oil and gas exploration industry (DCI 2002, Subsite 2002). Figure 2.12 shows the tracking receiver.

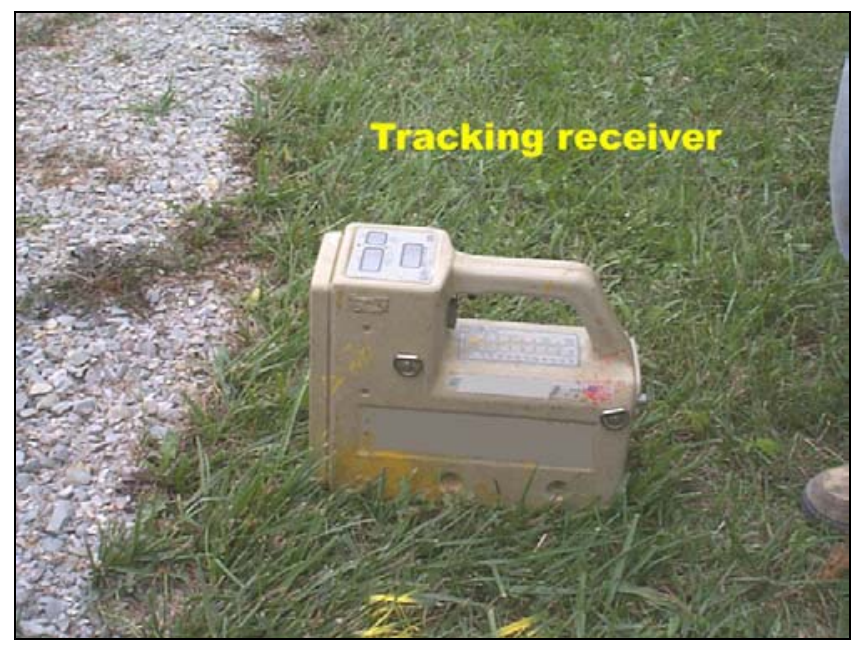

Figure 2.12 Receiver for walkover tracking system 


\section{- Advantages and disadvantages}

The first advantage of walkover tracking system is the cost. After the initial investment, the only major expense is the replacement of batteries and sondes. This system has a higher productivity than other systems. However, the tracking is restricted by geological conditions. For instance, if the drilling work crosses the freeway or river, it is not an easy task to walk over. The signal transmitted from the sonde often interferes with signals from other media such as overhead power lines, traffic signals, rebar in foundations, etc.

- Wireline system

- Basic features

The wireline runs with a steering tool located in a non-magnetic bottom hole assembly. Thus, the location can be positioned with the signal from the transmitter to the receiver through the wire. The remote device displays the position information.

$\circ$ Advantages and disadvantages

This system overcomes the depth limitation, because the power and signals are transmitted through the wire. It also provides better accuracy than the walkover system, because other materials do not interfere with the signal. The record keeping is easy when the system is hooked to a computer. It is more efficient than the walkover system, considering the time required for replacement of batteries which frequently occurs during hard rock drilling. Also, productivity is impacted because the wire interferes with threading pieces of drill rods. The relatively high initial cost for purchasing or rental fee of manpower and equipment is the primary obstacle when using this system.

\subsubsection{Main Features and Application Range (Iseley and Gokhale 1997)}

\subsubsection{Diameter range}

In maxi- and midi-HDD, the size of pipes installed can range from $75 \mathrm{~mm}(3 \mathrm{in})$ to 1,200 $\mathrm{mm}$ (48 in) in diameter. Multiple lines can be installed in a single pull, but only in the case of small-diameter pipes. The installation procedure for multiple lines is the same as for single lines, with the bundle being pulled back as a single unit along the prereamed 
profile. A significant multiple line crossing is more than $600 \mathrm{~m}(2,000 \mathrm{ft})$ in bore length and consists of five separate lines, pulled as one, ranging in size from $150 \mathrm{~mm}$ (6 in) to $400 \mathrm{~mm}$ (16 in). The maximum size pipe that can be installed by the mini-HDD system is $300 \mathrm{~mm}$ (12 in) in diameter.

\subsubsection{Depth of installation}

Mini-HDD can install pipes up to $4.5 \mathrm{~m}(15 \mathrm{ft})$ in depth. This depth limitation comes from the restriction in the capacity of walkover tracking system. However, for larger machines, such as midi- and maxi-HDD, the maximum installation depth for HDD is $61 \mathrm{~m}$ (200 ft).

\subsubsection{Drive length}

The length of bore in HDD is determined by the type of soil and site conditions. Bore spans can range from $120 \mathrm{~m}(400 \mathrm{ft})$ to $1,800 \mathrm{~m}(6,000 \mathrm{ft})$ for maxi- and midi-HDD. However, small lengths are not economically feasible because of the high operational costs of these systems. Mini-HDD is capable of installing pipelines and utilities $180 \mathrm{~m}(600 \mathrm{ft})$ in one continuous pass to a specified tolerance.

\subsubsection{Type of casing}

In general, the pipe to be installed is limited to one that can be joined together continuously, while maintaining sufficient strength to resist the high tensile stresses imposed during the pullback operation. In maxi- and midi-HDD, steel pipe is the most common type of casing used. However, butt-fused, high-density polyethylene pipe (HDPE) also can be used. HDPE pipe, small-diameter steel pipe, copper service lines, and flexible cables are some of the common types of pipe materials being used today in mini-HDD.

\subsubsection{Required working space}

The directional drilling process is a surface-launched method; therefore, it usually does not require access pits or exit pits. If utility installation is being undertaken, pits may be required to make connections with the existing utility. The rig working area should be reasonably level, firm, and suitable for movement of the rig. For maxi- and midi-HDD, an 


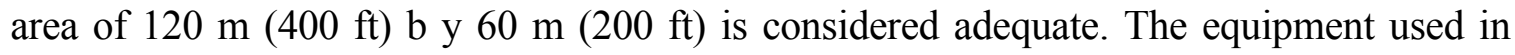
mini-HDD is portable, self-contained, and designed to work in congested areas.

\subsubsection{Soil condition}

Clay is considered ideal for HDD methods. Cohesionless fine sand and silt generally behave in a fluid manner and stay suspended in the drill fluid for a sufficient amount of time; therefore, they are also suitable for HDD.

High-pressure fluid drilling systems (mini-HDD and midi-HDD) normally do not damage on-line existing utilities and thus are safe for subsurface-congested urban areas. Fluid cutting systems, which are most suitable in soft soil conditions, have been used widely in sand and clay formations. Although small gravel and soft rock formations can be accommodated by higher fluid pressure and more powerful jets, steering accuracy might suffer.

Generally, mechanical drilling systems (mini-HDD) can be applied in a wider range of soil conditions than fluid jetting methods. A pilot hole can be drilled through soil particles ranging from sand or clay to gravel, and even in continuous rock formations, by using suitable drill heads; however, problems might occur in spoil removal, pilot hole stabilization, and backreaming operations. Today's technology enables large drilling operations to be conducted in soil formations consisting of up to 50 percent gravel.

\subsubsection{Productivity}

HDD systems have the highest pilot hole boring rate of advancement among all trenchless methods for new installation. For mini-HDD rigs, a three-person crew is sufficient. In suitable ground conditions, a $180 \mathrm{~m}(600 \mathrm{ft})$ conduit can be installed in 1 day by a regular work crew.

\subsubsection{Accuracy}

The accuracy of installation for maxi- and midi-HDD depends on the tracking system being used and the relative skill of the operator. However, the reported accuracy is within $1 \%$ of the length. For mini-HDD, the accuracy depends on the methods employed. When using fluid assisted mechanical cutting, the drill head can be located within $150 \mathrm{~mm}$ (6 in) range. 
The steering accuracy for this case is up to $300 \mathrm{~mm}$ (12 in) range. For the case of employing fluid jetting method, the drill head can be located to a precision of $\pm 2 \%$. The steering accuracy is up to $150 \mathrm{~mm}$ (6 in). If a higher accuracy is desired, it can be achieved by reducing the interval at which the location readings are taken. However, this process will take more time and money.

\subsubsection{Major advantages}

The major advantage of HDD is its steering capability. In case of obstacles being encountered the drill head can be guided around the obstacle. Since HDD system can drill from the ground surface, no vertical shafts are required for drive and reception pits. Hence, the set up time before the drilling operation is relatively shorter than other trenchless technologies. Since no shafts are required, the project costs are reduced. The single drive length that can be achieved by HDD is longer than any other non-man entry trenchless method (Iseley et al. 1999).

\subsubsection{Major disadvantages}

Since the HDD operation installs pipes through pullback process, the pipes chosen for the project should have sufficient axial tensile strength. For that reason, steel and HDPE pipes are most popular types of pipes for HDD operations. 


\subsection{MICROTUNNELING}

\subsubsection{Introduction}

According to the American Society of Civil Engineers (ASCE)'s Standard Construction Guidelines for Microtunneling, microtunneling (MT) can be defined as "a remotely controlled and guided pipe jacking technique that provides continuous support to the excavation face and does not require personnel entry into the tunnel (ASCE 1998)." The microtunneling boring machine (MTBM) is operated from a control panel, normally located on the surface. The system simultaneously installs pipe as spoil is excavated and removed. Personal entry is not required for routine operation. The guidance system usually references a laser beam projected onto a target in the MTBM, capable of installing gravity sewers or other types of pipelines to the required tolerance, for line and grade.

Microtunneling was developed in 1975 by Komatsu in Japan. Iseki, Inc. introduced their first microtunneling equipment in 1976. The development of the microtunneling technique allowed tunneling in soft unstable soil condition. Iseki introduced the Crunchingmole in 1981, which could crush boulders as large as $20 \%$ of the outside diameter of the pipe (Atalah and Hadala 1996).

Germany was the first European country to use microtunneling. Many microtunneling projects were undertaken by Iseki, Inc., a Japanese equipment manufacturer during the early 1980's. Germany has been the major user and manufacturer of MTBM in the world. In 1984, the microtunneling was first introduced into the North America. This project involved the installation of $188 \mathrm{~m}$ ( $615 \mathrm{ft})$ of $1.83 \mathrm{~m}$ (72 in) diameter pipe under I95, forth Lauderdale, Florida, for the Miami-Dada Water and Sewer Authority. Since 1984, there has been a growing demand for microtunneling in North America. According to microtunneling database for the USA and Canada from 1984 to 1995, the average growth rate for microtunneling from 1990 to 1995 in North America is 59\% (Atalah and Hadala 1996).

\subsubsection{Description}

Microtunneling is a trenchless construction method for installing conduits beneath roadways in a wide range of soil conditions, while maintaining close tolerances to line and 
grade from the drive shaft to the reception shaft. The microtunneling process is a cyclic pipe jacking process.

There are two types of microtunneling methods: slurry type and auger type. In the slurry type method, slurry is pumped to the face of the MTBM. Excavated materials mixed with slurry are transported to the driving shaft, and discharged at the soil separation unit above the ground. In an auger type method, excavated materials are transported by the auger in the casing, and directly discharged on the ground (Ueki 1999). However, since the auger type MTBM is not commonly used, only the slurry type MTBM will be discussed in this report.

\subsubsection{Slurry type MTBM}

In this method, soil is excavated mechanically by a rotating cutting head. The rotation of the cutting head can be eccentric or centric, and the speed of rotation (RPM) can be constant or variable. Cutterheads are bi-rotational. The head normally rotates in clockwise direction when looking from the rear of the machine. Reverse rotation can provide more flexibility in overcoming obstructions and difficult ground condition. The spoil excavated at the face is extruded through small parts located at the rear of the MTBM face into the mixing chamber. The main functions of this chamber are to mix the spoil with clean water from the separation system and control hydrostatic head imposed on the MTBM face by a body of water or groundwater. When the spoil and water are mixed to from slurry with suitable pumping consistency, typically less than $60 \%$ solids, the slurry is transported to the solids separation system hydraulically (Iseley et al. 1999). Figure 2.13 illustrates the inside structure of slurry type MTBM.

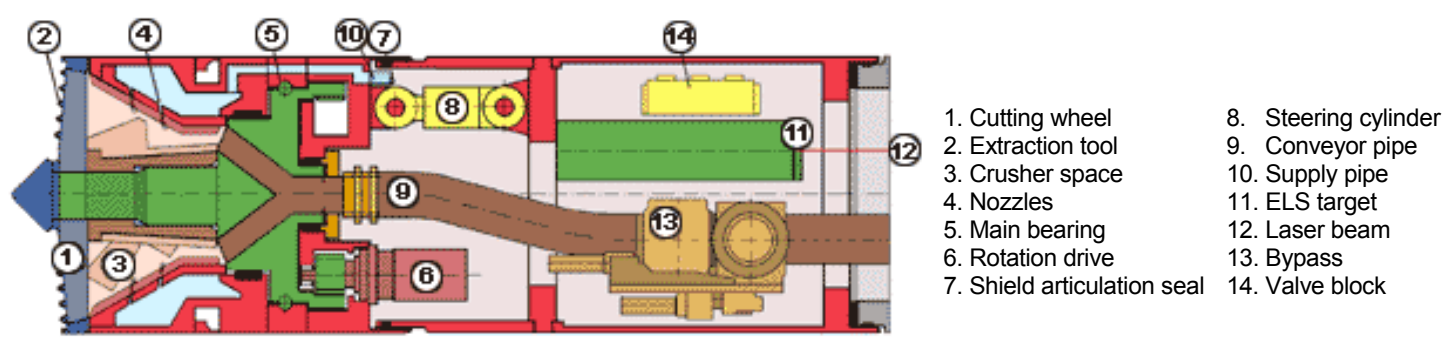

Figure 2.13 Typical slurry type MTBM (Herrenknecht Inc.) 
Some pictures of slurry type MTBMs are shown in Figure 2.14, 2.15, and 2.16.

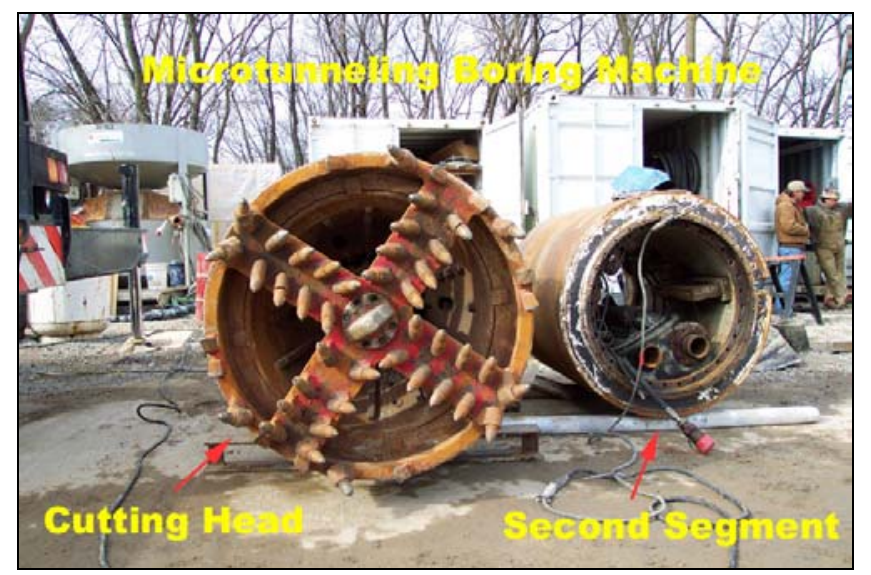

Figure 2.14 MTBM

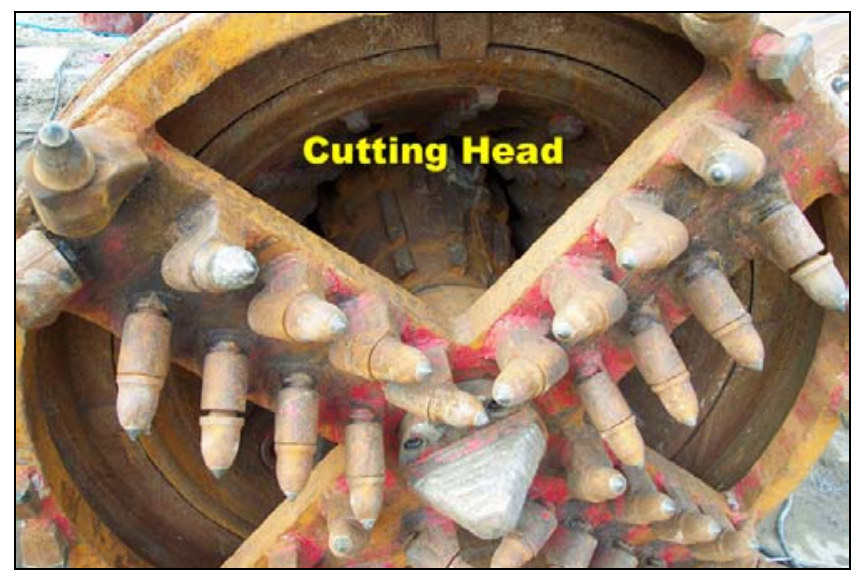

Figure 2.15 Cutting head

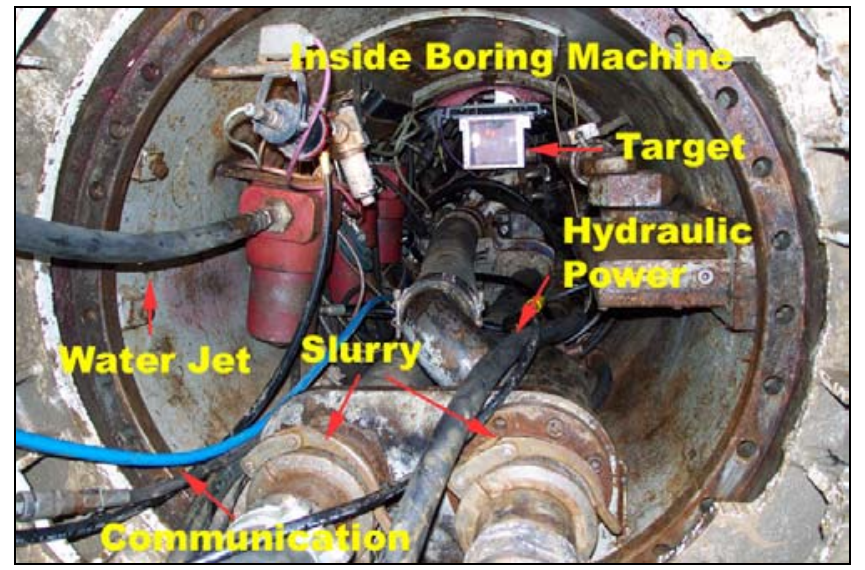

Figure 2.16 Inside of MTBM 


\subsubsection{Jacking system}

The jacking system consists of the jacking frame and jacks. A jacking frame is also shown in Figure 2.17. Figure 2.18 shows a 1,050 mm (42 in) steel casing with $6 \mathrm{~m}$ (20 ft) long section that is being jacked.

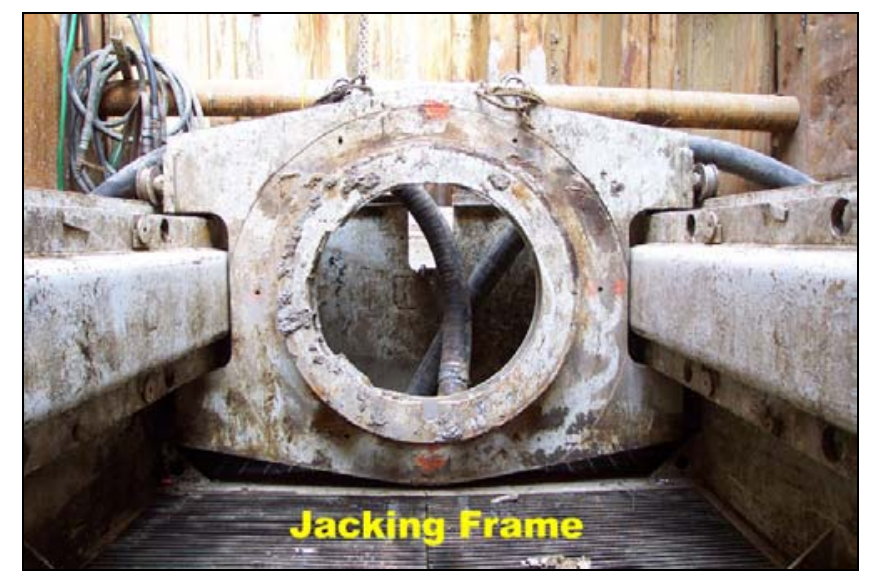

Figure 2.17 Jacking frame for microtunneling

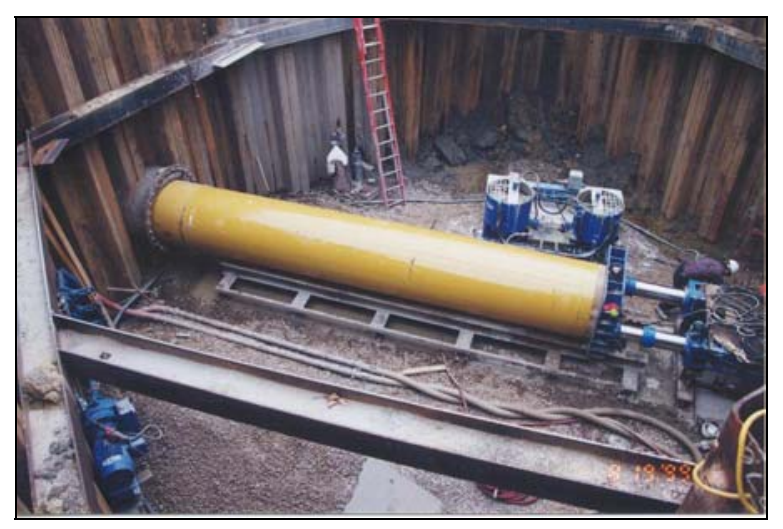

Figure 2.18 Steel casing being jacked (Kerr Construction Inc.)

The jacking capacity ranges from approximately 100 tons to over 1,000 tons. The jacking capacity is mainly determined by the length and diameter of the bore and the soil. The soil resistances are generated from face pressure, friction, and adhesion along the length of the steering head and pipe string. The jacking system determines two major 
factors of microtunneling operation: the total force or hydraulic pressure and penetration rate of pipe. The total jacking force and the penetration rate are critical to control the counterbalancing forces of the MTBM (Bennett et al. 1995).

\subsubsection{Spoil removal system}

The spoil is mixed into the slurry in a chamber located behind the cutting head of the MTBM. This mixed material is transported through the slurry discharge pipes and discharged into a separation system. This system is a closed-loop system because the slurry is recycled. The velocity of the flow and the pressure should be carefully regulated because the slurry chamber pressure is used to counterbalance the groundwater pressure. The machine can be sealed off from external water pressure, allowing underwater retrieval. Slurry is a mixture of bentonite (a clay material) in a powder form and water. The bentonite is used to increase the density of water so that it can transport heavy spoil particles. These heavy particles are filtered from the slurry at the separation units. The filtered slurry is sent to storage tanks, which will be recirculated through the system. Figure 2.19 (a) shows the soil separation system. One of the three screens for the separation system is shown in Figure 2.19 (b).

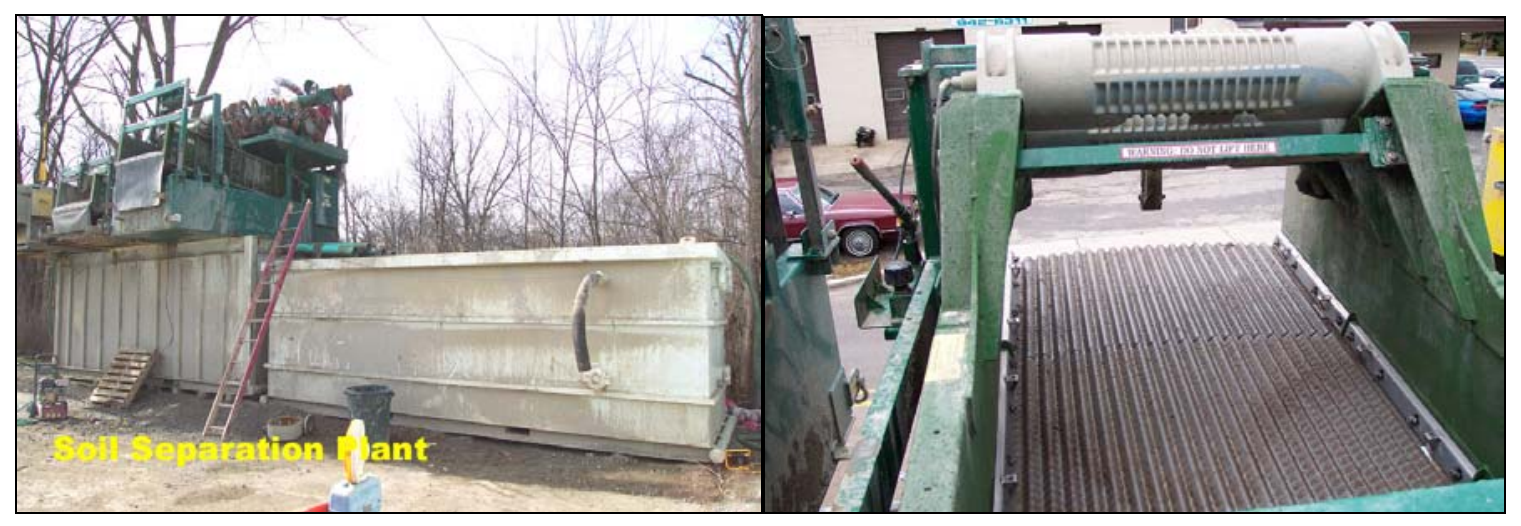

(a) Soil separation system

(b) A screen for soil separation system

Figure 2.19 Soil separation system

\subsubsection{Guidance and control system}

The laser is the most commonly used guidance system for microtunneling. The laser gives the line and grade information for the pipe installation. The laser is installed in 
the driving shaft and gives a fixed reference point. The laser target and a closed circuit television (CCTV) camera are installed in the MTBM. There should not be any obstruction along the laser beam pathway from the driving shaft to the laser target. There are two types of laser targets: the passive system and the active system. In the passive system, a target grid is mounted in the steering head. The CCTV monitors this target and the information obtained by this CCTV is transferred back to the operator's control panel. The operator can make any steering correction based on the information. In the active system, photosensitive cells are installed on the target and these cells convert information into digital data. Those data are electronically transmitted to the control panel and give the operator digital information of the location. Both active and passive systems are commonly used. Figure 2.20 shows the laser used for the Soltau microtunneling system. The target mounted in the MTBM is shown in Figure 2.21.

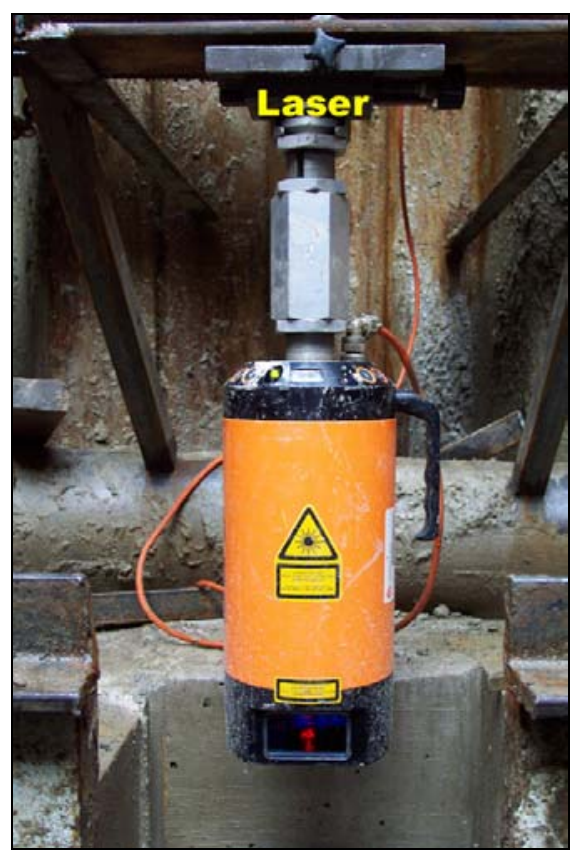

Figure 2.20 Laser for guidance of MTBM 


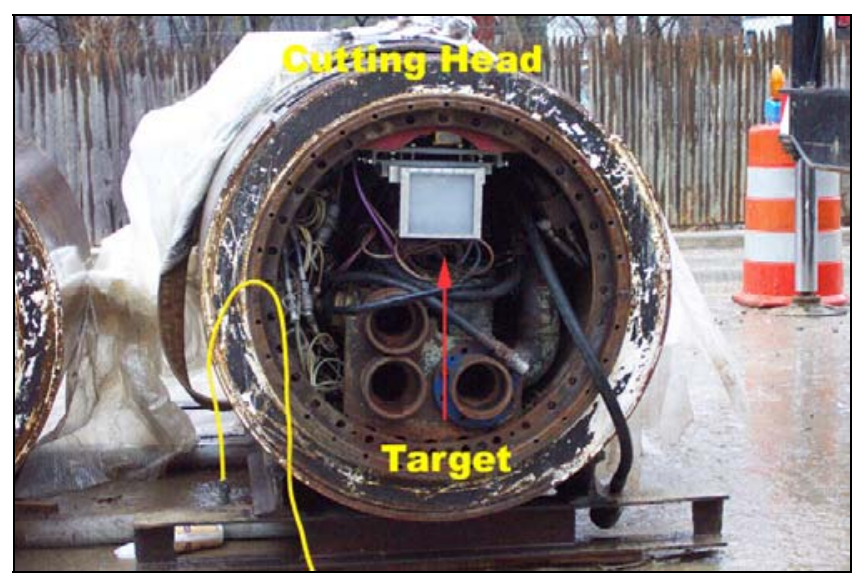

Figure 2.21 Target mounted in the MTBM

Operation boards are usually located in a standard container with 2.4 by $20 \mathrm{~m}$ ( 8 by $20 \mathrm{ft}$ ) dimensions. Operation board consists of control panel, computer and monitor, and a printer. Through the operation board, all the microtunneling operations such as tunneling machine, main jacks, interjack stations, direction / speed of the cutting wheel, and bentonite lubrication equipment, etc. can be controlled. An example of operation board of Soltau Microtunneling is shown in Figure 2.22. The screen of the computer in operation board is presented in Figure 2.23.

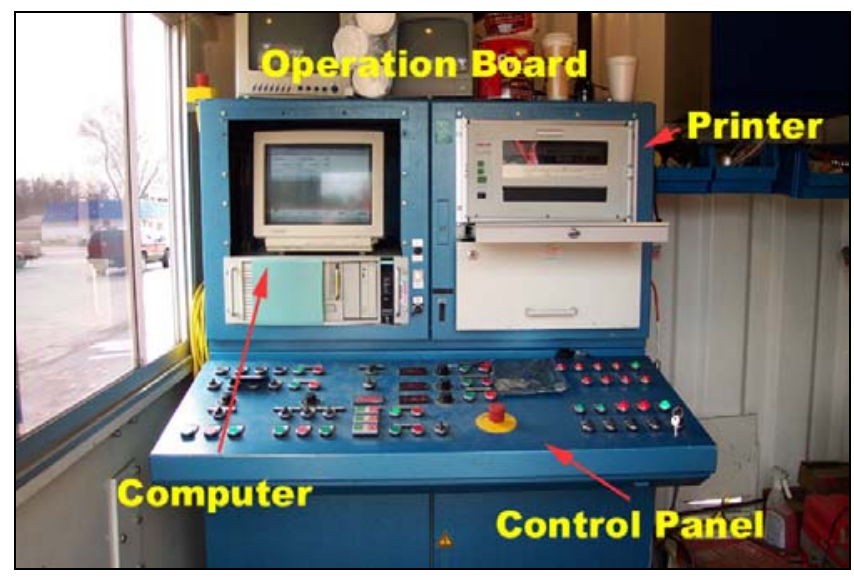

Figure 2.22 Operation board 


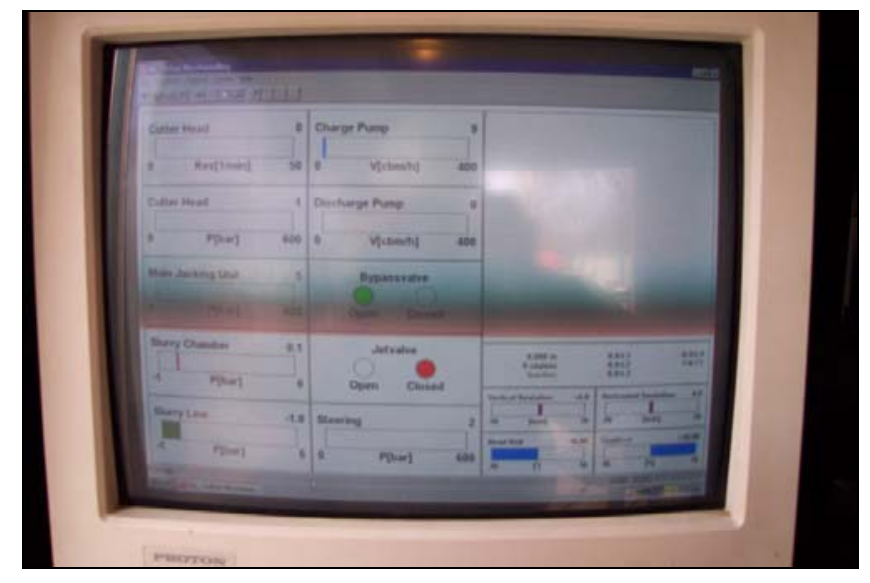

Figure 2.23 Computer screen

In addition to the computer monitor, two other monitors are used in the microtunneling operation. One is for communication purpose, and the other one is for monitoring the inside of MTBM. A small camera with microphone is installed at the top of sheet pile at driving shaft, which provides the overview of the operation. The operator in the cabin can see and hear the tunneling site so that he/she can control the equipment based on input from the crews on the site. Another small camera is installed inside the MTBM. This camera provides a view inside the MTBM. These two monitors are shown in Figure 2.24 and 2.25 .

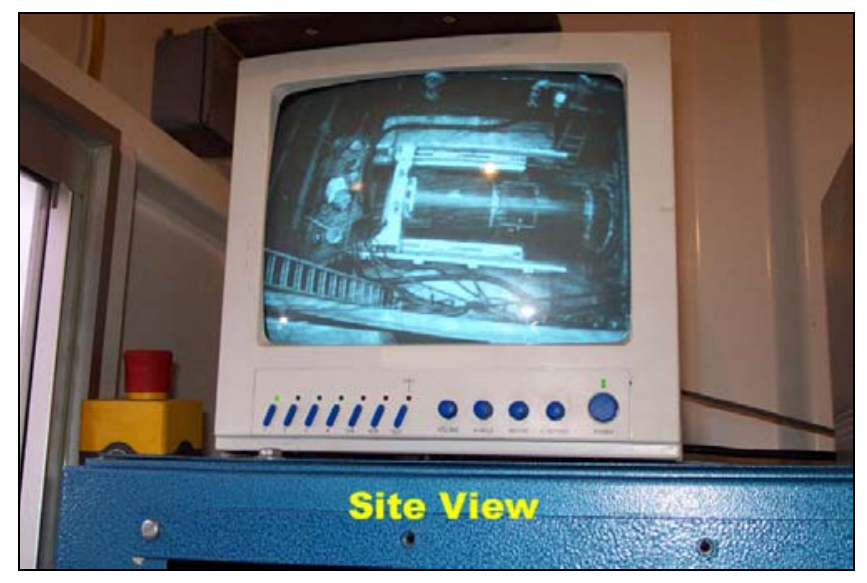

Figure 2.24 Monitor for communication 


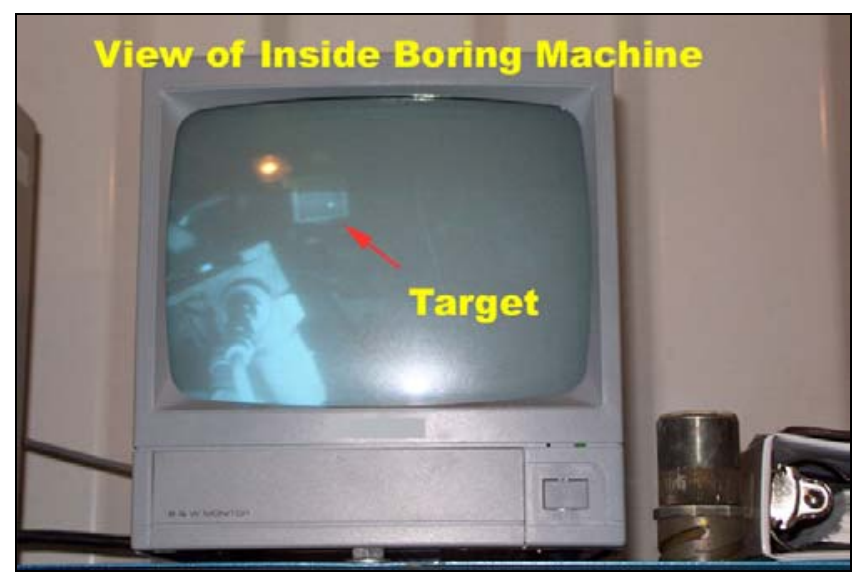

Figure 2.25 Monitor showing a view inside the MTBM

\subsubsection{Drilling process}

The typical layout of construction site for slurry type microtunneling is shown in Figure 2.26. Two shafts are required for the microtunneling operation: a driving shaft and a reception shaft. A MTBM is set up on the guide rail of the jacking frame in the driving shaft. The main jack pushes the machine, and excavation starts. After the machine is pushed into the ground, the first segment of the pipe is lowered. As main jack pushes the pipe, the MTBM simultaneously excavates soil (Ueki et al. 1999).

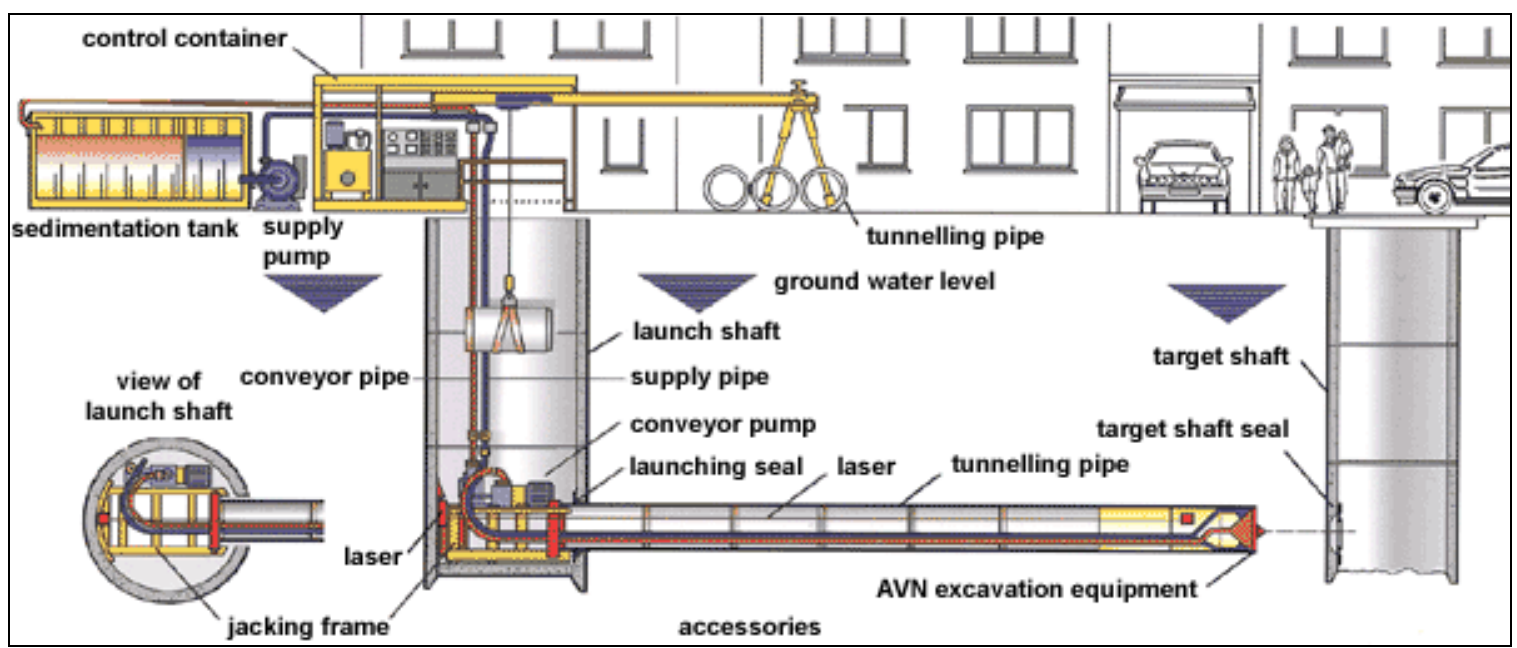

Figure 2.26 Overview of construction site for the slurry type method (Herrenknecht Inc.)

The drilling process for slurry type is as follows (Nido 1999):

1. Excavate and prepare the driving shaft. 
2. Set up the control container and any other auxiliary equipment beside the jacking shaft.

3. Set up the jacking frame and the hydraulic jacks.

4. Lower the MTBM into the driving shaft and set it up.

5. Set up laser guidance system and the MTBM in the driving shaft.

6. Set up the slurry lines and hydraulic hoses on the MTBM as shown in Figure 2.27 .

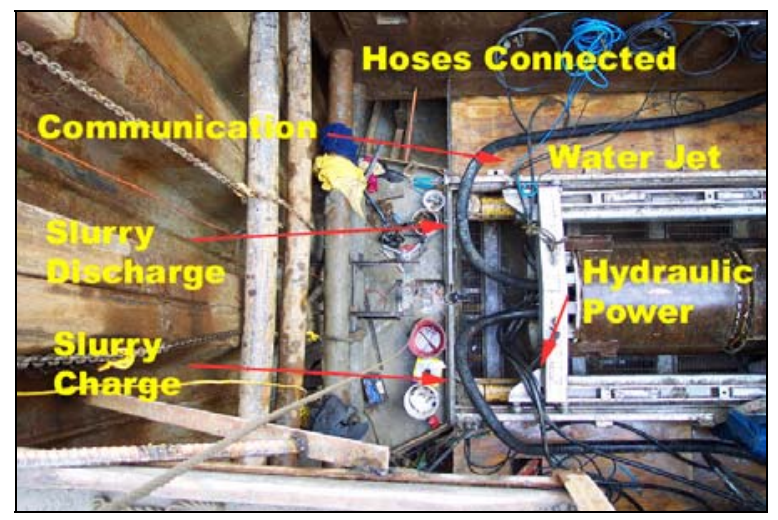

Figure 2.27 Slurry lines and hydraulic hoses

7. The main jack pushes the MTBM.

8. After the MTBM is pushed into the ground, the slurry lines and hydraulic hoses are disconnected from the jacked section (or MTBM).

9. The hydraulic jacks are retracted.

10. A new pipe segment is lowered in the driving shaft.

11. Connect the slurry lines and hydraulic hoses in the new pipe segment to the ones in the previously jacked segment (or MTBM).

12. Jack the new pipe segment and excavate, while removing the spoil.

13. Excavate and prepare the receiving shaft.

14. Repeat step 8 to 12 as required until the pipeline is installed.

15. Remove the MTBM through the receiving shaft. Figure 2.28 shows the MTBM entering the receiving shaft. 


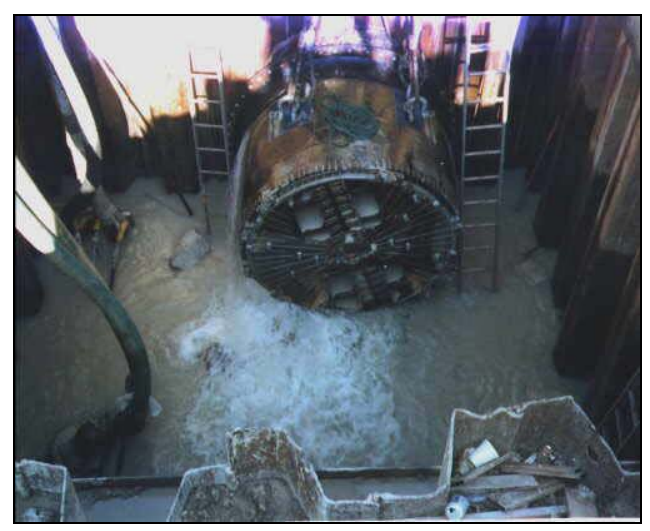

Figure 2.28 MTBM at the receiving shaft (Kerr Construction Inc.)

16. Remove jacking frame and other equipment from the driving shaft.

17. Grout the annular space between the exterior pipe surface and the tunnel.

18. In case of sewer applications, install manholes at the shaft locations.

19. Remove shoring, lining, or casing from the shaft and backfill them (Nido 1999).

\subsubsection{Main Features and Application Range (Iseley and Gokhale 1997)}

\subsubsection{Diameter range}

Based on experiences in the U.S., the range in diameter for microtunneling is from $250 \mathrm{~mm}$ (10 in) to $3,500 \mathrm{~mm}$ (136 in). The most common range is from $610 \mathrm{~mm}(24 \mathrm{in})$ to 1,220 mm (48 in). Slurry microtunneling systems can be applied for the larger sizes of pipes than the auger microtunneling systems.

\subsubsection{Depth of installation}

Since the microtunneling operation is performed in the driving and reception shaft, there is no theoretical limitation for the maximum depth of installation for microtunneling. However, a minimum of $5 \mathrm{ft}(1.5 \mathrm{~m})$ of cover or a depth-of-cover to diameter ratio of 3 is usually recommended for microtunneling to avoid heave or settlement of the surface (Staheli and Hermanson 1996). 


\subsubsection{Drive length}

The longest microtunneling drive from the drive shaft to the reception shaft installed in the United States is $475 \mathrm{~m}$ (1,560 ft). This project was located on Staten Island, New York (Essex 1993). The most common range for drive lengths is from $150 \mathrm{~m}(500 \mathrm{ft})$ to $303 \mathrm{~m}$ (1,000 ft) for slurry microtunneling systems and from $61 \mathrm{~m}(200 \mathrm{ft})$ to $122 \mathrm{~m}$ (400 ft) for auger microtunneling systems.

\subsubsection{Type of casing}

The most common types of pipe used with microtunneling are steel, reinforced concrete, vitrified clay, and glass-fiber reinforced plastic. A small amount of ductile iron pipe and PVC pipe have been installed with microtunneling.

\subsubsection{Required working space}

Adequate working space needs to be provided at the drive shaft to accommodate the required equipment and materials for the microtunneling operation. The space requirement is determined by the drive shaft size, which can range from 5 by $10 \mathrm{~m}$ ( $16 \mathrm{ft}$ by $33 \mathrm{ft}$ ) to $15 \mathrm{~m}$ by $30 \mathrm{~m}$ (50 ft by $100 \mathrm{ft}$ ), depending on pipe diameter and length and

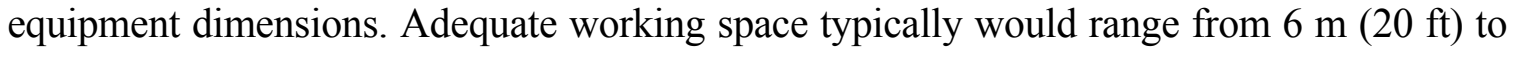
$12 \mathrm{~m}$ (40 ft) wide and from $23 \mathrm{~m}$ (75 ft) to $46 \mathrm{~m}$ (150 ft) long.

\subsubsection{Soil condition}

The most favorable ground condition for slurry microtunneling is wet sand, and the most favorable ground condition for auger microtunneling is the stable sandy clay. However, a wide selection of MTBM cutter heads are available that provide the capability to handle a range of soil conditions, including boulders and solid rock. Typically, boulders

of 20 to 30 percent of the machine diameter can be removed by microtunneling by crushing the boulders into particle sizes of $19 \mathrm{~mm}(0.75 \mathrm{in})$ to $25 \mathrm{~mm}$ ( 1 in) and smaller.

\subsubsection{Productivity}

Crews of four to eight can obtain a production rate of $9 \mathrm{~m}(30 \mathrm{ft})$ to $18 \mathrm{~m}(60 \mathrm{ft})$ per shift in microtunneling operations. 


\subsubsection{Accuracy}

The method is capable of installing gravity flow pipes to a high precision. Hence these are mainly used for the installation of gravity flow lines where a high degree of precision is required. The laser system for controlling the alignment permits systems to be installed to an accuracy of $\pm 25 \mathrm{~mm}$ (1 inch) (Essex 1993).

\subsubsection{Major advantages}

The method is capable of installing pipes to extremely accurate line and grade tolerances. It has the capability of performing in very difficult ground conditions without expensive dewatering systems and/or compressed air. Lines can be installed at a greater depth without a drastic effect on the cost. The factor becomes increasingly important as congestion is increased. Safety is enhanced because workers are not required to enter trenches or tunnels. The finished product (carrier) pipe can be jacked directly without the need of a separate casing pipe.

\subsubsection{Major disadvantages}

The capital cost in equipment is high. However, on projects where these methods have been competitively bid against other tunneling methods, the unit price costs have in line. Some MTBM systems have difficulty in soils with boulders which size more than 20 or 30 percent of the machine diameter. 


\subsection{PILOT TUBE MICROTUNNELING}

\subsubsection{Introduction}

Pilot Tube Microtunneling (PTMT), which is called by several names such as guided auger boring, guided boring method, and auger drilling, was introduced to the trenchless construction in the 1990s. According to the North American Society for Trenchless Technology (NASTT), guided auger boring is defined as "Auger boring systems which are similar to microtunneling, but with the guidance mechanism actuator sited in the drive shaft (e.g. a hydraulic wrench which turns a steel casing with a symmetric face at the cutting head). The term may also be applied to those auger boring systems with rudimentary articulation of the casing near the head activated by rods from the drive pit (NASTT 2002)."

The PTMT involves the installation of small diameter pipes of sewer lines or water lines. This technique also can be used for house connections direct from the main collector sewers. PTMT employs auger and accurate guidance system using camera mounted theodolite and target with electric Light Emitting Diodes (LEDs) to secure high accuracy in line and grade.

\subsubsection{Description}

PTMT can be applied for the installation of small diameter pipes which require high accuracy in line and grade. This method is appropriate for the installation of small diameter sewer pipelines and water lines. This technique is a combination of the existing trenchless technologies including auger boring, microtunneling, and horizontal directional drilling. PTMT employs augers for excavation and soil removal and the jacking system for pushing the pipes as does auger boring. It uses theodolite with camera for the accurate guidance system. The target with LEDs is mounted in the steering head and is monitored through the TV monitor, which is similar to the guidance system of microtunneling. The operation process of PTMT includes pilot boring and reaming, which is similar to the operation of HDD.

This method drills a bore hole with a steering head connected to pilot tubes of which size is smaller than the required size. Then the bore hole is enlarged by a reamer and 
auger casing with augers inside. The product pipes are then to follow the auger casing to be installed in the ground. Since the application of this technique is for smaller size pipes, the equipment and required space for the operation is smaller than that of other jacking methods such as auger boring, pipe jacking, and microtunneling.

PTMT employs a steering head for boring and adjustment of alignment and grade. The steering head has a slant on one side and several types of steering heads are available based on the degree of the slant. For instance, Akkerman Inc. provides three types of steering heads with different slants of 30, 45, and 60 degrees (Akkerman 2002). Two different types of steering heads are shown in Figure 2.29.

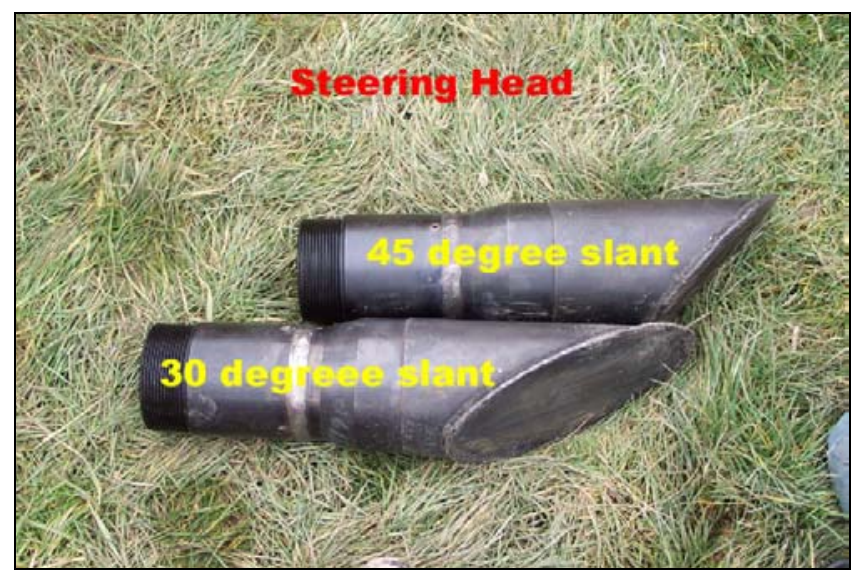

Figure 2.29 Steering heads for PTMT

For the accurate drilling using the PTMT, the target is one of the critical components. Figure 2.30 (a) shows the target used for PTMT operation, and Figure 2.30 (b) shows the target mounted in the steering head. LEDs are arrayed to compose two circles and one line from the center. It is operated by the battery which lasts about 10 days when charged. When the target is turned on, the LEDs are illuminated, as shown in Figure 2.30 (b), and they can be seen through the theodolite even though the target and the steering head are in the borehole. 


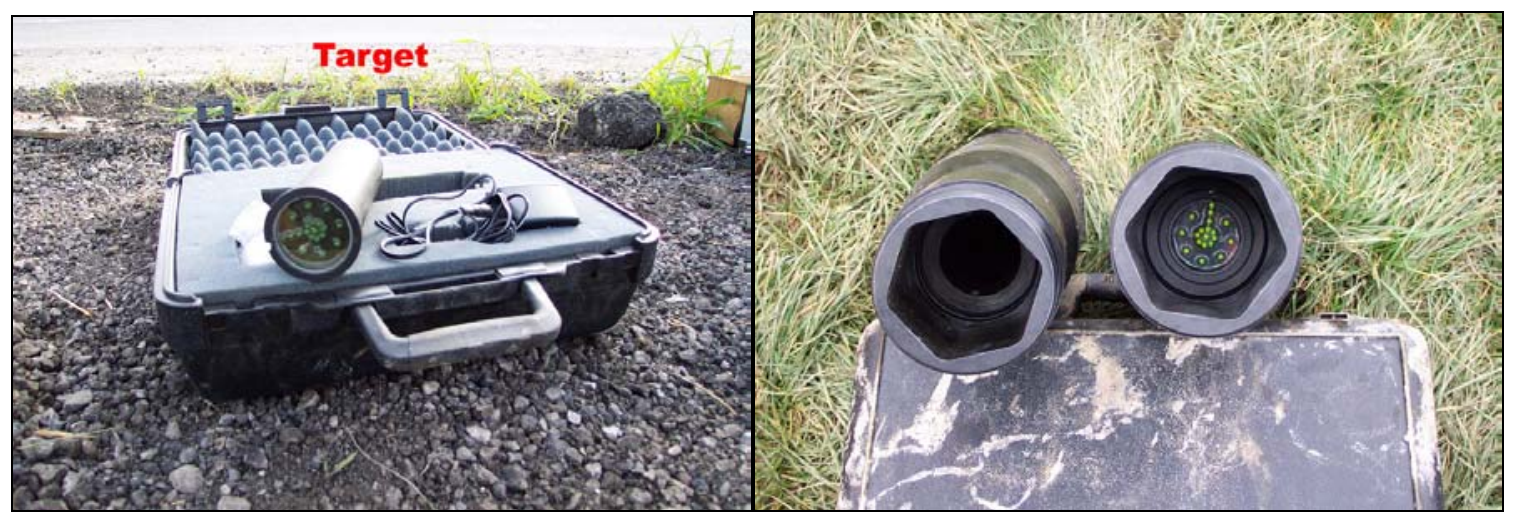

(a) Target

(b) Target in the steering head

Figure 2.30 Target for PTMT

The guidance system, consisting of target, theodolite, camera, and monitor, can detect the deviation of the drilling profile, and gives the operator continuous information about the location of the steering head. The structure of the guidance system is illustrated in Figure 2.31. If deviations are detected though the monitor, the operator can modify the direction of the steering head by thrusting it using the characteristic of slanted surface of steering head. Since the accuracy of the set up of theodolite and target determines the accuracy of entire project, prudent set up is required.

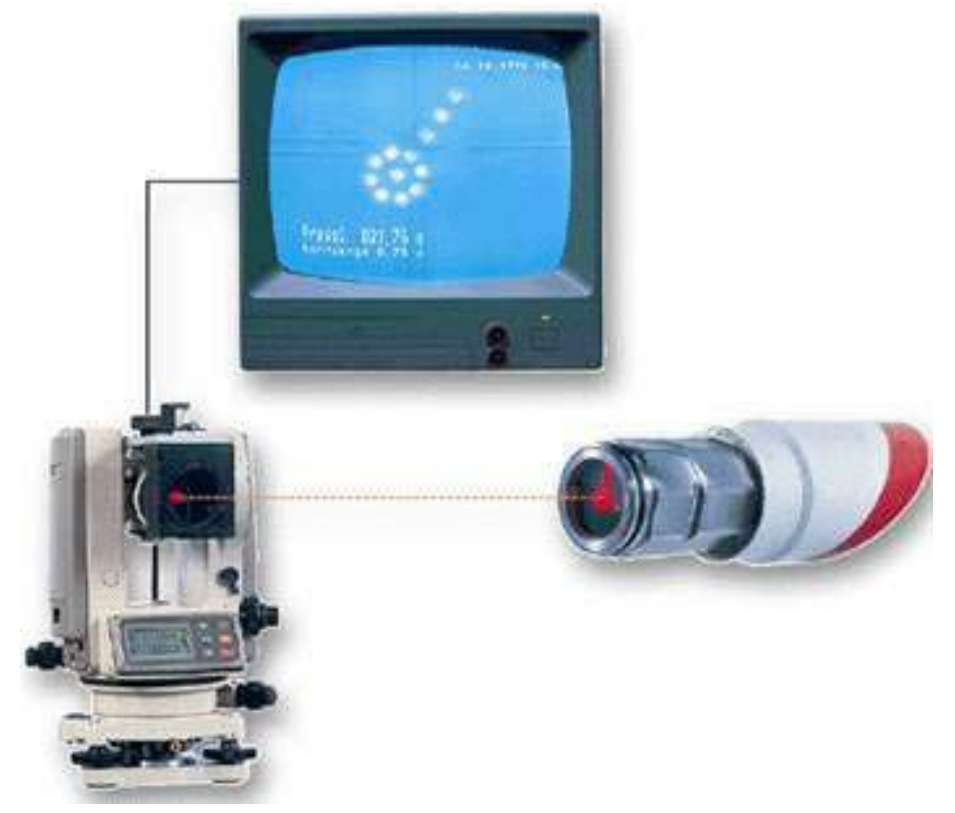

Figure 2.31 Guidance system for PTMT (Herrenknecht Inc.) 
The drilling process in PTMT can be described as follows:

1. Excavate and prepare the driving and receiving shaft.

2. Lower the thrust frame into the driving shaft and set it up. The thrust frame for PTMT is shown in Figure 2.32.

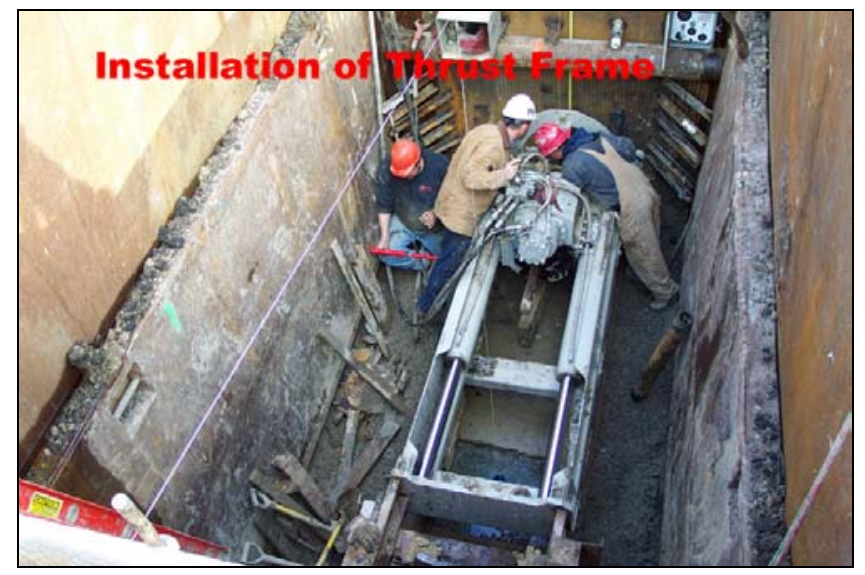

Figure 2.32 Installation of thrust frame

3. Set up guidance system in the driving shaft. Figure 2.33 shows the set up of camera-mounted theodolite. The camera will be connected to the video monitor installed at the driving shaft, as shown in Figure 2.34, and be used for monitoring the line and grade of the drilling profile.

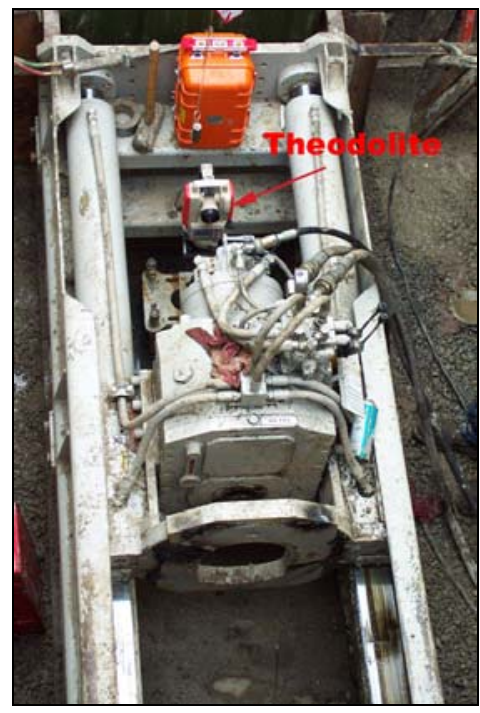

Figure 2.33 Installation of a theodolite 


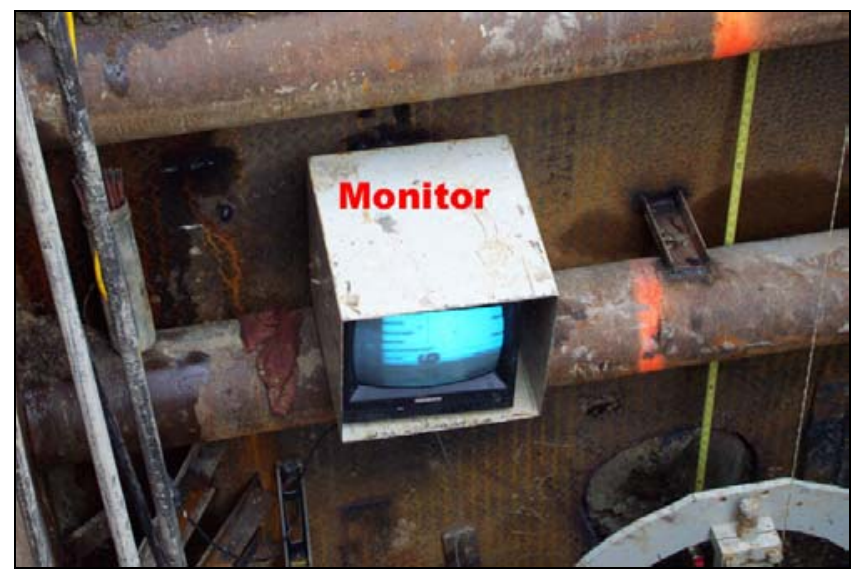

Figure 2.34 Video Monitor

4. Set up the steering head and target. Different steering head can be deployed based on the soil conditions.

5. Install the pilot tube behind the steering head. The boring process proceeds with the rotation and thrust of pilot tube. The deviations are continuously adjusted through the video monitor surveillance of the illuminated target via the theodolite. The process of pilot tube boring is illustrated in Figure 2.35. Pilot tubes used for this process are shown in Figure 2.36.

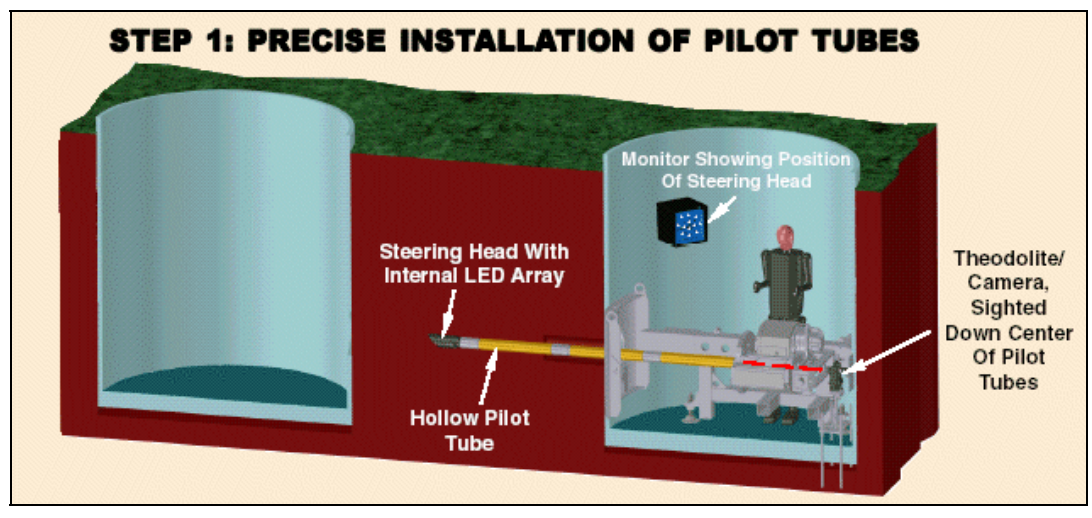

Figure 2.35 Pilot tube boring (Akkerman Inc. 2002) 


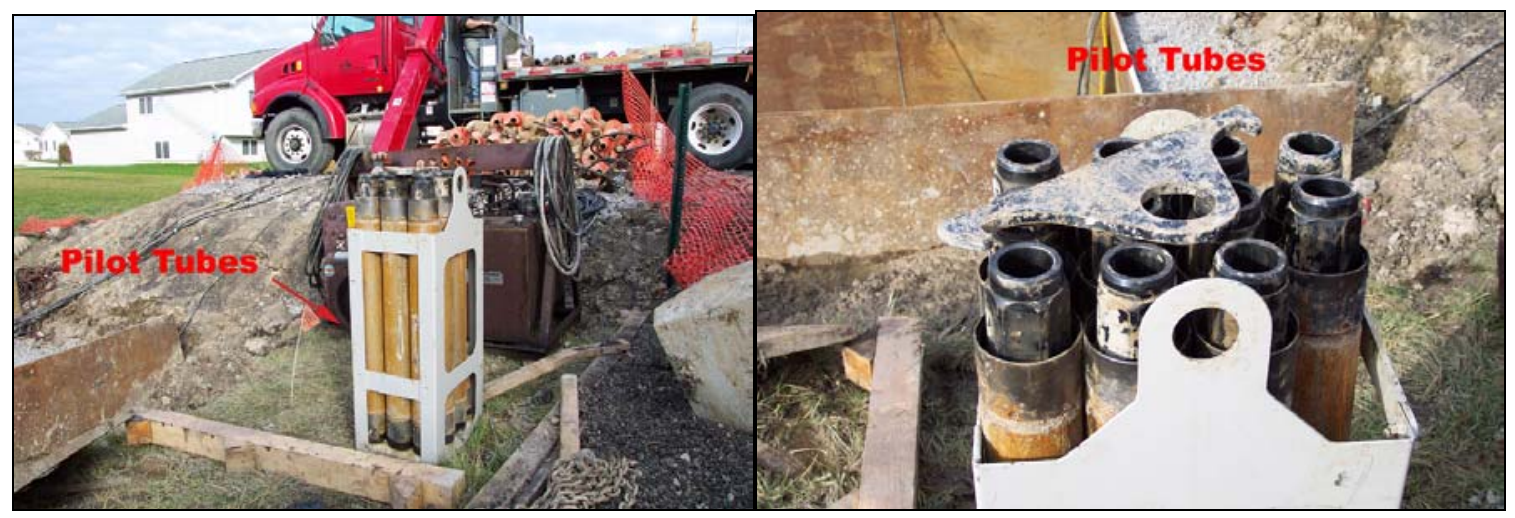

(a)

(b)

Figure 2.36 Pilot tubes

6. When the steering head reaches the receiving shaft, the reamer and casing with auger inside are connected to the last segment of pilot tube. Then the reamer and auger enlarges the pilot bore hole by rotating and thrusting the reamer and casing. The steering head and the pilot tubes can be retrieved at the receiving shaft. This process is repeated until all pilot tubes are removed. The illustration for this process is presented in Figure 2.37. Reamer, augers, and casings used for this process are shown in Figure 2.38, 2.39, and 2.40, respectively.

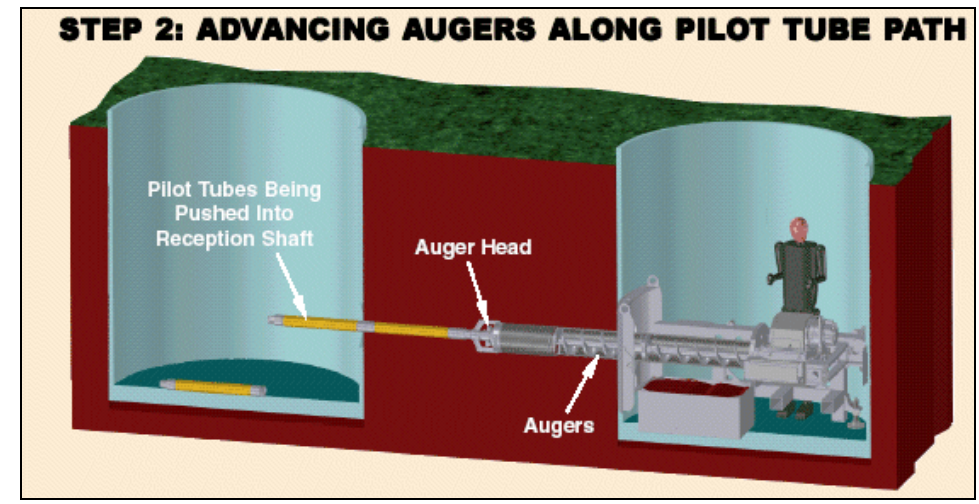

Figure 2.37 Reaming process (Akkerman Inc. 2002) 


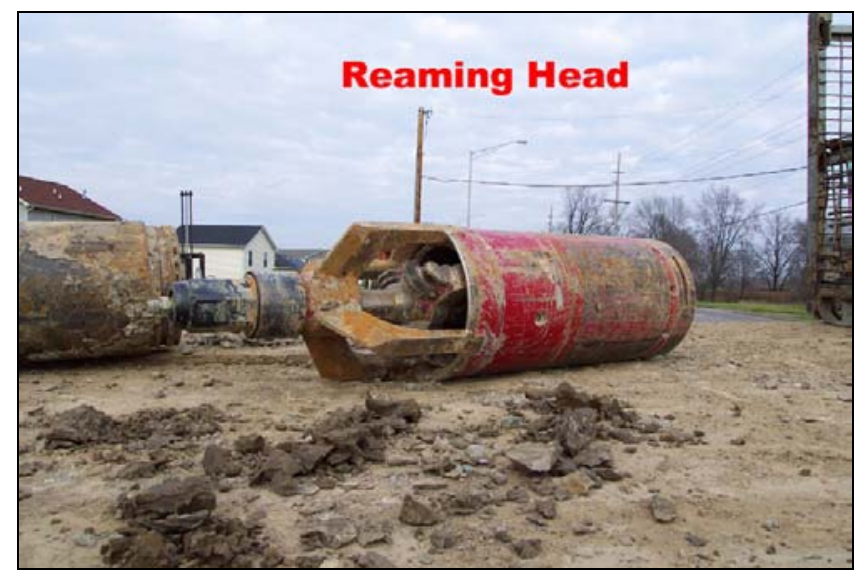

Figure 2.38 Reamer for PTMT

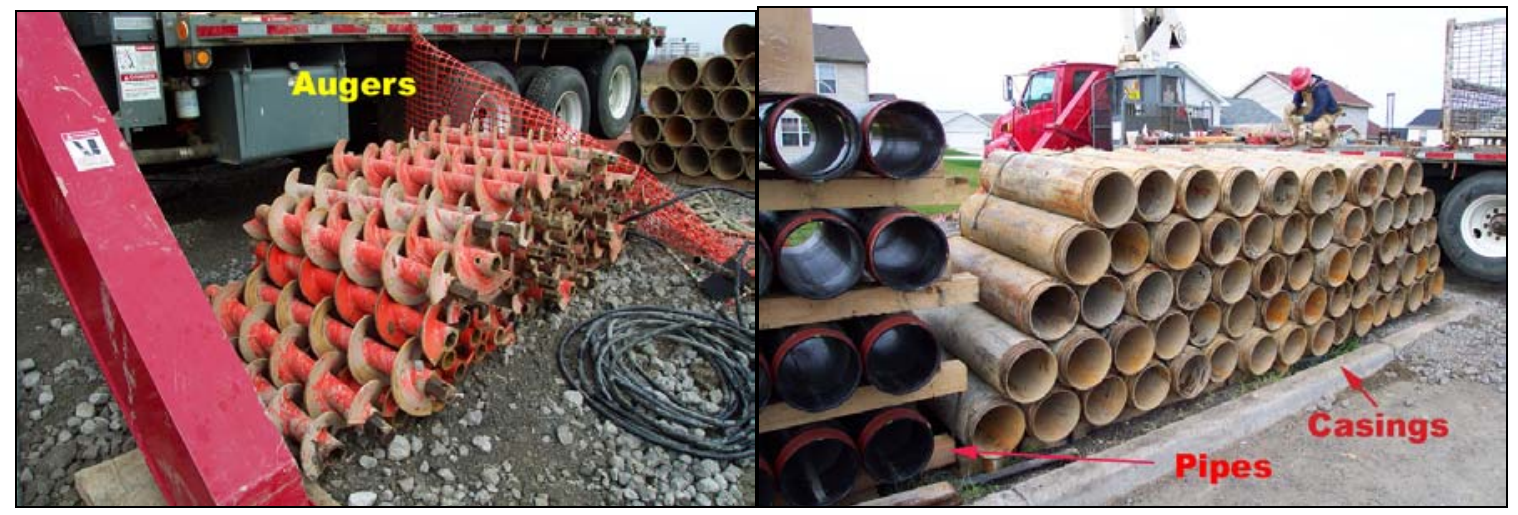

Figure 2.39 Augers for PTMT

Figure 2.40 Casings for PTMT

7. After the reamer has reached the receiving shaft, an adapter is installed at the end of the last casing. It connects the casing and product pipe. The product pipe is pushed by the jacking frame while the casings are retrieved at the receiving shaft. The augers remove the soil in the casings, and are then retrieved at the driving shaft. This process is repeated until all casings and augers are removed. Figure 2.41 illustrates the installation of product pipes. The pipe adapter is shown in Figure 2.42. 


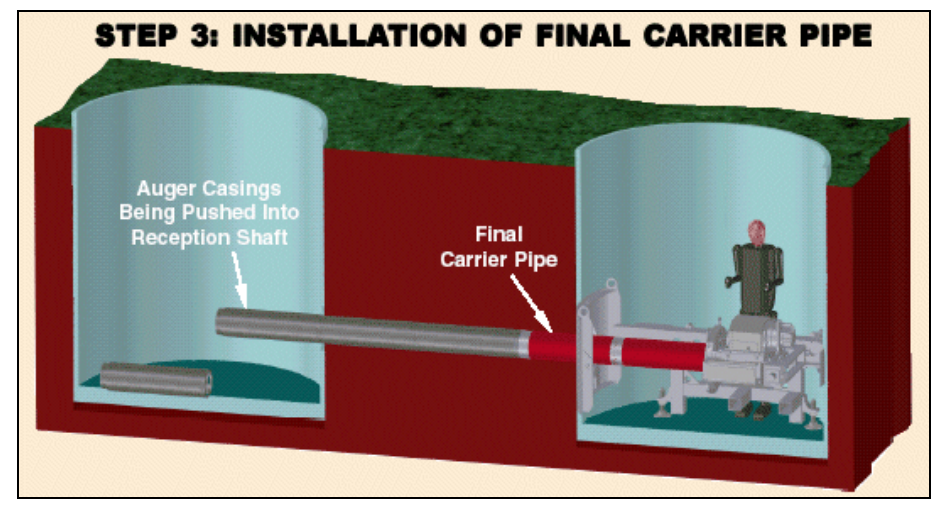

Figure 2.41 Installation of pipes using PTMT (Akkerman Inc. 2002)

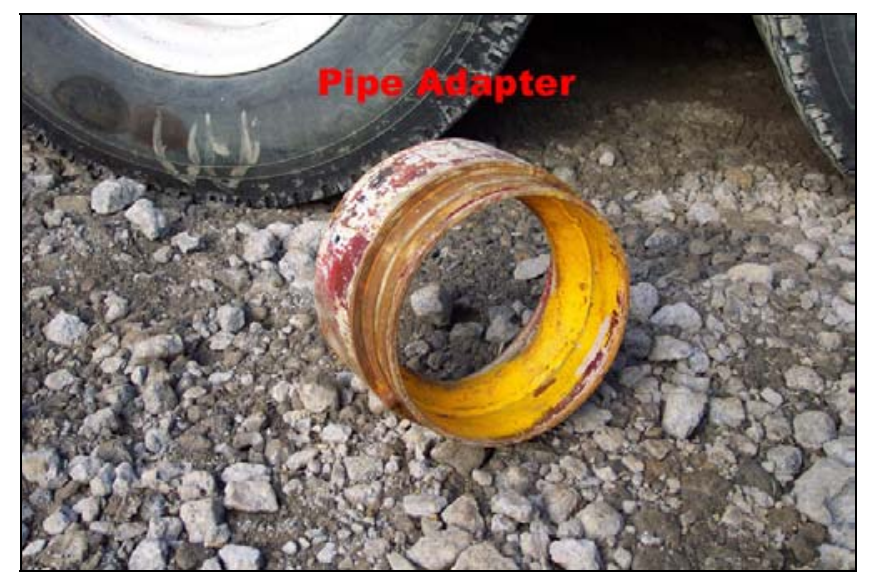

Figure 2.42 Pipe adapter for PTMT

\subsubsection{Main Features and Application Range}

PTMT can install pipes from $100 \mathrm{~mm}$ (4 in) to $600 \mathrm{~mm}$ (24 in) in diameter. The maximum drive length of PTMT is about $80 \mathrm{~m}(270 \mathrm{ft})$. PTMT operations have an accuracy of $6 \mathrm{~mm}(0.25 \mathrm{in})$ per $90 \mathrm{~m}(300 \mathrm{ft})$ pipe length. However, the accuracy depends on the capability of theodolite and the operator's skill. The productivity of pilot tube installation can be as high as $67 \mathrm{~m}$ (200 ft) per 8-hour shift (Akkerman Inc. 2002). PTMT can be applied in a variety of soil conditions. However, hard soil with relatively larger boulders and rocks can cause some challenges to the performance, as can runny sands and unstable soils (Borhtec BmbH 2002). 


\subsection{PIPE JACKING}

\subsubsection{Introduction}

The term "pipe jacking" can be used to describe an installation technique as well as a trenchless technology method process which generally means thrusting boring head and pipes using hydraulic thrust force. This concept of thrusting system is adapted by many trenchless technologies including auger boring and microtunneling. However, the term pipe jacking is regarded as an installation technique in this section.

Pipe jacking (PJ) is a trenchless technology method for installing a prefabricated pipe through the ground from a drive shaft to a reception shaft. The first use of pipe jacking was at the end of the nineteenth century. In the 1950s and 1960s, new techniques were added to the pipe jacking by European and Japanese companies including extended drive length to theoretically unlimited spans, upgraded line and grade accuracy, enhanced pipes and joints for pipe jacking, and improved excavation and face-stabilizing shields. These developments as well as the improved operator skills and experience have enabled pipe jacking to be a popular trenchless technology (Kramer and Thomson 1992).

In the pipe jacking operation, the pipe is propelled by jacks located in the drive shaft. The jacking force is transmitted through the pipe to the face of the pipe jacking excavation. When the excavation is accomplished, and the spoil is transported out of the jacking pipe and shaft manually or mechanically. Both the excavation and spoil removal processes require workers to be inside the pipe during the jacking operation. Even though it is theoretically possible for a person to enter a $900 \mathrm{~mm}$ (36 in) diameter pipe, it is practically very difficult for the person to work in it. Therefore, the minimum recommended diameter for pipe installed by pipe jacking is $1,075 \mathrm{~mm}$ (42 in). However, it is feasible to install Reinforced Concrete Pipes (RCPs) with $900 \mathrm{~mm}$ (36 in) (I.D.) and $1,100 \mathrm{~mm}$ (44 in) (O.D.).

\subsubsection{Description}

Figure 2.43 illustrates the typical components of a pipe jacking operation. The cyclic procedure uses the thrust power of the hydraulic jacks to force the pipe forward through the ground as the pipe jacking face is excavated. The spoil is transported through 
the inside of the pipe to the drive shaft, where it is removed and disposed of. After each pipe segment has been installed, the rams of the jacks are retracted so that another pipe segment can be placed in position for the jacking cycle to begin again.

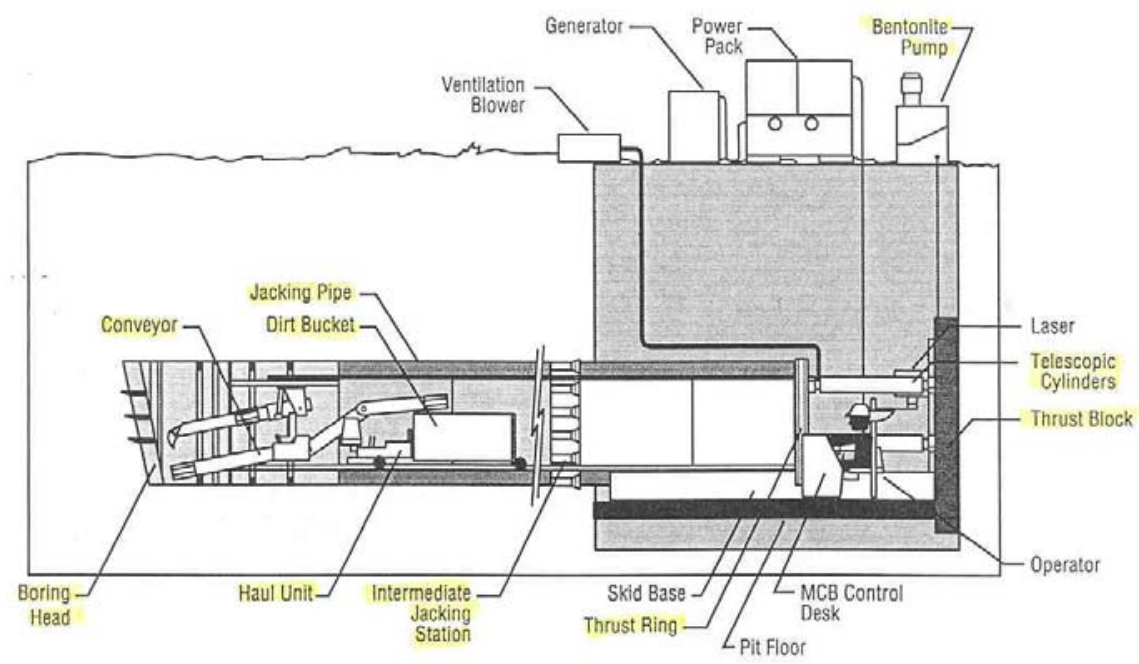

Figure 2.43 Typical components of a pipe jacking operation (Iseley and Gokhale 1997)

Excavation is accomplished by hand mining or mechanical excavation within a shield or by a Tunnel Boring Machine (TBM). The excavation method selection is based on a careful assessment of the subsurface for instability. If there is any possibility of excavation face collapse, soil stabilization techniques must be considered. Common soil stabilization techniques are dewatering and grouting. Alternatively, closed face earthpressure balance or slurry microtunneling methods may be appropriate.

Because of the large jacking forces required to push large diameter pipe through the ground, the design and construction of the jacking shaft are critical to the success of the project. The shaft floor and thrust reaction structure must be designed to withstand the weight of heavy pipe segments being placed on them repeatedly.

Important optional equipment available for the pipe jacking method includes a pipe lubrication system and intermediate jacking stations (IJSs). The pipe lubrication system consists of mixing and pumping equipment necessary for applying bentonite or polymer slurry to the external surface of the pipe. An adequate lubrication system can decrease jacking forces by $20-50$ percent; however, the most common reduction factor range would 
probably be 20-30 percent (Terzaghi 1950). IJSs are used for pipes, $1.2 \mathrm{~m}$ (36 in) in diameter or larger, between the drive shaft jacking plate and the jacking shield or TBM to redistribute the total required jacking force on the pipe. IJSs consist of a steel cylinder installed between two pipe segments in the pipeline being jacked. Hydraulic jacks are then placed around the internal periphery of the steel cylinder. The IJS is pushed forward through the ground with the pipeline until its operation is necessary. When the main jacks reach approximately 80 percent of the design load, the jacking force on the pipe behind the IJS is held constant, and the jacks in the IJS are activated to propel the forward section of the pipeline (Bennett et al. 1995). Figure 2.44 shows the IJS.

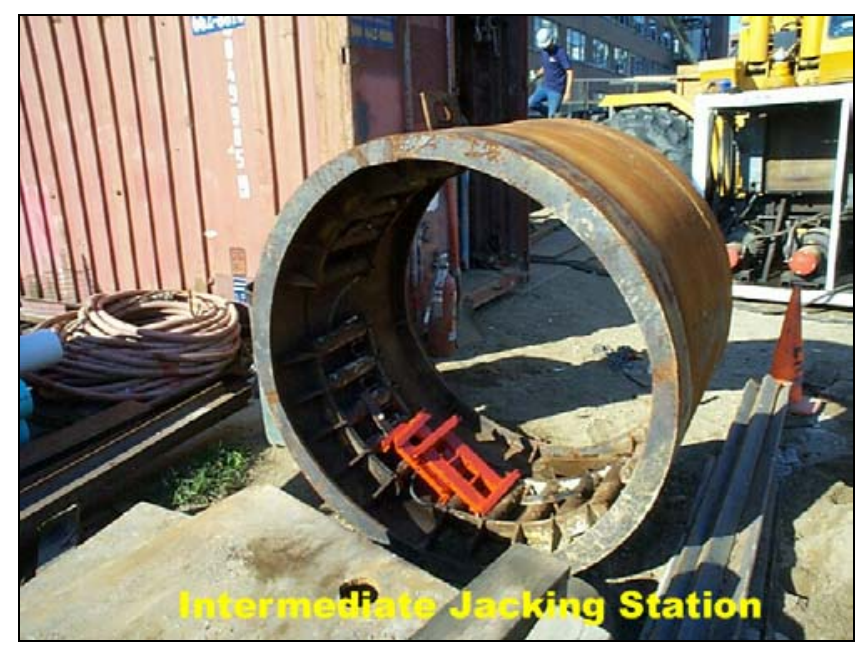

Figure 2.44 Intermediate Jacking Station

The basic pipe jacking procedure can be described as follows (Iseley and Gokhale 1997):

1. Excavate and prepare the driving shaft.

2. Set up the jacking frame and the hydraulic jacks to adjust to the proposed design line and grade.

3. Install laser guidance system in the driving shaft as shown in Figure 2.45. During the drilling operation, the operator who stays inside the boring machine continuously checks the mark on the steering head and the laser point. If the operator detects a deviation, the operator will articulate the steering head back 
to the correct alignment. The laser point for the alignment is shown in Figure 2.46 .

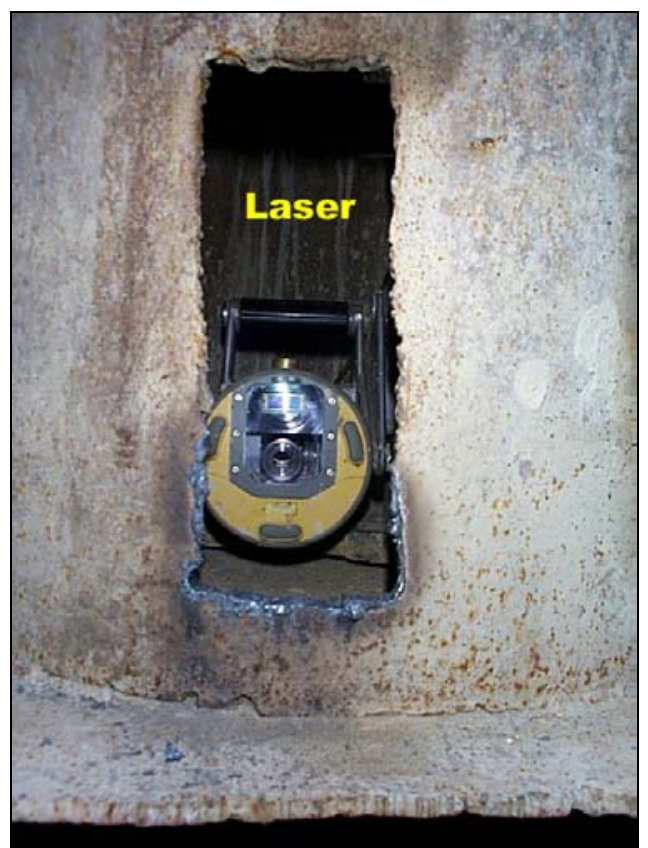

(a)

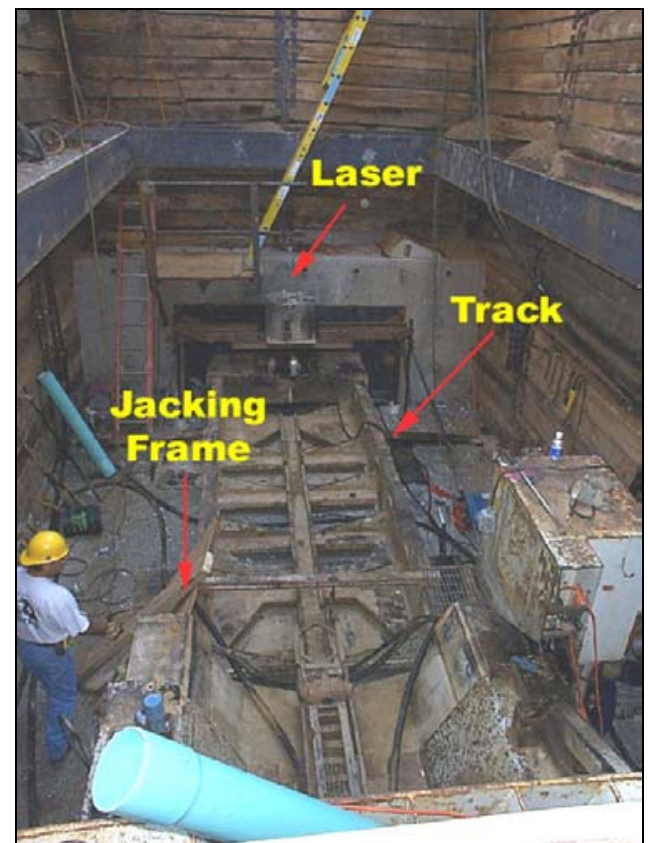

(b)

Figure 2.45 Laser guidance system for pipe jacking

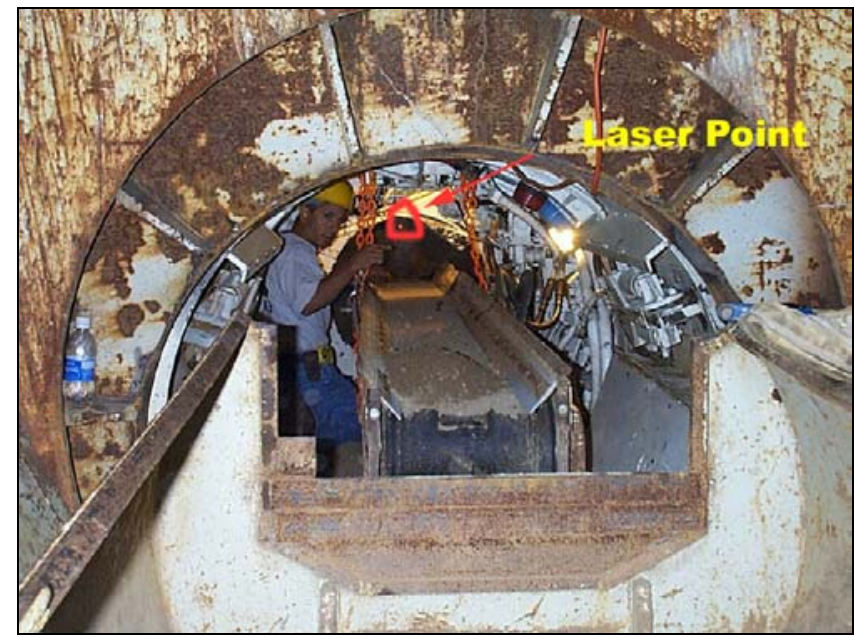

Figure 2.46 Laser point for alignment control

4. Lower the boring machine into the driving shaft and set it up. Figure 2.47 shows different views inside and outside the pipe jacking boring machine. 


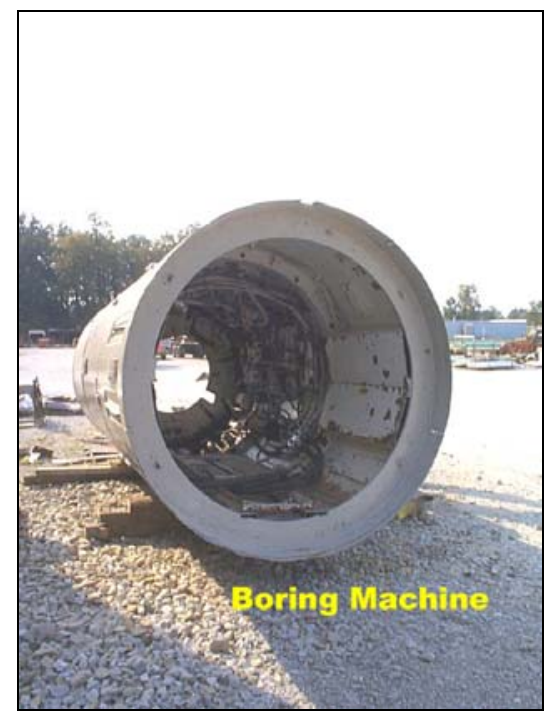

(a)

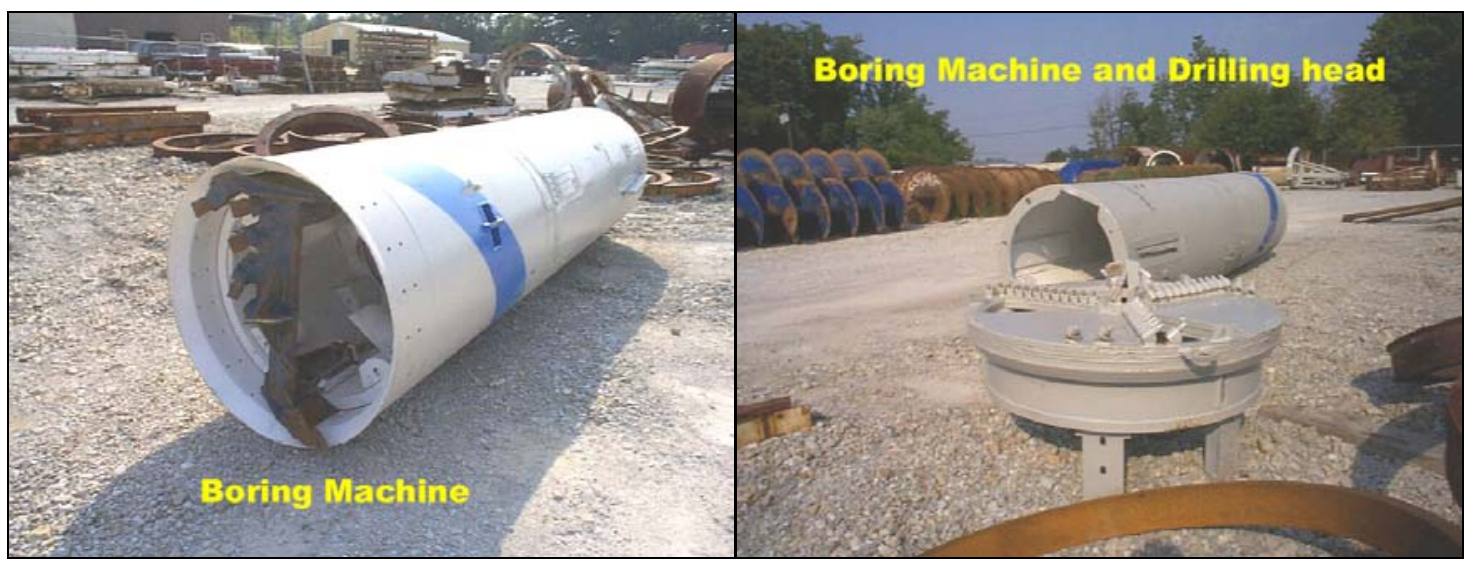

(b)

(c)

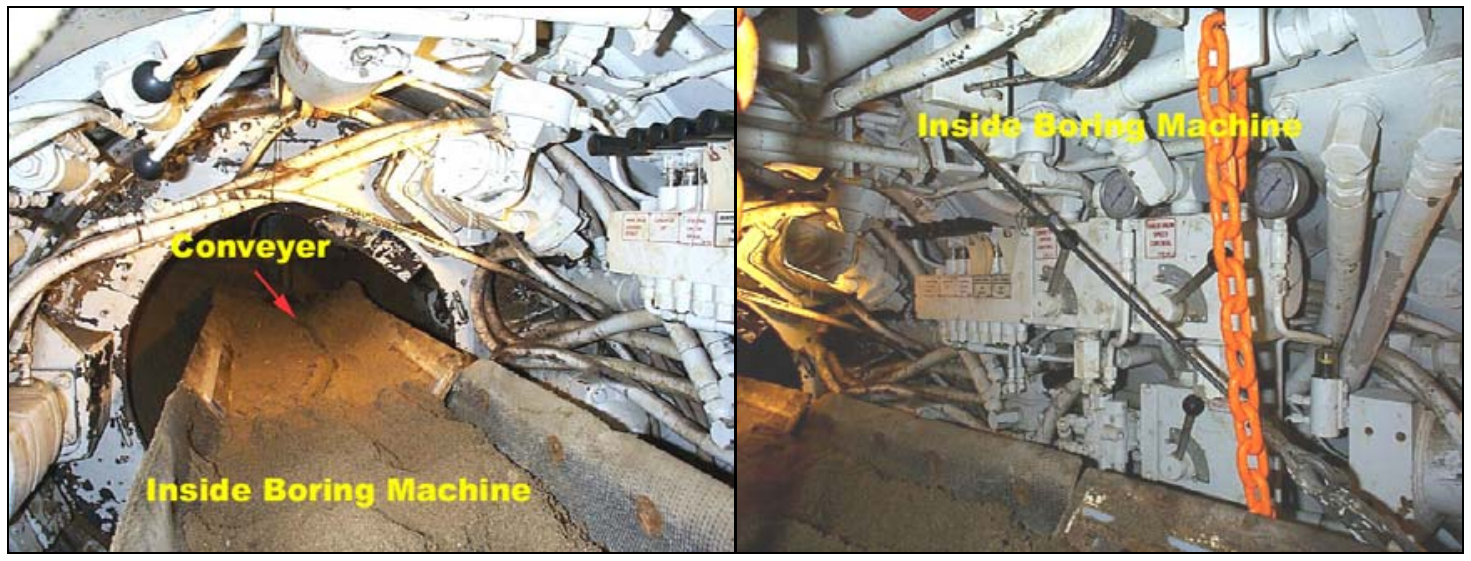

(d)

(e)

Figure 2.47 Pipe jacking tunnel boring machine 
5. Mate jacking push plate (thrust ring) to shield or TBM. The thrust ring is the frame that the main cylinders push against to advance the boring head and pipe. The ring provides a 360-degree surface against the pipe to minimize point pressure and reduce the chance of breakage (Akkerman Inc. 2002).

6. Advance shield or TBM through the prepared opening in the forward shaft support structure. Begin the excavation and spoil removal process. Continue excavation, spoil removal, and forward advancement until the shield or the TBM is installed. The movement of the jacking machine is controlled by the control panel outside the boring machine, whereas the drilling operation is controlled by the control levers inside the boring machine. The control panel for the jacking machine is shown in Figure 2.48.

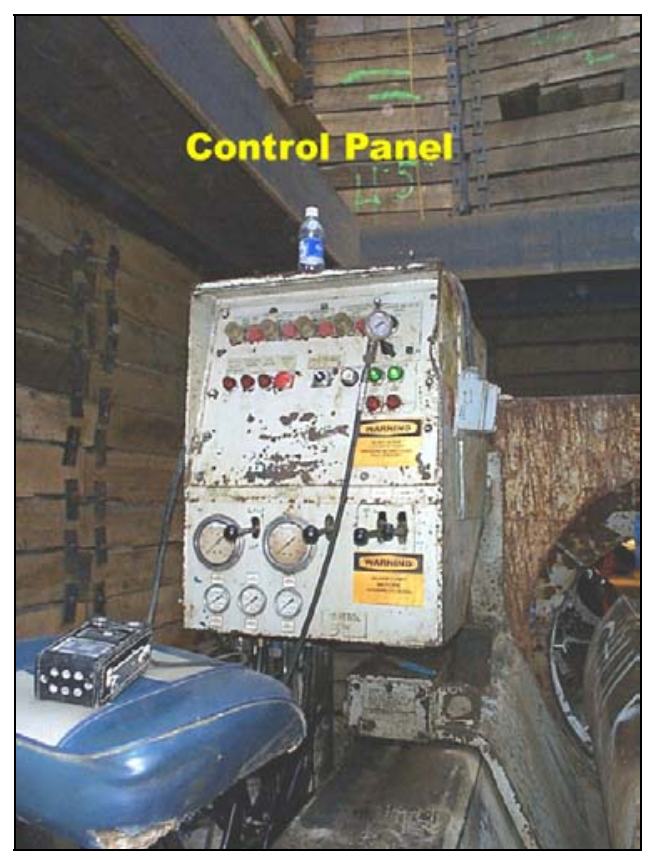

Figure 2.48 Control panel for the jacking machine

7. Retract jacks and push plate to provide a space for the pipe segment.

8. Place first pipe segment on the jacking tracks.

9. Mate push plate to pipe and pipe to the shield or TBM. Figure 2.49 shows the TBM, IJS, casing, and jacking machine. 


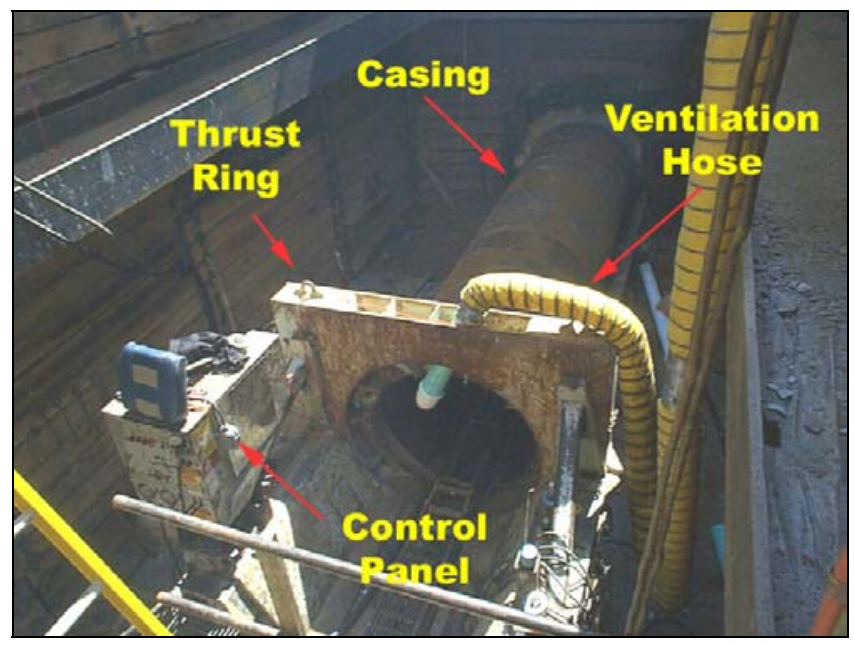

Figure 2.49 The set-up for pipe jacking operation

10. Initiate forward advancement, excavation, and spoil removal.

11. Repeat pipe jacking cycles until the complete line is installed.

12. Remove the shield or the TBM from reception shaft.

13. Remove the jacking equipment, IJS, and the tracks from drive shaft.

14. Restore the site as required.

2.5.3 Main Features and Application Range (Iseley and Gokhale 1997)

\subsubsection{Diameter range}

Since the method requires people working inside the jacking pipe, the method is limited to person-entry size pipes. This has been accomplished in pipes as small as $750 \mathrm{~mm}$ (30 in). However, the minimum recommended diameter for pipe installed by pipe jacking is $1,075 \mathrm{~mm}$ (42 in) (O.D.) or $900 \mathrm{~mm}$ (36 in) (I.D.) RCP. Theoretically, there is no limit to the size of pipe that can be jacked; however, the largest usually is approximately $3.7 \mathrm{~m} \mathrm{(12}$ $\mathrm{ft}$ ) in diameter, with the most common sizes ranging from 1,220 $\mathrm{mm}$ (48 in) to $1,830 \mathrm{~mm}$ (72 in) in diameter. 


\subsubsection{Drive length}

The length of pipe jacking drive is determined by the amount of available jacking thrust and the compressive strength of the pipe. The jacking thrust can be minimized or managed by providing an adequate over cut, applying adequate lubrication between the outside surface of the pipe and the bore hole, maintaining accurate line and grade control, using high-quality pipe products, and using IJSs. The longest pipe jacking project in the United States had a continuous jacking length from drive shaft to reception shaft of approximately $1,050 \mathrm{~m}(3,500 \mathrm{ft})$ (Roe 1995). The most common drive lengths range from $150 \mathrm{~m}(500 \mathrm{ft})$ to $305 \mathrm{~m}$ (1,000 ft).

\subsubsection{Type of casing}

The type of pipe used for the pipe jacking method must be capable of transmitting the required jacking forces from the thrust plate in the jacking shaft to the jacking shield or TBM. Steel pipe, reinforced concrete pipe (RCP), and glass-fiber reinforced plastic pipe (GFRP) are the most common types of pipe used in pipe jacking. Polymer concrete pipe (PCP) is commonly used in Europe for pipe jacking and microtunneling.

A cushioning material should be used between the pipe segments to assist with distributing the jacking loads evenly over the cross section of the pipe. The most common type of material used as a cushion material is plywood and particle board.

\subsubsection{Required working space}

The site must provide space for storage and handling of pipe and spoil and adequate space for the shaft. The size of the jacking shaft is determined by the pipe diameter, pipe segment length, jacking shield dimensions, jacking system dimensions, thrust wall design, pressure rings, and guide rail system. For example, the drive shaft size for a pipe jacking project using pipe $1,525 \mathrm{~mm}$ (60 in) in diameter with segments $3.3 \mathrm{~m}(10 \mathrm{ft})$ in length

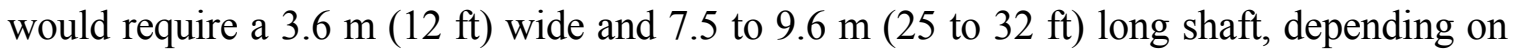
selection of jacking and excavation equipment. 


\subsubsection{Soil condition}

Cohesive soils are the most favorable soil conditions for pipe jacking. It is possible to use pipe jacking in unstable soil conditions as long as special precautions are taken, such as dewatering and using closed-face machines and earth pressure balance machines to counterbalance the ground pressure.

\subsubsection{Productivity}

A reasonable productivity range for pipe jacking projects is $10 \mathrm{~m}(33 \mathrm{ft})$ to $18 \mathrm{~m}$ (60 ft) per shift with a four or five person crew. Factors that can affect productivity include the presence of groundwater, unanticipated obstructions such as boulders or other utilities, and changed conditions such as encountering wet silty sand after selecting equipment for stable sandy clay.

\subsubsection{Accuracy}

Pipe jacking is capable of installations to a very high degree of accuracy. Since the laser is used for controlling the line and grade, installation to an accuracy of within an inch are common. A reasonable anticipated tolerance is $\pm 75 \mathrm{~mm}$ ( 3 in) for alignment and \pm 50 mm (2 in) for grade (Bennett et al. 1995).

\subsubsection{Major advantages}

Pipe jacking can be accomplished through almost all types of soils. A high degree of accuracy can be obtained. Since the operator is located at the excavation face, the operator can see what is taking place and take immediate corrective action for changing subsurface conditions. The face can be readily inspected personally or by using a video camera. When unforeseen obstacles are encountered, they can be identified and removed using appropriate means. Many options are available for handling the soil conditions.

\subsubsection{Major disadvantages}

Pipe jacking is a specialized operation. It requires a lot of coordination. While these

operations can be conducted on a radius, it is recommended that all direction changes be made at the shafts. The pipe and liners used for the operation should be strong enough to 
resist the jacking forces. Hence not all types of pipes and liner systems can be used for this operation. 


\subsection{PIPE RAMMING}

\subsubsection{Introduction}

Pipe ramming (PR) involves using the dynamic force and energy transmitted by a percussion hammer attached to the end of the pipe. The basic procedure consists of ramming a steel pipe through the soil by using a device, generally air powered, attached to the end of the pipe. Pipe ramming permits the installation of larger casings in a wide range of soil conditions. It provides continuous casing support during the drive with no overexcavation, and it does not require that water be used for excavation (Iseley and Gokhale 1997).

\subsubsection{Description}

The two major categories of pipe ramming are closed-face and open-face. With the closed-face pipe ramming technique, a cone-shaped head is welded to the leading end of the first segment of pipe to be rammed. This head penetrates and compresses the surrounding soil as the casing is rammed forward. The soil-pipe installation interaction that results when this method is used is similar to the interaction that takes place when soil compaction methods. The wedge or cone shaped end can be used for pipes up to $200 \mathrm{~mm}$ (8 in) in diameter (Iseley et al. 1999).

With the open-face pipe ramming technique, the front of the leading end of the steel casing/conduit remains open so that a borehole of the same size as the casing (i.e., a cookie-cutter effect) can be cut. This allows most of the in-line soil particles to remain in place, with only a small amount of soil compaction occurring during the ramming process. This technique is employed for pipes larger than $200 \mathrm{~mm}$ (8 in) in diameter (Iseley et al. 1999). Figure 2.50 shows the open-face pipe ramming process, and Figure 2.51 shows a rammer used for pipe ramming projects. 


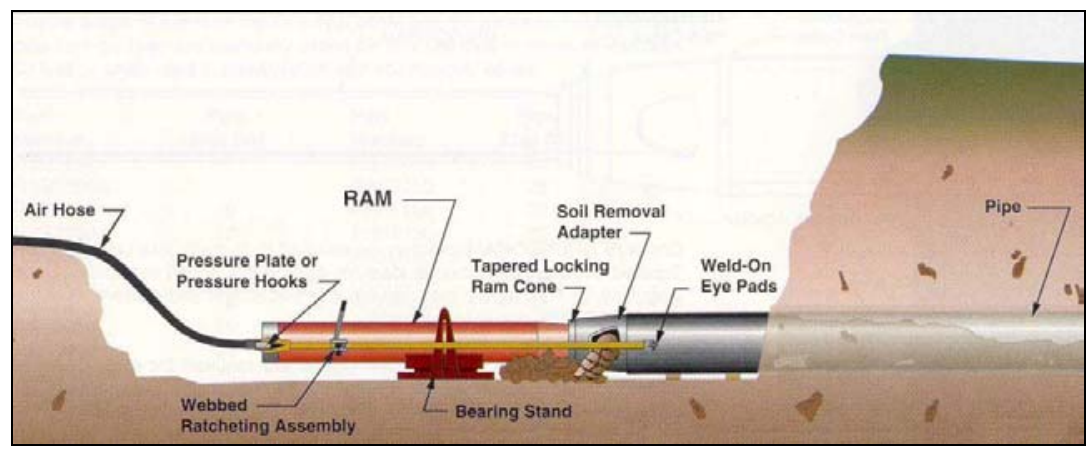

Figure 2.50 Open-face pipe ramming process (ACCU-Pipe)

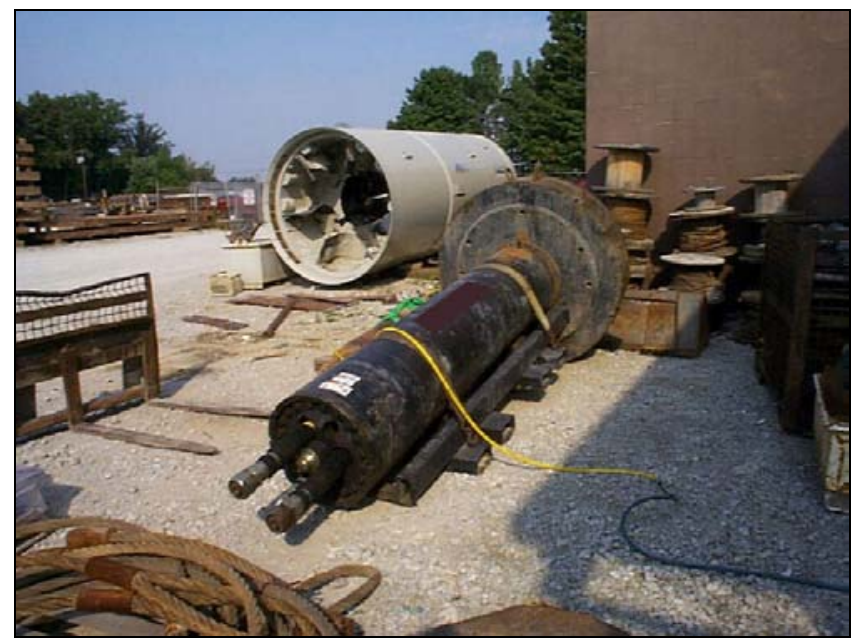

Figure 2.51 Rammer for pipe ramming operation

To facilitate the pipe ramming process, the leading edge of the first casing usually is reinforced by welding a steel band 305 to $610 \mathrm{~mm}$ (12 to $24 \mathrm{in})$ wide around the exterior surface of the pipe. The banding provides two advantages: (1) it reinforces the leading edge, (2) it decrease the friction around the casing. A band can also be installed on the inside edge of the leading section of the pipe. This band also reinforces the leading edge of the pipe and creates a clearance for the soil to move inside the casing. This clearance will help during the cleanout process as well as reduce the friction that exists inside the casing (Iseley and Gokhale 1997).

After the casing installation process is complete, the soil that has entered the casing is removed by applying compressed air or water from either end for small-diameter casings. For large casings, augers can be used to mechanically remove the soil from the 
inside of the pipe. Steel casings and augers used for pipe ramming projects are shown in Figure 2.52 .

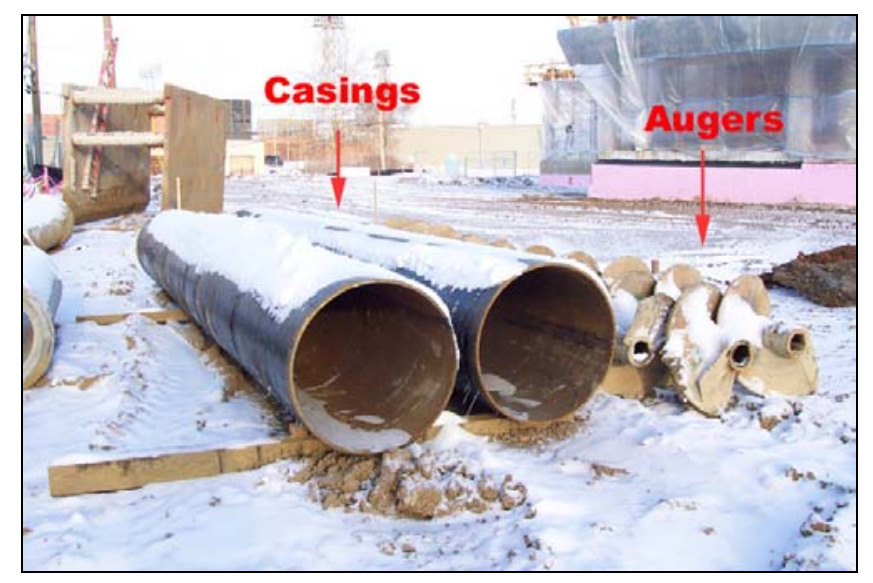

Figure 2.52 Steel casings and augers for pipe ramming projects

For large diameter pipes with long lengths or in certain soil conditions (such as stiff clays or sands) a steel pipe is installed on the top of the pipe being installed at point approximately $600 \mathrm{~mm}$ (24 in) from the front of the casing. This line is used to supply water, bentonite, or other drilling lubricants inside and/or outside of the casing to facilitate spoil removal, reduce friction, and maintain the integrity of the hole being cut (Iseley et al. 1999).

The pipe ramming procedure is as follows (Iseley and Gokhale 1997):

1. Construct an adequate shaft.

2. Install a cone or band on the leading edge of the casing.

3. Place casing in drive shaft and adjust for desired line and grade. When the line and grade are not critical, the pipe can be supported by construction equipment such as backhoes, cranes, side-boom tractors, by wood or block supports, or it can be supported directly on the pit floor. When the casing pipe is unguided, the line and grade accuracy is determined by the initial setup as well as the ground conditions encountered. Thus, a properly constructed driving shaft is a major component of a successful pipe ramming project. In cases where the line and grade are critical, the pipe is supported by adjustable bearing stands, launch 
cradles or platforms, I-beams, and auger boring machine tracks. Figure 2.53 shows that the backhoe is supporting the rammer and casing.

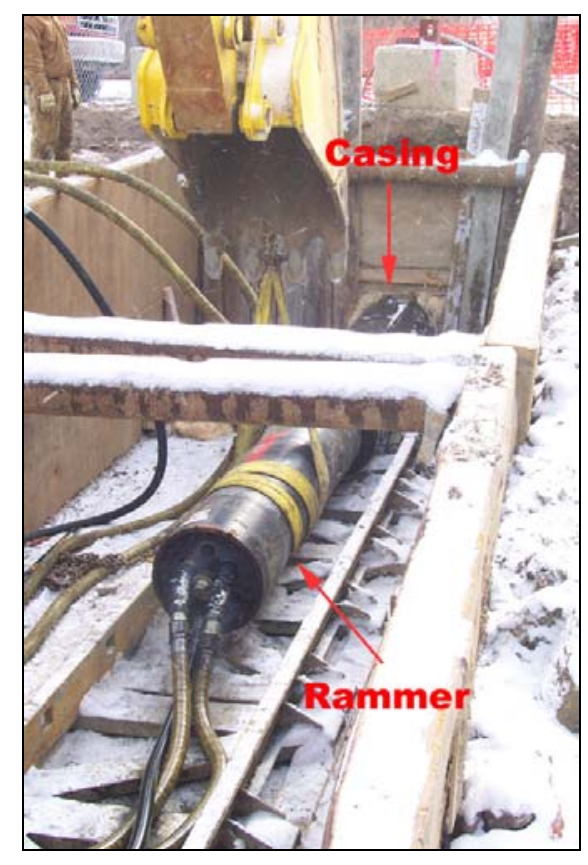

Figure 2.53 Rammer and casing supported by a backhoe

4. Attach hammer device and connect to pneumatic or hydraulic power source. This is accomplished by utilizing special adapters for each size of pipe. After the adapters are in place, the tool is connected to the pipe with lugs welded to the pipe. These lugs are used to hold the straps, chains, or hoists linked to the ramming tool. A rammer connected to the leading casing is shown in Figure 2.54 . 


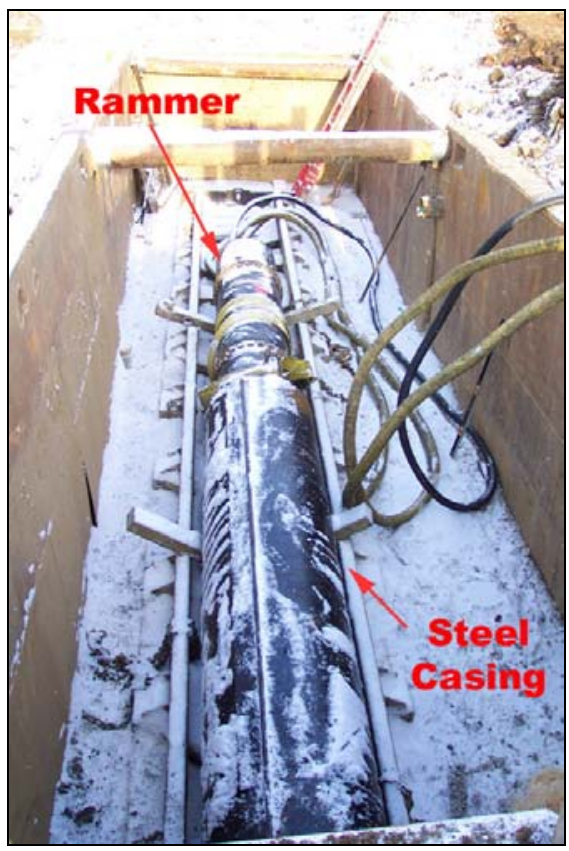

Figure 2.54 Rammer connected to the casing

5. Initiate the drive and continue until installation is complete. (If multiple pipe segments are being used, after each segment is installed, remove the hammer, weld another pipe segment to the end of the previous casing, and repeat the cycle until the installation is complete.)

6. Remove the cone, if used, or clean out the casing as required.

7. Remove the equipment.

8. Restore the area as required.

2.6.3 Main Features and Application Range (Iseley and Gokhale 1997)

\subsubsection{Diameter range}

Typical diameters of pipe installed by pipe ramming are 100 to $1,524 \mathrm{~mm}$ (4 to 60 in) for open-face pipe ramming and 100 to 200 (4 to 8 in) for closed-face pipe ramming. However, casings of 3,000 mm (120 in) in outside diameter have been installed in Tampa, Florida (Rush 2001). 


\subsubsection{Drive length}

Typical drive lengths are less than $60 \mathrm{~m}$ (200 ft), although crossings have been bored up to $120 \mathrm{~m}$ (400 ft) in length. However, the bore span, diameter of pipe, and most importantly soil conditions must be considered to determine length and to provide an accurate bore.

\subsubsection{Type of casing}

The type of casing and conduit is limited to steel pipe. The pipe must be able to endure the repeated impact loads of the percussive hammer. Therefore, the pipe's wall thickness is a very important design consideration.

\subsubsection{Required working space}

Adequate site access and working space are essential for a successful installation. Drive shaft size is determined by the installation process. For example, a $30 \mathrm{~m}(100 \mathrm{ft})$ drive could be accomplished in a single drive as long as the casing pipe is welded together before the drive begins, or it could be accomplished using five $6 \mathrm{~m}(20 \mathrm{ft})$ pipe segments. The required working space at the drive shaft typically is 1.8 to $3.6 \mathrm{~m} \mathrm{(6} \mathrm{to} 12 \mathrm{ft}$ ) in width by 10 to $20 \mathrm{~m}$ ( 33 to $66 \mathrm{ft})$ in length.

\subsubsection{Soil condition}

A significant feature of the pipe ramming technique is its versatility. It is suitable for a wide range of soil conditions, from stable to unstable, with or without the presence of high groundwater. Installation experience through cobbles and boulders has been positive. The hammering effect tends to break up the boulders or force them out of the path either to the outside or inside the casing.

\subsubsection{Productivity}

Usually a 2- to 3-person crew is all that needed for small applications. Under suitable soil conditions, the typical rate of penetration ranges from 50 to $250 \mathrm{~mm} / \mathrm{min}$ ( 2 to $10 \mathrm{in} / \mathrm{min})$. 


\subsubsection{Accuracy}

The accuracy of pipe ramming method depends on the initial setup. Once the ramming has begun, there is limited amount of control in changing the direction of the bore. Occasionally, a wedge or shoe can be placed in larger diameter pipes at the leading edge and at the required location to help redirect the bore. This shoe is generally made of metal or wood. Also, grade control of the pipe can be aided by removing a portion of the soil during the ramming process. The removal of this soil reduces the weight of the casing, reduces friction, and can help redirect the bore.

\subsubsection{Major advantages}

The pipe ramming method is an effective method for installing medium to large diameter pipes. The versatile pit sizes, varying lengths of pipe that can be installed, and ability to handle almost all types of soil conditions make this method a practical and economical technique for installing pipes. This method does not require any thrust reaction structure as the ramming action is due to impulses induced in the pipe by the percussion tool. The pipe ramming method is also multi-functional. A single size of pipe ramming tool and the air compressor can be used to install a wide variety of pipe lengths and sizes. Ramming can also be used for vertical pile driving, angular ramming, or pipe replacement.

\subsubsection{Major disadvantages}

The major disadvantage of the pipe ramming method is the minimal amount of control over line and grade. Therefore, the initial setup is of major importance. Also, in the case of obstructions, like boulders or cobbles, especially with small diameter pipe, the pipe may be deflected. Therefore, sufficient information on the existing soil conditions must be available to determine the proper size of casing to be used. 


\subsection{PIPE BURSTING}

\subsubsection{Introduction}

Pipe bursting $(\mathrm{PB})$ is a trenchless pipe replacement method for the deteriorated and undersized gas, water or sewer pipelines. The existing pipes are size-for-size or up-sized with a new pipe in the same location (Sterling and Thorne 1999). The bursting head, one of the major components of pipe bursting operation, bursts or splits the existing pipelines and pushes broken fragments into surrounding soil while simultaneously pulling a new pipeline. Other commonly used terms for pipe bursting are pipe splitting and upsizing.

Pipe bursting was first developed in the United Kingdom in late 1970's by a company named Ryan \& Sons in conjunction with British Gas Corporation (Howell 1995). The technology was patented by British Gas Corporation now BG plc in 1980 (Strychowskyj 1998). Cast iron gas distribution pipes with diameters of 75 and $100 \mathrm{~mm}$ (3 and 4 in) were replaced using a pneumatically driven head when the first time pipe bursting was used. Then, pipe bursting expanded to include water and sewer lines with diameter up to $400 \mathrm{~mm}$ (16 in) by 1985 (Strychowskyj 1998).

\subsubsection{Description}

In the pipe bursting operation, the bursting head is inserted into the pipes at the driving shaft and breaks the existing pipes by the expansion of bursting head using mechanical power. The bursting head is pulled through a cable or pulling rod by the winch at the receiving shaft. Figure 2.55 shows the typical pipe bursting process.

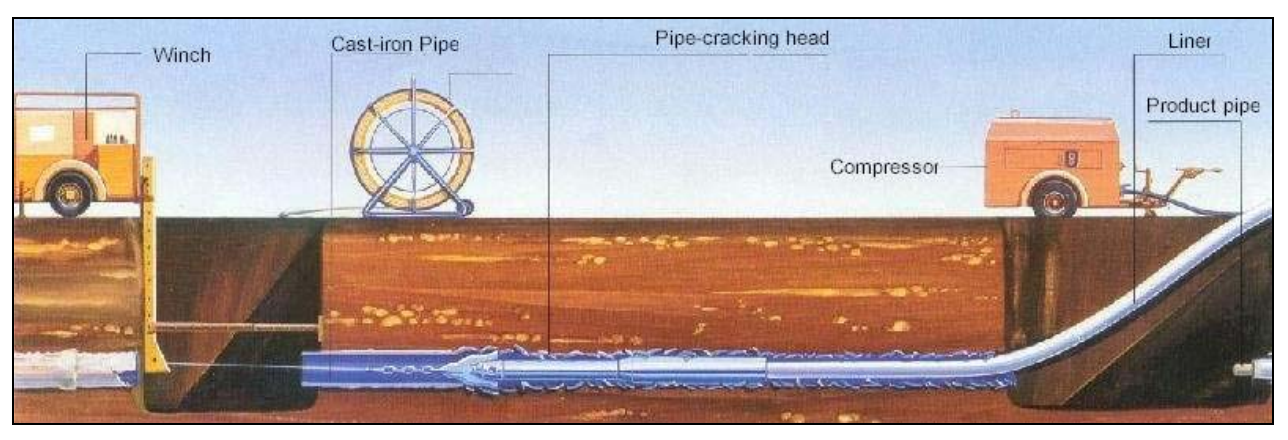

Figure 2.55 Typical pipe bursting process (ACCU-Pipe) 
The bursting head and the pipe to be connected are shown in Figure 2.56. The base of bursting head is larger than the inside diameter of the old pipe in order to fracture the existing pipelines and slight larger than the outside diameter of the new pipe in order to reduce the friction generated during the pipe bursting operation and to provide more space for the installation of new pipes.

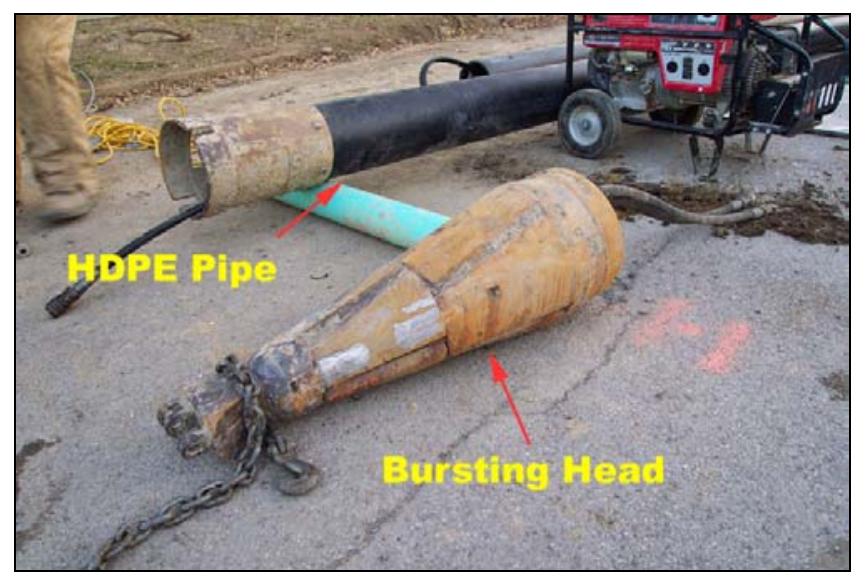

Figure 2.56 Bursting head and product pipe

The winch plays a key roll in pipe bursting operations. With the constant tension, the winch provides the constant and consistent pulling force to the bursting head and prevents slack that can be developed in the line. The pulling string linked to the winch guides the bursting head through the existing utility pipe (ACCU-Pipe 2002). A winch used for a pipe bursting project is shown in Figure 2.57. 


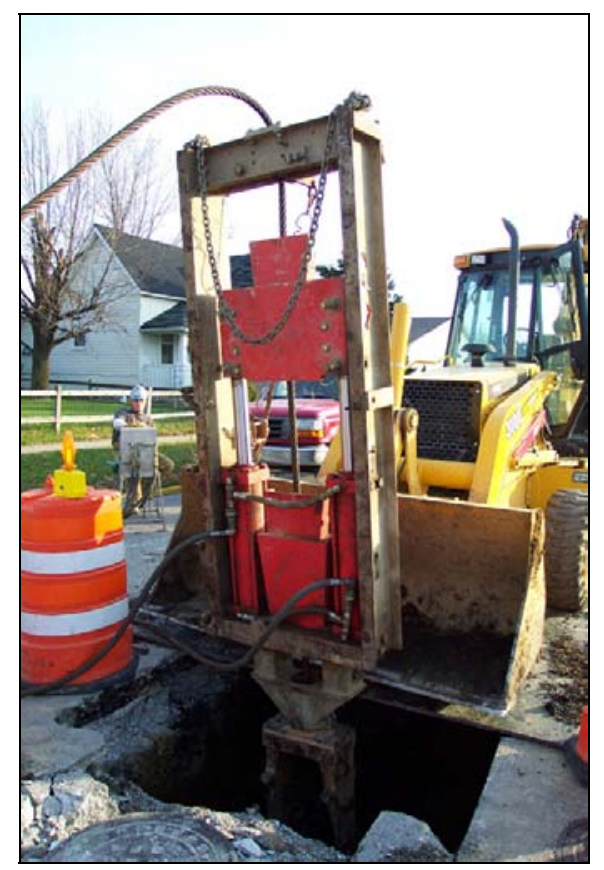

Figure 2.57 Winch for pipe bursting operation

\subsubsection{Types of pipe bursting}

Based on the source of energy and method of breaking pipes, bursting can be divided into four categories (Strychowckyj 1998): Pneumatic System, Static Pull System, Hydraulic Expansion System, and Implosion system.

\section{Pneumatic System}

A hammer driven by compressed air pushes the head forward with blows, and cracks open the old pipe. The expander of the head combined with percussive action pushes the fragments to surrounding soil to make room for the new pipe. The tension cable only maintains directional stability. This is similar to a horizontal pile driving operation. The air supply hose is inserted through the new pipe to the hammer in the head. The air pressure at the hose and the hydraulic tension at the cable, maintaining directional stability, are set to remain constant (Strychowckyj 1998). The most frequently used type of pipe bursting is pneumatic. This method was used in $90 \%$ of pipe bursting projects in the world prior to 1995 (Howell 1995). However, the static head pipe bursting is making inroads and takes about $50 \%$ of pipe bursting projects these days. Figure 6.58 shows the typical pneumatic pipe bursting operation. 


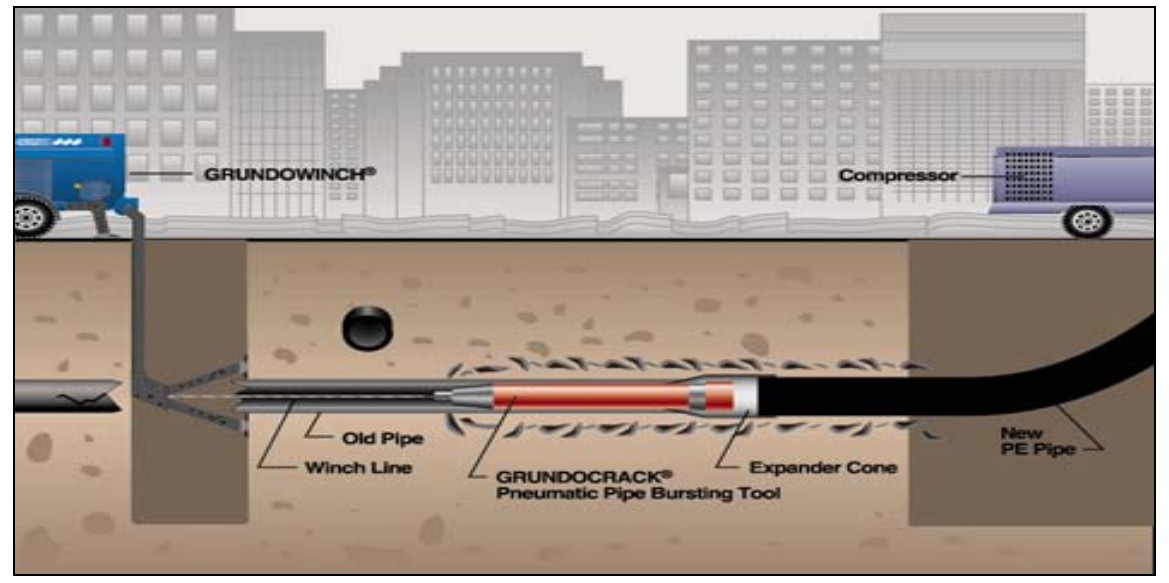

Figure 2.58 Pneumatic pipe bursting process (Trenchless Data Service)

The equipment used in pneumatic method is a special kind of hammer-driven head, a winch that provides a hydraulic constant tension to the pulling cable maintaining a directional stability, and an air compressor that drives the hammer with compressed air. Figure 2.59 shows the pneumatic bursting head.

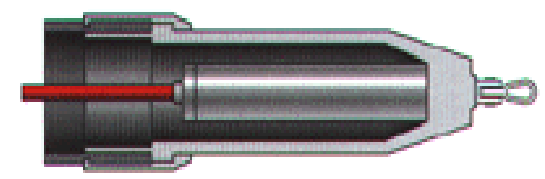

Figure 2.59 Pneumatic bursting head (Trenchless Data Service)

This method is very good for continuous pipe installation, takes less time than other methods, and bursts and splits strong pipes and even ductile materials, as it applies force by impact. But it has certain limitations. A high noise level and vibration are generated during the bursting operation. There is unwanted compaction of soil in the range of pipe run, and there is possibility of damage to nearby structures due to the high level of vibration in problematic soil (Strychowckyj 1998).

\section{Static Pull System}

In the static pull system, no hammering action is used. Pipes are broken by large tensile force applied to the cone shaped expansion head through a pulling rod assembly or 
cable inserted through the existing pipe. The horizontal pulling force is converted to radial force by the expansion head. Either rod or cable can be used for pulling action. Rods provide greater rigidity while pulling the head, but cable interrupts the process less. The cable has superiority in continuous operation, but the force that can be transmitted to the bursting head is less. The interruption while using the rod is from disconnecting or unscrewing of rods after each pull. The length of the pull depends on the length of the rod segment being disconnected or on the length of the segments of the new pipe being installed. Figure 2.60 illustrates the static pull system process and static head.

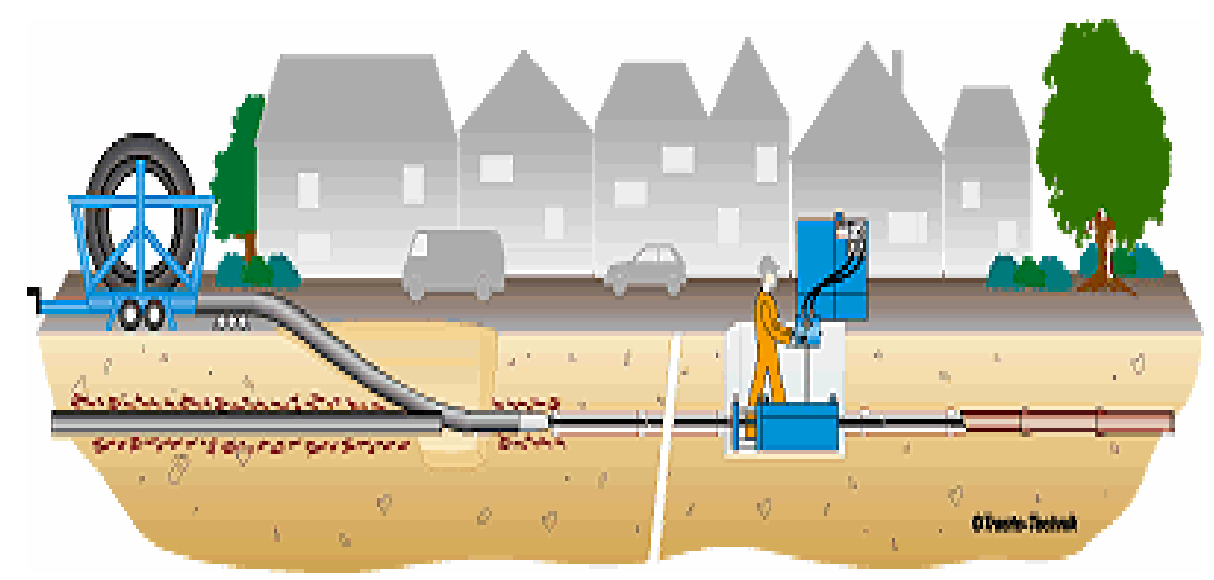

(a) Static pull system (Tracto-technik)

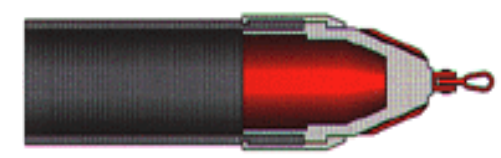

(b) Static head (Trenchless data service)

Figure 2.60 Static Pull System and static head.

This method can be used in challenging soil conditions. It generates much less vibration and noise level. It can also be used to install small segmental pipes through a small pit, even through a manhole. The size and weight of the equipment is reduced. There is a lower chance for cave-in sideways during installation. 


\section{Hydraulic Expansion System}

In this method, a special type of head, usually divided into parts, is used. These parts can expand and contract by hydraulic action. The head is pulled with a cable running through the old pipe by a winch from the pulling shaft. It is also connected to the new pipe from the back end. The hydraulic supply lines are inserted through the new pipe and are connected to the head. The contracted head is pulled into the old pipe, then expanded to break the old pipe and to compress the fragments into the surrounding soil. The contracted head proceeds by being pulled by the winch at the pulling shaft. The process repeats itself until the head reaches the pulling shaft. This method is applicable for only segmental construction (Strychowckyj 1998). The conceptual and actual illustrations of hydraulic bursting head are presented in Figure 2.61. Figure 2.62 illustrates the control panel used for hydraulic bursting system.

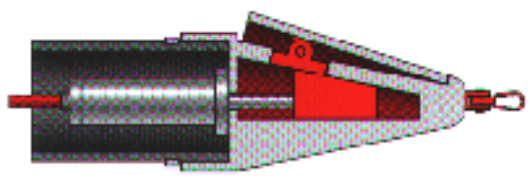

(a) Conceptual illustration (Trenchless data service)

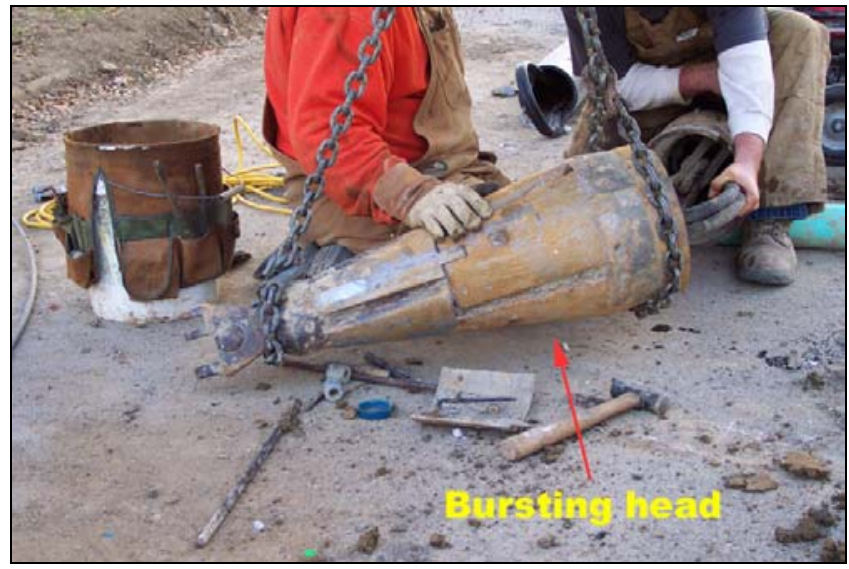

(b) Actual hydraulic bursting head

Figure 2.61 Hydraulic bursting head 


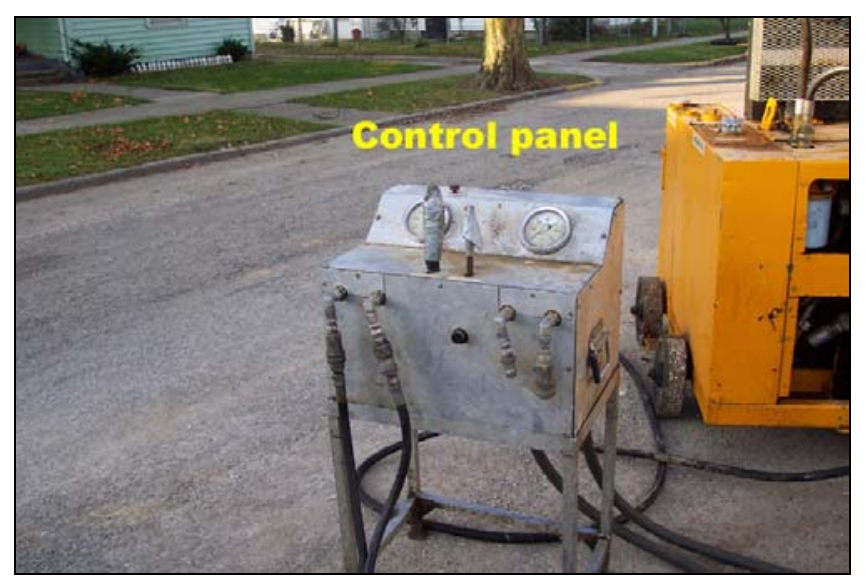

Figure 2.62 Control panel for hydraulic bursting system

\section{Implosion System}

As shown in Figure 2.63, implosion system involves the use of a cylinder-shaped head, with inside diameter slightly larger than the maximum diameter of the old pipe. Steel blades inside the cylinder extend radially from the center, and fracture and crash the old pipe. Pipe fragments are crushed into the old pipe. The rear end of the crushing head is connected to the expansion head which is attached to a new pipe. This expansion head provides space for the new pipe.

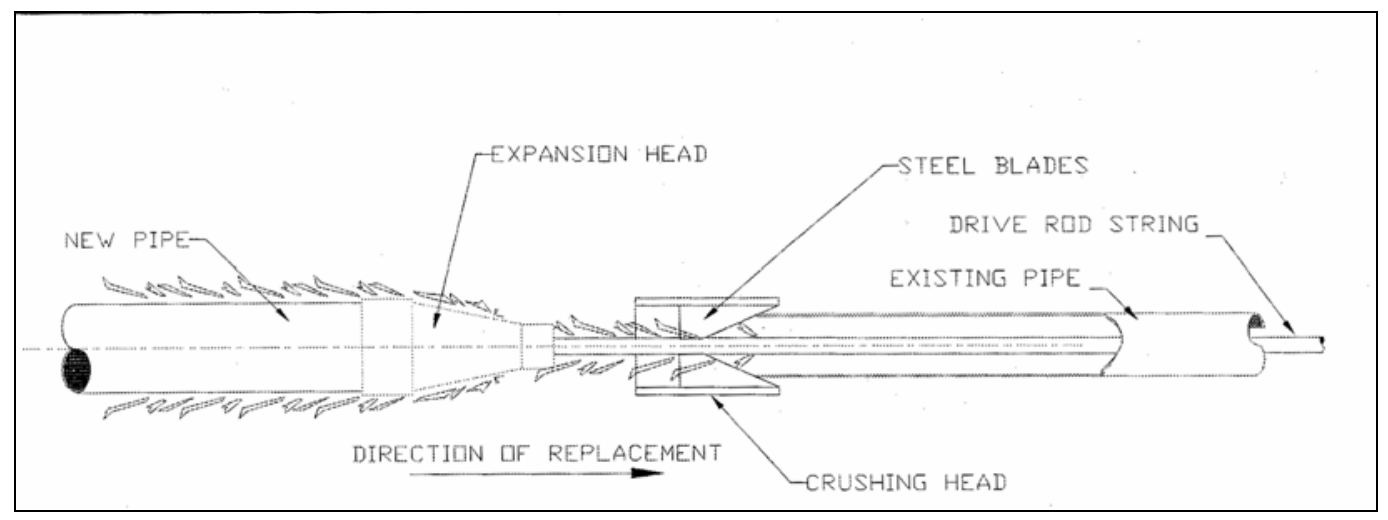

Figure 2.63 Implosion system (Strychowckyj 1998)

\subsubsection{Pipe bursting procedure}

1. Excavate the entrance and exit shafts. For shafts, the places where laterals are joined to the pipe are better locations. It is desirable to set up the alignment 
between the shafts as straight as possible. Thus, manholes are usually selected as the shafts.

2. Joint the pipes. HDPE pipes are most common type of pipe used for pipe bursting. For this pipe, butt fusion method is used for joint (Figure 2.64).

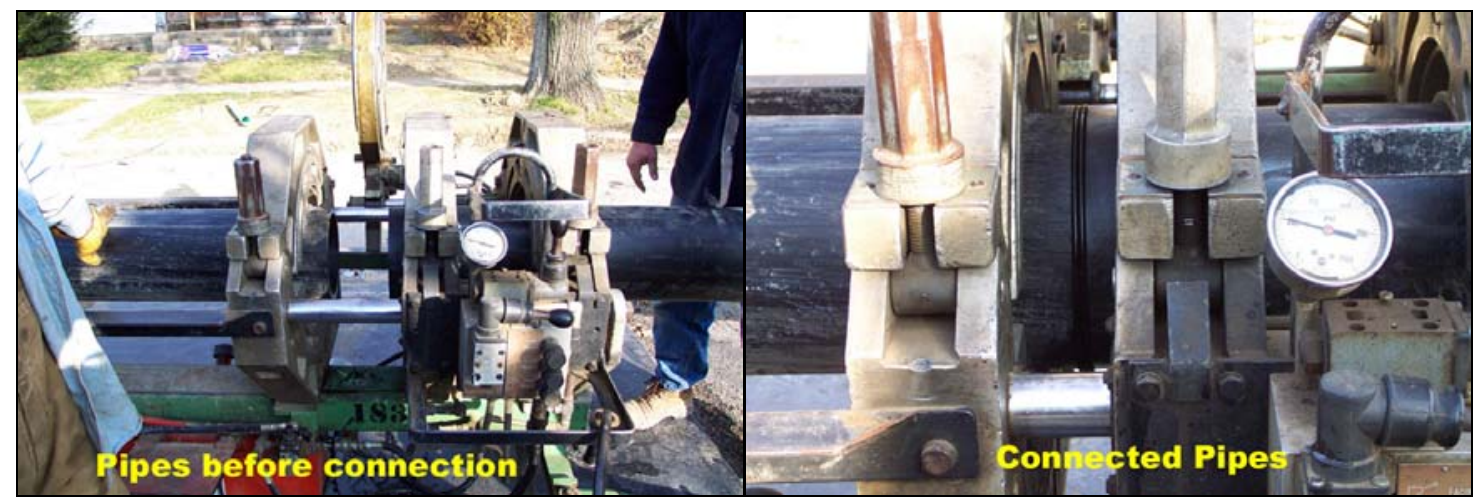

Figure 2.64 Pipe joint using butt fusion

3. Setup the winch or hydraulic pulling unit. The layout of exit shaft with winch is shown in Figure 2.65.

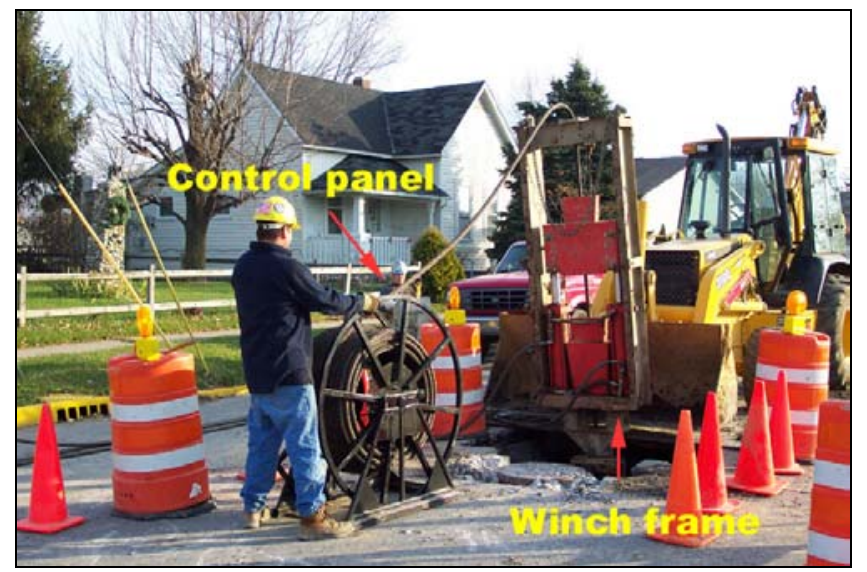

Figure 2.65 Layout of exit shaft

4. Insert the pulling cable or rod through the existing pipe.

5. Install the air supply or hydraulic hoses through the pipes to attach to the bursting head. 
6. Connection of the pipe to the bursting head. The process of connecting pipe and bursting head is shown in Figure 2.66.

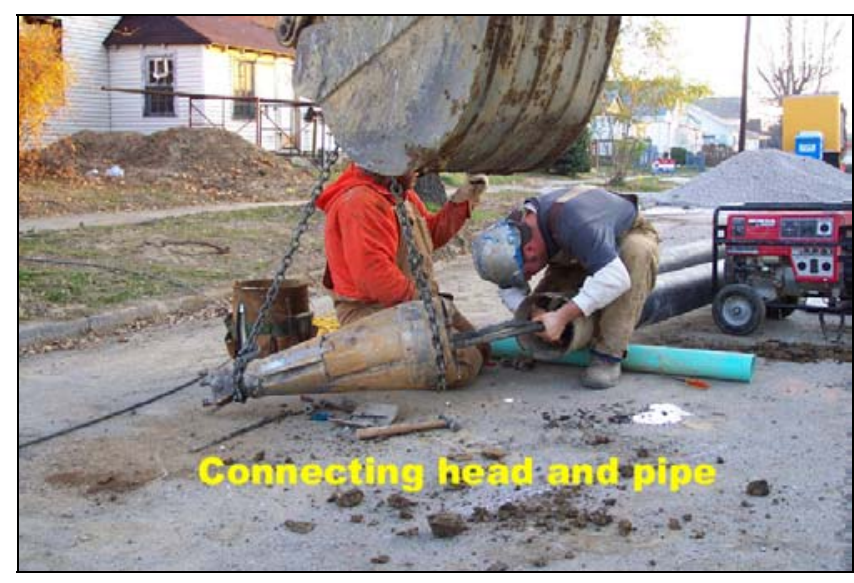

Figure 2.66 Connection of bursting head and pipe

7. Connect the bursting head to the pulling cable.

8. Start pipe bursting operation and replacement. Figure 2.67 shows the commencement of the bursting process and Figure 2.68 shows the bursting process in progress.

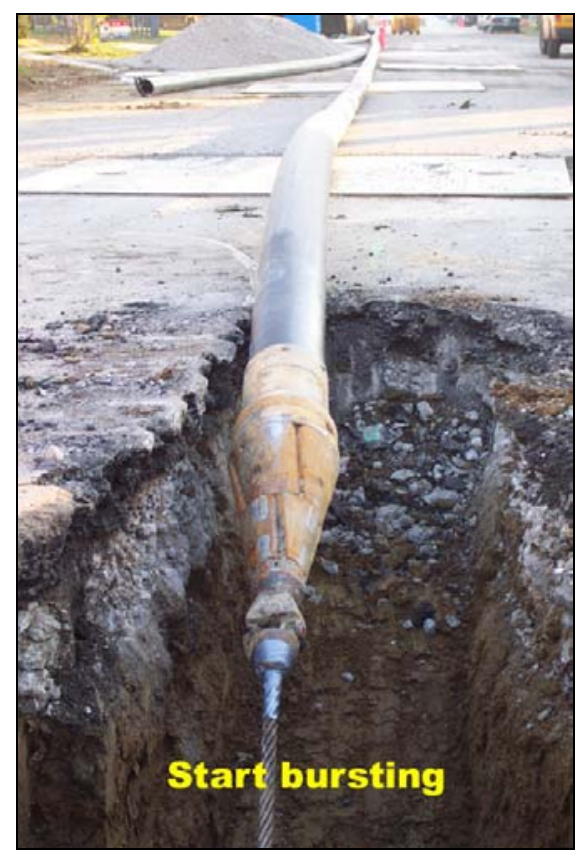

Figure 2.67 Start bursting 


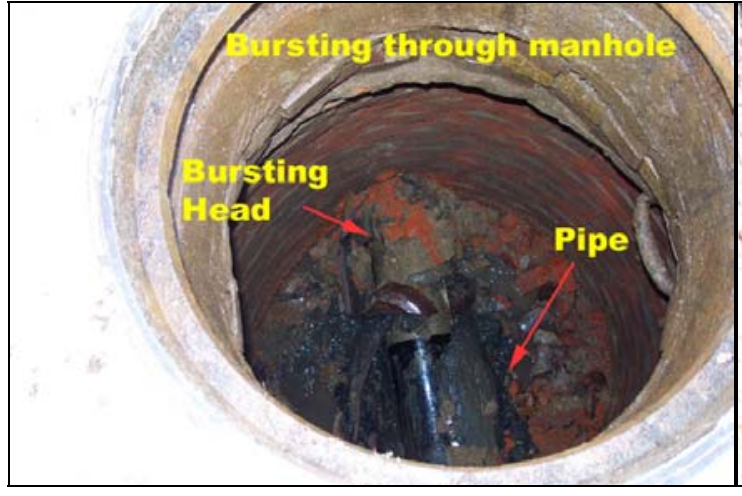

(a) Bursting in a manhole

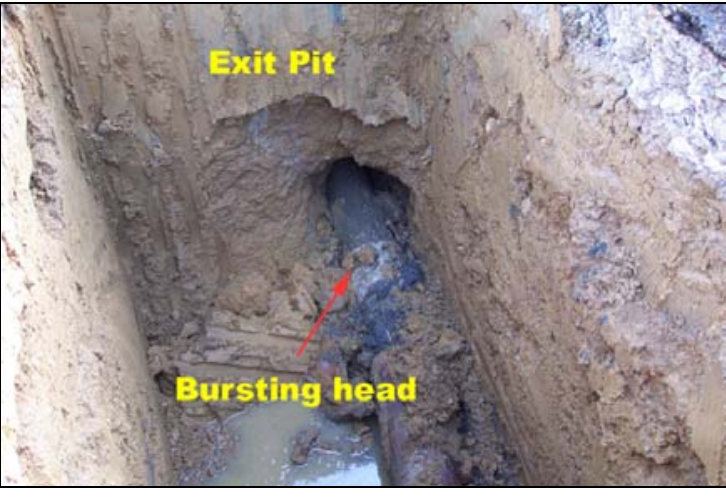

(b) Bursting at the exit pit

Figure 2.68 Pipe bursting in progress

9. Remove the bursting head at the exit pit.

10. Remove the hoses.

11. Reconnect the laterals

12. Test the pipeline.

13. Restore the site.

2.7.3 Main Features and Application Range (Sterling and Thorne 1999)

\subsubsection{Diameter of pipe}

The size of the pipe currently being replaced by pipe bursting typically ranges from 50 to $900 \mathrm{~mm}$ ( 2 to $36 \mathrm{in}$ ), although the bursting of larger diameter pipes is increasing (pipes up to 1,200 $\mathrm{mm}$ (48 in) diameter have been replaced).

\subsubsection{Drive length}

A length of 90 to $120 \mathrm{~m}$ (300 to $400 \mathrm{ft}$ ), which is a typical distance between existing manholes, is a typical length for bursting; however, much longer runs have been replaced. A longer run may require more powerful equipment to ensure completion of the job. 


\subsubsection{Type of existing pipe}

Existing pipes suitable for pipe bursting are typically made of brittle materials, such as vitrified clay, cast iron, plain concrete, asbestos, or some plastics. Reinforced concrete pipe (RCP) can also be successfully replaced if it is not heavily reinforced or if it is substantially deteriorated. Ductile iron and steel pipes are not suitable for most bursting techniques but in smaller sizes can be replaced using pipe splitting techniques.

\subsubsection{Soil conditions}

The most favorable ground conditions for pipe bursting projects are where the ground surrounding the pipe can be compacted somewhat by the bursting operation as it is displaced. Conversely, less favorable soil conditions for pipe bursting are the densely compacted soils and backfills. Such soils can prevent the smooth operation of pipe bursting, or at least it can delay the project completion. For soils that generate high friction during the pipe bursting operation, bentonite or polymer lubrication mud may be injected into the annular space behind the bursting head. High ground water causes difficulties during the pipe bursting operation.

\subsubsection{Major advantages}

Pipe bursting has several advantages over the open cut method. Substantial project cost can be saved when pipe bursting is used for the replacement of old pipelines. Cost savings of using pipe bursting are as high as $44 \%$ with average savings of $25 \%$ compared to open-cut method (Fraser et al. 1992).

\subsubsection{Major disadvantages}

The pipe bursting operation cause unwanted compaction of soil within the range of pipe run. Expansive soil causes difficulty to nearby structure including other utilities during bursting operation. The dynamic method of pipe bursting causes high vibration and noise level. If the old sewer line is out of line and grade, the new line will also tend to be out of line and grade (Atalah 1998). 


\section{CHAPTER 3 SPECIFICATIONS FOR TRENCHLESS TECHNOLOGIES}

The specifications are developed during the course of this study, are presented in this chapter. These specifications were adopted by the Specifications Committee of Indiana Department of Transportation (INDOT) in March 2002.

\section{SECTION 716 - TRENCHLESS PIPE INSTALLATION}

716.01 Description. This work shall consist of installing pipes underground using construction techniques that eliminate open cutting of the pavement or of the ground all in accordance with 105.03.

The techniques included are auger boring, guided boring, horizontal directional drilling, microtunneling, pipe jacking, and pipe ramming. Other methods may be utilized when approved.

The size of installations by the directional drilling method shall be limited to those that can be accomplished by using a $600 \mathrm{~mm}$ (24 in.) maximum sized reamer unless otherwise approved.

\section{MATERIALS}

716.02 Materials. The materials shall be in accordance with the following.

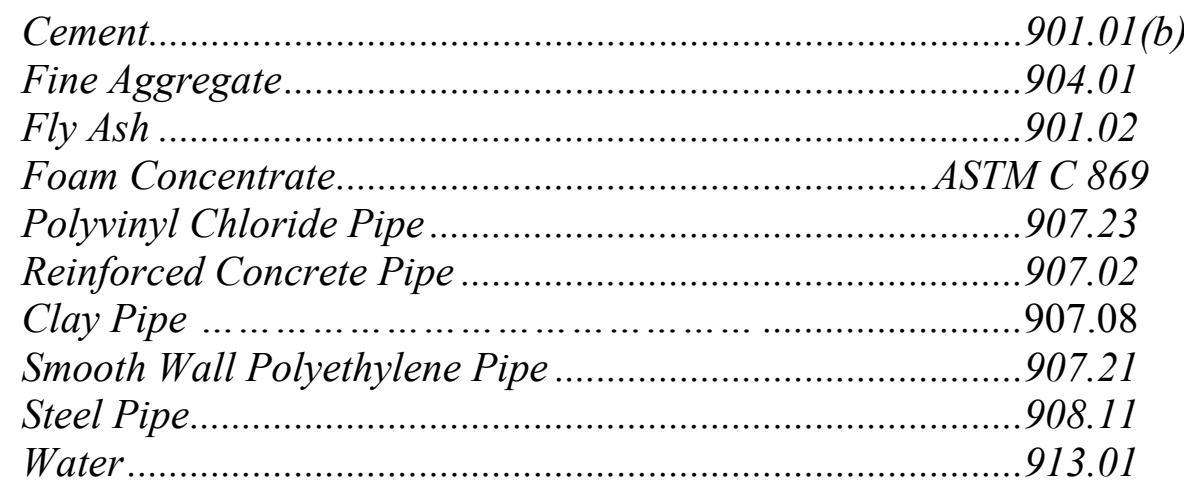

Concrete pipe shall be class IV or stronger and shall have tongue and groove joints. All reinforced concrete pipes shall have steel reinforcement concentric with the pipe wall, and where required, additional reinforcement at the ends of the pipe.

Steel pipe used as a carrier pipe shall have the following minimum wall thickness. 


\begin{tabular}{|c|c|}
\hline $\begin{array}{c}\text { Outside Diameter, } \\
\text { mm (in.) }\end{array}$ & $\begin{array}{c}\text { Wall Thickness } \\
\text { mm (in.) }\end{array}$ \\
\hline 457 or less (18 or less) & $6(1 / 4)$ \\
\hline $483-508(19-20)$ & $8(5 / 16)$ \\
\hline $533-660(21-26)$ & $10(3 / 8)$ \\
\hline $686-762(27-30)$ & $13(1 / 2)$ \\
\hline $787-1070(31-42)$ & $13(1 / 2)$ \\
\hline $1092-1219(43-48)$ & $14(9 / 16)$ \\
\hline
\end{tabular}

The cellular concrete grout shall be designed and produced in accordance with ASTM C 796 except as herein modified.

Admixtures, retarders, and plasticizers used shall be in accordance with the foam concentrate supplier's specifications.

The grout shall be made using the preformed foam process using foam generating equipment calibrated daily by the foam manufacturer to produce a precise and predictable volume of foam. The foam concentrate shall be certified by the manufacturer to have specific liquid/foam expansion ratio at a constant dilution ratio with water.

The specific job mix shall be submitted by the foam concentrate supplier certified or licensed grouting contractor to the Engineer for approval prior to use on the project. The mix shall have a minimum 28 day compressive strength of $1040 \mathrm{kPa}(150 \mathrm{psi})$. The mix shall be tested and will be approved based on the test results or will be approved based on prior acceptance and suitable performance on Department projects.

Grout mixed off site shall be delivered to the job site in a truck mixer in accordance with 702.09 filled to half its capacity. The foam concentrate shall then be added to the cement mix in the truck and mixed to a uniform consistency.

Grout mixed on site shall be batched in a deck mate or a similar device. Small batches of approximately 1 cubic meter (1 cubic yard) shall be mixed and pumped in a continuous operation.

For each day worked or for each 100 cubic meters (100 cubic yards) placed, four test cylinders measuring $75 \mathrm{~mm}$ by $150 \mathrm{~mm}$ (3 in. by 6 in.) shall be cast at the point of placement of the grout. The cylinders shall be prepared, cured, and transported in accordance with ASTM C 31.

The compressive strength shall be determined in accordance with ASTM C 39, except as modified herein. Initial curing shall be at room temperature and shall be from 2 to 5 days. After the initial curing, the test specimens shall be placed in a moist closet or moist room. All specimens shall be kept in their molds in the moist closet or moist room for the remainder of the curing period. The specimens shall be tested at 28 days. At that time the specimens shall be stripped, capped, and tested in compression as rapidly as possible to minimize drying. If more than one specimen is removed from the moist closet 
or moist room at the same time, these specimens shall be covered with a damp cloth until time of testing.

\section{CONSTRUCTION REQUIREMENTS}

716.03 General Requirements. Entry and exit pits or trenches shall be excavated sufficiently deep enough to allow the installation. All safety precautions shall be taken to protect the travelling public, the workers, the existing roadway, railroads, or other existing conditions. Upon completion of the installation of the pipe, all excavated areas not occupied by the pipe shall be backfilled with suitable material and compacted in accordance with 203.

When ground water is known or anticipated, a dewatering system of sufficient capacity to handle the flow shall be maintained at the site until its operation can be safely halted. The dewatering system shall be equipped with screens or filter media sufficient to prevent the displacement of fines.

When the use of explosives is necessary for performing the work, their use shall be in accordance with 107.13.

Bentonite or other suitable lubricants, may be applied to the outside surface of the pipe to reduce frictional forces.

Joints in steel pipe shall be water tight. Where welded joints are utilized, they shall be welded in accordance with 711.32. Joints in concrete pipe shall be designed to withstand the additional forces that are created in the joints during the installation process. The joints in concrete pipe shall be protected with a resilient material around the circumference of the pipe. Resilient material shall also be used between the pipe and the thrust ring.

The installed pipe shall have full bearing against the surrounding ground. When installation is to be performed under railroads, highways, or streets, care shall be taken to prevent interference with the operations of the railroads, highways, or streets. The Contractor shall submit a QC plan of the installation process including, as a minimum, the chosen method of installation, the equipment to be used, and the materials to be utilized, for review and acceptance, at least seven calendar days prior to the start of the operations.

Pavement or ground surface heave or settlement above the installation will not be permitted. To confirm if heave or settlement is occurring, the Contractor shall undertake surface monitoring. The plan for monitoring the surface shall be included in the Contractor's QC plan.

Installations shall have a bored hole essentially the same diameter as the outside of the installed pipe. If voids develop or if the bored diameter is greater than the outside 
diameter of the pipe by more than $25 \mathrm{~mm}$ (1 in.), grouting shall be used to fill such voids. The Contractor's QC plan shall address the method of grouting.

When the installation is $100 \mathrm{~mm}$ (4 in.) or larger and the casing is used as the carrier pipe, a visual or a video inspection shall be performed using high resolution, high sensitivity color video camera/recording equipment. The pipe shall be cleaned of debris prior to the inspection. Cleaning shall be accomplished by water jetting or other approved methods.

The camera/recording equipment shall be specifically designed for continuous viewing/recording of detailed images of the interior wall of pipes and transitions of the specified sizes. The equipment shall include sufficient lighting to view the entire periphery of the pipe. The equipment shall have appropriate attachments to maintain a position in the center of the pipe and an electronic counter to continuously record the location of the equipment in the pipe. The recording equipment shall be a minimum four head industrial grade VHS recorder or a digital archiving and reviewing system. A color video printer shall be included in the equipment for printing observations during inspection. A copy of the video inspection shall be submitted to the Engineer.

All sections of pipe found to be damaged or where joint failure is evident shall be repaired as approved by the Engineer or removed and replaced.

For installations not utilizing tunnel shields or tunnel boring machines, if an obstruction is encountered during installation which stops the forward progress of the pipe, and it becomes evident that it is impossible to advance the pipe, and if ordered, operations shall cease and the pipe shall be abandoned in place and filled with grout or other approved materials.

When a gravity-flow carrier pipe is placed inside a casing pipe, the gravity-flow carrier pipe shall be shimmed to proper line, elevation, and grade and then the void between the two pipes shall be grouted.

716.04 Method of Measurement. Pipe installed by trenchless installation methods will be measured by the meter (linear foot) along the center line of the pipe installed.

716.05 Basis of Payment. Pipe installed by trenchless installation methods will be paid for by the meter (linear foot) for pipe installation of the size specified, complete and in place.

Payment will be made under:

\section{Pay Item}

Pay Unit Symbol

Pipe Installation, Trenchless, $m(L F T)$ 
The cost of the QC plan, the excavating and backfilling of the entrance and receiving pits, video inspection, camera/recording equipment, bentonite or other lubricant, grout, and the casing when installed shall be included in the cost of pipe installation, trenchless.

If a partial installation has to be abandoned in place and filled with grout due to the encountering of an obstruction, the abandoned work will be paid for at $75 \%$ of the contract unit price of the pipe installed.

For installations where unknown obstructions such as boulders, concrete, and other unforeseen obstructions are encountered, and the crossing cannot be abandoned or where tunnel shields or tunnel boring machines are being utilized, the additional cost as a result of encountering the unforeseen conditions will be paid for as differing site conditions in accordance with 104.02(a). 


\section{CHAPTER 4 MULTIMEDIA EDUCATIONAL TOOL}

\subsection{INTRODUCTION}

Although trenchless technologies have been used for the installation of new utility lines and for the rehabilitation of existing ones since the $1980 \mathrm{~s}$, educational tools in this area are few. To assist in providing entry-level engineers and infrastructure asset managers a basic understanding of trenchless technologies, web pages were developed using photographs and video clips that were collected from project sites. The webpage can be accessed at www.purdue.edu/trenchless. The following sections describe the framework of this multimedia educational tool.

\subsection{MAIN PAGE}

The main page contains of small thumbnails of seven trenchless technologies, i.e., auger boring, horizontal directional drilling, microtunneling, pilot tube microtunneling, pipe bursting, pipe jacking, and pipe ramming. These thumbnails lead the users to the web page linked to detailed description of each technology. In addition, the main page is linked to the specifications in a PDF file that were developed during this study (Figure 4.1).

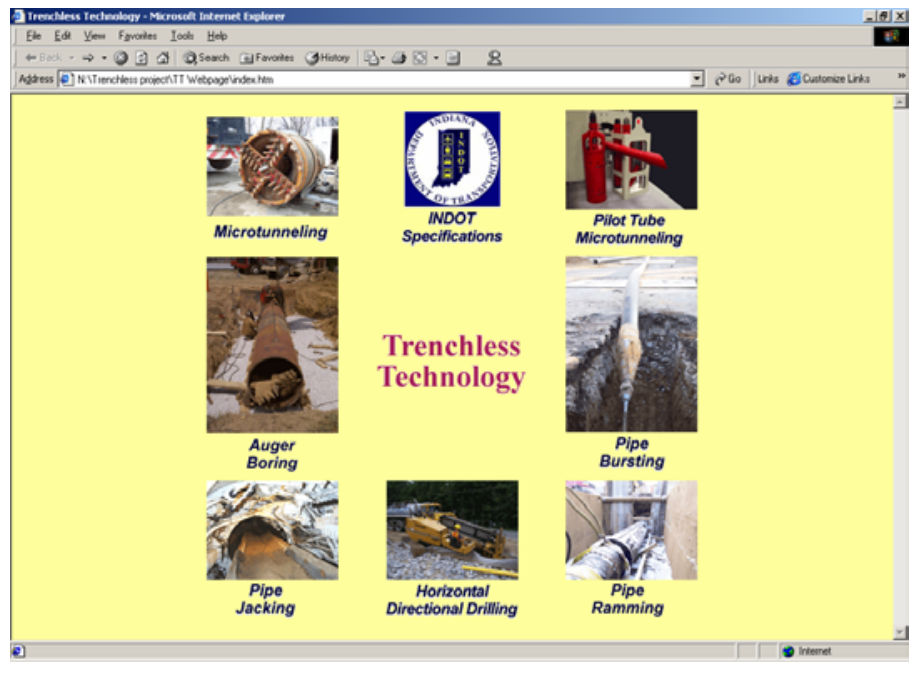

Figure 4.1 Layout of main web page 


\subsection{WEB PAGES FOR TRENCHLESS TECHNOLOGIES}

Web pages describing each trenchless technology have a similar format. As shown in Figure 4.2, there is a frame on the left side, which is linked to other trenchless technologies, an overview of the features of trenchless technologies, summary tables of trenchless technologies, specifications, and links to trenchless related web sites.

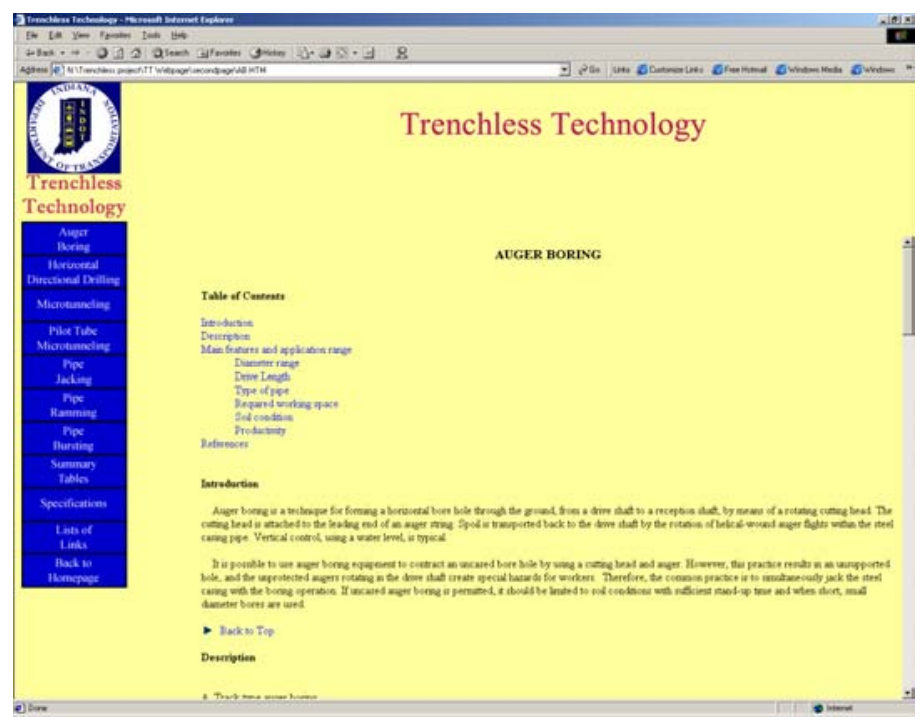

Figure 4.2 Layout of the web page for auger boring

The contents of the web page of each trenchless technology are summarized from the overview provided in Chapter 2 of this report. Photographs and video clips are linked to the related procedures to assist the users in understanding the features of the trenchless technologies.

Arrow marks and short descriptions are added to the photographs to further explain special features. For example, as shown in Figure 4.3, the different components in a HDD operation are highlighted. 


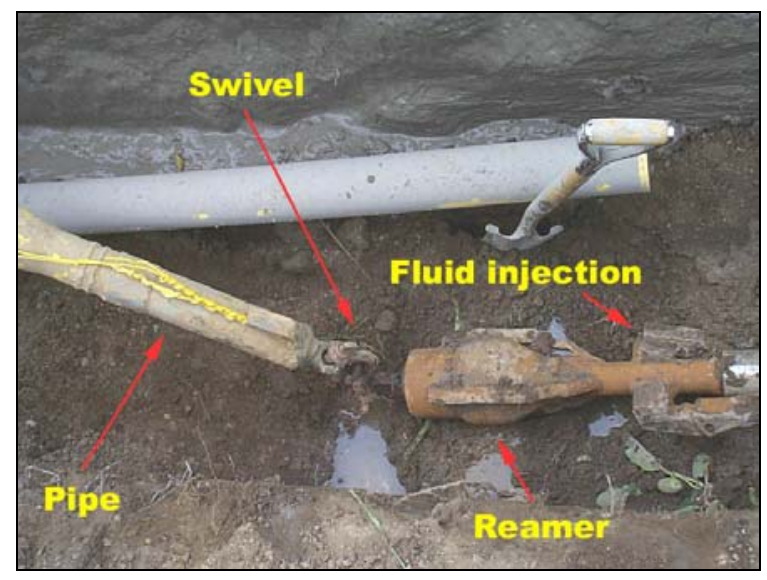

Figure 4.3 Descriptions for HDD equipment

The video clips enable the users to "see" the procedures of the method, installation of equipment, the drilling mechanisms, and so on. In Figure 4.4, captured image of video clip for the starting of auger boring is shown.

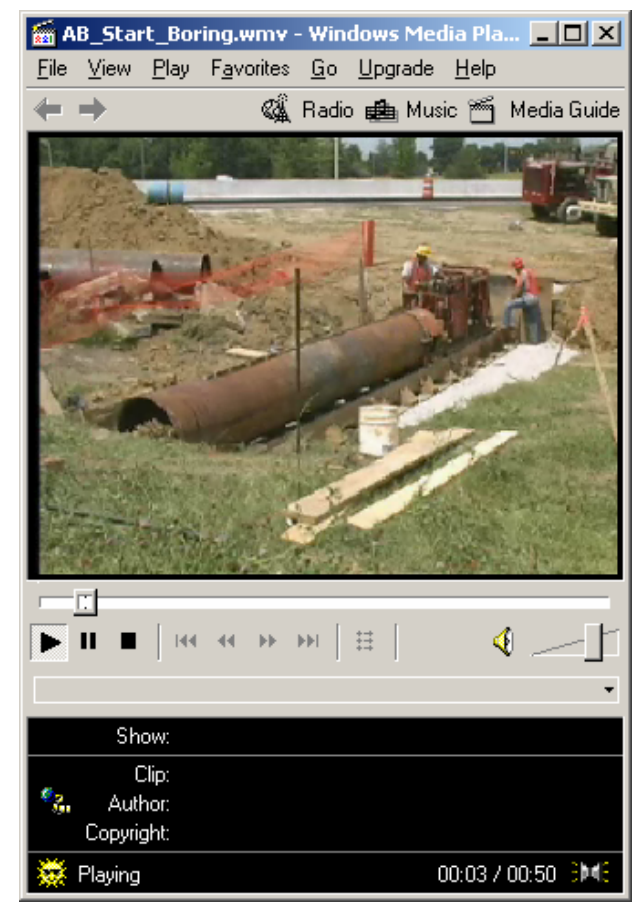

Figure 4.4 Captured image of video clip movie 


\subsection{WEB PAGE FOR RELATED LINKS}

The web page also contains links to other web sites related to trenchless technologies. The web page is categorized into several sections such as organizations, journals and magazines, conferences, contractors, equipment manufacturers, and other sites providing information about trenchless technologies. The layout is shown in Figure 4.5 .

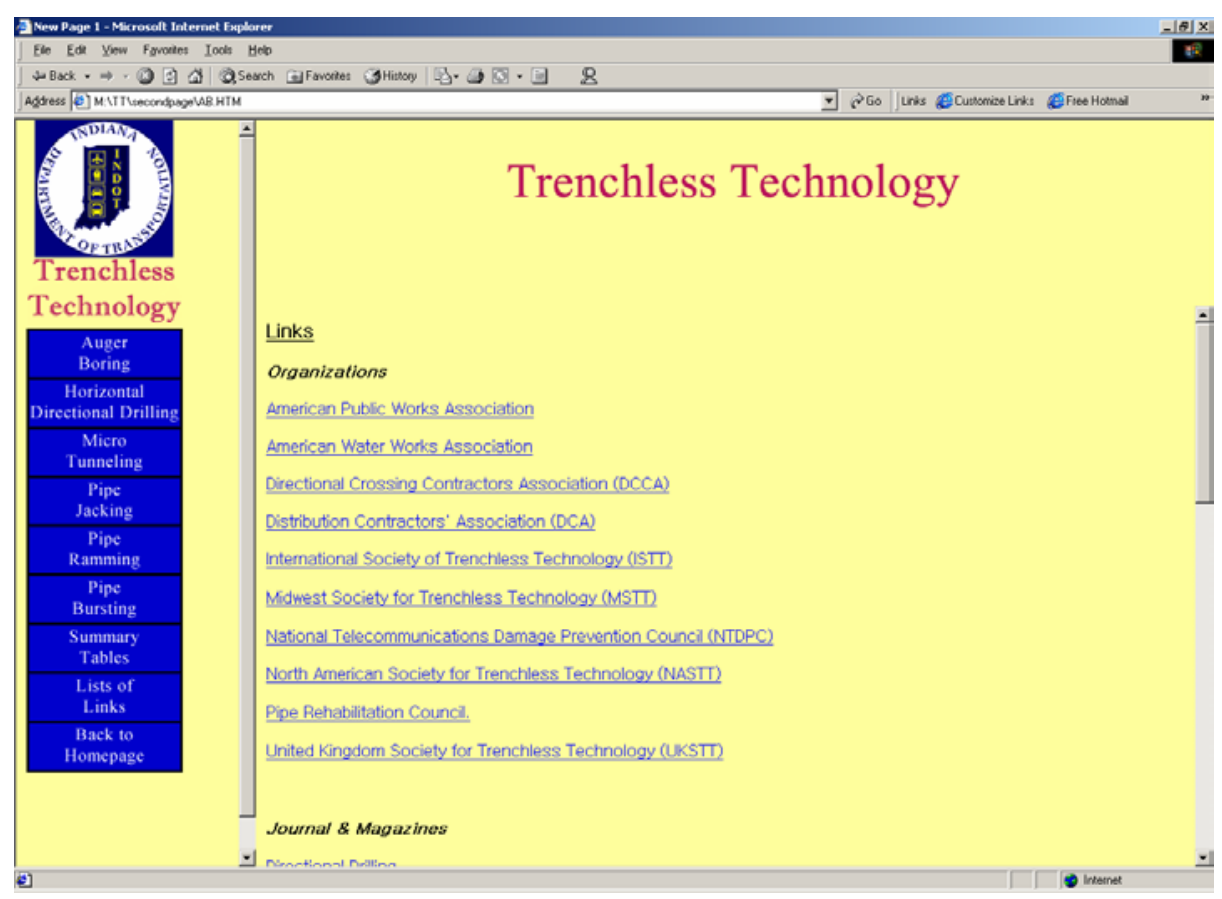

Figure 4.5 Layout of page titled "Links"

\subsection{SITE VISIT}

For each trenchless technology, data was collected using the questionnaire. Photographs were edited using the Adobe Photoshop Version 5.5, and movies for the trenchless operations were edited to produce video clips using Pinnacle Systems microVideo DV Tools Version 1.6. This software allows to convert the movies stored in the cassette tape to computer files, and to edit the movies. The file size of original movies ranged from $80 \mathrm{MB}$ to $1 \mathrm{~GB}$, which is too large to process through the network. Through the video streaming, the file size was reduced to $1.8 \mathrm{MB}$ for a 35-second long video clip. Video streaming is a technique that enables to send the images of movie files as a 
compressed form through Internet. Web users can see the movies as the compressed images arrive and do not have to wait until the entire file is downloaded.

The following sections describe the projects at which data was collected for the development of the multimedia tool.

\subsubsection{Auger Boring}

The project involved the installation of storm water pipes under the ramp of Interstate Highway 65 on Kessler Blvd. in Indianapolis (Figure 4.6). The Indiana Department of Transportation (INDOT) wanted to install pipes under the ramp to ensure more capacity for their dredging system. The installation of casing was performed using auger boring.

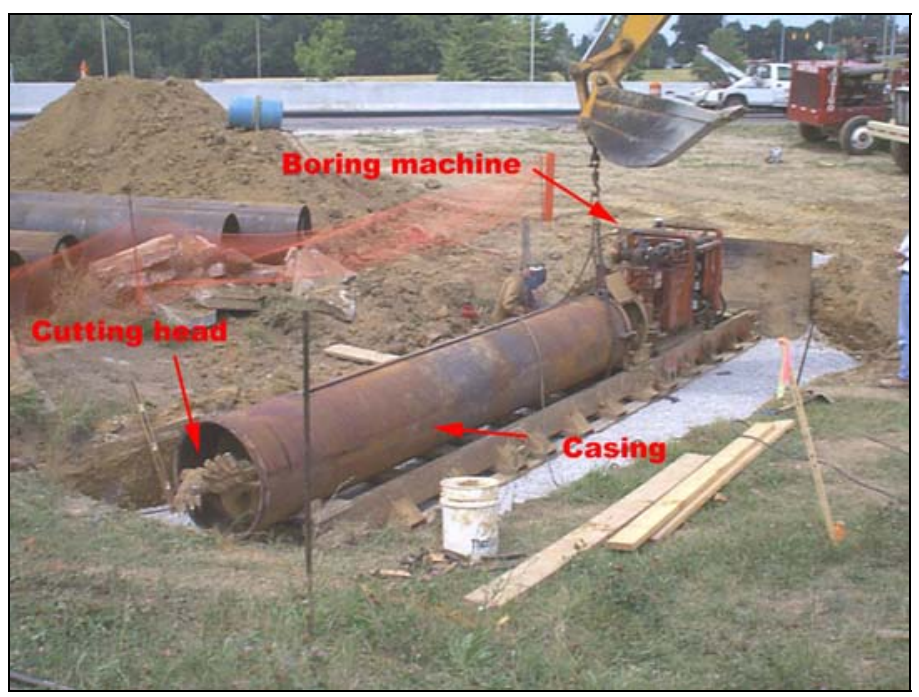

Figure 4.6 Installation of storm water pipe using auger boring

Telephone lines and gas lines were buried under the ground, which would have made open cut installation difficult. Since the construction site was located at the ramp of an interstate highway and there was sufficient empty space around the ramps, the condition of access to the site was good. The contractor installed steel pipe of $900 \mathrm{~mm}$ (36 in) in diameter. No carrier pipe was installed inside the steel casing. The entire project consisted of three installations, i.e., $71 \mathrm{~m}(238 \mathrm{ft}), 26 \mathrm{~m}(86 \mathrm{ft})$, and $23 \mathrm{~m}(75 \mathrm{ft})$

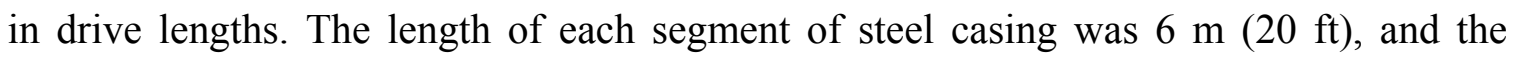


casings were welded at the joints. The average depth of installation was about $2.1 \mathrm{~m}(7 \mathrm{ft})$ for the drive length of $22.5 \mathrm{~m}$ ( $75 \mathrm{ft}$ ). The required grade for the pipe was $0.35 \%$, which was regularly checked. The soil consisted of dry clays with some large boulders.

The size of the entrance shaft was $3.6 \mathrm{~m}(12 \mathrm{ft})$ wide and $11.4 \mathrm{~m}(38 \mathrm{ft})$ long. A three-man crew operated the auger boring machine and backhoe, and could install the pipe about $12 \mathrm{~m}$ ( $40 \mathrm{ft}$ ) per 10-hour shift. Soil was removed by the auger installed inside the steel casing.

\subsubsection{Horizontal Directional Drilling}

This project included the installation of a gas pipeline of $100 \mathrm{~mm}$ (4 in) in diameter using HDD at Zionsville, Indiana (Figure 4.7). The total drive length for this project was $1,470 \mathrm{~m}(4,400 \mathrm{ft})$ and one of the drives included the installation of $87 \mathrm{~m}$ (260 ft) of pipeline. The average depth of installation was $1.1 \mathrm{~m}(3.7 \mathrm{ft})$. The pipe was installed across county road 300 and the street had telephone lines under the ground. The contractor had good access to the site and sufficient space to store the equipment and construction materials. The soil was dry sand.

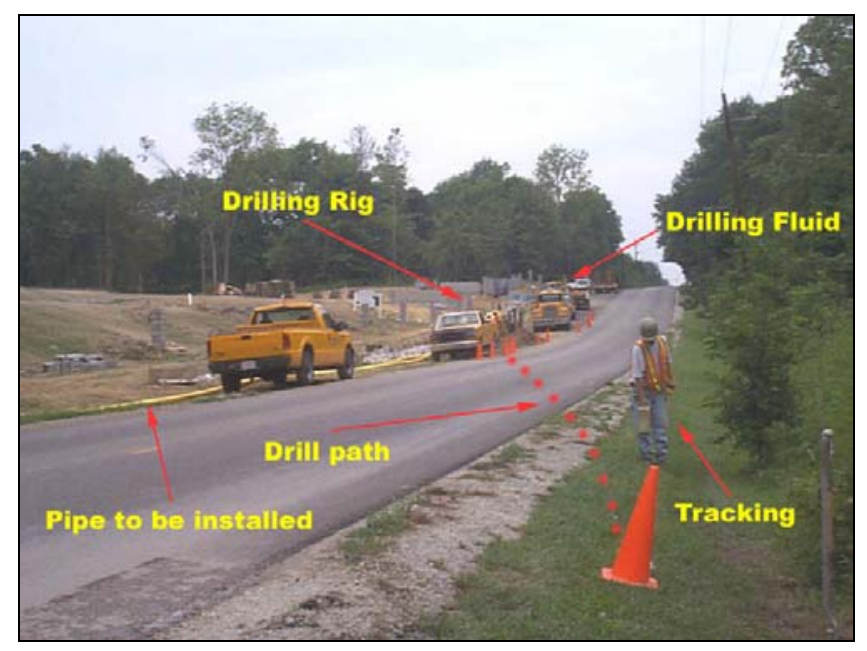

Figure 4.7 Installation of gas line using horizontal directional drilling

The pipe used for this gas line was HDPE (High Density Polyethylene Pipe). Pipe segments were joined by butt fusion. No grade control was required on this project. However, the contractor had to maintain the minimum depth of installation to secure the 
gas line from damage. The overcut for this installation was $250 \mathrm{~mm}$ (10 in). A nineperson crew was employed on project. The productivity for this project ranged from 225 $\mathrm{m}(750 \mathrm{ft})$ to $300 \mathrm{~m}(1,000 \mathrm{ft})$ per 10-hour shift. The drilling rig used for the project was Vermeer D24x40A model which has maximum torque of 5,424 N-m (4,000 ft-lb) and pullback capacity of $10,796 \mathrm{kgf}(23,800 \mathrm{lbs})$.

\subsubsection{Microtunneling}

Sanitary sewer lines were installed on a project in Merrillville, Indiana using microtunneling. The estimated project duration to install sewer pipes of 1,050 mm (42 in) in inside diameter and $120 \mathrm{~m}$ (400 ft) of drive length was three weeks. The depth of installation for the sewer project was $5.4 \mathrm{~m}(18.08 \mathrm{ft})$. The Microtunneling Boring Machine (MTBM) used on this project was Soltau RVS 600AS, a slurry type MTBM, which is applicable for diameters up to 2,250 $\mathrm{mm}$ (90 in) (outer diameter), maximum torque of 352,560 N-m (260,000 ft-lb), and jacking force of 5,338 KN (600 ton). The MTBM consisted of three segments, i.e., one cutting head and two trailers. The first segment is adjustable and leads the remainder of the MTBM segments and pipes. The other two segments maintain stability while the cutting head changes direction. The setup of MTBM is shown in Figure 4.8.

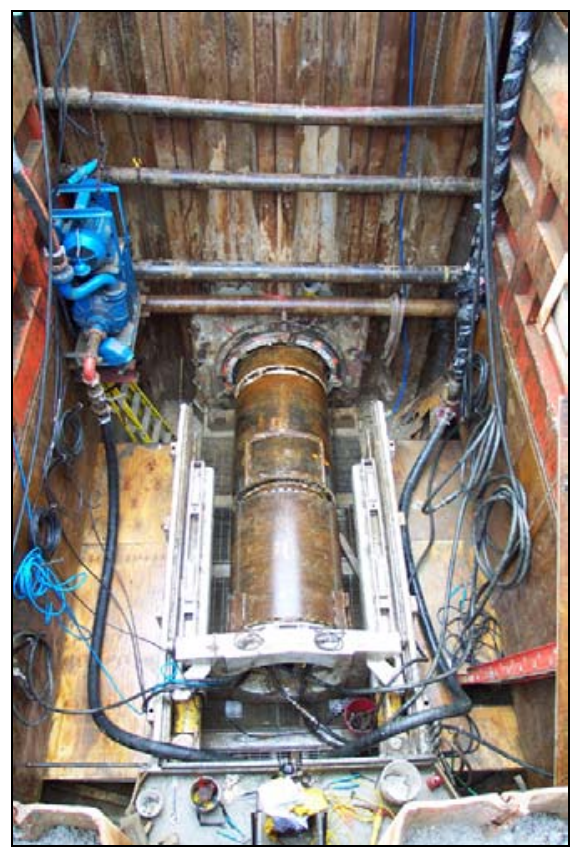

Figure 4.8 Installation of sewer pipe using microtunneling 
The installation occupied one lane of two-lane local street, Colorado Street, in Merrillville. The type of pipe used for the project was HOBAS Glass-Fiber Reinforced Plastic (GFRP) pipes. The $3 \mathrm{~m}(10 \mathrm{ft})$ long segments of pipes were joined using gaskets.

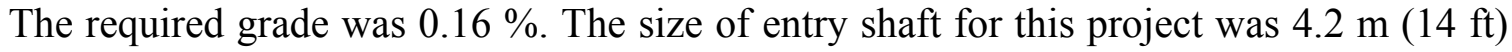
wide and $7.2 \mathrm{~m}(24 \mathrm{ft})$ long. The soil condition was wet clay which caused some challenges during boring. There was seven-person crew at the site including 3 operators

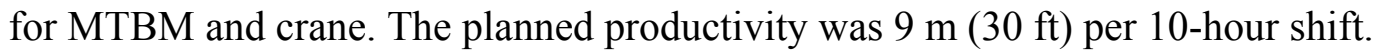

\subsubsection{Pilot Tube Microtunneling (Guided Boring)}

The installation of $250 \mathrm{~mm}$ (10 in) diameter sewer pipes using Pilot Tube Microtunneling (PTMT) was performed on a project in Merrillville, Indiana. This was the first application of PTMT method in State of Indiana. A primary reason for selecting this trenchless technology alternative was the presence of many utility lines such as gas, electricity, and telephone lines buried below the alignment of sewer pipelines (Figure 4.9).

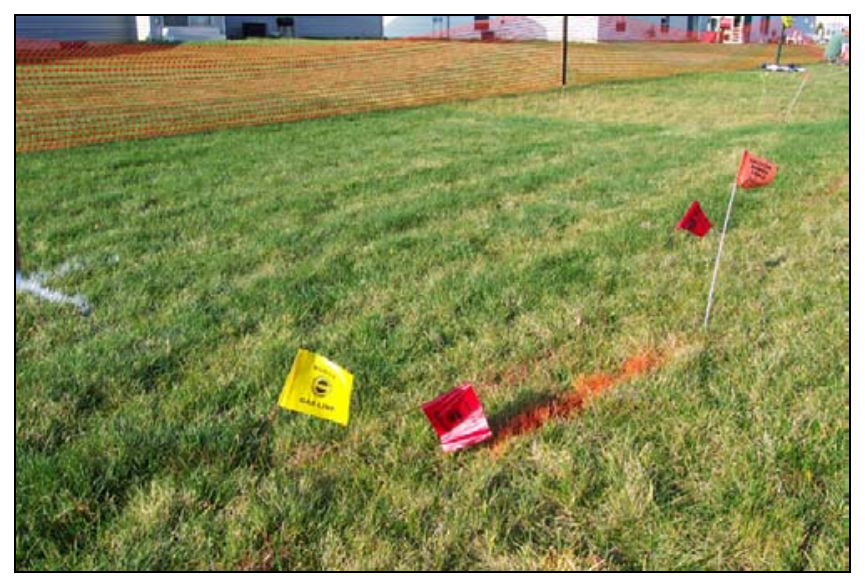

Figure 4.9 Existing underground utility lines

The installation had to cross a local street, a subdivision area, and a landscaped area (Figure 4.10). 


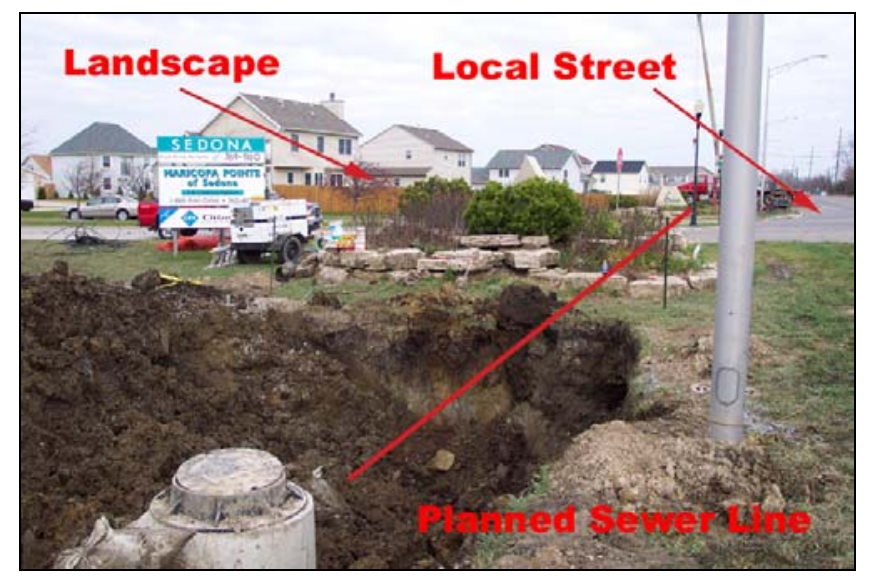

Figure 4.10 Crossings of PTMT project

A total of $240 \mathrm{~m}(800 \mathrm{ft})$ of pipe was installed in four $60 \mathrm{~m}(200 \mathrm{ft})$ drive lengths. The Ductile Iron Pipes (DIP) were joined using double ' $O$ ' rings. The pipes were installed at a depth of $4.8 \mathrm{~m}(16 \mathrm{ft})$. The grade for the sewer line was $0.37 \%$. The entrance and exit shafts were $2.4 \mathrm{~m}(8 \mathrm{ft})$ wide and $4.8 \mathrm{~m}(16 \mathrm{ft})$ long. The soil consisted primarily of moist stiff clay. The soil was removed by auger. A five-person crew drilled

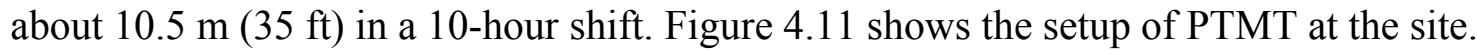

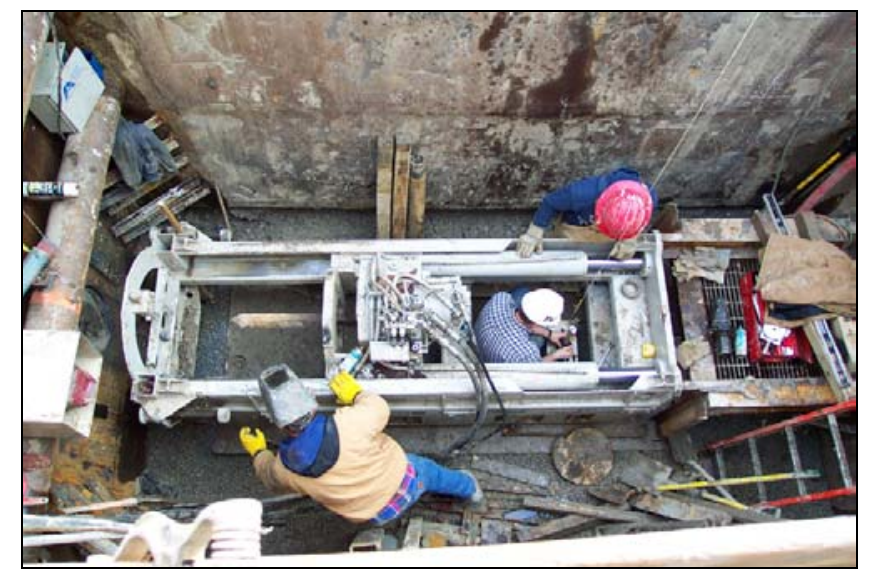

Figure 4.11 Setup of PTMT

\subsubsection{Pipe Jacking}

A chilled water pipeline was installed at Indiana University Purdue University Indianapolis (IUPUI) as a part of the renovation of the hospital and medical school area. Pipe jacking was used to install the $1,450 \mathrm{~mm}$ (58 in) (O.D.) steel casings. The drive 
length was $84 \mathrm{~m}(280 \mathrm{ft})$. Like other areas in developed cities, the ground contained a lot of utility lines such as gas lines, water lines, electricity lines, and steam lines. Since the site was located in the middle of congested area with buildings and other above ground and underground facilities, the working area was very tight (Figure 4.12).

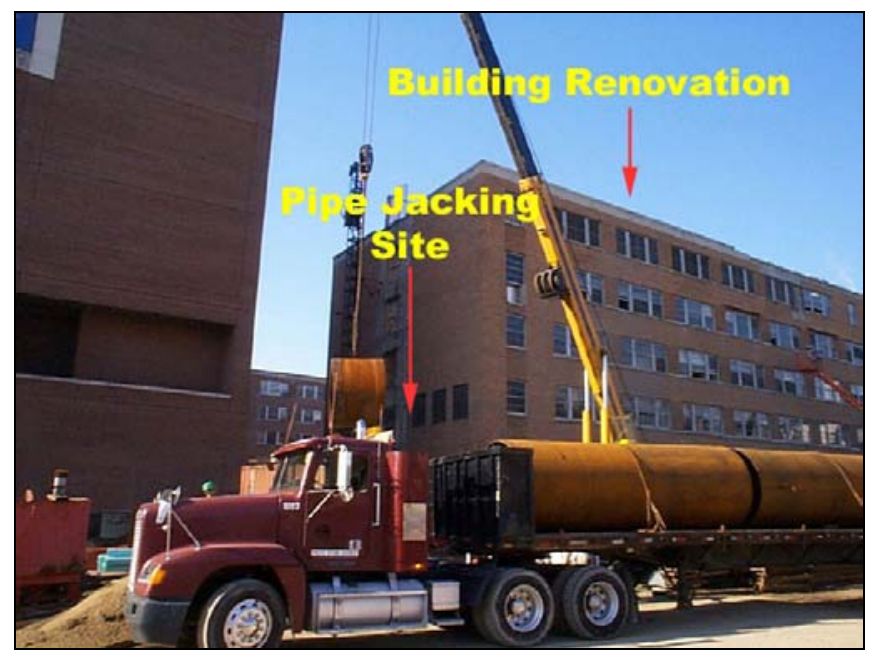

Figure 4.12 Layout of working area of pipe jacking

The pipe segments were $4.8 \mathrm{~m}(16 \mathrm{ft})$ long except the first segment whose length was $4.4 \mathrm{~m}$ (14.8 ft). The pipes were connected using slip joints. Two of $600 \mathrm{~mm}$ (24 in) in diameter steel pipes were installed in the casing as carrier pipes. The depth of installation for this project was $9.6 \mathrm{~m}(32 \mathrm{ft})$.

The shafts for entrance pit and exit pit were $4.8 \mathrm{~m}(16 \mathrm{ft})$ wide by $9.6 \mathrm{~m}(32 \mathrm{ft})$ long and $4.8 \mathrm{~m}(16 \mathrm{ft})$ by $4.8 \mathrm{~m}(16 \mathrm{ft})$, respectively. As shown in Figure 4.13, the soil condition of this site was well-grained dry sand which was used as the backfill material during the construction of the existing buildings. 


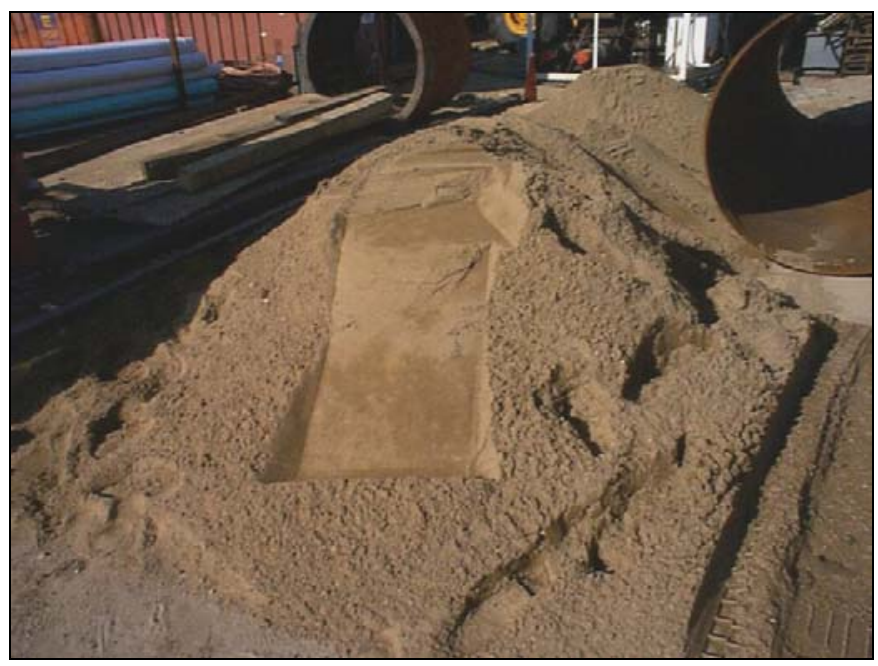

Figure 4.13 Soil excavated from the bore hole

A five-person crew, including crane operator, worked for 10-hour shift and proceeded about $9 \mathrm{~m}(30 \mathrm{ft})$ per day. The excavated soil was delivered through the conveyor belt from the boring machine to a muck car and lifted up and dumped by a crane.

\subsubsection{Pipe Ramming}

Pipe ramming was used to install a gravity sewer under railroad crossing located at the corner of the building construction site at $130116^{\text {th }}$ Street in Indianapolis, IN (Figure 4.14).

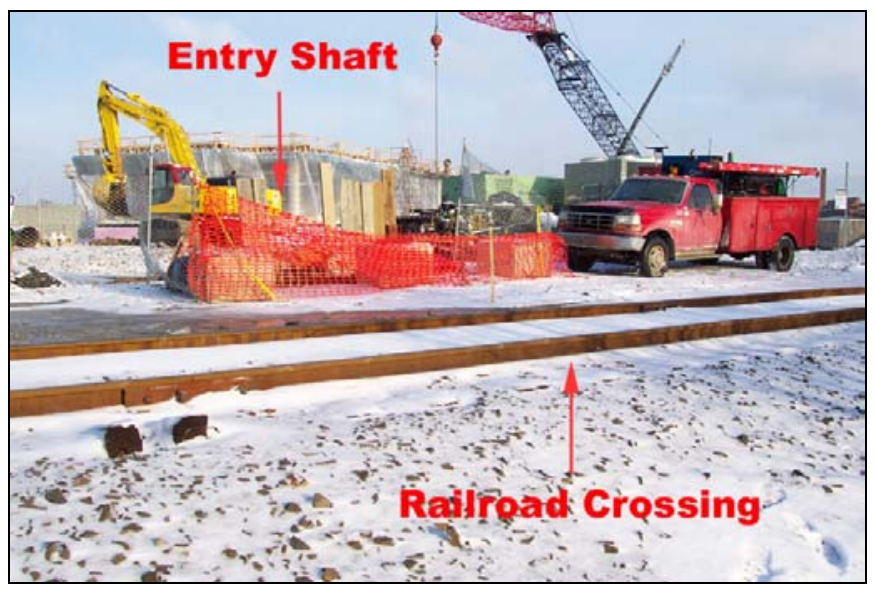

Figure 4.14 Railroad crossing for pipe ramming project 
The size of the casing was $750 \mathrm{~mm}$ (30 in) (O.D.). Once the steel casing was installed, a $625 \mathrm{~mm}$ (25 in) diameter Polyvinyl Chloride Pipe (PVC) was installed in the casing as a carrier pipe. The annulus in the casing was grouted at the end of the operation. The drive length for this project was $18 \mathrm{~m}(60 \mathrm{ft})$. The planned productivity was $6 \mathrm{~m}(20$

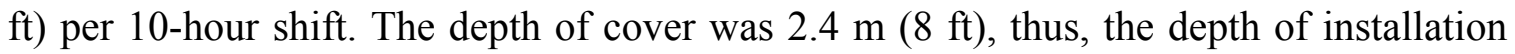
was $3.2 \mathrm{~m}(10.5 \mathrm{ft})$. The planned grade was $3.33 \%$. The size of the entry shaft was $3 \mathrm{~m}$ $(10 \mathrm{ft})$ by $10.8 \mathrm{~m}(36 \mathrm{ft})$, which provided sufficient space for the operation of rammer as shown in Figure 4.15.

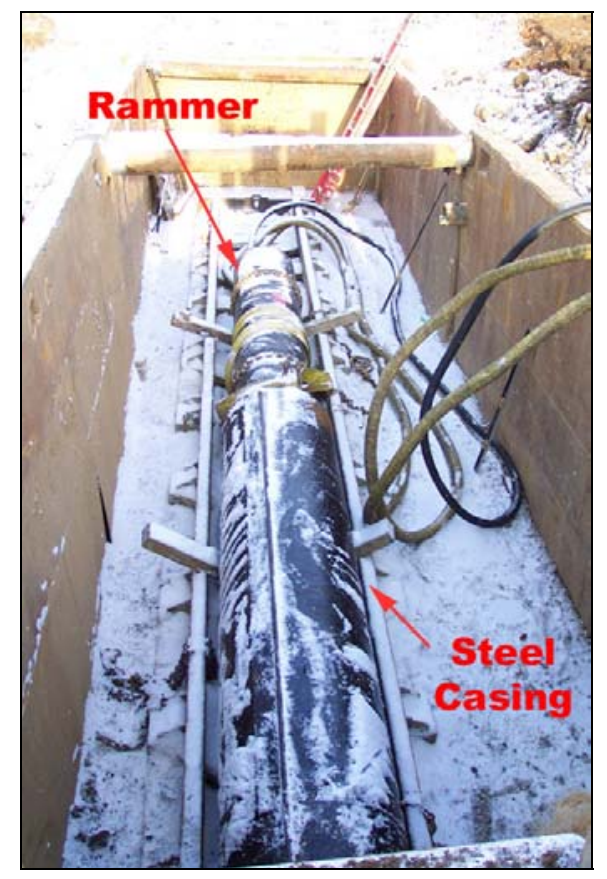

Figure 4.15 Layout of pipe ramming site

The rammer used for the project was the pneumatic type. Since the soil to be bored was backfill, it consisted of various kinds of soil including concrete blocks (Figure 4.16). Once the casing reached the exit shaft, an auger and accompanied boring machine was installed and the soil inside the casing was removed. 


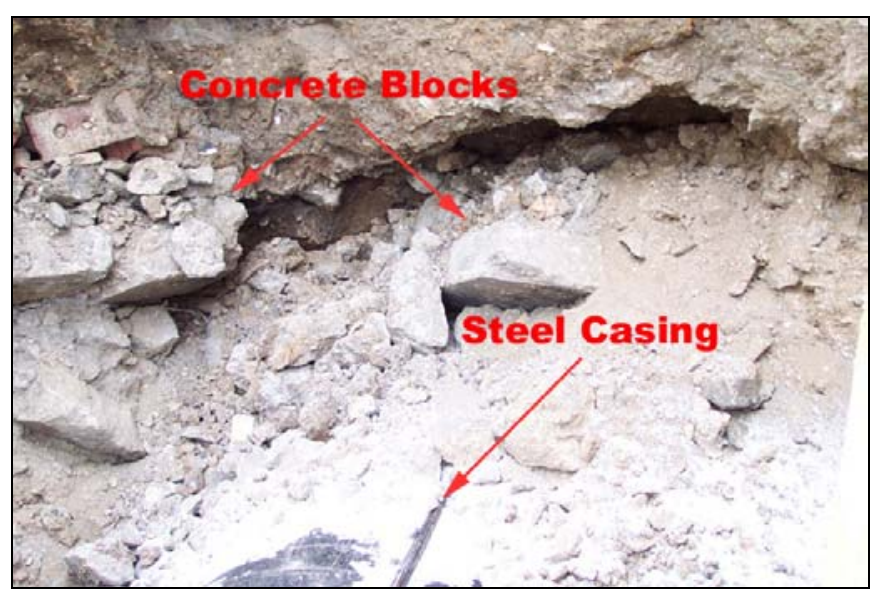

Figure 4.16 Soil condition of pipe ramming project

\subsubsection{Pipe Bursting}

Existing clay sewer pipes on a project in Greenfield, IN, were rehabilitated using pipe bursting with High Density Polyethylene (HDPE) pipes as shown in Figure 4.17.

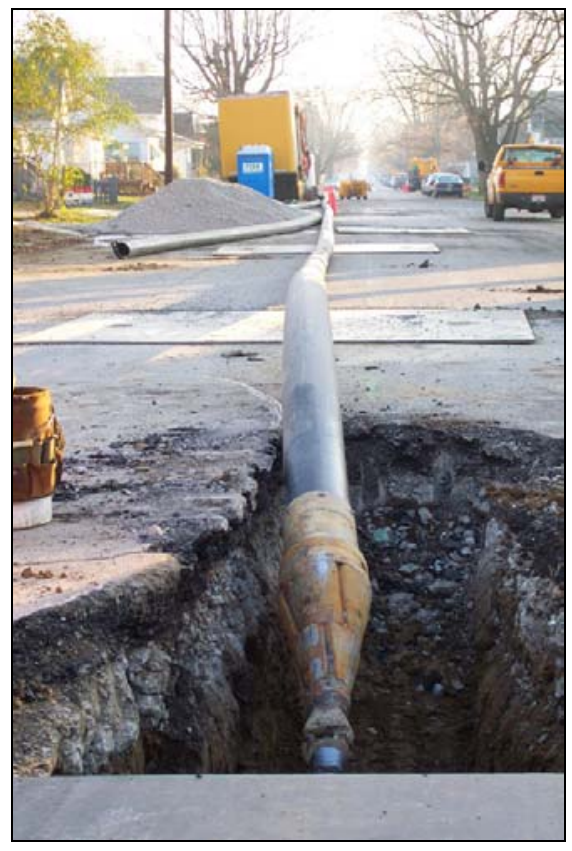

Figure 4.17 Overview of pipe bursting site

The project included the installations of three new sewer lines, i.e., $219 \mathrm{~m}$ (730ft),

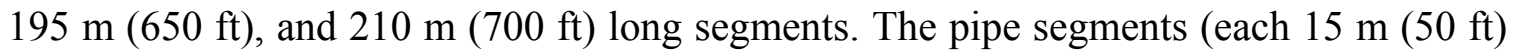
long) were joined using butt fusion. The depth of installation ranged from $1.8 \mathrm{~m}(6 \mathrm{ft})$ to 
$2.1 \mathrm{~m} \mathrm{(7ft)}$. The entrance and exit shaft were $1.2 \mathrm{~m} \mathrm{(4ft)} \mathrm{by} 4.8 \mathrm{~m}(16 \mathrm{ft})$ and $1.2 \mathrm{~m}(4 \mathrm{ft})$ by $3 \mathrm{~m} \mathrm{(10} \mathrm{ft),} \mathrm{respectively.} \mathrm{A} \mathrm{five-person} \mathrm{crew} \mathrm{was} \mathrm{employed} \mathrm{for} \mathrm{the} \mathrm{project} \mathrm{and}$ planned to install $210 \mathrm{~m}(700 \mathrm{ft})$ of pipe a day. 


\section{CHAPTER 5 A DECISION SUPPORT SYSTEM FOR THE SELECTION OF TRENCHLESS TECHNOLOGIES}

\subsection{INTRODUCTION}

For the successful completion of trenchless construction projects, selection of appropriate equipment and tools is critical. However, the selection of appropriate methods for trenchless project is not always an easy task. This situation is especially difficult for the people who do not have enough information or knowledge about trenchless technologies.

To assist the decision makers in the selection of appropriate trenchless technologies for utility installation projects, a Decision Support System (DSS) was developed as part of this research project. First, criteria for selection of trenchless technologies were identified. Then, the framework for decision making using the identified criteria was established. A tool, named "Selection and Evaluation of Trenchless Technologies (SETT)," was developed to facilitate the decision making processes.

Microsoft Visual Basic programming language was used as the programming language and Microsoft Access was employed as the database management program for this project.

The entire program consists of 12 forms: Main, Project information, Search result, Site conditions, Diameter of pipe, Depth of installation, Drive length, Soil conditions, Typical application, Type of pipe, Summary report, and Possible concerns. A part of the source code for each form is given in Appendix A. To run this program using a computer on which the MS Visual Basic is not installed, an additional file, named MSVBVM60.dll, is required.

\subsection{DECISION MAKING CRITERIA}

Six primary criteria were identified for decision-making regarding the use of trenchless technology. These include: site conditions, diameter of pipe, depth of installation, drive length, soil conditions, and typical applications. 


\subsubsection{Site conditions}

The criteria for site conditions are identified to rate the level of difficulty experienced when the open cut method is used. The existence of crossings (such as rivers, creeks, railways and roadways) can be an obstacle for the adoption of open cut method. Recent environmental regulations do not allow utility companies to install the utility pipelines at the bottom of rivers or wetlands. If the planned alignment to install pipelines has to cross a historic area, a landscaped area, or a paved road, the cost to restore these areas to their original state may be very high. Besides, the restoration reduces the life cycle time of the built-up structures. For instance, pavement cutting and restoring can cause more frequent pavement repairs and additional traffic impacts derived from repair works, which result in great budget requirements for pavement maintenance (Riccio 1990). In a study performed for the city of Burlington, Vermont, it was determined that "streets without utility cut patching have a life of 18.5 years while streets with utility cut patching have a life of 10.9 years (Shahin and Crovetti 1985)."

One of the advantages of trenchless technology is that it causes minimum interference with traffic. Since traffic impact is one of the major concerns in many urban areas, excavations for new facilities may face resistance from pedestrians or residents around the construction area and the drivers passing the site. Thus, high traffic volume can be a factor in the selection of trenchless technologies for the installation of pipes. The complexity of the existing underground utilities should be included as a criterion in the selection of trenchless construction method. Accessibility to the construction site is another factor to be considered.

\subsubsection{Diameter of pipes}

The appropriate trenchless technology should be selected based on the diameter of pipes to be installed. $\mathrm{AB}$ can be used for the pipe diameter ranging from $200 \mathrm{~mm}$ ( 8 in) to 1,500 $\mathrm{mm}$ (60 in). MT can be applied when the diameter of the pipe ranges from $250 \mathrm{~mm}$ (10 in) to $3 \mathrm{~m} \mathrm{(10} \mathrm{ft)} \mathrm{or} \mathrm{more.} \mathrm{To} \mathrm{simplify} \mathrm{the} \mathrm{decision} \mathrm{making} \mathrm{process,} 3 \mathrm{~m} \mathrm{(10} \mathrm{ft)} \mathrm{is}$ selected as the maximum applicable diameter for MT application in this study. Most of the ranges used in this research study are adopted from the National Cooperative 
Highway Research Program (NCHRP) report titled "Trenchless installation of conduits beneath roadways" (Iseley and Gokhale 1997). Some were obtained from interviews with contractors. These ranges are summarized in Table 5.1.

Table 5.1 Applicable diameter ranges

\begin{tabular}{|l|l|}
\hline Trenchless technology & Range of Diameter \\
\hline Auger boring & $200-1,500 \mathrm{~mm}(8-60 \mathrm{in})$ \\
\hline Horizontal directional drilling & $50-1,200 \mathrm{~mm}(2-48 \mathrm{in})$ \\
\hline Microtunneling & $250-3,000 \mathrm{~mm}(10-120 \mathrm{in})$ \\
\hline Pipe jacking & $1,070-3,000 \mathrm{~mm}(42-120 \mathrm{in})$ \\
\hline Pipe ramming & $100-1,500 \mathrm{~mm}(4-60 \mathrm{in})$ \\
\hline
\end{tabular}

\subsubsection{Depth of installation}

Since all trenchless technologies except HDD require entrance and exit shafts, pipes can be installed using these trenchless technologies to any depth. However, HDD does not need any pits for the installation of pipes unless there are specific requirements for the shafts. HDD also employs tracking systems for the navigation of the test bore and pipe. Hence the depth of installation is limited to about $50 \mathrm{~m}(160 \mathrm{ft})$ in case of HDD. The summary of applicable depth ranges is shown in Table 5.2.

Table 5.2 Applicable depth of installation ranges

\begin{tabular}{|l|l|}
\hline Trenchless technology & Range of Depth \\
\hline Auger boring & Varies \\
\hline Horizontal directional drilling & $<50 \mathrm{~m}(160 \mathrm{ft})$ \\
\hline Microtunneling & Varies \\
\hline Pipe jacking & Varies \\
\hline Pipe ramming & Varies \\
\hline
\end{tabular}

\subsubsection{Drive length}

Typically, as the drive length increases, the complexity and risks associated with the project also increase. The maximum drive length is defined by the capacity of the drilling machine. However, the minimum boundary of drive length is determined by economic factors. Drive lengths below the minimum boundary are generally considered to be uneconomical due to the high costs of mobilization and demobilization of trenchless equipment. 
The drive length for $\mathrm{AB}$ ranges from $12 \mathrm{~m}$ ( $40 \mathrm{ft})$ to $150 \mathrm{~m}(500 \mathrm{ft})$. HDD can be applied from $12 \mathrm{~m}(40 \mathrm{ft})$ to $1,800 \mathrm{~m}(6,000 \mathrm{ft})$. MT can drill bores from $25 \mathrm{~m}(80 \mathrm{ft})$ to $225 \mathrm{~m}$ (750 ft). The longest PJ project in the United States had a continuous drive length

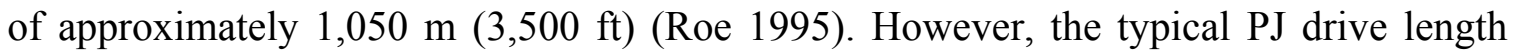
ranges from $150 \mathrm{~m}(500 \mathrm{ft})$ to $300 \mathrm{~m}(1,000 \mathrm{ft})$. $\mathrm{PR}$ is capable of installing pipelines from $12 \mathrm{~m}$ (40 ft) to $60 \mathrm{~m}(200 \mathrm{ft})$. These drive length ranges are summarized in Table 5.3.

Table 5.3 Applicable drive length ranges (Iseley and Gokhale 1997)

\begin{tabular}{|l|l|}
\hline Trenchless technology & Range of drive length \\
\hline Auger boring & $12-150 \mathrm{~m}(40-500 \mathrm{ft})$ \\
\hline Horizontal directional drilling & $12-1,800 \mathrm{~m}(40-6,000 \mathrm{ft})$ \\
\hline Microtunneling & $25-225 \mathrm{~m}(80-750 \mathrm{ft})$ \\
\hline Pipe jacking & $150-305 \mathrm{~m}(500-1,000 \mathrm{ft})$ \\
\hline Pipe ramming & $12-60 \mathrm{~m}(40-200 \mathrm{ft})$ \\
\hline
\end{tabular}

\subsubsection{Soil conditions}

$\mathrm{AB}$ can be used in a wide range of soil conditions. Typically, firm sandy soil is the most compatible soil condition for using $\mathrm{AB}$. However, $\mathrm{AB}$ is not recommended for sandy soil below water table, because of the high possibility of subsidence of the ground. In the case of HDD, cohesive soil (clay) is considered to be the ideal material for drilling. However, cohesionless sand and silts are considered to be acceptable for the utilization of HDD, because these soils behave in a fluid manner, and are able to remain in suspension in the drill fluid for a sufficient period of time and can then be washed out of the borehole.

MT can be applied in a wide range of soil conditions except for solid rocks. Typically, when boulders are encountered, MT crushes the boulders and then removes them. PJ can be employed in various types of soil. However, it is difficult to use PJ in sandy soils below the water table and in soils containing solid rocks because the use of PJ can cause subsidence of the ground in the case of sandy soils, and frequent stoppage during the operation when rocks are encountered. PR can be used in a wide range of soil conditions. When the PR machine hits cobbles and boulders, it can cause the deflection of pipes, especially small diameter pipes. Detailed information about the soil condition is 
required in order to determine the appropriate size of the casing. The soil conditions and suitability of trenchless technologies used for the SETT are summarized in Table 5.4.

Table 5.4 Applicability of trenchless technologies in various soil conditions (Iseley and Gokhale 1997)

\begin{tabular}{|c|c|c|c|c|c|c|}
\hline Soil Type & $\begin{array}{l}\text { N Value (Standard } \\
\text { Penetration Value } \\
\text { as per ASTM D } \\
1452 \text { ) }\end{array}$ & $\mathrm{AB}$ & HDD & MT & PJ & PR \\
\hline \multirow{3}{*}{$\begin{array}{l}\text { Cohesive Soils } \\
\text { (Clay) }\end{array}$} & $\mathrm{N}<5$ (Soft) & 0 & 0 & - & 0 & - \\
\hline & $\mathrm{N}=5-15$ (Firm) & $\bullet$ & $\bullet$ & - & $\bullet$ & $\bullet$ \\
\hline & $\begin{array}{l}\mathrm{N}>15 \text { (Stiff- } \\
\text { Hard) }\end{array}$ & - & - & • & - & - \\
\hline \multirow{4}{*}{$\begin{array}{l}\text { Cohesionless } \\
\text { Soils } \\
\text { (Sand/Silt) }\end{array}$} & $\mathrm{N}<10$ (Loose) & 0 & $\mathrm{O}$ & - & $\mathrm{O}$ & $\bullet$ \\
\hline & $\begin{array}{l}\mathrm{N}=10-30 \\
\text { (Medium) }\end{array}$ & - & - & - & - & - \\
\hline & $\mathrm{N}>30$ (Dense) & $\bullet$ & $\bullet$ & $\bullet$ & $\bullet$ & $\bullet$ \\
\hline & High Ground Water & $\mathrm{X}$ & 0 & - & $\mathrm{O}$ & 0 \\
\hline Boulders & & $\leq 33 \% \varphi$ & 0 & $\leq 33 \% \varphi$ & $\mathrm{O}$ & $\leq 90 \% \varphi$ \\
\hline Full-face Rock & & $\leq 12 \mathrm{ksi}$ & $\leq 15 \mathrm{ksi}$ & $\leq 30 \mathrm{ksi}$ & $\leq 30 \mathrm{ksi}$ & $\mathrm{X}$ \\
\hline
\end{tabular}

If the detailed soil information such as $\mathrm{N}$ values, sizes of boulders, and strengths of rocks is not available, the applicability of trenchless technologies is evaluated based on the soil conditions shown in Table 5.5. 
Table 5.5 Applicability of trenchless technologies for soil conditions using general classification (Iseley et al. 1999).

\begin{tabular}{|c|c|c|c|c|c|}
\hline Soil Conditions & $\mathrm{AB}$ & HDD & MT & PJ & PR \\
\hline Soft to very soft clays, silts \& organic deposits & $\mathrm{Y}$ & $\mathrm{Y}$ & Y & M & Y \\
\hline Medium to very stiff clays and silts & Y & $\mathrm{Y}$ & $\mathrm{Y}$ & $\mathrm{Y}$ & Y \\
\hline Hard clays and highly weathered shales & Y & Y & Y & $\mathrm{Y}$ & M \\
\hline Very loose to loose sands above watertable & $\mathrm{M}$ & $\mathrm{Y}$ & Y & $\mathrm{M}$ & $\mathrm{Y}$ \\
\hline Medium to dense sands below watertable & $\mathrm{N}$ & $\mathrm{Y}$ & $\mathrm{Y}$ & $\mathrm{N}$ & $\mathrm{N}$ \\
\hline Medium to dense sands above watertable & Y & $\mathrm{Y}$ & Y & $\mathrm{Y}$ & $\mathrm{Y}$ \\
\hline $\begin{array}{l}\text { Gravels \& cobbles less than } 2-4 \text { in. (50-100 } \\
\text { mm) diameter }\end{array}$ & $\mathrm{Y}$ & M & Y & $\mathrm{Y}$ & Y \\
\hline $\begin{array}{l}\text { Soils with significant cobbles, boulders and } \\
\text { obstructions larger than } 4-6 \text { in. (100-150 mm) } \\
\text { diameter }\end{array}$ & M & M & M & $\mathrm{M}$ & $\mathrm{Y}$ \\
\hline $\begin{array}{l}\text { Weathered rocks, marls, chalks and firmly } \\
\text { cemented soils }\end{array}$ & $\mathrm{Y}$ & $\mathrm{Y}$ & $\mathrm{Y}$ & $\mathrm{M}$ & M \\
\hline Slightly weathered to unweathered rocks & $\mathrm{Y}$ & $\mathrm{M}$ & $\mathrm{N}$ & $\mathrm{N}$ & M \\
\hline \multicolumn{6}{|c|}{$\begin{array}{l}\text {-Y (Yes): Generally used by experienced contractors with suitable equipmen } \\
\text {-M (Marginal): Difficulties may occur, some modifications of equipment or } \\
\text { procedure may be required } \\
\bullet \mathrm{N} \text { (No): Substantial problems, generally unsuitable or unintended for these } \\
\text { conditions }\end{array}$} \\
\hline
\end{tabular}

\subsubsection{Typical applications}

Underground utilities that can be installed by the trenchless technologies are sewer, water, gas, electricity, telephone, and gas lines. Many of the trenchless technologies can be adopted to install these utilities. HDD can be used for the installation of force main conduits. However, it is not common to employ HDD for the installation of gravity sewers. MT is usually used for the installation of sewers where accurate operation is required for installation. Typical application areas of trenchless technology are shown in Table 5.6. 
Table 5.6 Typical applications of trenchless technology

\begin{tabular}{|l|l|}
\hline Trenchless technology & Typical Applications \\
\hline Auger boring & Crossings (All types) \\
\hline Horizontal directional drilling & $\begin{array}{l}\text { Force main, pressure lines, } \\
\text { water, gas, cable }\end{array}$ \\
\hline Microtunneling & Sewer \\
\hline Pipe Jacking & Sewer, pressure lines, crossings \\
\hline Pipe ramming & Crossings \\
\hline
\end{tabular}

\subsection{SETT FOR THE SELECTION OF TRENCHLESS TECHNOLOGIES}

As shown in Figure 5.1, the SETT consists of six verification processes; site conditions, diameter of pipe, depth of installation, drive length, soil conditions, and typical applications. Then, the SETT provides information regarding the possible type of pipe used for the project, summary of the decision making process, and the possible concerns that must be addressed during the preplanning phase. 


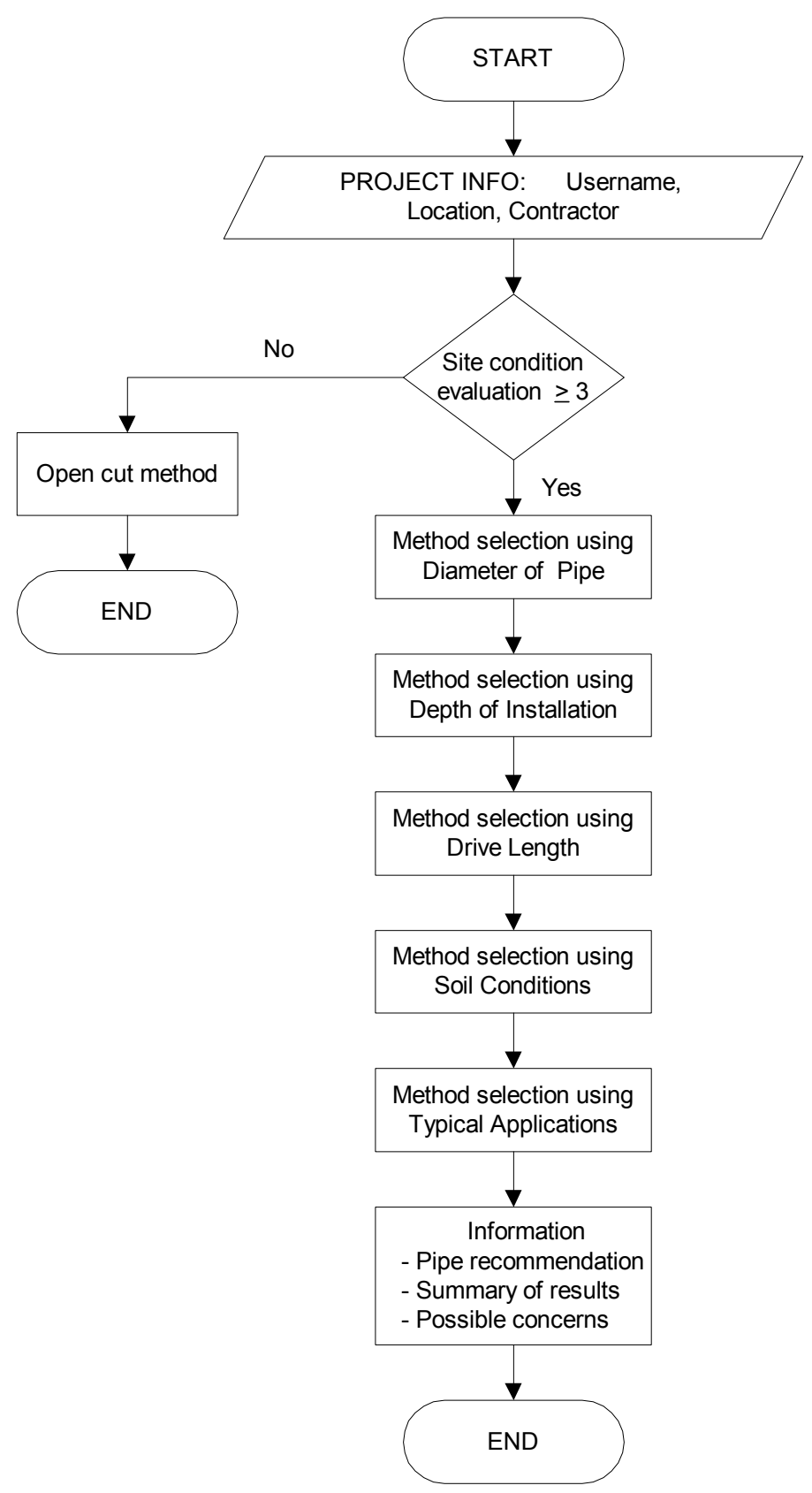

Figure 5.1 Logical flow of the SETT

\subsubsection{Main form}

Once the user runs the program named "SETT.exe," the main form is displayed as shown in Figure 5.2. 


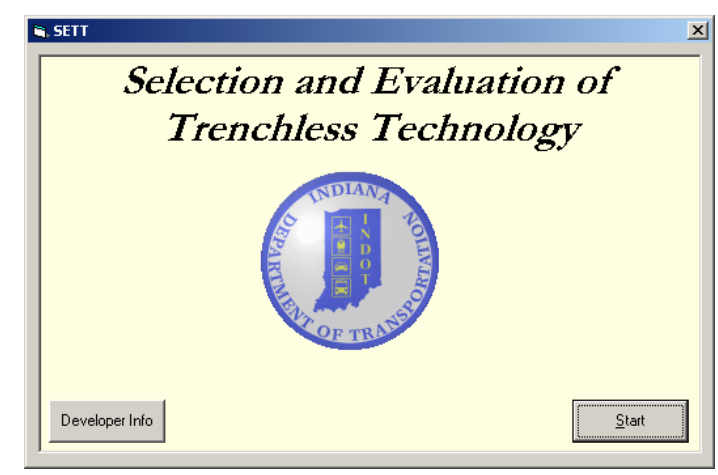

Figure 5.2 Main form of SETT

By selecting the "Start" button, the SETT begins to examine the project under consideration. The Screen Flow Diagram of the SETT is shown in Figure 5.3. The diagram explains the logical flow of the program screens, inputs and output requirements. 


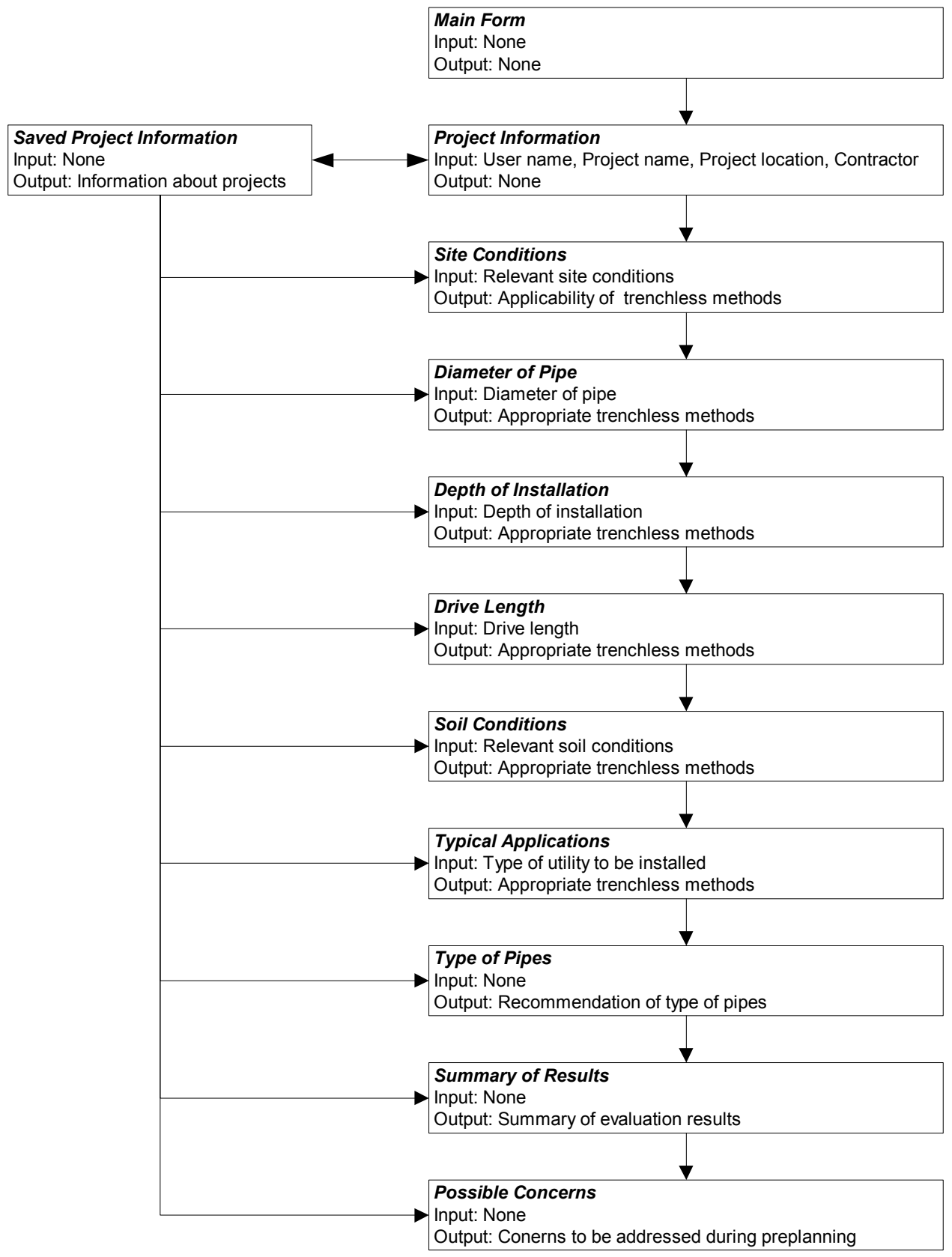

Figure 5.3 Screen Flow Diagram

\subsubsection{Project information}

At this stage, the SETT requires user inputs regarding user name, project name, project location, and contractor as shown in Figure 5.4. 


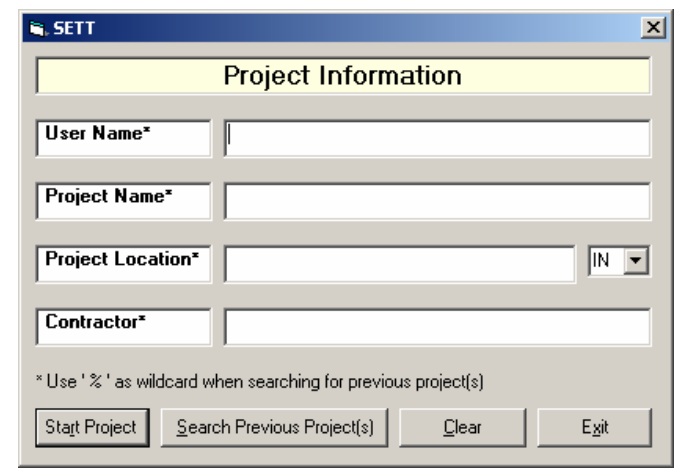

Figure 5.4 Project information form

First, if users want to input data regarding a new project, they are required to input the data in the project information form and select "Start Project" button. If there is a missing data, the SETT will show the error message as shown in Figure 5.5.

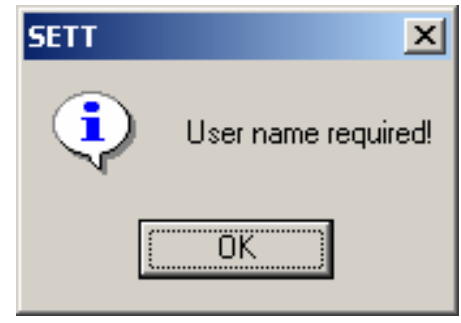

Figure 5.5 Error message for missing input data (in this case username)

The "Clear" button deletes all the data entered in the textboxes and allows the users to provide new project data. The last button, "Exit," allows the user to terminate the program whenever he/she wants. However, to prevent the accidental end of program, a warning message pops up as shown in Figure 5.6.

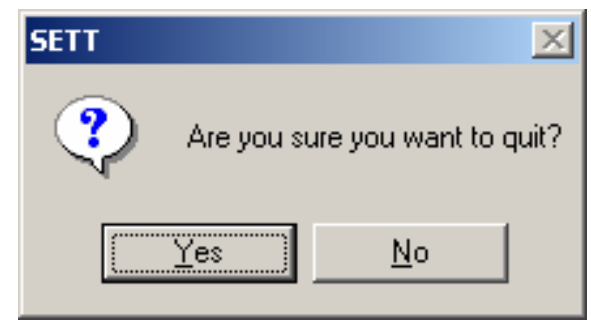

Figure 5.6 Message box for exit confirmation 
The SETT also asks the users whether or not they want to save the data before the termination of the session by presenting the message box shown in Figure 5.7.

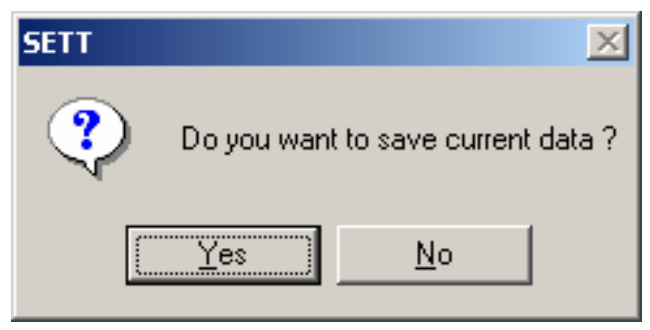

Figure 5.7 Message box for data save

This information is stored in a database file, which is Microsoft Access file, so that future users can retrieve the information about the trenchless projects. By selecting the "Search Previous Project(s)" button on the project information form, users can find information about the previous projects. Users can retrieve the data based on each category. For instance, by putting a user name in "User Name" textbox and selecting the "Search Previous Project(s)" button, users can find the information about projects entered by the specific user. The example of the search results is shown in Figure 5.8.

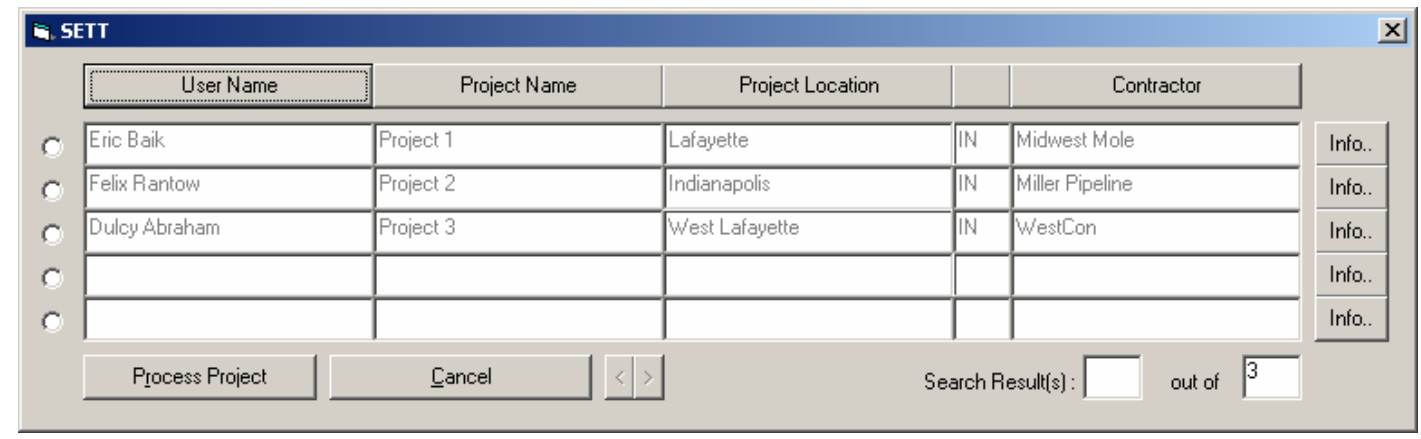

Figure 5.8 Search results

The sample data set includes 25 records of trenchless projects. The records are shown in ascending order based on user name. Users can sort the data using the buttons such as "Project Name," "Project Location," and "Contractor" which are available at the top of the form. By selecting the "Info..." button on the right side, users can find the information about the selected project stored in the database. The "Process Project" 
button leads the users to the form where it was inputted or modified last time. The left and right bracket, i.e., "<" and ">”, will show the previous or next five data, respectively.

\subsubsection{Evaluation of site conditions}

This stage includes the identification of the existence of crossings (crossings), developments above ground (developments), traffic volume (traffic), conflict with existing underground utilities (utilities), and difficult accessibility along the planning pipeline (accessibility). The "crossings" category includes seven sub-items such as river, creek, railroad, highway, urban street, rural road, and residential street. In addition, "not applicable" option is also provided. The "developments" option consists of seven sub items: park, historic area, scenic area, landscaped area, cemetery, business/residential/industrial development and not applicable. The "traffic" category includes four sub items: high, medium, low, and not applicable depending on the traffic volume. The layout of the site condition form is shown in Figure 5.9.

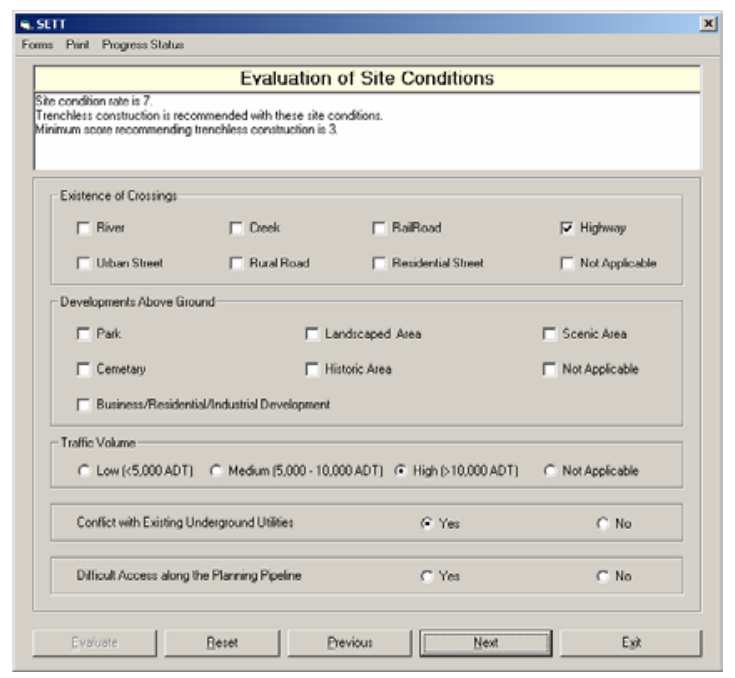

Figure 5.9 Site condition form

Two factors, i.e., "utilities" and "accessibility" have some impact on selection of construction method. The impact, however, is not sufficiently large to forgo the open cut alternative and select trenchless technology for installation of conduits. Thus, the score for these factors is one point. The "developments" condition has a greater influence than the two aforementioned factors. Reinstatement of original structures and facilities results 
in higher costs and also in reducing service lives of the facilities. This results in the assignment of two points to the "developments" sub factors except the landscaped areas and the scenic areas which have lower impact than other items. "Crossings" make it more difficult to trench ditches traversing the rivers or roadways. Hence, three points are assigned to most of these factors. Since large traffic volume is one of the motivations to select trenchless technology for the installation of pipelines, three points are assigned to high traffic volume (greater than 10,000 ADT), and two points and one point are allocated to medium (between 5,000 and 10,000 ADT) and low traffic volume (less than 5,000 ADT), respectively. The threshold score for recommending trenchless methods is three. Table 5.6 shows the scores to be assigned to each of the items.

Table 5.7 Site condition score

\begin{tabular}{l|l}
\hline Site Condition & Score \\
\hline Existence of crossings & \\
$\quad$ river, creek, railroad, highway & 3 \\
$\quad$ urban street & 2 \\
$\quad$ rural road, residential street & 1 \\
Developments above ground & \\
$\quad$ park, historic area, cemetery, & 2 \\
$\quad$ business/residential/industrial development & 2 \\
$\quad$ landscaped area, scenic area & 1 \\
Traffic volume & 3 \\
$\quad$ high & 2 \\
$\quad$ medium & 1 \\
low & 1 \\
Conflict with existing underground utilities & 1 \\
Difficult accessibility along the planning pipeline & 0 \\
Not applicable &
\end{tabular}

In the site condition form, users can select as many conditions as required in order to describe the conditions of the project sites. If a selection is made in error, users can cancel the selection by clicking the selected checkboxes again. By pressing "Enter" key or selecting "Evaluate" button, the user requests the SETT to evaluate whether trenchless technologies are appropriate for the project under consideration based on site conditions.

When the form is loaded at the beginning of this step, the "Next" button is not available. The "Next" button is enabled when the user completes the evaluation by 
selecting the "Evaluate" button. This is to prevent the user from selecting the next button by accident, and moving to next step without any evaluation process. At the same time,

the "Evaluate" button is locked. Thus the user cannot press the "Evaluate" button twice with the same input. However, the "Evaluate" button is enabled again whenever the user changes the selections of site conditions.

If the user wants to examine the project with a few different site conditions, the users can select the "Reset" button then select the new conditions. The "Next" button leads the user to the next form depending on the result of evaluation. If the total score of site condition evaluation is greater than three, the "Next" button leads the users to the form titled "diameter of pipe." However, if the score is less than three, the SETT will display a message saying, "The trenchless construction option is less attractive for this project" and asks the users whether or not they want to try another project.

\subsubsection{Evaluation of diameter of pipe}

After the evaluation of site conditions, appropriate trenchless technologies are determined based on the diameter of pipe. Using the input provided by the user, the SETT evaluates which trenchless technologies are appropriate for the project. By inserting the diameter of pipe (in $\mathrm{mm}$ or inch) in the textbox and pressing "Enter" key, the user can see the evaluation results in the display panel in the form. As shown in Figure 5.10, the criteria for diameter are displayed in a table format. These criteria are stored in a database file. Thus, if the applicable ranges for each trenchless technology are changed due to technical developments in the future, the criteria can be modified by updating the minimum and maximum values of each trenchless technology in the database file. 


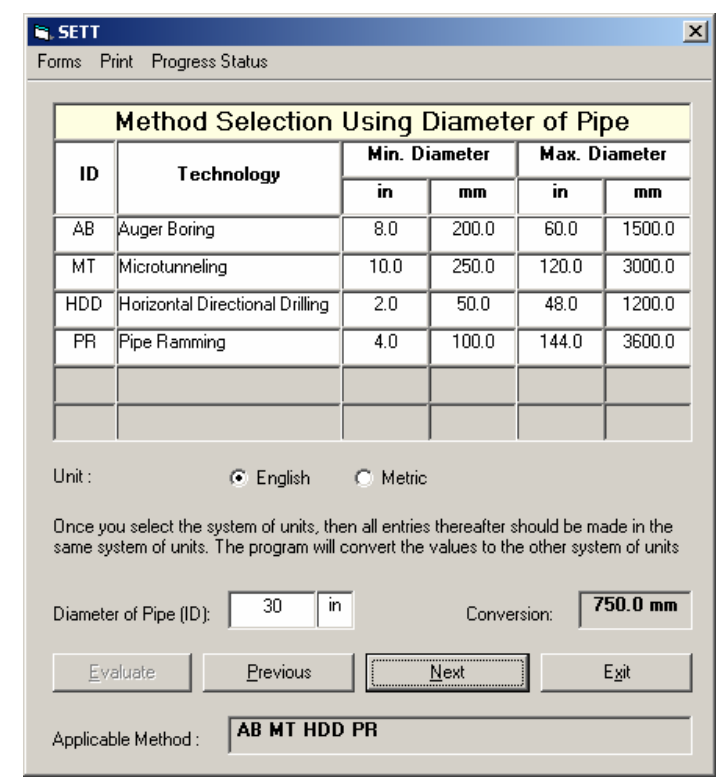

Figure 5.10 Diameter of pipe form

Users can input the diameter of pipe in either of English or metric units. By selecting the preferred unit, unit system displayed in the unit panel will be switched automatically between inch and $\mathrm{mm}$. The SETT also provides the conversion function from one system of units to another. For instance, if the user inputs 30 inch (diameter), then selects the "Evaluate" button, the "Conversion" textbox will show the conversion$750.0 \mathrm{~mm}$. Once the system of units is selected at this stage, the SETT considers it as the default system during the decision making process.

Once the appropriate trenchless technologies are determined, the capacity of the designated technologies to operate under specific depths and for specific drive lengths is investigated.

\subsubsection{Evaluation of depth of installation}

The soil between the ground surface and borehole becomes very vulnerable to resist the pressure or high flow rate generated during the trenchless operation, resulting in the heaving of the ground surface. In addition, the pressure and high flow rate may induce the soil to erode. Erosion generates voids in the ground, which can consequently result in surface subsidence. To eliminate these problems, the minimum depth of 
application must be taken into consideration during the design and construction phases of trenchless technology projects.

The minimum depths for HDD used in this research were established through interviews with HDD contractors. The minimum depth for HDD is $600 \mathrm{~mm}$ (24 in). The depth of cover-to-diameter ratio is also important in identifying the minimum depth, because minimum depth can vary depending on the diameter. The depth of cover is defined as the depth from the ground surface to the crown of the product pipe. The depth of cover-to-diameter ratio used in this research is 1.5 , which is set up by the review of completed HDD projects (Gokhale and Haskin 1999). A minimum depth-of-cover to diameter ratio of 3 is usually recommended for MT to avoid heave or settlement of the surface (Staheli and Hermanson 1996). Since AB, PJ, and MT have similar characteristics in their operations, the value of three is used as the minimum depth-ofcover to diameter ratio when these three trenchless technologies are used.

The interface for this stage is shown in Figure 5.11. As shown in the figure, the form has criteria in table format, input textbox for depth of installation, and four display panels such as conversion to the other unit, recommended depth-of-cover, actual depthof-cover, and appropriate trenchless methods for the project.

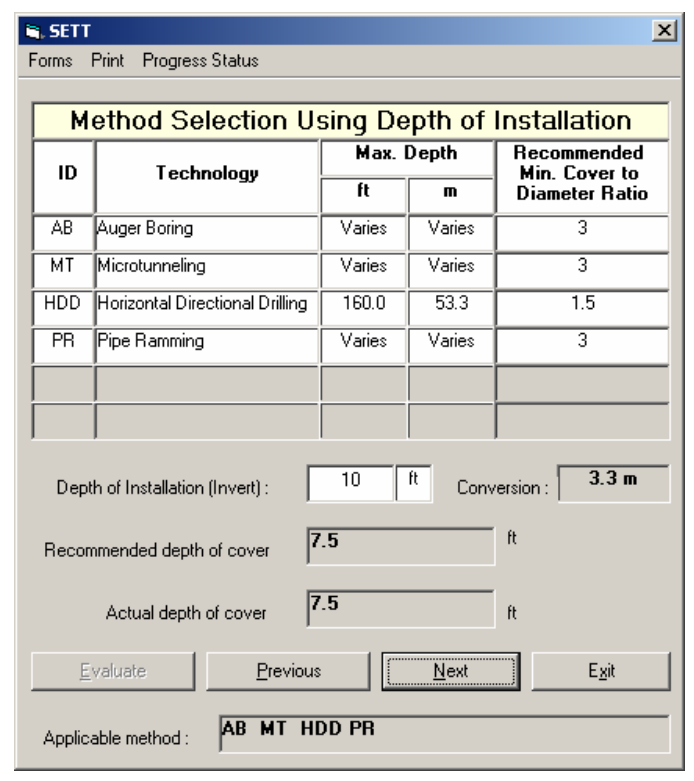

Figure 5.11 Depth of installation form 


\subsubsection{Evaluation of drive length}

If the planned drive length does not satisfy the minimum or maximum drive length boundaries of the designated trenchless technologies, the system rules out trenchless technologies from the selections at the previous stages. However, even if the planned drive length is not within the optimal boundary, contractors can select the specific method to eliminate other problems or use supporting equipment.

The form for the evaluation of drive length is given in Figure 5.12. Users can input the required drive length for the project, and the SETT will provide the evaluation result based on the limitations of each trenchless method.

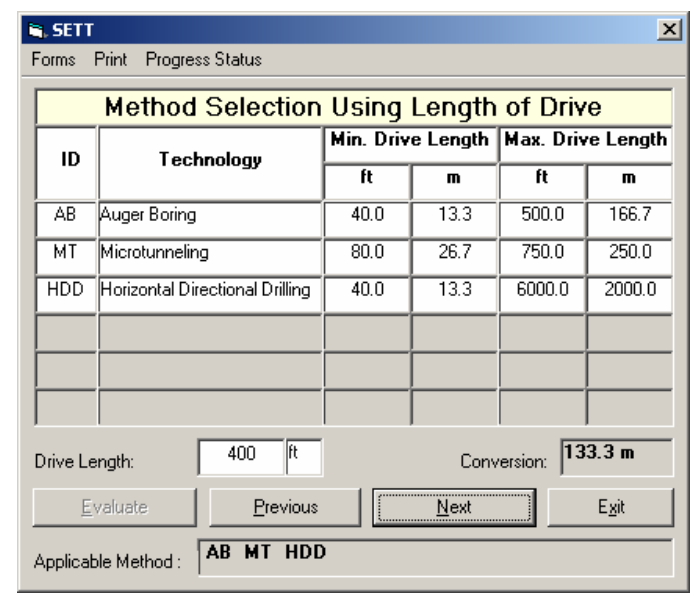

Figure 5.12 Drive length form

\subsubsection{Evaluation of soil conditions}

The users select all soil conditions representing the geotechnical characteristics of the construction site. As shown in Figure 5.13, the soil condition form has four primary alternatives; clay, sand, boulders, and rock. Users can select either of two radio buttons of "detail" and "general." The "detail" radio button can be selected when users have detailed information about soils such as $\mathrm{N}$ values for clay and sand, diameter of boulders, and strength for rocks. If the information is not available, users can select the "general" radio button. By selecting the "general" radio button, users can describe the soil conditions using general terms such as soft clay, hard clay, loose sand, medium sand, and so on. These options are disabled when the form is loaded. When users select clay and sand, and the "detail" radio button, the $\mathrm{N}$ value textbox will be enabled so that users can input the $\mathrm{N}$ 
value of the clay and sand. In the same way, the diameter of boulders and strength textboxes will be enabled when boulders and rock option, and the "detail" radio button are selected, respectively. Otherwise, users can select the soil conditions with general terms for boulders and rocks. With the ground water level, input in the textbox, the SETT will recommend appropriate trenchless technologies based on soil conditions.

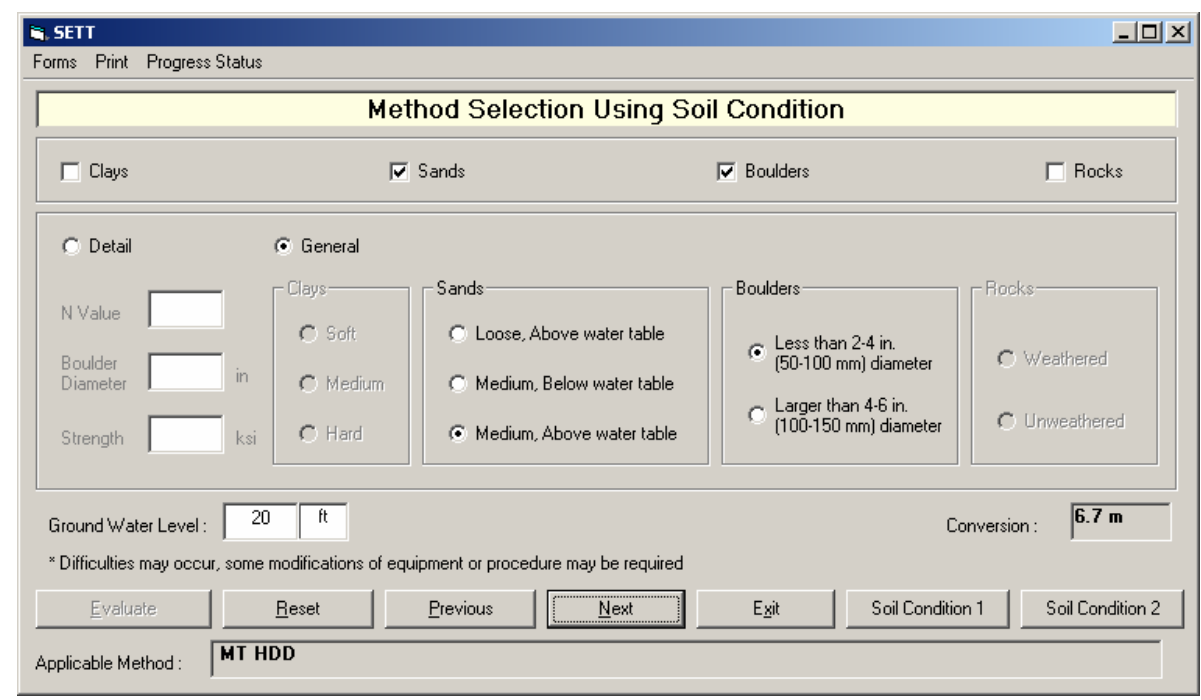

Figure 5.13 Soil condition form

\subsubsection{Evaluation of typical application}

At this stage, the SETT finds the appropriate trenchless technology based on the application areas. HDD will not be recommended for the installation of gravity sewer lines by the SETT. However, other trenchless technologies can be employed for the installation of both gravity and force main sewer lines. MT can be applied primarily for the installation of sewer lines. For other utilities, all the four trenchless methods, i.e., AB, HDD, PJ, and PR, are considered. The layout for this process is shown in Figure 5.14. 


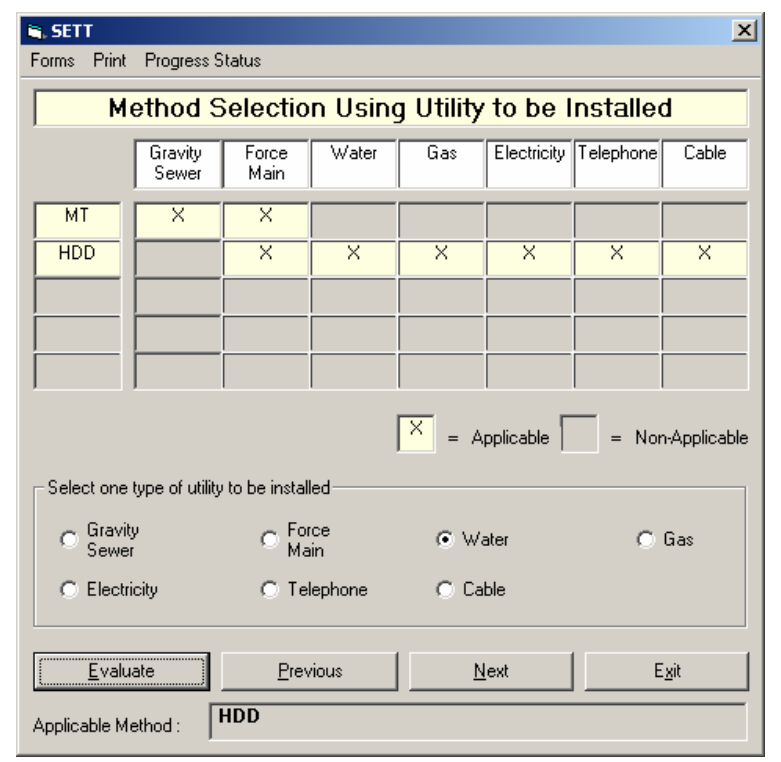

Figure 5.14 Typical application

\subsubsection{Information phase}

Three phases are presented for information; 'Type of pipe,' 'Summary report,' and 'Possible concerns to be addressed during preplanning.' Depending on the designated trenchless technologies and based on common practices, types of pipes that can be used for the project are presented. The types of pipes that can be used for each trenchless technology is summarized in Table 5.7.

Table 5.8 Type of pipe used for trenchless technology

\begin{tabular}{|l|l|}
\hline Trenchless technology & Type of pipe \\
\hline Auger Boring & Steel \\
\hline Horizontal Directional Drilling & HDPE, Steel, PVC \\
\hline Microtunneling & Steel, RCP, GFRP, PCP, VCP, DIP \\
\hline Pipe Ramming & Steel \\
\hline Pipe Jacking & Steel, RCP, GFRP \\
\hline Steel-Steel Casing Pipe \\
HDPE-High Density Polyethylene Pipe \\
PVC-Polyvinyl Chloride Pipe \\
RCP-Reinforced Concrete Pipe \\
GFRP-Glass-Fiber Reinforced Plastic Pipe \\
PCP-Polymer Concrete Pipe \\
VCP-Vitrified Clay Pipe \\
DIP-Ductile Iron Pipe.
\end{tabular}


The form provided by the SETT for type of pipes is shown in Figure 5.15.

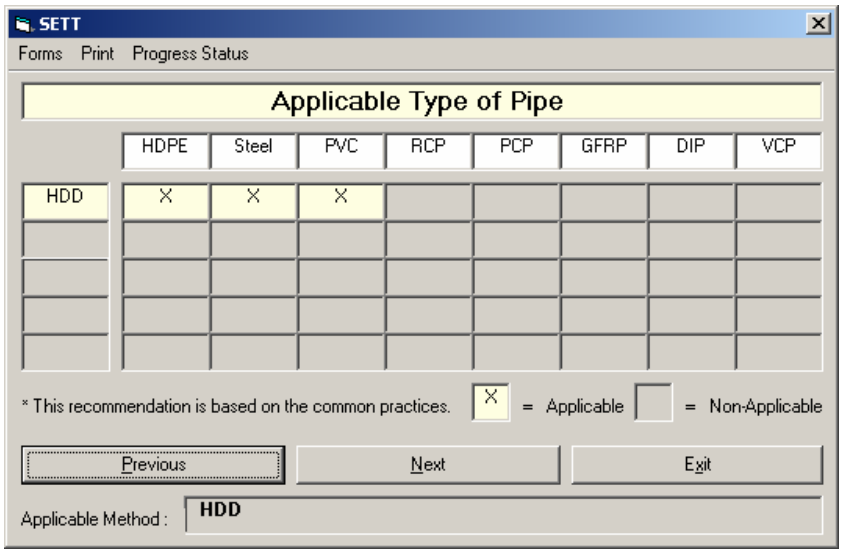

Figure 5.15 Type of pipes used for trenchless technologies

The final summary report, as shown in Figure 5.16, lists the project information (username, project name and location, and contractor), diameter of pipe, depth of installation, drive length, site conditions, soil conditions, recommended type of pipes, and appropriate trenchless technologies that can be used for the planning project.

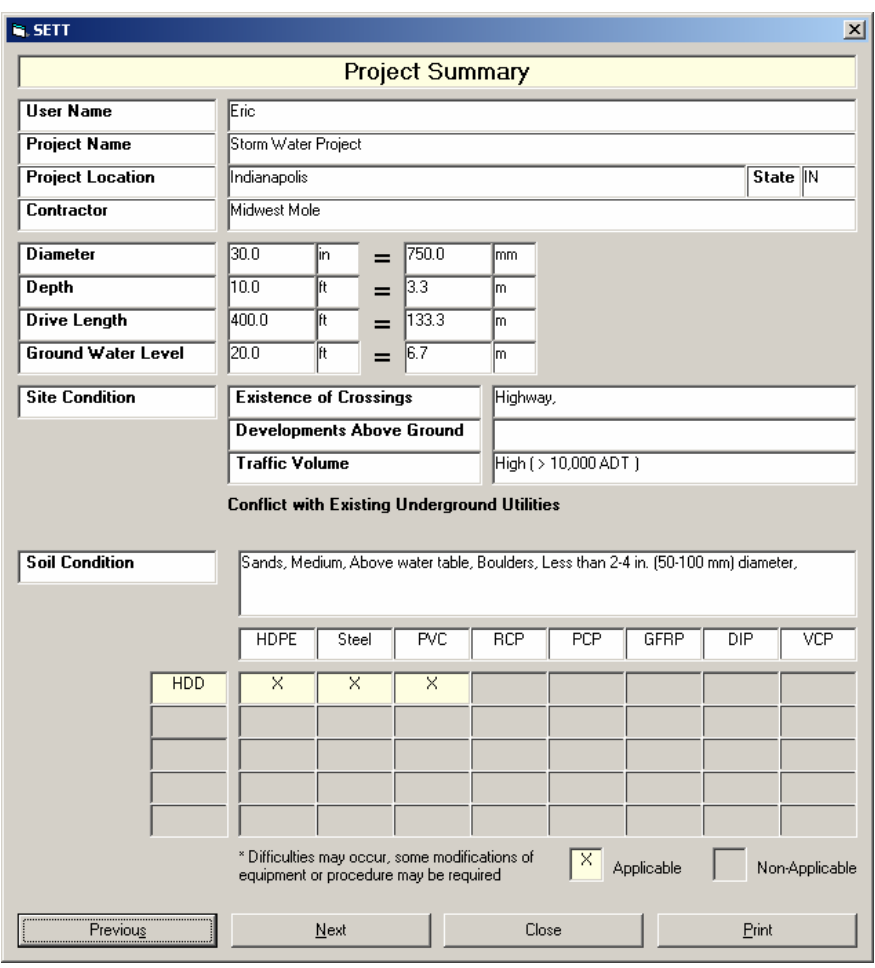

Figure 5.16 Project summary report 
Possible obstacles that are to be addressed during the preplanning phase are presented. These concerns were identified through literature reviews (Allouche et al. 2000, Iseley and Gokhale 1997). Some of the concerns listed below can be applied to the specific trenchless technologies.

\subsection{CASE STUDIES}

5.4.1 CASE STUDY 1: Storm water project crossing ramp of I-65, Indianapolis, IN

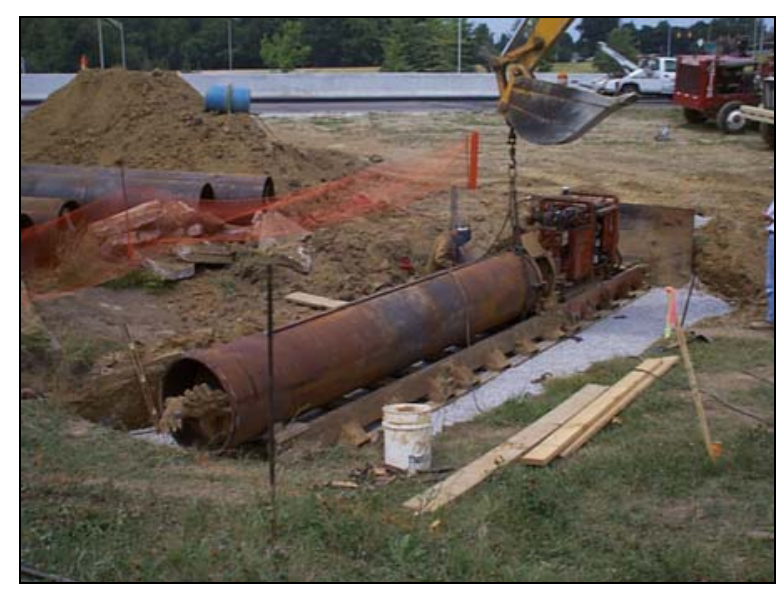

Figure 5.17 Storm water installation using auger boring

The project involved the installation of storm water pipelines under the ramp of Interstate 65 to Kessler Blvd at Indianapolis (Figure 5.17). The Indiana Department of Transportation (INDOT) wanted to install pipes under the ramp to ensure more capacity for their dredging system. Steel pipe of $900 \mathrm{~mm}$ (36 in) (O.D.) was installed for the project. The average depth of installation and drive length were about $3 \mathrm{~m}(10 \mathrm{ft})$ and $22.5 \mathrm{~m}$ (75 ft), respectively. The soil consisted of sand with some larger boulders. The borehole had to be drilled under the existing utility lines (telephone and gas). The input data is summarized in Table 5.8. 
Table 5.9 Data summary for storm water project

\begin{tabular}{|l|l|}
\hline Item & Data \\
\hline Site condition & Crossing (Interstate highway) \\
\hline Diameter of pipe & $900 \mathrm{~mm}(36 \mathrm{in})$ \\
\hline Depth of installation & $3 \mathrm{~m}(10 \mathrm{ft})$ \\
\hline Drive length & $22.5 \mathrm{~m}(75 \mathrm{ft})$ \\
\hline Soil condition & Sand $/$ rocks and boulders \\
\hline
\end{tabular}

The first stage of the decision making process is the evaluation of site conditions. The installation had to cross the ramp of interstate highway (which experienced high traffic volumes). Conflicts with existing underground utility lines were expected. Based on these site conditions, the SETT recommended the use of trenchless technology for this project (Figure 5.18).

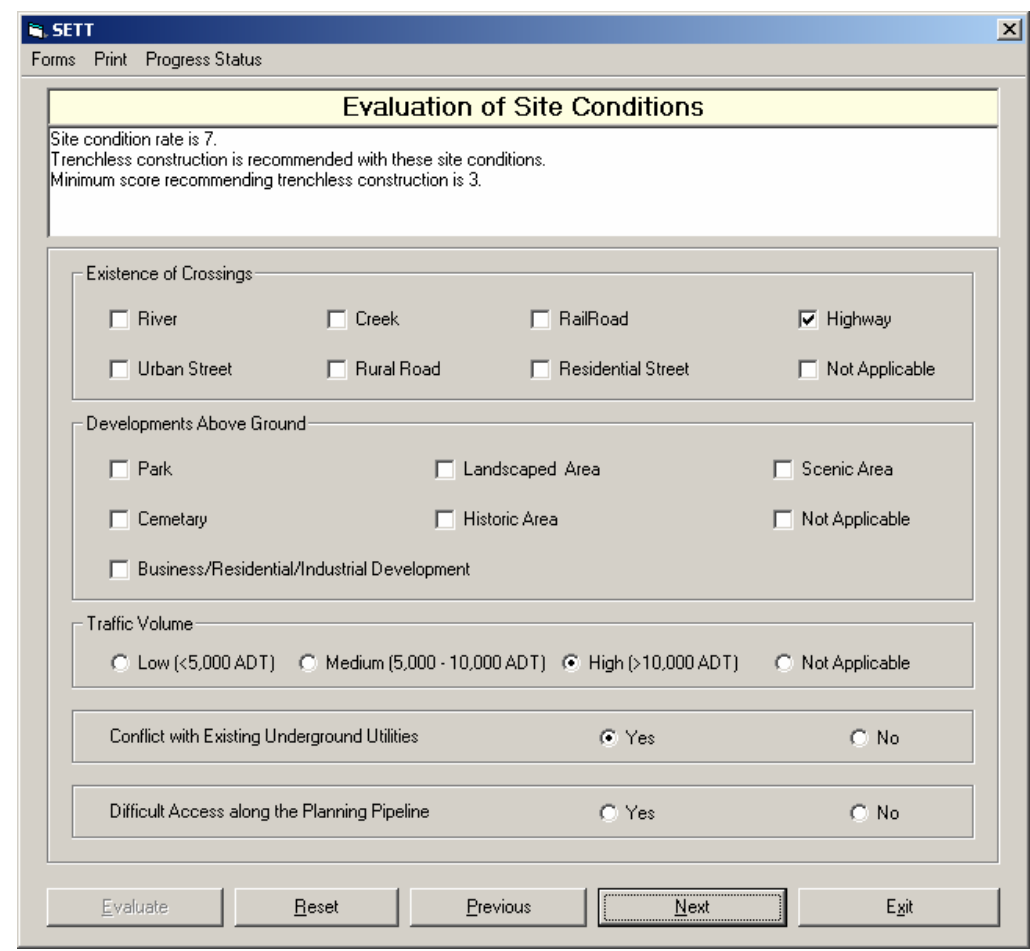

Figure 5.18 The evaluation of site conditions

Since a $900 \mathrm{~mm}$ (36 in) pipe was to be installed, AB, MT, HDD, and PR are deemed to be appropriate for this project as shown in Figure 5.19. The selections are narrowed down by considering other criteria such as depth of installation, drive length, soil conditions, and typical applications. 


\begin{tabular}{|c|c|c|c|c|c|c|}
\hline \multicolumn{7}{|l|}{ G. SETT } \\
\hline \multicolumn{7}{|c|}{ Forms Print Progress Status } \\
\hline \multicolumn{7}{|c|}{ Method Selection Using Diameter of Pipe } \\
\hline \multirow{2}{*}{ ID } & \multirow{2}{*}{\multicolumn{2}{|c|}{ Technology }} & \multicolumn{2}{|c|}{ Min. Diameter } & \multicolumn{2}{|c|}{ Max. Diameter } \\
\hline & & & in & $\mathbf{m m}$ & in & $\mathbf{m m}$ \\
\hline $\mathrm{AB}$ & \multicolumn{2}{|l|}{ Auger Boring } & 8.0 & 200.0 & 60.0 & 1500.0 \\
\hline MT & \multicolumn{2}{|c|}{ Microtunneling } & 10.0 & 250.0 & 120.0 & 3000.0 \\
\hline $\mathrm{HDD}$ & \multicolumn{2}{|c|}{ Horizontal Directional Drilling } & 2.0 & 50.0 & 48.0 & 1200.0 \\
\hline PR & \multicolumn{2}{|c|}{ Pipe Ramming } & 4.0 & 100.0 & 144.0 & 3600.0 \\
\hline \multicolumn{7}{|c|}{ c. English } \\
\hline \multicolumn{7}{|c|}{$\begin{array}{l}\text { Once you select the system of units, then all entries thereafter should be made in the } \\
\text { same system of units. The program will convert the values to the other system of units }\end{array}$} \\
\hline \multicolumn{2}{|c|}{ Diameter of Pipe (ID): } & 36 & & \multicolumn{2}{|c|}{ Conversion: } & $900.0 \mathrm{~mm}$ \\
\hline \multicolumn{2}{|c|}{ Evaluate } & Previous & \multicolumn{2}{|r|}{ Next } & \multicolumn{2}{|r|}{ Exit } \\
\hline \multicolumn{2}{|c|}{ Applicable Method: } & AB MT HDD & PR & & & \\
\hline
\end{tabular}

Figure 5.19 Method selection using diameter of pipe

The results of the evaluation are summarized in a form as shown in Figure 5.20. The final recommendation of the SETT for this project is to use AB or PR. The actual trenchless technology used for the project was AB.

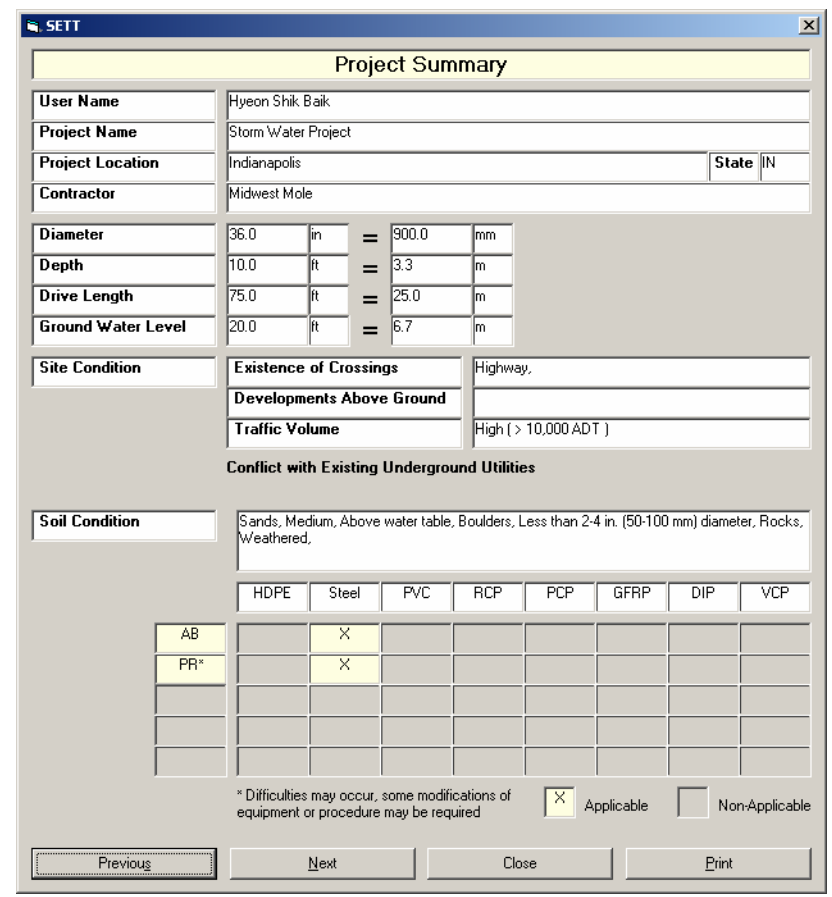

Figure 5.20 Summary of the evaluation results 


\subsubsection{CASE STUDY 2: Gas line project in Zionsville, IN}

This project included the installation of a gas pipeline of $100 \mathrm{~mm}$ (4 in) in diameter in Zionsville, Indiana. The total drive length for this project was 1,470 $\mathrm{m}(4,400$ $\mathrm{ft})$ and one of the drives included the installation of $87 \mathrm{~m}(260 \mathrm{ft})$ of pipeline. The average depth of installation was $1.1 \mathrm{~m}(3.7 \mathrm{ft})$. The pipe was installed across county road 300 and the street had telephone lines under the ground. The soil was dry sand. The overview of the project is shown in Figure 5.21.

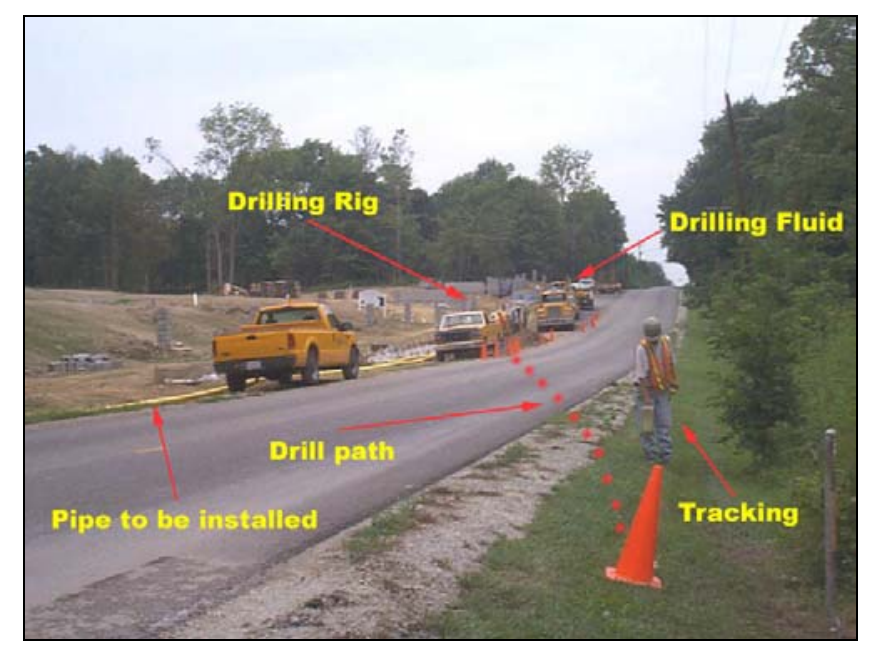

Figure 5.21 Overview of the gas project

The input data for the SETT are summarized in Table 5.9.

Table 5.10 Data summary for gas project

\begin{tabular}{|l|l|}
\hline Item & Data \\
\hline Site condition & Crossing $($ rural road $)$, telephone line \\
\hline Diameter of pipe & $100 \mathrm{~mm}(4 \mathrm{in})$ \\
\hline Depth of installation & $1.1 \mathrm{~m}(3.7 \mathrm{ft})$ \\
\hline Drive length & $87 \mathrm{~m}(260 \mathrm{ft})$ \\
\hline Soil condition & Sand \\
\hline
\end{tabular}

For the selection of appropriate trenchless technologies, the SETT was used to compare the results obtained using the SETT and the technology that was used on the project. Based on the diameter of pipe and depth of installation, the SETT recommends 
the use of either HDD or PR. However, at the stage of selecting appropriate methods using drive length, only HDD is recommended for the project (as shown in Figure 5.22) because PR has a limitation of $60 \mathrm{~m}$ (200 ft) in drive length.

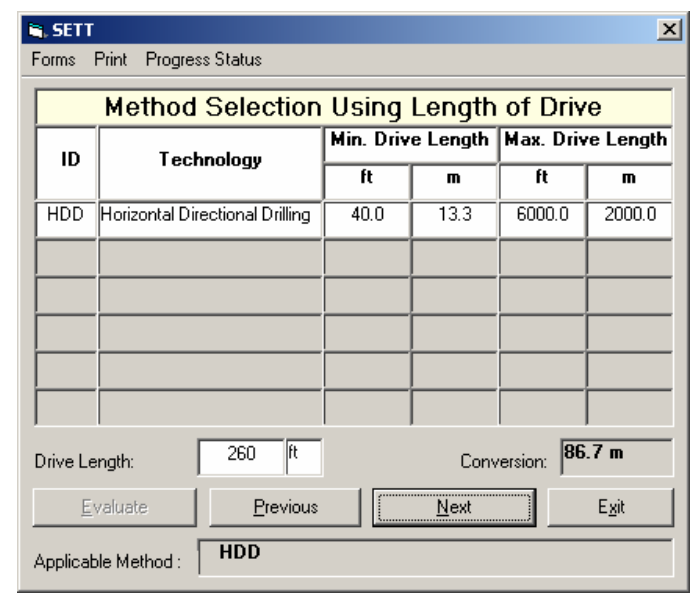

Figure 5.22 Method selection using length of drive

The SETT suggests that HDPE, Steel, and PVC be used for this project. In the Zionsville project HDPE was actually used. The SETT provides the summary of the results and possible concerns that must be addressed during preplanning as shown in Figures 5.23 and 5.24. 


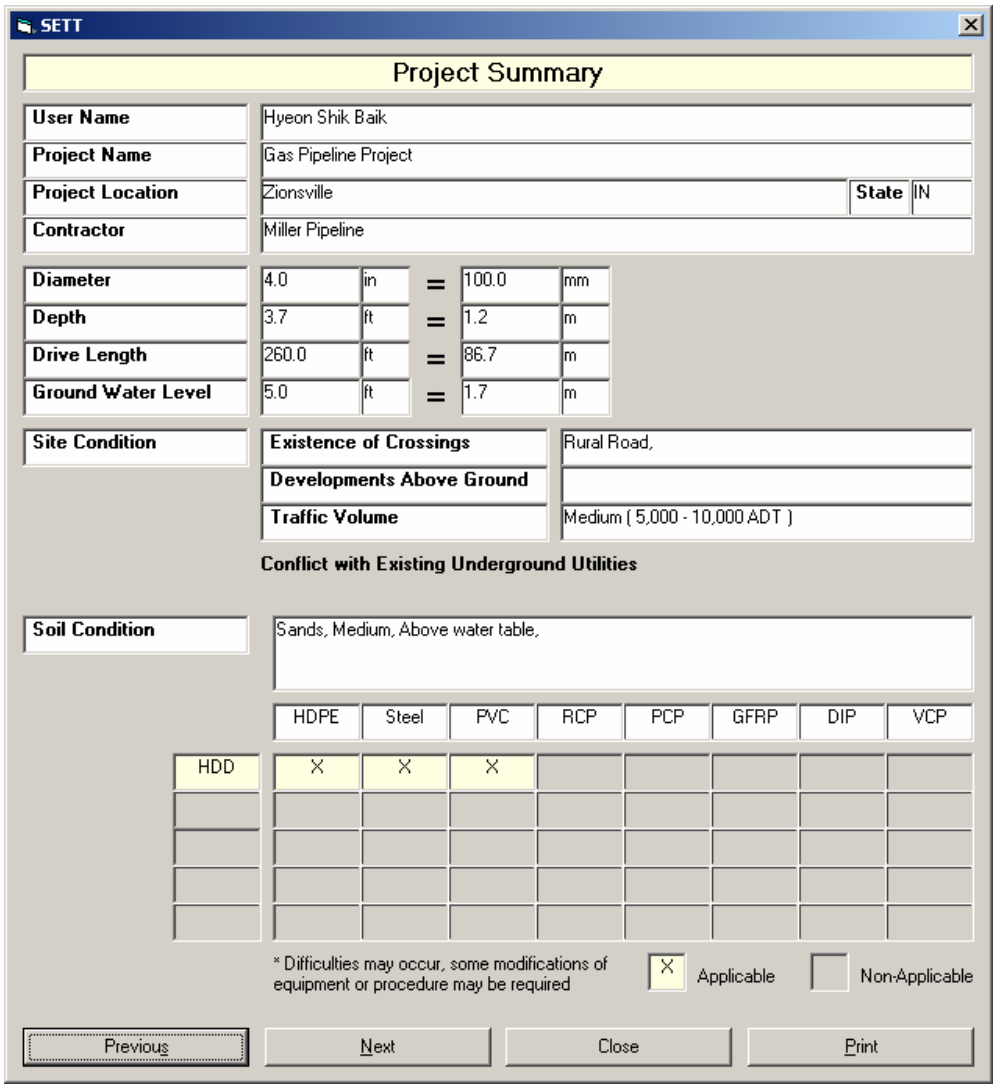

Figure 5.23 Summary of the evaluation results of gas project

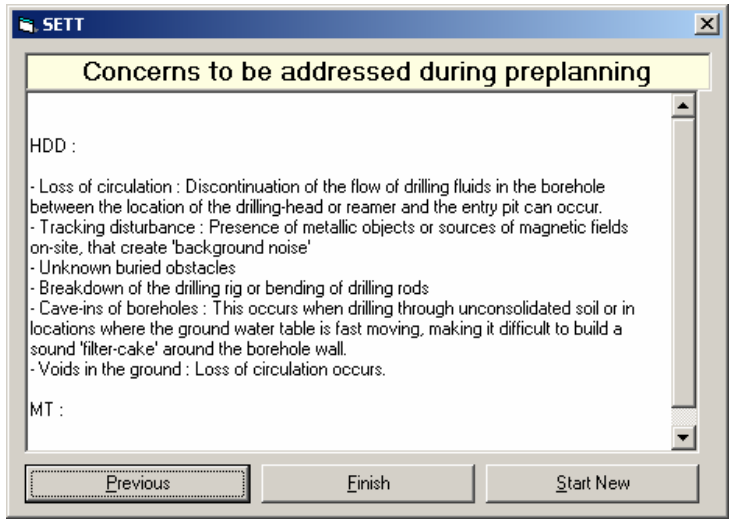

Figure 5.24 Concerns to be addressed during preplanning 


\section{CHAPTER 6 SUMMARY, RECOMMENDATIONS AND IMPLEMENTATION}

\subsection{SUMMARY}

The trenchless technology (TT) industry has expanded from the use of basic road boring techniques to a full range of techniques with highly advanced capabilities for installing complete, complex underground utility systems with minimum excavation. Considerable development in the trenchless technology domain has taken place in the past two decades. By all indications, developments in this sector of the industry will continue. This presents major challenges to those who specify the use of trenchless technologies, and to those who stand to benefit from the use of these technologies These challenges include keeping current with the state-of-the-art and the state-of-practice (i.e., discovering what works and what does not work), and developing design and construction guidelines that result in the use of the "best" trenchless alternative for a particular application.

The safety of the public is at risk when underground utilities intersect with transportation systems. This risk can be managed and minimized by ensuring that only trenchless techniques that are compatible with the parameters of each project are permitted. Protecting public safety is, without question, the responsibility of DOTs (Iseley and Gokhale 1997).

There is no single trenchless technology method that is the "best" for all types of crossings. Site conditions and constraints as well as the purpose of the crossing must be considered when a trenchless alternative is selected and permitted. A full accesscontrolled highway presents different risks and liabilities from urban roads and streets and even limited access-controlled highways. A good understanding of site conditions relies upon extensive surface and subsurface investigations. Accurate, sufficient subsurface data that describe anticipated conditions throughout the borehole length should be required.

Table 6.1 presents brief descriptions of the trenchless methods, analyzed during the course of this study. This table provides basic information about these methods when 
they are considered as "possible construction methods" for the installation of conduits under roadways.

Table 6.1 Description of trenchless construction methods (Iseley and Gokhale 1997)

Method Type Method description

1. Techniques not requiring personnel entry

A technique that forms a borehole from a drive shaft to a reception shaft by means of a rotating cutting head. Soil is transported back to the drive shaft by helical wound auger flights rotating inside a steel Auger Boring (AB) casing that is being jacked in place simultaneously. AB may provide limited tracking and steering capability. The casing provides continuous support of the bore hole, but ground support at the excavation face is limited. AB is typically a 2 -stage process (i.e., casing installation and product pipe installation).

Horizontal Directional Drilling (HDD)

Microtunneling (MT)

Pipe Ramming (PR)
A 2-stage process that consists of drilling a small diameter pilot directional hole along a predetermined path and then developing the pilot hole into a suitable bore hole that will accommodate the desired utility and then pulling the utility into place. The HDD process provides the ability to track the location of the drill bit and steer it during the drilling process. The vertical profile of the borehole is typically in the shape of an arc entrapping drilling fluid to form a slurry pathway rather that an open hole. This entrapped slurry provides continuous support to bore hole.

A remotely controlled, guided pipe jacking process that provides continuous support to the excavation face. The guidance system usually consists of a laser mounted in the drive shaft communicating a reference line to a target mounted inside the MT machine's articulated steering head. The MT process provides ability to control excavation face stability by applying mechanical or fluid pressure to counterbalance the earth and hydrostatic pressures.

A technique for installing steel casings from a drive shaft to a reception shaft utilizing the dynamic energy from a percussion hammer attached to the end of the pipe. A continuous casing support is provided and over excavation at the face is generally prohibited. This method has very limited tracking and steering capability. This is a 2-stage process. 
2. Technique requiring personnel entry

A pipe is jacked horizontally through the ground from the drive shaft to the reception shaft. People are required inside the pipe to perform the excavation and/or spoil removal. The excavation can be

Pipe Jacking (PJ) accomplished manually or mechanically with tunnel boring machines or shield mounted excavator arms. Tunnel shields can provide articulated steering. Generally, guidance is provided via a laser mounted in the drive shaft which communicates a reference line to a target at the face.

Table 6.2 provides an overview of trenchless technology methods. The table presents the following information on each method: (1) range of applications (i.e., depth, length, and diameter), (2) primary application, (3) type of pipe, (4) accuracy, (5) working space requirement, and (6) primary limitations. 
Table 6.2 Overview of trenchless technology methods (Iseley and Gokhale 1997)

\begin{tabular}{|c|c|c|c|c|}
\hline \multirow{2}{*}{ Method } & \multicolumn{3}{|c|}{ Range of Applications } & \multirow{2}{*}{ Primary Application } \\
\hline & Depth & Length & Diameter & \\
\hline Auger Boring (AB) & Varies & $\begin{array}{l}12-150 \mathrm{~m} \\
(40-500 \mathrm{ft})\end{array}$ & $\begin{array}{l}200-1,500 \mathrm{~mm} \\
(8-60 \mathrm{in})\end{array}$ & Crossings (All types) \\
\hline $\begin{array}{l}\text { Horizontal Directional } \\
\text { Drilling (HDD) }\end{array}$ & $\begin{array}{l}<15 \mathrm{~m}(50 \mathrm{ft}) \text { with } \\
\text { walkover system }\end{array}$ & $\begin{array}{l}12-1,800 \mathrm{~m} \\
(40-6,000 \mathrm{ft})\end{array}$ & $\begin{array}{l}50-1,200 \mathrm{~mm} \\
(2-48 \mathrm{in})\end{array}$ & $\begin{array}{l}\text { Pressure lines, water, gas, } \\
\text { cable }\end{array}$ \\
\hline Microtunneling (MT) & Varies & $\begin{array}{l}25-225+\mathrm{m} \\
(80-750+\mathrm{ft})\end{array}$ & $\begin{array}{l}250-3,000 \mathrm{~mm} \\
(10-120 \mathrm{in})\end{array}$ & Sewer installations \\
\hline Pipe Ramming (PR) & Varies & $\begin{array}{l}12-60 \mathrm{~m} \\
(40-200 \mathrm{ft})\end{array}$ & $\begin{array}{l}100-1,070 \mathrm{~mm} \\
(4-42 \mathrm{in})\end{array}$ & Crossings \\
\hline Pipe Jacking (PJ) & Varies & $\begin{array}{l}\text { No theoretical limit- } \\
490 \mathrm{~m}(1,600 \mathrm{ft})\end{array}$ & $\begin{array}{l}1,060-3,000 \mathrm{~mm} \\
(42-120 \mathrm{in})\end{array}$ & $\begin{array}{l}\text { Sewers, Pressure lines, } \\
\text { Crossings }\end{array}$ \\
\hline
\end{tabular}


Table 6.2 Overview of TT methods (Continued)

\begin{tabular}{|c|c|c|c|c|}
\hline Method & Type of Pipe & Accuracy & Working Space Requirement & Primary Limitations \\
\hline Auger Boring (AB) & Steel & Medium & $\begin{array}{l}\text { Entry \& Exit pits. Length 8-11 m (26- } \\
36 \mathrm{ft})\end{array}$ & $\begin{array}{l}\text { High capital cost for equipment, high } \\
\text { setup cot (bore pits); can not be sued in } \\
\text { set runny sands, soil with large } \\
\text { boulders }\end{array}$ \\
\hline $\begin{array}{l}\text { Horizontal Directional } \\
\text { Drilling (HDD) }\end{array}$ & $\begin{array}{l}\text { HDPE, Steel, } \\
\text { PVC }\end{array}$ & Medium & $\begin{array}{l}\text { Access pits not required. Space for set } \\
\text { up of rig and drilling fluid tank: } 120 \mathrm{~m} \\
\text { x } 60 \mathrm{~m}(400 \mathrm{ft} \times 200 \mathrm{ft})\end{array}$ & $\begin{array}{l}\text { Requires very high degree of operator } \\
\text { skill. Not suitable for high degree of } \\
\text { accuracy such as gravity sewer } \\
\text { application. Accuracy dependent on } \\
\text { the capacity of tracking system. }\end{array}$ \\
\hline Microtunneling (MT) & $\begin{array}{l}\text { Steel, RCP, } \\
\text { GFRP, PCP, } \\
\text { VCP, DIP }\end{array}$ & High & $\begin{array}{l}\text { Primary jacking pit: } 4 \mathrm{~m}(20 \mathrm{ft}) \text { long, } 3 \\
\mathrm{~m}(10 \mathrm{ft}) \text { wide. Smaller retrieval pit }\end{array}$ & High capital cost and setup costs \\
\hline Pipe Ramming (PR) & Steel & Low & $\begin{array}{l}\text { Large surface area required to } \\
\text { accommodate bore pit, excavated soil, } \\
\text { air compressor, pipe to be installed, } \\
\text { etc. }\end{array}$ & $\begin{array}{l}\text { No control over line and grade. A large } \\
\text { piece of rock or boulder can easily } \\
\text { deflect pipe from design path. Pipe has } \\
\text { tendency to drop and/or come up to the } \\
\text { surface. For larger pipe diameters } \\
\text { equipment cost increases substantially }\end{array}$ \\
\hline Pipe Jacking (PJ) & $\begin{array}{l}\text { Steel, RCP, } \\
\text { GFRP }\end{array}$ & High & $\begin{array}{l}\text { Jacking pit is a function of pipe size. } \\
\text { Pie sized vary from } 3-9 \mathrm{~m}(10-30 \mathrm{ft})\end{array}$ & $\begin{array}{l}\text { Specialized operation requiring great } \\
\text { deal of planning and coordination. } \\
\text { High capital cost. }\end{array}$ \\
\hline
\end{tabular}


Specifications for the use of trenchless technologies by the Indiana Department of Transportation (INDOT) were developed with assistance from the Study Advisory Committee and other INDOT personnel. These specifications will replace Section 716 in the current INDOT Specifications, and will be utilized for the designs of trenchless construction, issuances of permits and inspections of the trenchless works.

A survey conducted in 1996 indicated that trenchless technology use by U.S. and Canadian transportation agencies increased from 1993 to 1995. Survey respondents represented 33 states and 6 provinces. Seventy-three (73\%) indicated that they had received no training in trenchless technology. Those who had received trenchless technology training indicated that the training consisted primarily of demonstrations by equipment manufacturers and contractors. Thus, this training was not comprehensive and tended to be more promotional than educational in nature (Iseley and Gokhale, 1997). A multimedia educational tool was developed to assist INDOT personnel who are relatively unfamiliar with trenchless technologies in learning more about these technologies. Brief descriptions for the trenchless technologies are presented in html files that contain hyperlinks to the photographs and video clips captured from site visits.

The selection of trenchless methods is site specific and highly dependent on subsurface conditions. In addition, the selection of appropriate trenchless methods requires the consideration of factors, such as depth of installation, drive length, diameter of the utility, etc. The selection process can be challenging to those who are not familiar with the features of different trenchless technologies. To facilitate the selection process, a Decision Support System, named Selection and Evaluation of Trenchless Technologies (SETT) was developed during the course of this study. Six primary criteria were identified for decision-making regarding the use of trenchless technology. These include: site conditions, diameter of pipe, depth of installation, drive length, soil conditions, and typical applications. Information generated through the use of SETT is stored in a Microsoft Access database file; and this database can be accessed for further analyses. 


\subsection{RECOMMENDATIONS FOR FUTURE WORK}

a) Regular updating of the criteria in the decision support tool, and descriptions in the multimedia education tool

SETT, the decision support tool developed during the course of this study, provides a framework to assist INDOT engineers and other asset managers in the preliminary evaluation of trenchless technology alternatives during the planning and design stages of a project. This tool does not include details about different equipment, modes of operation, and detailed cost factors associated with the use of these technologies. As advancements are made in trenchless technologies and as INDOT personnel use trenchless technologies and collect data regarding their experiences with the use of these technologies, the criteria table in the decision support tool, SETT, and the descriptions in the multimedia education tool, should be updated to reflect these advancements.

b) Regular evaluation and updating of specifications related to trenchless technologies

Prior to March 2002, the last updates in Section 716 - Trenchless Pipe Installations in the INDOT Specifications Manual were done in 1990. It is crucial that the impacts of the advancements in trenchless technologies, on their design, installation and inspection be revisited frequently. In addition to making the specifications more relevant and current, it will also provide INDOT with more value-added products in the form of improved technologies and services.

c) Investigation of the utility accommodation policy

During the course of this study, several members of the Study Advisory Committee suggested that the research team undertake an evaluation of INDOT's Utility Accommodation Policy, since the specifications for the use of trenchless technologies could have significant influence on the utility accommodation policy. Hence, a research needs statement (RNS) related to this issue was 
prepared and submitted to the Joint Transportation Research Board (JTRB) in April 2002.

d) Evaluation of the effectiveness of SETT and the multimedia education tool

The research team and the Study Advisory Committee felt that it would be prudent to perform an evaluation of the utilization of the decision tool, SETT and the multimedia education tool, after they have been deployment. Such an evaluation will provide valuable information when updates are planned on these tools.

\subsection{IMPLEMENTATION OF THE FINDINGS OF THE STUDY}

Personnel from the Information Technology group at INDOT have been involved with the research team and the Study Advisory Committee regarding implementation issues. The source code of Decision Support Tool, SETT, will be transferred to Mr. James Synder, INDOT Information Technology group. The multimedia educational tool will be hosted on the JTRP server. Issues related to the updating of the technical details in SETT and the descriptions in multimedia educational tool have not been finalized. The specifications developed as part of this study have been adopted by the INDOT Specifications Committee and are available to INDOT engineers. 


\section{APPENDIX A: PART OF VISUAL BASIC CODE}

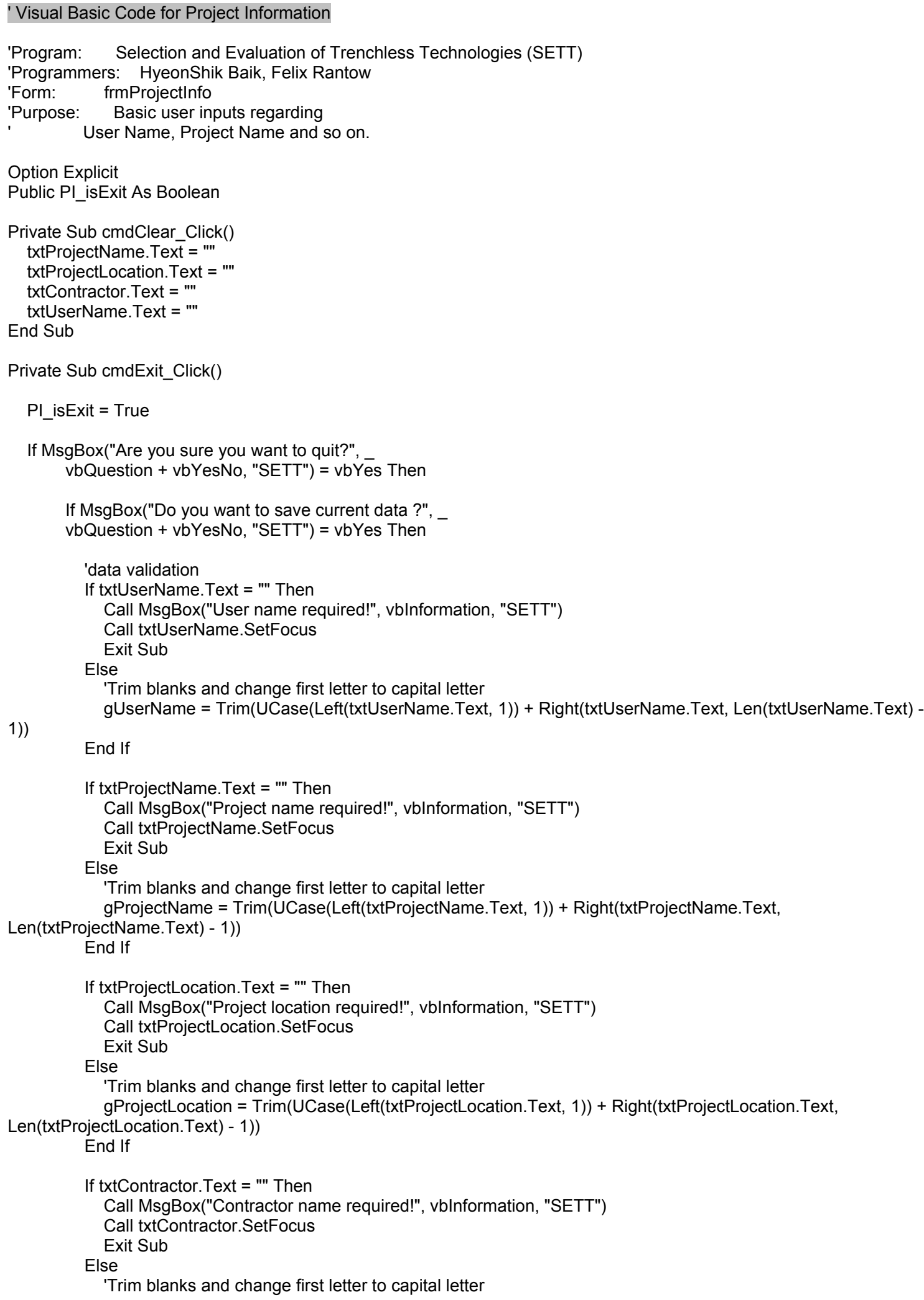


1))

gContractor $=$ Trim $($ UCase $($ Left $(t x t$ Contractor. Text, 1) $)+$ Right(txtContractor. Text, Len(txtContractor. Text) -

End If

gState $=$ cboState. Text

If (glsPreviousProject) Then

Call updateRecord

Else

Call addRecord

End If

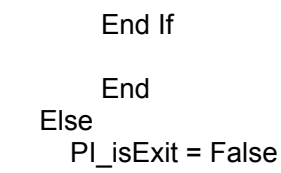

End If

End Sub

Private Sub cmdNewProject_Click()

PI_isExit $=$ True

'Data Validation

If txtUserName.Text = "'" Then

Call MsgBox("User name required!", vblnformation, "SETT")

Call txtUserName.SetFocus

Exit Sub

Else

'Trim blanks and change first letter to capital letter

gUserName $=$ Trim $($ UCase $($ Left(txtUserName.Text, 1) $)+$ Right(txtUserName.Text, Len(txtUserName.Text) -1$))$

End If

If txtProjectName. Text = "'" Then

Call MsgBox("Project name required!", vblnformation, "SETT")

Call txtProjectName.SetFocus

Exit Sub

Else

'Trim blanks and change first letter to capital letter

1))

gProjectName $=$ Trim $($ UCase $($ Left(txtProjectName.Text, 1) $)+$ Right(txtProjectName.Text, Len(txtProjectName.Text) -

End If

If txtProjectLocation. Text $=$ "'" Then

Call MsgBox("Project location required!", vblnformation, "SETT")

Call txtProjectLocation.SetFocus

Exit Sub

Else

'Trim blanks and change first letter to capital letter

gProjectLocation $=$ Trim(UCase $($ Left(txtProjectLocation. Text, 1)) + Right(txtProjectLocation.Text, Len(txtProjectLocation. Text) - 1))

End If

If txtContractor.Text $=$ "'" Then

Call MsgBox("Contractor name required!", vblnformation, "SETT")

Call txtContractor.SetFocus

Exit Sub

Else

'Trim blanks and change first letter to capital letter

gContractor $=\operatorname{Trim}($ UCase $($ Left(txtContractor. Text, 1) $)+$ Right(txtContractor. Text, Len(txtContractor.Text) -1$))$

End If

gState $=$ cboState. Text

Call frmSiteCon.Show

Unload frmProjectInfo 
End Sub

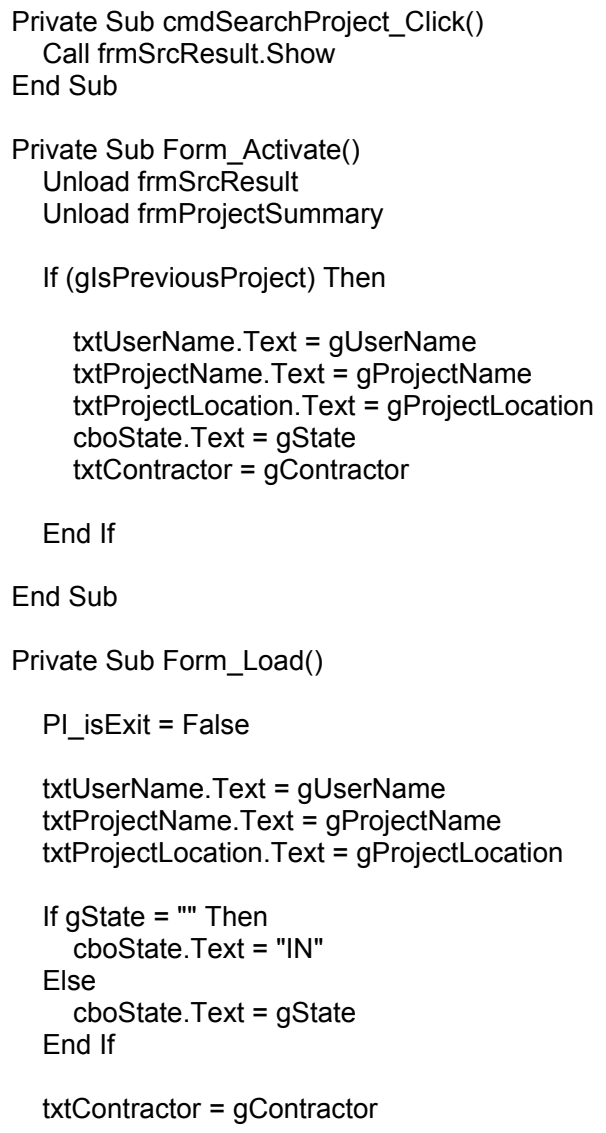

End Sub

Private Sub Form_QueryUnload(Cancel As Integer, UnloadMode As Integer) If Not PI_isExit Then

If MsgBox("Are you sure you want to quit?", vbQuestion + vbYesNo, "SETT") = vbYes Then

If MsgBox("Do you want to save current data ?", vbQuestion + vbYesNo, "SETT") = vbYes Then

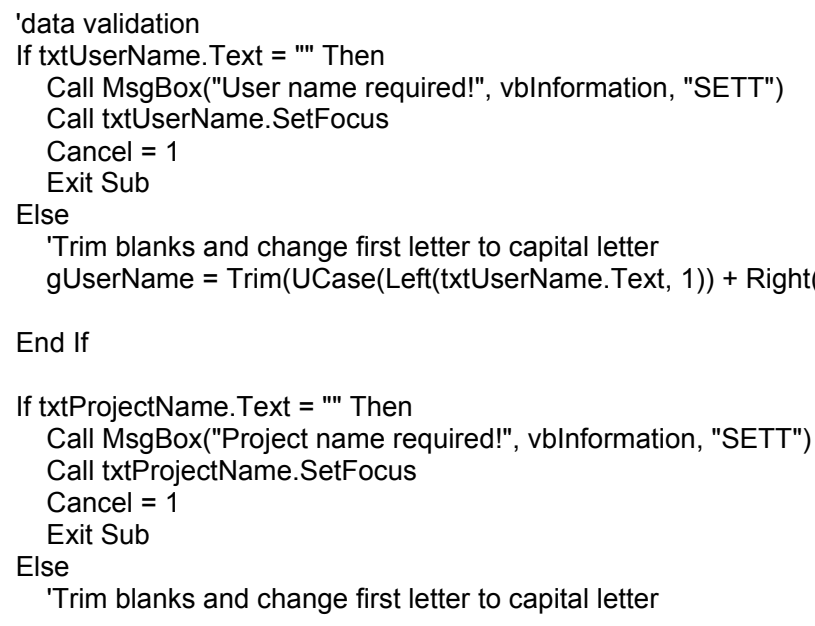


Len(txtProjectName.Text) - 1))

gProjectName $=$ Trim $($ UCase $($ Left $($ txtProjectName.Text, 1$))+$ Right $($ txtProjectName. Text,

End If

If txtProjectLocation. Text $=$ "' Then

Call MsgBox("Project location required!", vblnformation, "SETT")

Call txtProjectLocation.SetFocus

Cancel $=1$

Exit Sub

Else

'Trim blanks and change first letter to capital letter

gProjectLocation $=$ Trim $($ UCase $($ Left(txtProjectLocation. Text, 1) $)+$ Right(txtProjectLocation. Text,

Len(txtProjectLocation.Text) - 1))

End If

If txtContractor. Text $=$ "' Then

Call MsgBox("Contractor name required!", vblnformation, "SETT")

Call txtContractor.SetFocus

Cancel $=1$

Exit Sub

Else

'Trim blanks and change first letter to capital letter

1))

gContractor $=$ Trim(UCase $($ Left(txtContractor.Text, 1) $)+$ Right(txtContractor.Text, Len(txtContractor.Text) -

\section{End If}

gState $=$ cboState. Text

If (glsPreviousProject) Then

Else

Call updateRecord

Call addRecord

End If

End If

End

Else

Cancel $=1$

End If

End If

End Sub

Private Sub IblState_Click()

End Sub 


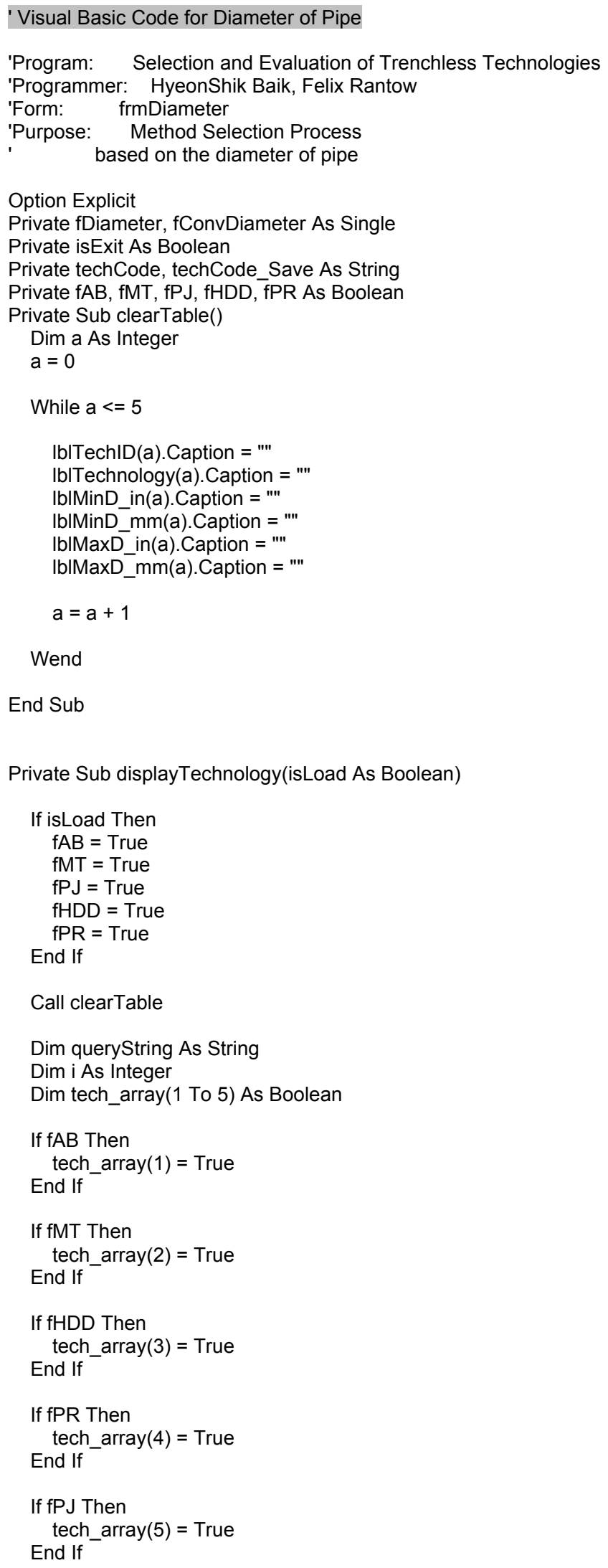

Private fDiameter, fConvDiameter As Single

Private isExit As Boolean

Private techCode, techCode_Save As String

Private $\mathrm{fAB}, \mathrm{fMT}$, fPJ, fHDD, fPR As Boolean

Private Sub clearTable()

Dim a As Integer

$a=0$

While $\mathrm{a}<=5$

Wend

End Sub

Private Sub displayTechnology(isLoad As Boolean)

Call clearTable

Dim queryString As String

Dim i As Integer

Dim tech_array(1 To 5) As Boolean

If $f A B$ Then

tech $\operatorname{array}(1)=$ True

End If

If fMT Then

tech_array $(2)=$ True

End If

If fHDD Then

End If

If fPR Then

tech_array $(4)=$ True

End If

If fPJ Then

tech_array $(5)=$ True

End If 


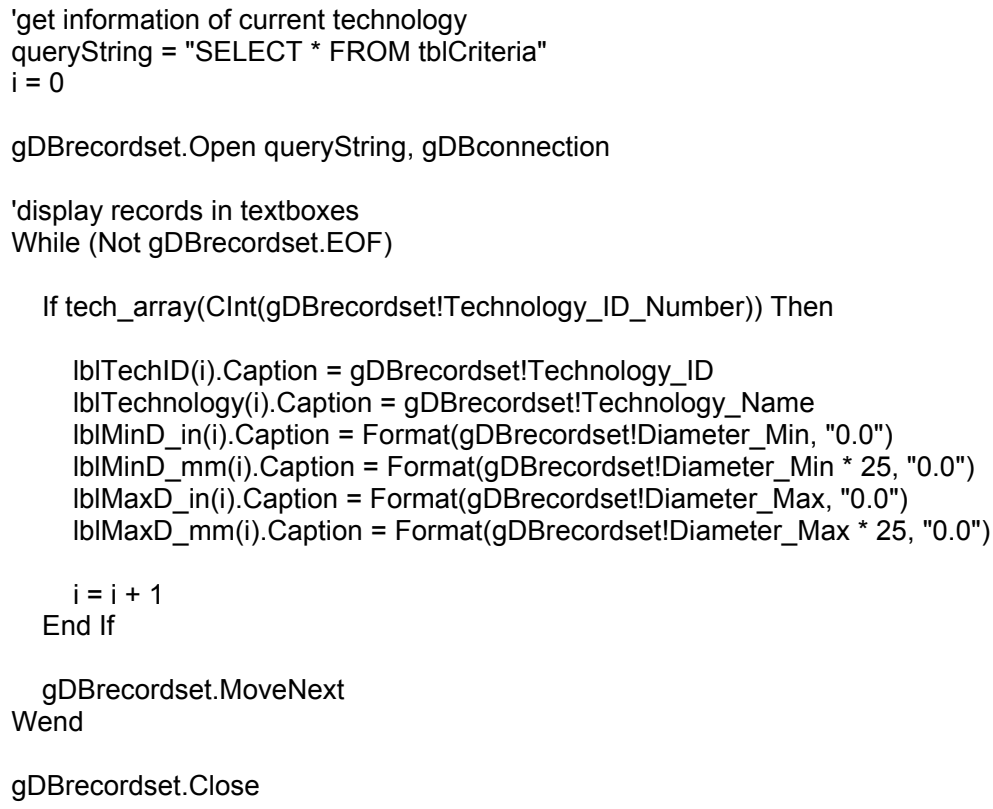

Wend

End Sub

Private Sub cmdEvaluate_Click()

'Data validation

If txtDiameter. Text = "' Then

Call MsgBox("Data input required!", vbCritical, "SETT")

Call txtDiameter.SetFocus

Elself IsNumeric(txtDiameter.Text) $=$ False Then

Call MsgBox("Numerical data required!", vbCritical, "SETT")

txtDiameter.Text $=$ ""

Call txtDiameter.SetFocus 


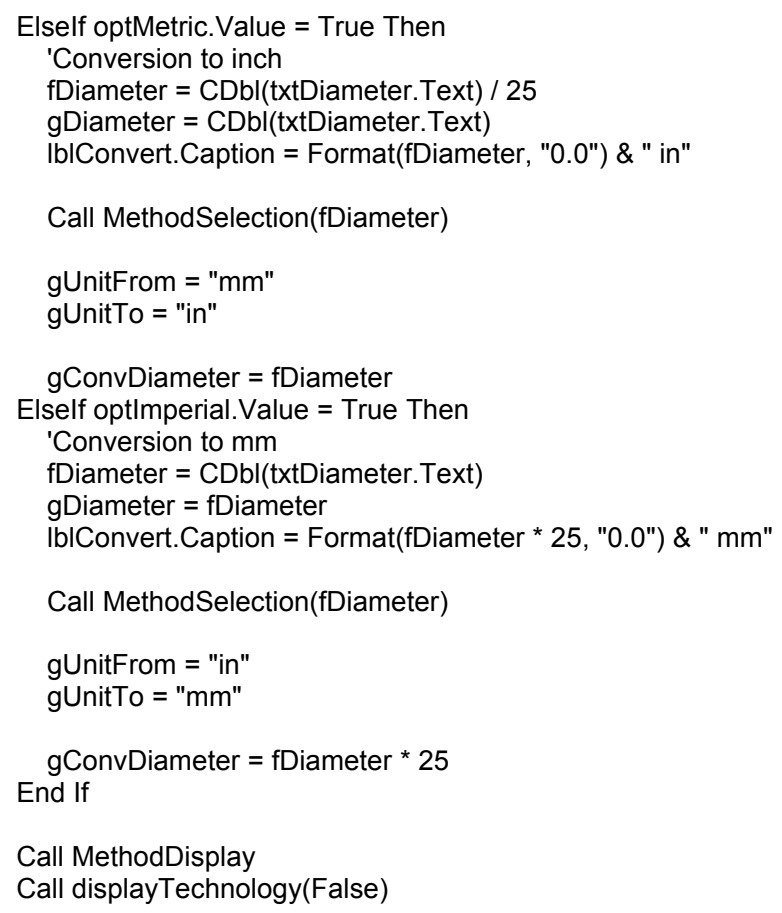

End Sub

Private Sub cmdExit_Click()

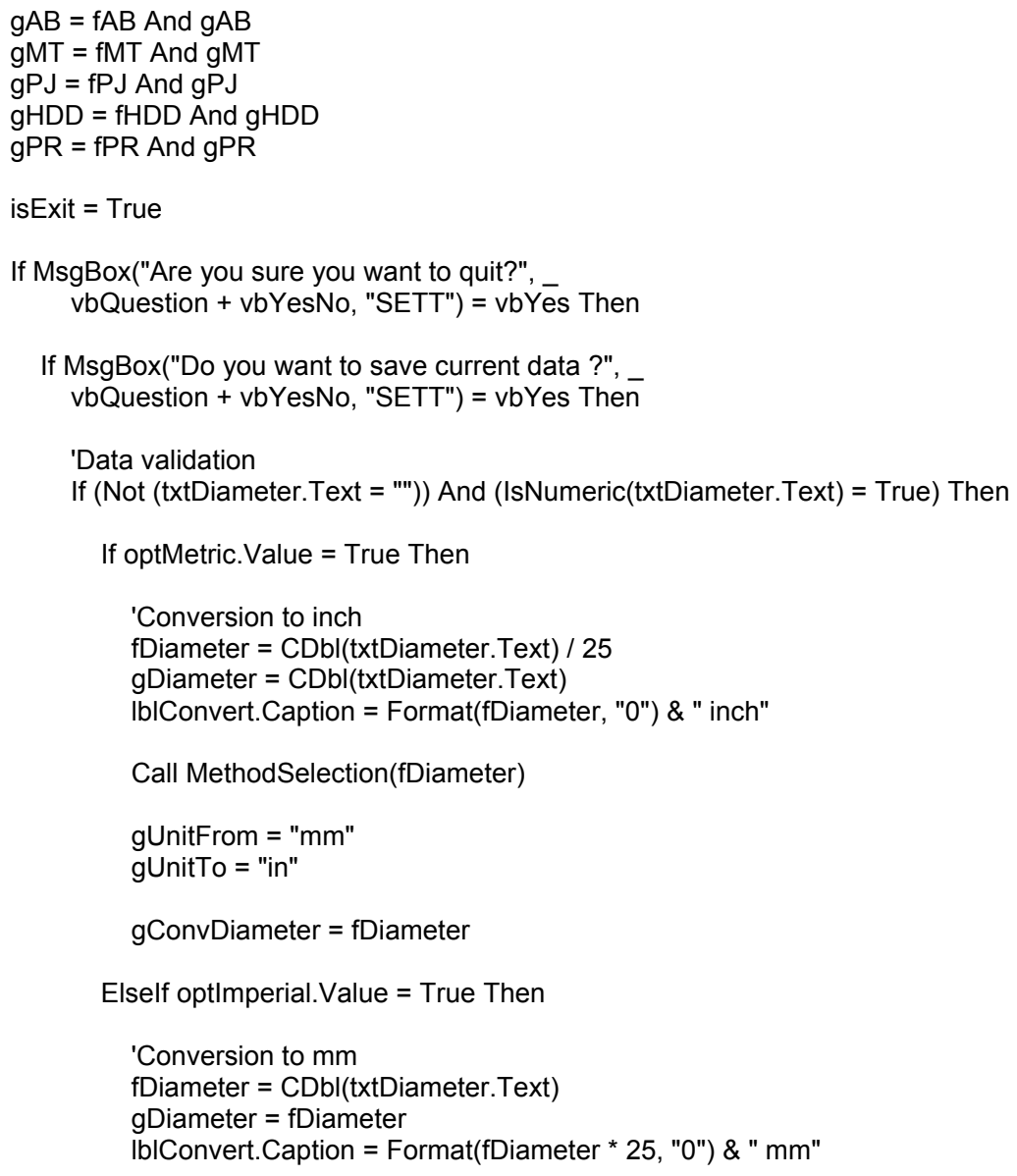




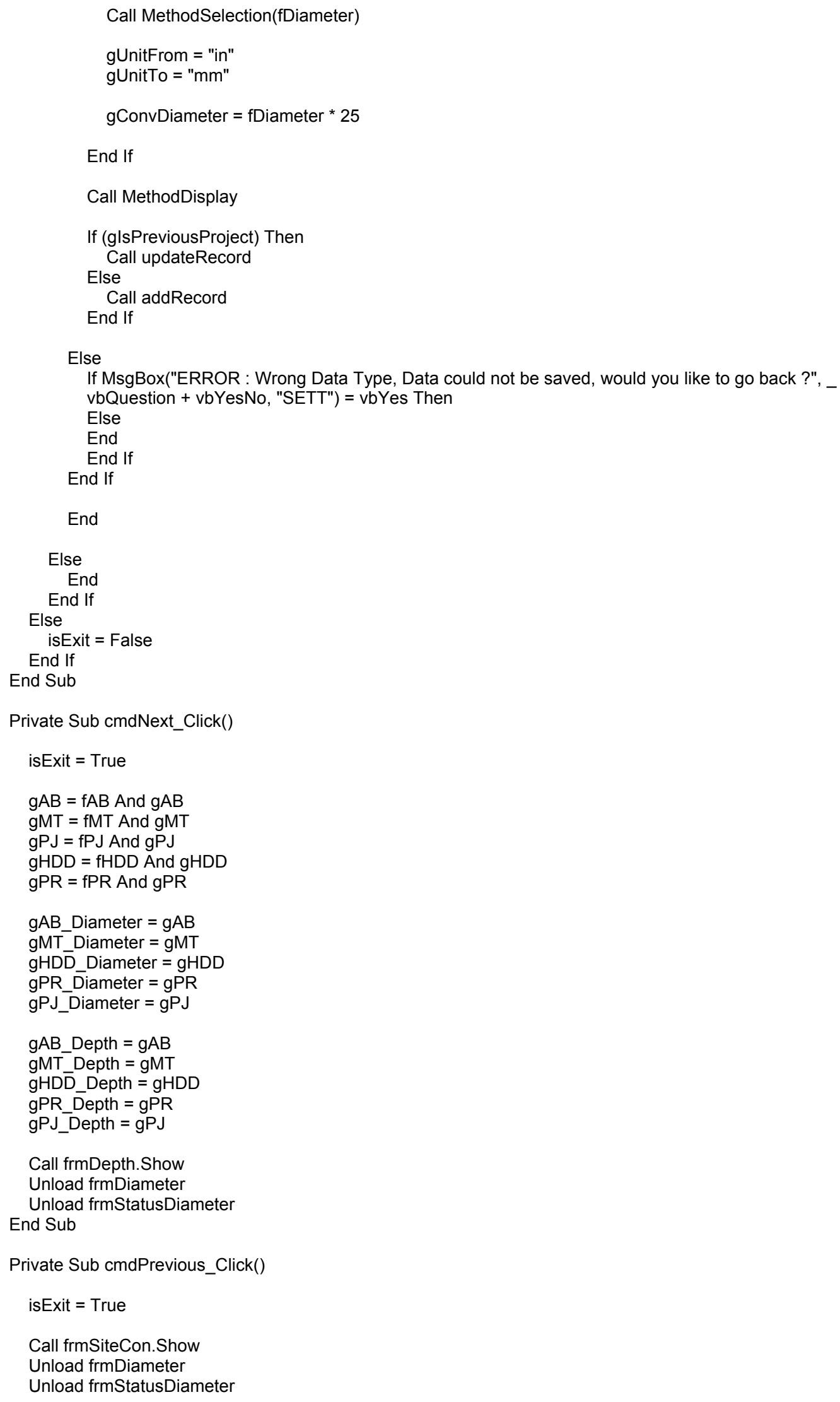

Private Sub cmdNext_Click()

isExit $=$ True

$g A B=f A B$ And $g A B$ 
End Sub

Private Sub Form_Load()

isExit $=$ False

fDiameter $=0$

cmdNext. Enabled $=$ False

mnuNext. Enabled $=$ False

IbIDiameterUnit.Caption = "in"

If gDiameter $=0$ Then

txtDiameter.Text $=$ " "

Else

txtDiameter.Text $=$ Format $(g D i a m e t e r, ~ " 0.0 ")$

End If

If (gUnitFrom <> "') Then

IblDiameterUnit.Caption = gUnitFrom

End If

If $\mathrm{gConvDiameter}=0$ Then

IblConvert.Caption = Format("'", "0.0") \& gUnitTo

Else

IblConvert.Caption = Format(gConvDiameter, "0.0") \& " " \& gUnitTo

End If

$\mathrm{fAB}=\mathrm{gAB}$ Diameter

$\mathrm{fMT}=$ gMT_Diameter

fHDD = gHDD Diameter

$\mathrm{fPR}=\mathrm{gPR}$ Diameter

$\mathrm{fPJ}=\mathrm{gPJ}$ Diameter

$\mathrm{gAB}=\mathrm{gAB}$ Diameter

gMT = gMT_Diameter

$\mathrm{gHDD}=\mathrm{gHDD}$ Diameter

gPR = gPR_Diameter

gPJ $=$ gPJ_Diameter

Call displayTechnology(False)

Call MethodDisplay

End Sub

Private Sub Form_QueryUnload(Cancel As Integer, UnloadMode As Integer)

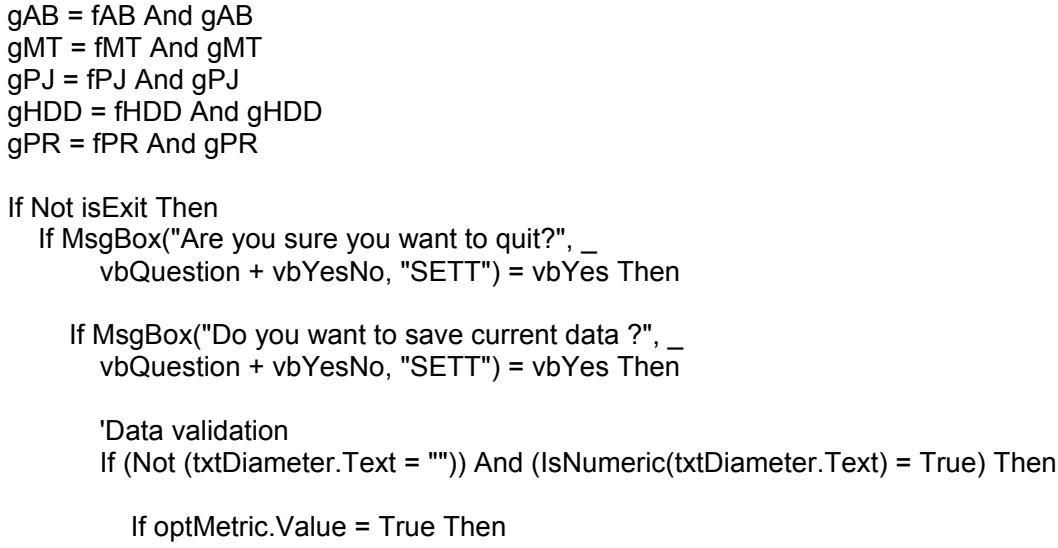


Call MethodSelection(fDiameter)

gUnitFrom = "mm"

gUnitTo = "in"

gConvDiameter $=$ fDiameter

Elself optImperial. Value $=$ True Then

'Conversion to $\mathrm{mm}$

fDiameter $=\mathrm{CDbl}($ txtDiameter .Text $)$

gDiameter $=$ fDiameter

IblConvert.Caption = Format(fDiameter * 25, "0") \& " mm"

Call MethodSelection(fDiameter)

gUnitFrom = "in"

gUnitTo = "mm"

gConvDiameter $=$ fDiameter ${ }^{*} 25$

End If

Call MethodDisplay

If (glsPreviousProject) Then

Call updateRecord

Else

Call addRecord

End If

Else

If MsgBox("ERROR : Wrong Data Type, Data could not be saved, would you like to go back ?", _ vbQuestion + vbYesNo, "SETT") = vbYes Then

Else

End

End If

End If

End

Else

End

End If

Else

Cancel $=1$

End If

End If

End Sub

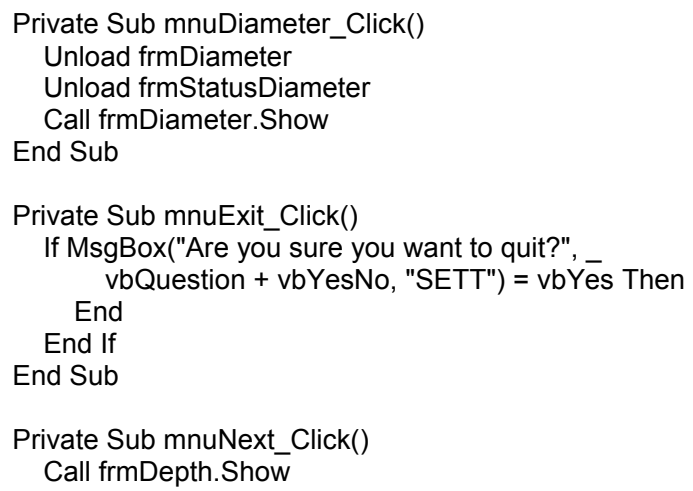




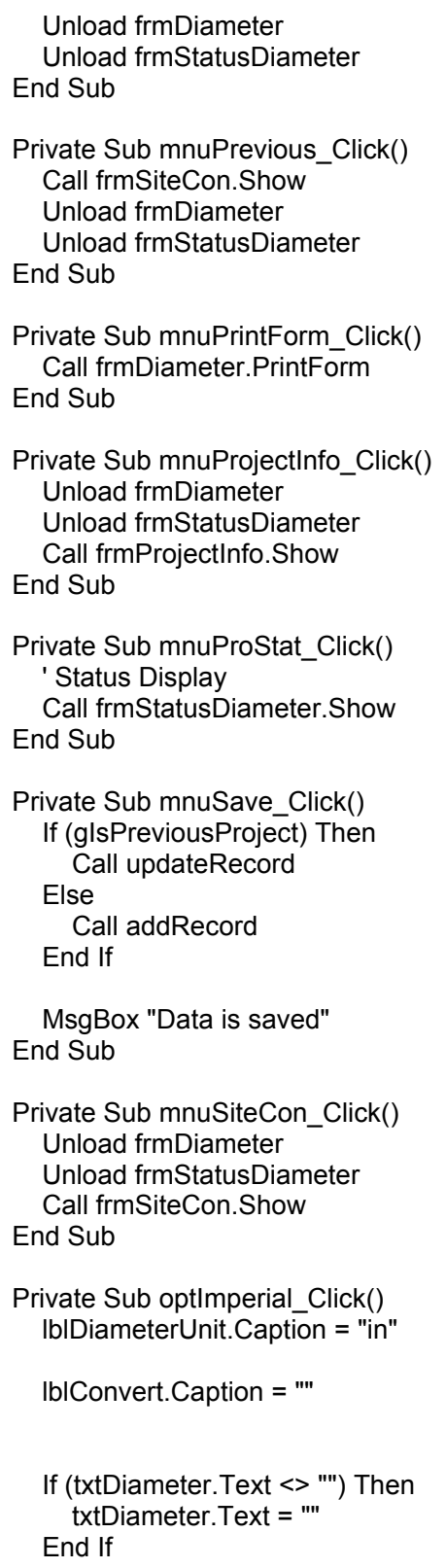




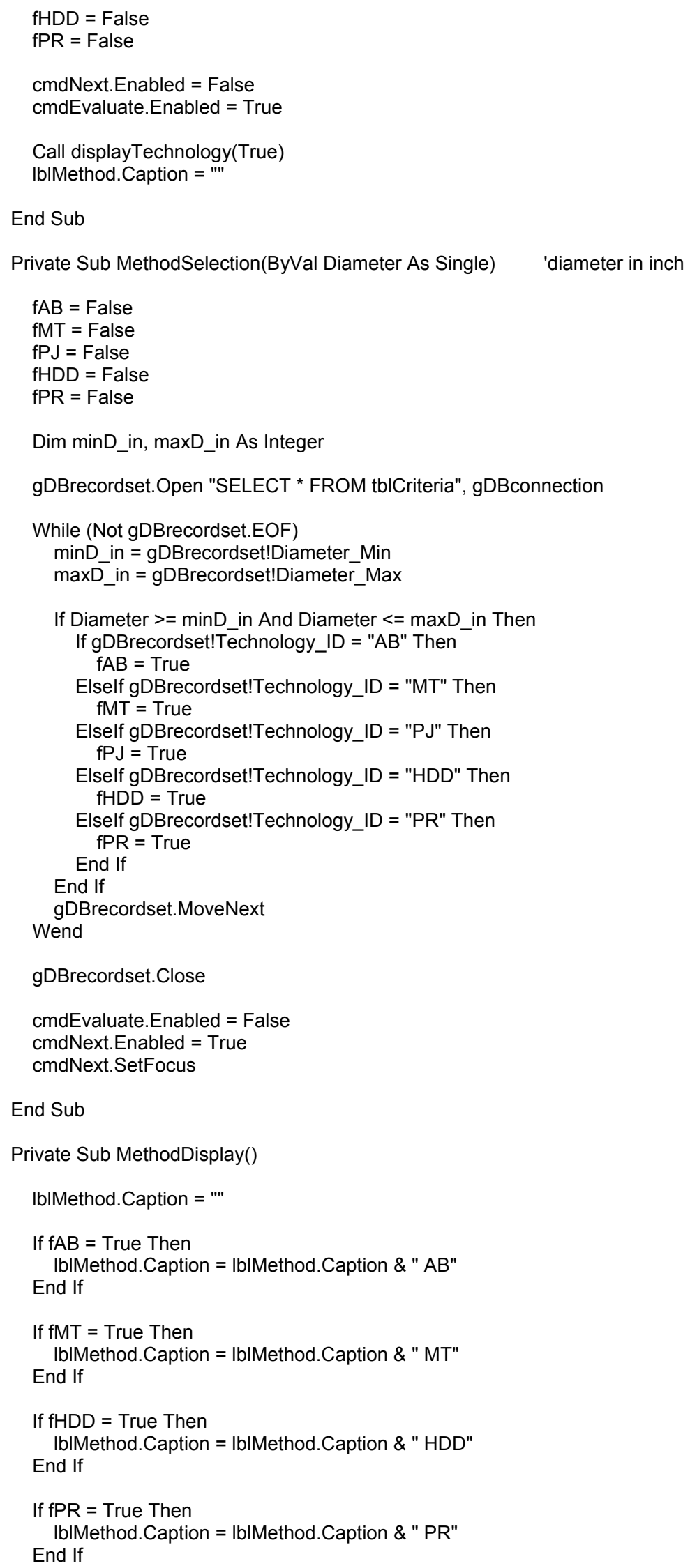


If $\mathrm{fPJ}=$ True Then

IblMethod.Caption = IblMethod. Caption \& " PJ"

\section{End If}

If $\mathrm{fAB}=$ False And $\mathrm{fMT}=$ False And $\mathrm{fHDD}=$ False And $\mathrm{fPR}=$ False And $\mathrm{fPJ}=$ False Then

IblMethod.Caption = " N/A"

$$
\text { End If }
$$

End Sub 


\section{APPENDIX B: QUESTIONNAIRE USED FOR DATA COLLECTION}

\section{PURDUE UNIVERSITYI INDIANA DEPARTMENT OF TRANSPORTATION JOINT TRANSPORTATION RESEARCH PROGRAM \\ DEVELOPMENT OF A DECISION SUPPORT SYSTEM FOR SELECTION OF TRENCHLESS TECHNOLOGIES TO MINIMIZE IMPACT OF UTILITY CONSTRUCTION ON ROADWAYS}

\begin{tabular}{|c|c|c|c|c|c|c|c|c|}
\hline \multicolumn{9}{|l|}{ Project Overview } \\
\hline \multicolumn{9}{|l|}{ 1. Project Name } \\
\hline 2. Duration & \multicolumn{3}{|l|}{ Start date } & \multicolumn{2}{|l|}{ Finish date } & \multicolumn{3}{|c|}{ No of shifts } \\
\hline 3. Location & \multicolumn{4}{|l|}{ City } & \multicolumn{4}{|l|}{ State } \\
\hline $\begin{array}{l}\text { 4. Contractor/ } \\
\text { Consultant }\end{array}$ & \multicolumn{8}{|c|}{ Name of company } \\
\hline 5. Contact person & \multicolumn{2}{|l|}{ Name } & \multicolumn{2}{|c|}{ 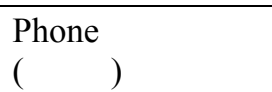 } & \multicolumn{2}{|c|}{$\left.\begin{array}{ll}\text { Fax } \\
(\end{array}\right)$} & \multicolumn{2}{|l|}{ Email } \\
\hline 6. Type of Work & $\begin{array}{l}\square \text { Auger } \\
\text { Boring }\end{array}$ & \multicolumn{2}{|c|}{$\begin{array}{l}\square \text { Horizontal } \\
\text { Directional } \\
\text { Drilling }\end{array}$} & \multicolumn{2}{|c|}{$\begin{array}{l}\square \text { Microtunneling } \\
\text { (Method) } \\
\square \text { Slurry } \\
\square \text { Auger }\end{array}$} & $\begin{array}{l}\square \text { Pipe } \\
\text { Bursting }\end{array}$ & $\begin{array}{l}\square \text { Pipe } \\
\text { Jacking }\end{array}$ & $\begin{array}{l}\square \text { Pipe } \\
\text { Ramming }\end{array}$ \\
\hline 7. Type of Utility & \multicolumn{8}{|c|}{$\begin{array}{l}\square \text { Force Main Sewer } \square \text { Gravity Sanitary Sewer } \square \text { Gravity Storm Water Sewer } \\
\square \text { Water } \square \text { Gas } \square \text { Electricity } \square \text { Telephone } \square \text { Cable } \square \text { Other ( }\end{array}$} \\
\hline \multicolumn{9}{|l|}{$\begin{array}{l}\text { 8. Permit No./ } \\
\text { Contract No. }\end{array}$} \\
\hline $\begin{array}{l}\text { 9. Construction } \\
\text { Cost }\end{array}$ & \multicolumn{4}{|c|}{$\$(\quad)$ per foot } & \multicolumn{4}{|c|}{ Shaft cost included? $\square$ Yes $\square$ No } \\
\hline \multicolumn{9}{|l|}{ Site Conditions } \\
\hline $\begin{array}{l}\text { 10. Existence of } \\
\text { Underground } \\
\text { Utilitities }\end{array}$ & \multicolumn{3}{|c|}{$\begin{array}{l}\square \text { Yes } \square \text { No } \\
\text { If yes, type? }\end{array}$} & \multicolumn{2}{|c|}{$\begin{array}{l}\text { 11. Existence of } \\
\text { Above Ground } \\
\text { Structures }\end{array}$} & \multicolumn{3}{|c|}{$\begin{array}{l}\square \text { Yes } \square \text { No } \\
\text { If yes, type }\end{array}$} \\
\hline 12. Site Access & \multicolumn{8}{|c|}{$\square$ Good Access $\square$ Poor Access } \\
\hline 13. Working Area & \multicolumn{8}{|c|}{$\square$ Open - Good Working Area $\square$ Tight - Poor Working Area } \\
\hline \multicolumn{9}{|l|}{ Construction Data } \\
\hline \multicolumn{9}{|l|}{ 14. Bore Length } \\
\hline 15. Pipe Size & \multicolumn{4}{|c|}{ Inside Diameter } & \multicolumn{4}{|c|}{ Outside Diameter } \\
\hline 16. Pipe Material & \multicolumn{8}{|c|}{$\square$ RCP $\square$ Steel $\square$ HDPE $\square$ GFRP $\square$ PCP $\square$ VCP $\square$ DIP $\square$ PVC $\square$ Other ( ) } \\
\hline $\begin{array}{l}\text { 17. Pipe Segment } \\
\text { Length }\end{array}$ & \multicolumn{4}{|c|}{ 18. Type of Joint } & & & & \\
\hline
\end{tabular}




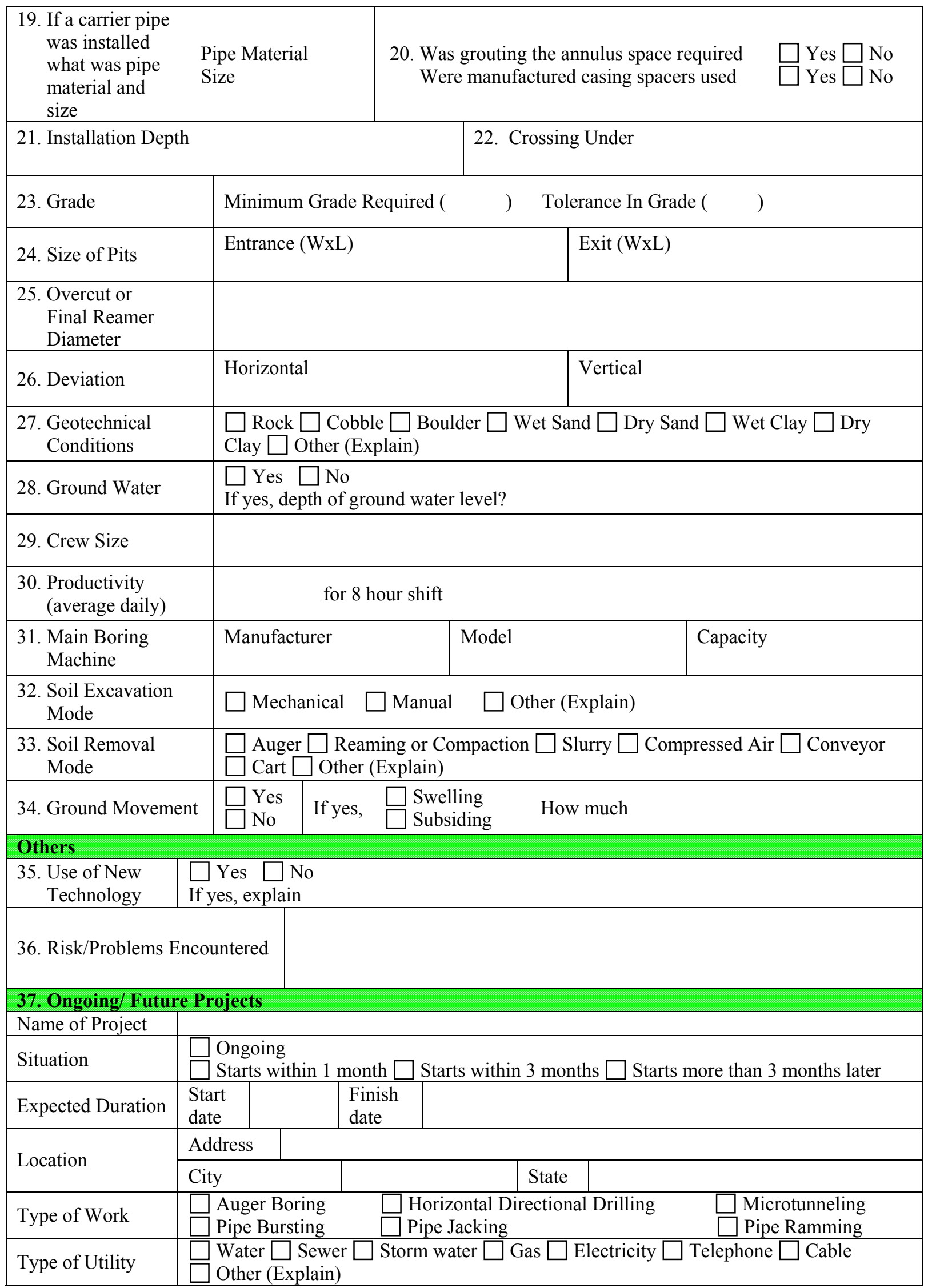


This questionnaire is part of the project to develop a Decision Support System for selection of trenchless technologies. The project is supported by the Joint Transportation Research Program (JTRP) of Indiana Department of Transportation (INDOT) and performed under the supervision of Dr. Dulcy Abraham at Purdue University and Dr. Sanjiv Gokhale at Indiana University-Purdue University at Indianapolis (IUPUI). We appreciate your insight and comments.

\section{Instructions regarding each question}

\section{General}

- Move cursor from cell to cell: Tab key (for reverse direction Shift Tab) or use mouse

- Mark the checkbox: click or spacebar

1. Name of Project

2. Duration: Note the total number of working shifts to complete project.

3. Location

4. Contractor/ Consultant: Name of the company

5. Contact person

6. Type of work: Mark one of six trenchless technologies used in the project. Six technologies are under consideration for this research project. Select subcategories also (e.g. in case of Microtunneling, slurry or auger), if applicable.

7. Type of utility: Mark one that represents the installed utility.

8. Permit Number: Note highway permit number or Contract number

9. Construction cost: Cost per linear foot. Mark whether cost for shaft is included or not.

10. Existence of Underground Utilities: During the planning phase, which utilities are considered as obstacles along the planned alignment? Use the following code. Water - W, Sewer - S, Storm water - SW, Gas - G, Electricity - E, Telephone - T and Cable - C.

11. Existence of Above Ground Structures: Name the type of the structures that affected the selection of the type of trenchless technology that was used.

12. Site Access

13. Working area

14. Bore length: Total length bored by trenchless technologies.

15. Pipe size: Note inside and outside diameter

16. Pipe material: RCP - Reinforced Concrete Pipe, HDPE - High Density Polyethylene Pipe, GFRP - Glass-Fiber Reinforced Plastic Pipe, PCP - Polymer Concrete Pipe, VCP - Vitrified Clay Pipe, DIP - Ductile Iron Pipe, PVC - Polyvinyl Chloride Pipe

17. Pipe segment length

18. Type of joint: Joint type to link the pipe segments. 
19. If a carrier pipe was installed, what was pipe material and size?

20. Was grouting the annular space required and were manufactured casing spacers used?

21. Installation depth: Depth from the ground to the bottom of the pipe (Invert).

22. What was the crossing under i.e., state highway, RR, Interstate?

23. Grade: Was a "tight" or minimum grade required or was there some tolerance?

24. Size of pits

25. Overcut or final reamer diameter: The difference between the bored hole and the pipe OD.

26. Deviation: The difference between the target position and actual position.

27. Geotechnical conditions: Mark as many types of soil as you encountered during the construction.

28. Ground water

29. Crew size

30. Productivity: Average daily progress in length per $8 \mathrm{hr}$ shift or per hour.

31. Main boring machine: Information about the machine that was used for the project.

32. Soil excavation mode: Power source of the excavation method.

33. Soil removal mode: Method used for removal of soil.

34. Ground movement: Ground movement that occurred during the construction.

35. Use of new technology: Whether new trenchless related techniques were introduced to the project or not.

36. Risk/problems encountered: Briefly describe the problems encountered and solutions adapted.

37. Ongoing/Future projects: We would like to visit your job sites in the future to gather detailed data for our research project. If you have any ongoing or planned trenchless construction projects in Indiana, Ohio, Illinois, and northern Kentucky, please give us information about them.

If you have any questions, contact us.

Dulcy M. Abraham, Associate Professor, Ph.D.

Purdue University

Construction Engineering and Management

School of Civil Engineering

Room 1241

1294 Civil Engineering Building

West Lafayette, IN 47907-1294

Phone: (765) 494-2239 Fax: (765) 494-0644

E-mail: dulcy@ecn.purdue.edu 
Sanjiv B. Gokhale, Professor, Ph.D., P.E.

Indiana University - Purdue University at Indiana University

Construction Technology

School of Engineering and Technology

799 West Michigan Street

Indianapolis, IN 46202-5160

Phone: (317) 274-5541 Fax: (317) 274-4567

E-mail: gokhale@engr.iupui.edu

Hyeonshik Baik, Graduate Research Assistant.

Purdue University

Construction Engineering and Management

School of Civil Engineering

1294 Civil Engineering Building

West Lafayette, IN 47907-1294

Phone: (765) 494-7948 Fax: (765) 494-0644

E-mail: baikh@purdue.edu 


\section{REFERENCES}

ACCU-Pipe Ramming Systems Inc. (2002) <www.accupipe.com>

Akkerman Inc. (2002). <www.akkerman.com>

Allouche, E. N., Ariaratnam, S. T., and Lueke, J. S. (2000). "Horizontal Directional Drilling: Profile of an emerging industry.” ASCE J. of Const. Engrg. and Mgmt., 126(1), 68-76.

American Society of Civil Engineers (1998), Standard Construction Guidelines for Microtunneling, ASCE Committee Ballot, Revision 7.

Atalah, A. (1998). "The Effect of Pipe Bursting on Nearby Utilties, Pavement, and Structures,” Technical Report No. TTC-98-01, Trenchless Technology Center, Louisiana Tech University, Ruston, LA.

Atalah, A. and Hadala, P. (1996). "Microtunneling database for the USA and Canada from 1984 to 1995." Proc., Pipeline Crossings 1996, Burlington, Vt., June 1996, ASCE, Reston, Va., 332-339.

Bennett, R.D., Guice, L. K., Khan, S., and Staheli, K. (1995) "Gudielines for Trenchless Technology: CIPP, FFP, Mini-HDD, and Microtunneling” Construction Productivity Advancement Research (CPAR) Program Technical Report. September. U.S. Army Corps of Engineers. Washington, D.C. (4.1-4.54)

Bohrtec GmbH (2002). <http://www.bohrtec.de/>

Digital Control Incorporated (2002). Product Manual. Renton.

Directional Crossing Contractors Association (DCCA). (1994). "Guidelines for a Successful Directional Crossing Bid Package."

Directional Crossing Contractors Association. (DCCA) "Guidelines for successful midsized directional drilling projects."

$<$ http://www.dcca.org/guidelines/dccaguidemidsize.htm> (2000, Sep. 11). 
Essex, R.J. (1993). "Subsurface Exploration Considerations for Microtunneling/Pipe Jacking Projects." Proc. Trenchless Technology: An advanced Technical Seminar for Trenchless Pipeline Rehabilitation, Horizontal Directional Drilling, and Microtunneling, Vicksburg, MS, January 26-30.

Fraser, R., Howell, N., and Torielli, R. (1994). "Pipe Bursting: The Pipeline Insertion Method," Proc. of NO-Dig international '92, Washington DC, ISTT, UK.

Gas Research Institute (1991). "Guidelines for Pipelines Crossing Highways," Gas Research Institute, Chicago, IL, December.

Gokhale, S. and Haskin, M. (1999). "HDD saves Indiana highway project." Directional Drilling, Trenchless Technology, Inc., 7(5), 32-33.

Herrenknecht, Inc. $<$ http://www.herrenknecht.com>

Higgins, S.K. (1994). "Trenchless Excavation Construction in Federal Contracting.” MS Independent Research Study, School of Civil Engineering, Purdue University, West Lafayette, Indiana.

Howell, N. (1995). “The Polyethylene Pipe Philosophy for Pipeline Renovation.” Proc. of NO-Dig International '95. Dresden, Germany, ISTT, U.K.

Indianapolis Star (1997). "Incredible Shock: 1 dead, 1 hurt in gas blast that destroys 7 Northeastside Homes," July 22.

ISCO Industries, LLC (2002).

$<$ http://www.isco-pipe.com/products_services/buttfusion_animation.htm>

Isleley, T., Hancher, D.E., and White, T.D. (1989). "Construction Specifications for Highway Projects Requiring Horizontal Earth Boring and/or Pipe Jacking Techniques," Joint Highway Research Project 89/8, Prepared for the Indiana Department of Transportation, July.

Iseley, T. and Gokhale, S. (1997). "Trenchless installation of conduits beneath roadways." NCHRP Synthesis 242. Transportation Research Board/National Research Council, Washington, D.C., 36. 
Iseley, T. and Tanwani, R. (1993). Trenchless Excavation Construction Equipment and Methods Manual. Trenchless Technology Committee, National Utility Contractors Association (NUCA), Arlington, Va.

Iseley, T., Tanwani, R., and Najafi, M. (1999) "Trenchless construction methods and soil compatibility manual" Trenchless Technology Committee, National Utility Contractors Association (NUCA), Arlington, Va.

Kerr Construction Inc. $<$ http://www.kerrconstruction.com>

Kirby, M. J., Kramer, S. R., Pittard, G. T., and Mamoun, M. (1997). "Design guidelines and procedures for guided horizontal drilling, part II." No-Dig Engrg., 3(4), 13-15.

Kramer, S., McDonald, W., and Thomson, H. (1992). “An introduction to trenchless technology", Van Nostrand Renhold, New York.

Miller the Driller (2002). <http://www.millerthedriller.com>

North American Society for Trenchless Technology (NASTT) (2002). $<$ http://www.nastt.org/glossary/g.html $>$

Nido, A. (1999). "Productivity Projection Model for Microtunneling Operations based on a Quantitative Analysis of Expert Evaluation.” MS Independent Research Study, School of Civil Engineering, Purdue University, West Lafayette, Indiana.

Riccio, L. (1990). “Why streets are so mean?” Asphalt, National Paving Association, Riverdale, MD 20737-1333, Winter 1989-90.

Roe, M.R. "Guide to Best Practice for the Installation of Pipe Jacks and Microtunnels." ISBN 095259820 5. Pipe Jacking Association, London, U.K.

Rush, J. W. (2001). "Florida Horizontal Pile Driving Project Sets Standard.” Trenchless technology. 10(10). p. 42. 
Shahin, M. Y. and Crovetti, J. A. (1985). Final report for the street excavation impact assessment for the City of Burlington, Vermont. Prepared by ERES Consultants, Champaign, IL, June 12, 1985.

Soltau Microtunneling (2002). < http://www.microtunneling.com/soltau/index.htm>

Staheli, K. and Hermanson, G. E. (1996). "Microtunneling, when, where, and how to use it." Water Environment and Technology 8(3), 31-36. The Federation. Alexandria, VA.

Sterling, R.L. and Thorne, J.D. (1999). "Trenchless Technology Applications in Public Works." American Public Works Association (APWA). Kansas City, MO. pp. 176-203.

Strychowskyi, P. (1998). "Trenchless Replacement Techniques." Proc. of Fifth Canadian Construction Research Forum, Trenchless Technology, Alberta, Canada.

Subsite Electronics (2002). Product Manual. Perry, OK.

Terzaghi, K. (1950). "Geologic Aspect of Soft Ground Tunneling, Applied Sedimentation.” P. Trask, ed. John Wiley and Sons, New York, NY.

Thomson, J. Trenchless Pipelaying Applications and Market. Proc. $2^{\text {nd }}$ International conference and Exhibition on Trenchless Construction for Utilities, London, April 1987.

Tracto-technik (2002). <http://www.tracto-technik.de>

Trenchless Data Service. (2000, Aug. 30). <http://www.trenchlessdataservice.com>

Ueki, M., Haas, C. T., and Seo, J. (1999). "Decision tool for microtunneling method selection.” ASCE Journal of Construction Engineering and Management. 1252), March/April 123-131.

Underground Construction (1999). "News Box: Storm Sewers To Remain Largest Large Diameter Pipe Market.” September, pp. 14. 